Jorge Rodolfo Beingolea Garay

\title{
CyberSens: Uma Plataforma Para Redes de Sensores em Sistemas Ciber-Físicos
}

\author{
Tese apresentada à Escola Politécnica da \\ Universidade de São Paulo para obtenção do \\ Título de Doutor em Ciências.
}


Jorge Rodolfo Beingolea Garay

\section{CyberSens: Uma Plataforma Para Redes de Sensores em Sistemas Ciber-Físicos}

Tese apresentada à Escola Politécnica da Universidade de São Paulo para obtenção do Título de Doutor em Ciências.

Área de concentração:

Sistemas Eletrônicos

Orientador:

Prof. Dr. Sergio Takeo Kofuji 
Este exemplar foi revisado e alterado em relação à versão original, sob responsabilidade única do autor e com a anuência de seu orientador.

São Paulo, 05 de Dezembro de 2012

Assinatura do autor

Assinatura do orientador

\section{Ficha Catalográfica}

Garay, Jorge Rodolfo Beingolea

CyberSens: Uma Plataforma Para Redes de Sensores em Sistemas CiberFísicos / J. R. Beingolea Garay - ed. rev. - São Paulo, 2012.

$135 \mathrm{p}$.

Tese (Doutorado) - Escola Politécnica da Universidade de São Paulo. Departamento de Engenharia de Sistemas Eletrônicos.

1. Middleware 2. Sistemas Ciber-Físicos 3. Redes de Sensores sem fio 4. Arquitetura orientada a serviços 5. Gerenciamento I. Universidade de São Paulo. Escola Politécnica. Departamento de Engenharia de Sistemas Eletrônicos II. t. 
A minha Mãe e ao Meu Amor Caroline. 


\section{AGRADECIMENTOS}

Agradeço a Deus que me abençou e guiou nessa ardua caminhada. Agradeço a minhã mãe Luisa Virginia e ao meu Difunto pai Jorge Henrique, por estimular sempre meus sonhos e pelo apoio incondicional al longo do meu Doutorado.

Agradeço ao meu orientador Sergio Takeo, pelo conhecimento que soube me brindar, pela paciência e dedicação durante todos estes anos.

Agradeço aos meus colegas do PAD-LSI, Kenji, Stelvio, Juan Carlos, José, Hugo, por ter sido como uma segunda família durante todos estes anos, pois sua colaboração, motivação e suporte foram sempre importantes.

Agradeço a Caroline, o meu amor, por compartilhar meus sonhos, pela sua força e apoio ao longo do meu Doutorado e pelos gratos momentos vividos durante os último anos. Deus lhe mantenha sempre ao meu lado. 


\section{Resumo}

O recente surgimento de um novo conceito que propõe a integração do mundo físico com sistemas computacionais leva as redes de sensores a serem unicamente parte de um processo colaborativo para fins de integração, com um objetivo maior do que só observar o ambiente. Este novo conceito é conhecido como Sistema Ciber-Físico (tradução do inglês Cyber Physical System - CPS), e consiste numa rede de elementos que atuam entre o meio físico e as aplicações computacionais (Sensoriamento - Atuação - Controle - Aplicação), concluindo num sistema de gestão capaz de agrupar diversas aplicações com capacidade de funcionamento autônomo, assim como distribuído. Entretanto, para que esta tecnologia se torne viável para os diversos contextos do mundo físico, é necessário considerar as limitações dos elementos computacionais que a integram e, para o caso, essas limitações passam a ser maiores quando se trata de uma rede de sensores. Este trabalho de tese tem foco na camada de sensoriamento, discute inicialmente alguns dos pressupostos supracitados e define algumas características e requisitos dos CPS necessárias para a padronização de alguns processos. Propõe também o desenvolvimento de uma Plataforma para redes de sensores em Sistemas Ciber-Físicos, um middleware, capaz de se adaptar às limitações e necessidades, que serão apresentadas posteriormente numa aplicaçãoexemplo. Como primeiro ponto: i) $\mathrm{O}$ trabalho apresenta as necessidades para estes tipos de sistemas e aborda definições relevantes; ii) Discute-se a definição em camadas do middleware CiberSens iii) Aplicação da proposta numa aplicação-exemplo. Do primeiro ponto: Os CPS constituem uma pesquisa relativamente nova, como resultado, muitos aspectos precisam ser definidos com o intuito de facilitar o entendimento da arquitetura e implementação. Do segundo ponto: Os dispositivos transdutores representam um papel de relevante importância nas diversas aplicações, na área de automação residencial e nas aplicações biomédicas, esta última com exponencial crescimento de aplicações que procuram melhorar a qualidade de vida dos pacientes. Nesse contexto, se faz necessário um minucioso estudo dos conceitos e características que deverão ser consideradas no desenho em camadas da plataforma de gerenciamento para redes de sensores em CPS. No desenho a flexibilidade do sistema deverá estar sujeita ao fácil domínio e controle por parte de usuário final, que será o verdadeiro responsável pelo funcionamento do Sistema Ciber-Físico e da aplicação em curso.

Do terceiro ponto: Com o intuito de eliminar possíveis erros e identificar limitações no uso do sistema por parte dos atores do sistema (usuário e administrador), além de demonstrar a viabilidade da proposta, é levado o modelamento e definição de conceitos para sua aplicação num caso real. Nesta etapa é realizada simultaneamente a implementação de um módulo integrador encarregado da captura e abstração de protocolos na camada de comunicação e conexão com o módulo de armazenamento, e a camada de serviços. Uma avaliação é necessária não só para validar a técnica e o modelo utilizado na implementação da arquitetura do CiberSens e sim também para determinar a confiabilidade da comunicação e eficácia ante um evento critico, a validação acontece através da formalização de processos de controle, sensoriamento e atuação com a ferramenta SysML. 


\section{Abstract}

Recently, the emergence of a new concept that proposes the integration of the physical world with computing systems, is taking sensor networks to be only part of a collaborative process with a larger goal than just observing the environment. This new paradigm is known as Cyber-Physical Systems, and consists of a network of elements that act between the physical environment and computational applications (Sensing - Actuation - Control - Application), ending in a management system able to group several applications with standalone and distributed operation capabilities. However, to this technology become viable for the diverse contexts of the physical world, it is necessary to consider the limitations of computational elements that compose it, and in this case, these limitations increase when it comes to sensor networks. This thesis focuses on the sensing layer, discusses some of the assumptions aforementioned and defines some characteristics and requirements of the CPS necessary to standardize some processes. It also proposes the development of a platform for sensor networks on Cyber-Physical Systems, a service-oriented middleware capable of adapting the limitations and needs presented later in a use case. As first item: $i$ ) The document presents the requirements for these types of systems and approaches relevant definitions. Secondly: ii) It is discussed the layered definition of the CiberSens service-oriented middleware. And third: iii) It is presented the proposal implementation in application-example. From the first item: The CPS are a relatively new field of research, as a result, many aspects need to be defined in order to simplify the understanding of the architecture and implementation. From the second item: The transducer devices have a relevant role on diverse applications used on the fields of home automation and in biomedical applications, the latter with an exponential growth of applications that try to improve the quality of life of patients. In this context, it is necessary a detailed study of the concepts and characteristics that should be considered during the layered design of the management platform for sensor networks in CPS. In the design, the system flexibility should be subject to an easy control and domain by the end user, who will be responsible for the actual functioning of the Cyber-Physical System and the ongoing application.

From the third item: In order to eliminate possible errors, identify limitations in the system use by the system actors (user and administrator), and demonstrate the feasibility of the proposal, the modeling and concepts definition are applied in a real case. On this step is performed simultaneously an efficiency evaluation of the protocols capture and abstraction methods in the communication layer, the storage modulus, and the services layer. The evaluation is needed not only to validate the technique and the model used in the CiberSens architecture implementation, but also to determine the reliability the of communication and the effectiveness facing a critical event, validation occurs through the control process formalization, sensing and actuation, with SysML tool.

keywords: Middleware, Cyber-Physical System, Wireless Sensor Network, Service Architecture, Management. 


\section{Lista de Abreviaturas}

CPS Cyber Physical-System

MVC Model-VIew-Controller

WLAN Wireless Local Area Network

API Application Programming Interface

HTTP Hypertext Transfer Protocol

MVC Model View Controller

SOA Service Oriented Architecture

DCM Dynamic Control Middleware

CD Control Drive

XML Computer Aided Design

AC Admission Controller

DCM Digital Clock Manager

LB Load Balancer

FOSD Feature Oriented Software Design

RSSI Received Signal Strength Indicator

MST Módulo Sensor Transmissor

MSB Módulo Sensor Base

SOAP Simple Object Access Protocol

RSSF Rede de Sensores Sem Fio

ELA Esclerose Lateral Amiotrófica

MOS Middleware Orientado a Serviços

RF Radio Frequency

ISM Industrial, Scientifical and Medical

USB Universal Serial Bus 


\section{Lista de Figuras}

2.1 Diagrama de Requisitos Globais num Sistema Ciber-Físico. . . . . . . . . . . . 25

3.1 Arquitetura do WebMed $[1] . \ldots \ldots \ldots \ldots$

3.2 Procedimento de seleção de um CDM proposto em [2] . . . . . . . . . . . . . . 32

3.3 Arquitetura em camadas do DCM [2]. . . . . . . . . . . . . . . . . . . 32

3.4 Arquitetura em camadas proposto em [3]. . . . . . . . . . . . . . . . 33

3.5 Middleware Framework proposto em [4]. . . . . . . . . . . . . . . 36

4.1 Modelo de Camadas do Middleware CiberSens. . . . . . . . . . . . . . . . . . 43

4.2 Especificação de Requisitos para Middleware [5] . . . . . . . . . . . . . . . . 45

4.3 Especificação de Requisitos Funcionais para o CiberSens. . . . . . . . . . . . . 46

4.4 Especificação de Requisitos Não Funcionais para o CiberSens. . . . . . . . . . . . 47

4.5 Representação de requisitos de ativação periódica. . . . . . . . . . . . . . . . . 50

4.6 Representação de requisito segundo o prazo de execução. . . . . . . . . . . . . 51

4.7 Estilo Arquitetônico em camadas - hierarquia de comunicação. . . . . . . . . . . 52

4.8 Diagrama da camada de Comunicação e Suporte - Módulo Integrador (MI). . . 53

4.9 Diagrama de Operação do Módulo Integrado - MI. . . . . . . . . . . . . . . . 54

4.10 Diagrama de Sequência do Módulo Integrado - MI. . . . . . . . . . . . . . 54

4.11 Código de Inicialização do MI. . . . . . . . . . . . . . . . . . . . . . 55

4.12 Código do método StartCapture do MI. . . . . . . . . . . . . . . . 55

4.13 Código do Service facade do MI. . . . . . . . . . . . . . . . 56

4.14 Código do método serialEvent. . . . . . . . . . . . . . . . . . . . . 56

4.15 Código da classe CaptureProcess. . . . . . . . . . . . . . . . . 57

4.16 Código de inicialização do DAO na classe CaptureProcess . . . . . . . . . . 57 
4.17 Código de método $r u n . \ldots \ldots \ldots \ldots$

4.18 Diagrama de blocos do Módulo de Comunicação. . . . . . . . . . . . . . . . . 60

4.19 Cenário de comunicação heterogênea (Singlehop - Multihop). . . . . . . . . . . 60

4.20 Diagrama do Módulo de Armazenamento. . . . . . . . . . . . . . . . . . 61

4.21 Diagrama de blocos da Camada de Integração e Serviços). . . . . . . . . . . 63

4.22 Diagrama de blocos da camada de Domínio de Serviços) . . . . . . . . . . . 66

4.23 Diagrama de blocos da camada de abstração de programação. . . . . . . . . . . 68

4.24 Diagrama de tipos de abstração de informações no middleware. . . . . . . . . . . 69

4.25 Modelo Arquitetônico em camadas - hierarquia de comunicação. . . . . . . . . 70

4.26 Diagrama do Middleware - Modelo MVC para Implementação. . . . . . . . . . 71

4.27 Diagrama do Middleware / Aplicação-Exemplo. . . . . . . . . . . . . . . . 72

4.28 Diagrama do Modelo de Serviços para o CiberSens. . . . . . . . . . . . . . . 73

5.1 Dispositivos de Hardware - Ambiente Experimental . . . . . . . . . . . . . 76

5.2 Diagrama simplificado de Caso de Uso, Ambiente CiberSens . . . . . . . . . 77

5.3 Diagrama simplificado de Caso de Uso Eventos e Consultas . . . . . . . . . . 77

5.4 Interface Principal do CiberSens $\ldots \ldots \ldots \ldots \ldots$

5.5 Diagrama do MI - Eventos e Requisitos . . . . . . . . . . . . . . . . . 79

5.6 Diagrama SysML de Descrição de Blocos - MI . . . . . . . . . . . . . . . . 80

5.7 Diagrama SysML de Descrição de Blocos do Ambiente Supervisório . . . . . . 80

5.8 Diagrama SysML de Descrição de Blocos do Controle Supervisório . . . . . . 81

5.9 TmoteSky - Arduino Duemilanove - Hardware para o Caso de uso . . . . . . 84

5.10 Descrição da Estrutura do Frame - Atributos . . . . . . . . . . . . . . . . . . 84

5.11 Código de configuração para o payload do Singlehop. . . . . . . . . . . . . . 85

5.12 Código de configuração para o payload do Multihop. . . . . . . . . . . . . . . 85

5.13 Diagrama de Classes - Armazenamento. . . . . . . . . . . . . . . . . . . 86

5.14 Diagrama de Especificação - Nível de Serviços. . . . . . . . . . . . . . . . . 87 
5.15 Diagrama UML - Nível de Controle. . . . . . . . . . . . . . . . 88

5.16 Diagrama de Análises da Interface. . . . . . . . . . . . . . . . . 89

5.17 Interface de Cadastro de Ambiente e Mapa. . . . . . . . . . . . . . . . . . . . 90

5.18 Interface de Seleção de ambiente. . . . . . . . . . . . . . . . . . 90

5.19 Decomposição do Ambiente em Cenários da Aplicação. . . . . . . . . . . . . . 90

5.20 Identificação da área do cenário no Mapa. . . . . . . . . . . . . . . . . . 91

5.21 Interface Sensor - Cadastro MST . . . . . . . . . . . . . . . . . 91

5.22 Interface Monitoramento - Relação Ambiente - Cenário - MSTs. . . . . . . . . 92

5.23 Casa Ecológica Inteligente (Cenário de controle, sensoriamento e atuação) . . . 95

5.24 Diagrama da Infraestrutura de operação) . . . . . . . . . . . . . . . . . 96

5.25 Exemplo da lógica dos estados Pessoa Casa - Ausente - Ferias . . . . . . . . 97

5.26 Interface da Aplicação de Analises Textual para Caso de Uso . . . . . . . . . . 99

5.27 Caso de Uso-Segurança . . . . . . . . . . . . . . . . . . . . . . 99

5.28 Caso de Uso - Estado Ocupado e os eventos na Casa . . . . . . . . . . . . 100

5.29 Caso de Uso - Eventos e Condições - Entrada Principal - Porta . . . . . . . . . 101

5.30 Diagrama simplificado de Caso de Uso Casa Ecológica Inteligente . . . . . . . 104

5.31 Diagrama de Caso de Uso - Sensor de Temperatura . . . . . . . . . . . . . 105

5.32 Diagrama de Caso de Uso - Sensor de Temperatura - Evento Principal . . . . . 105

5.33 Diagrama de Caso de Uso - Sensor de Movimento . . . . . . . . . . . . . . 106

5.34 Diagrama de Caso de Uso - Sensor de Movimento - Evento Principal . . . . . . 106

5.35 Diagrama de Indice - Classes e Blocos . . . . . . . . . . . . . . . 107

5.36 Diagrama SysML de Descrição de Bloco - Fluxo e Loop Principal . . . . . . 108

5.37 Diagrama SysML de Descrição de Bloco - Detalhamento de Blocos . . . . . . 108

5.38 Diagrama SysML de Descrição de Bloco - Detalhamento do Pacote da Estrutura do Loop Principal de Controle . . . . . . . . . . . . . . . . . . . . 109 


\section{Lista de Tabelas}

3.1 Características dos middlewares. . . . . . . . . . . . . . . . . 38

4.1 Classes do Ambiente - Modelo . . . . . . . . . . . . . . . . . . . . . 62

4.2 Descrição de Classes . . . . . . . . . . . . . . . . . . . . . . . 62

4.3 Serviços na camada de Integração . . . . . . . . . . . . . . . . 65

4.4 Serviços e Classes na camada de Controle . . . . . . . . . . . . . . . . . 67

5.1 Eventos e Condições - Segurança . . . . . . . . . . . . . . . . . . . . 98

5.2 Eventos e Condições - Estado Ocupado - Ambientes . . . . . . . . . . . . . 100

5.3 Eventos e Condições - Entrada Principal - Porta . . . . . . . . . . . . . . . 101

5.4 Entrada Principal $-\mathrm{Luz} \ldots \ldots$. . . . . . . . . . . . . . . . 102

5.5 Eventos e Condições - Luz Sala . . . . . . . . . . . . . . . . . . 102

5.6 Eventos e Condições - Água e Energia . . . . . . . . . . . . . . . . . 103

6.1 Tabela de Resultados de contribuições - CiberSens) . . . . . . . . . . . . . . 114 


\section{Sumário}

1 Introdução 1

1.1 Motivação do Trabalho . . . . . . . . . . . . . . . . . 1

1.2 Objetivos do Trabalho . . . . . . . . . . . . . . 5

1.2.1 Objetivos Específicos ................... 5

1.3 Delimitação do Trabalho . . . . . . . . . . . . . . . . . 6

1.4 Visão Geral do Texto . . . . . . . . . . . . . . . . . . 6

2 Referencial Teórico 9

2.1 Sistemas Ciber-Físicos . . . . . . . . . . . . . . 9

2.1.1 Definições para Sistemas Ciber-Físicos . . . . . . . . . . . . . 10

2.1.2 Cenário Atual dos Sistemas Ciber-Físicos . . . . . . . . . . . . . . 12

2.1.3 Objetivos dos Sistemas Ciber-Físicos . . . . . . . . . . . . 13

2.1.4 Áreas de Aplicação dos Sistemas Ciber-Físicos. . . . . . . . . . . . . . . 14

2.1.5 Relevância dos Sistemas Ciber-Físicos . . . . . . . . . . . . . . . . . 15

2.1.6 Características e Propriedades dos Sistemas Ciber-Físicos . . . . . . 15

2.2 Sistemas Ciber-Físicos e os Sistemas Críticos f . . . . . . . . . . . . 17

2.2.1 Padrões De Comunicação em Sistemas Criticos e Considerações no CPS 18

2.2.2 Observações Gerais dos Sistemas Ciber-Físicos e os Sistemas Críticos. 18

2.3 Middlewares . . . . . . . . . . . . . . . . . . . . . . . 19

2.3.1 Características de um Middleware . . . . . . . . . . . . . . 20

2.3.2 Interfaces do Middleware . . . . . . . . . . . . . . 21

2.3.3 Middleware e Redes de Sensores . . . . . . . . . . . . . . . . 21 
2.3.4 Observações para os Middlewares de Integraçao Redes de Sensores e Sistemas Ciber-Físcos . . . . . . . . . . . . . . . . . . . . . 24

2.4 Padrões de Projeto (Design Patterns) . . . . . . . . . . . . . . . . . . . . 25

2.4 .1 Padrão GoF . . . . . . . . . . . . . . . . . . . . . . . 25

2.4 .2 Padrão Facade . . . . . . . . . . . . . . . . . . . . 26

2.4 .3 Padrão DAO . . . . . . . . . . . . . . . . . . . 26

2.4.4 Padrão MVC (Model-View-Controler) . . . . . . . . . . . . . . . . . . 27

\section{Trabalhos Correlatos}

3.1 Middlewares e Sistemas Ciber-Físicos. . . . . . . . . . . . . . . . . . . . . . 29

3.1.1 Arquitetura de Middleware Orientada a Serviços para Sistemas Ciber-Físicos (Service-Oriented Middleware Architectures for CyberPhysical Systems $)[1] \ldots \ldots \ldots \ldots$. . . . . . . . . . . .

3.1.2 Um Middleware de Controle Dinâmico para Sistemas Ciberfisicos para uma Rede Global Baseada em Ipv6 (A dynamic control middleware for cyber physical systems on an IPv6-based global network) [2] . . . . . .

3.1.3 Osgi - Arquitetura Baseada em Serviços para Sistemas Ciber-Físicos para Sistemas de Controle de Casas. (OSGi-based services architecture for Cyber-Physical Home Control Systems) [3]. . . . . . . . . . . . . .

3.1.4 Middleware Reconfigurável em Tempo Real para Sistemas Distribuídos Ciber-Físicos Com Eventos Aperiódicos (Reconfigurable Real-Time Middleware for Distributed Cyber-Physical Systems with Aperiodic Events $[6] \ldots \ldots \ldots \ldots \ldots$. . . . . . . . . . . . . . . . . . . .

3.1.5 Um Middleware Framework Cyber-Físico para Monitoramento Contínuo de Sistemas de Distribuição De Água (A Cyber-physical Middleware Framework for Continuous Monitoring of Water Distribution Systems) [4] . . . . . . . . . . . . . . . 35

3.2 Características e Observações Gerais . . . . . . . . . . . . . . . . . 37

4 Proposta e Metodologia 41

4.1 Fundamentação . . . . . . . . . . . . . . . . . . . . 41 
4.2 O CiberSens . . . . . . . . . . . . . . . . . . . . . 42

4.3 Especificações do Middleware . . . . . . . . . . . . . . . . . . . . 44

4.3.1 Requisitos e considerações para o CiberSens . . . . . . . . . . . . . . 44

4.3.2 Requisitos Funcionais e Não Funcionais para um Sistema Ciber-Físico 45

4.4 Descrição de Camadas . . . . . . . . . . . . . . . . . . . 51

4.4.1 Camada de Comunicação e Suporte . . . . . . . . . . . . . . . . 52

4.4.2 Camada de Integração de Serviços . . . . . . . . . . . . . . . . . 63

4.4.3 Camada de Domínio de Controle de Serviços . . . . . . . . . . . . . . 66

4.4.4 Camada de Interface de Abstração de Programação . . . . . . . . . . . . 68

4.4.5 Modelo de Projeto para o CiberSens . . . . . . . . . . . . . . . 70

5 Descrição da Aplicação-Exemplo $\quad 75$

5.1 Aplicação Exemplo - I . . . . . . . . . . . . . . . . . . 76

5.2 CiberSens - Descrição do Módulo Integrador - MI - Implementação . . . . . . 78

5.2.1 Resumo do Fluxo de Eventos . . . . . . . . . . . . . . . . . 81

5.3 Ferramentas para o Caso de Estudo . . . . . . . . . . . . . . . . . . . 82

5.3.1 Sistema Operacional TinyOS . . . . . . . . . . . . . . . . . . 82

5.3.2 Interface de Programação Arduino . . . . . . . . . . . . . . . . . 83

5.3.3 Nível de Acesso - Sensoriamento - Descrição . . . . . . . . . . . . . . 83

5.3.4 Nível de Serviço - Controle - Descrição . . . . . . . . . . . . . . . . 87

5.3.5 Nível de Aplicação . . . . . . . . . . . . . . . . . . . . . . . 88

5.4 Aplicação-Exemplo - II (Casa Ecológica Inteligente) $\ldots$. . . . . . . . . . . 93

5.4 Definição: ............................... 93

5.5 Modelo de distribuição - Infraestrutura e Processos . . . . . . . . . . . . . 95

5.6 Descrição dos Principais Estados para Controle da Casa Ecológica Inteligente 96

5.7 Ambiente Externo . . . . . . . . . . . . . . . . . . . . . 97

5.7.1 Controle de Segurança . . . . . . . . . . . . . . . . . . 97 
5.7.2 Estado - Ocupado . . . . . . . . . . . . . . . . . . . 99

5.7 .3 Porta Principal - Entrada . . . . . . . . . . . . . . . . . . . 100

5.7.4 Luz Principal - Entrada . . . . . . . . . . . . . . . . . . . . 101

5.7 .5 Luz Sala . . . . . . . . . . . . . . . . . . . 102

5.7 .6 Água e Energia . . . . . . . . . . . . . . . . . . . . . . . 102

5.7.7 Aplicação-Exemplo - II (segunda fase) . . . . . . . . . . . . . . . . 103

6 Resultados - Conclusões - Contribuições 11

$\begin{array}{ll}\text { Anexo A - Códigos } & 115\end{array}$

A.1 Código da Classe Captureconfig . . . . . . . . . . . . . . . . . 115

A.2 Código da Classe Capturebean . . . . . . . . . . . . . . . . . . 118

A.3 Código da classe Capturesensor _ . . . . . . . . . . . . . . . . . . . 121

A.4 Código da classe CaptureProcess do Módulo de Integração MI . . . . . . . . 124

A.5 Código do Sensor de temperatura . . . . . . . . . . . . . . . . . . . 128 


\section{Introdução}

Neste capítulo são descritos os motivadores para o desenvolvimento da Plataforma de Gerenciamento para Redes de Sensores em Sistemas Ciber-Físicos, um Middleware chamado de CiberSens.

\subsection{Motivação do Trabalho}

Os Sistemas Ciber-Físicos (Cyber Physical System - CPS) consistem numa rede de elementos que interagem entre o meio físico e as ferramentas computacionais (hardware e software). A maior parte destes elementos é constituída por dispositivos de hardware embarcado (sensores e atuadores) para monitoramento e controle de processos físicos. Em geral, o conceito de sistemas Ciber-Físicos surge como um processo de integração dos elementos computacionais que conhecemos com os elementos físicos, deixando os primeiros de serem totalmente dependentes, porém, sua autonomia e funcionalidade estarão sempre condicionadas a outros sistemas que estendem suas atividades em função dos fenômenos físicos monitorados, e reagem com certa autonomia, exigindo, no processo, a execução de outros sistemas sincronizados e em tempo real.

Os Sistemas Ciber-Físicos exploram mecanismos de adaptação de determinados hardwares e aplicações em sua capacidade de integração com o mundo físico. Entretanto, é necessário facilitar esta integração definindo e conceitualizando princípios básicos dos Sistemas CiberFísicos, até hoje inexistentes. Aliás, faz-se necessário, como ponto de partida para a integração de aplicações autônomas existentes, o desenvolvimento de uma plataforma de gerenciamento que possibilite de forma quase intuitiva e transparente, a programação, adequação, projeção e gerenciamento de uma rede de sensores num sistema Ciber-Físico.

Como supracitado, os CPS são constituídos em grande parte por dispositivos ou componentes embarcados, os quais possuem comumente ciclos de retro-alimentação nos quais os processos físicos afetam os cálculos predeterminados, diminuindo a confiabilidade 
do sistema. No mundo físico, os fenômenos naturais, assim como o passar do tempo, são inexoráveis e a concorrência entre estes eventos é intrínseca, isto exige nos atuais projetos das diversas arquiteturas de sistemas embarcados, que estas propriedades sejam consideradas, tanto nas abstrações dos processos informáticos (aplicações e plataformas operacionais), quanto nas arquiteturas de redes de sensores, razão pela qual cada estrutura de software e hardware deverá ser minuciosamente projetada, considerando alguns parâmetros como de variação, adaptação, eficiência, funcionalidade, abstração, sincronização, confiabilidade, segurança e usabilidade num CPS.

Apesar de existir uma crescente pesquisa sobre CPS são poucos os resultados alcançados em relação a este novo conceito de sistemas híbridos, isto devido a que ainda não contamos com uma ciência madura para suportar as características e exigências de sistemas de engenharia de CPS com alto nível de confiança, as consequiências de fato são profundas. As atuais ferramentas tradicionais de análises são incapazes de lidar com o alto nível de complexidade dos CPS ou, ao menos, prever adequadamente o comportamento destes sistemas. Um claro exemplo seria os últimos eventos na rede elétrica, blackout sobre grandes regiões como resultado de falhas generalizadas no sistema. Isto provavelmente ilustre as deficiências e limitações das atuais tecnologias, o qual dificulta a conceituação e criação de projetos independentes de sistemas de engenharia que interajam com o mundo natural, e com o mundo físico. Ao mesmo tempo as exigências dos atuais governos para desenvolver tecnologias renováveis como a energia, telemedicina, fabricação avançada de materiais inteligentes, veículos movidos a energia elétrica, transporte aéreo, criam oportunidades sem precedentes para repensar muitos dos sistemas existentes.

As recentes pesquisas em CPS evidenciaram alguns dos desafios na construção de projetos de CPS e entre estes desafios temos a necessidade de investigação de novos projetos de middleware que permitam tratar características como a heterogeneidade, escalabilidade de componentes e aspectos críticos relacionados a sensoriamento, controle e aplicação. As propostas incluem o middleware WebMed [1], uma Arquitetura de middleware Orientada a Serviços para CPS. Na sua construção o WebMed considera cinco componentes sobre os quais repousa sua arquitetura: Nó WebMed, Serviço Web, Serviço de Repositório, Motor e Aplicação de Desenvolvimento. No trabalho destaca-se a necessidade da importância de middlewares mais ágeis e reutilizáveis aproveitando as características inovadoras das tecnologias web. A proposta apresenta algumas lacunas em relação à integração dos padrões de comunicação especificados na camada física para dar suporte a heterogeneidade de padrões de comunicação e determinar a característica de escalabilidade de dispositivos no WebMed. 
Segundo as características heterogêneas dos CPS e sua alta tendência à escalabilidade, é fácil predizer a excessiva fonte de sobrecarga de desempenho que existirá dentro deste tipo de sistemas. Em [2] se propõe um middleware de controle dinâmico (DCM) sobre a possibilidade de integração de um CPSs com outros CPSs. A proposta é restrita ao controle de dispositivos que utilizam o protocolo IPV6. Para [2] o IPV6 seria a escolha mais adequada considerando a característica de escalabilidade dos CPS. Na arquitetura se propõe dois tipos de dispositivos: os dispositivos de controle e os dispositivos de controle de middleware. A proposta inclui um mecanismo destinado a reduzir a troca de mensagens geradas por um dispositivo de busca.

A diversidade de aplicações associadas ou que compõem um CPS demandam de técnicas que permitam o gerenciamento de eventos dos dispositivos, em tempo real; isto, sem dúvida, exige dos dispositivos de hardware uma alta disponibilidade de recursos para o processamento de tarefas com características periódicas e aperiódicas. Em muitos sistemas distribuídos, processos se comunicam basicamente por meio da propagação de eventos, os quais opcionalmente, também, transportam dados. A propagação de eventos segue o conceito básico de Sistemas Publicar e Subscrever [7]. Eventos são publicados e o middleware assegura que somente os processos que foram associados (que se subscreveram) para esse evento os receberão. Em [6] as combinações e métodos utilizados para tratar estes eventos correspondem a um modelo CORBA Real-Time otimizado. O modelo é otimizado na sua interface de comunicação com o objetivo de flexibilizar a configuração e tratamento de eventos aperiódicos e periódicos que resultam das camadas subjacentes, resultando num maior desempenho dada a robusteza da arquitetura CORBA.

As arquiteturas CORBA se caracterizam pela variedade de aplicações que podem ser criadas e integradas sobre esta arquitetura, mesmo assim suas exigências de desempenho, troca excessiva de mensagens entre componentes para conclusão de um processo ou sua interrupção em tempo de execução, deixam a arquitetura restrita a cenários de aplicação com baixa mobilidade e maior recurso de processamento.

A diversidade de aplicações associadas a um CPS confirma a existência de uma variedade de meios de comunicação inclusive num ambiente doméstico, meios tais como WLAN, ZigBee, LonWorks e ECHONET os quais dificultam a interoperabilidade de protocolos nas diferentes redes. Para resolver este problema em [3] se propõe uma arquitetura serviços de controle de métodos. A proposta afirma que os usuários conseguirão controlar aparelhos no ambiente físico através de operações intuitivas que reagem sobre as mudanças dos dispositivos no ambiente físico, o contexto virtual aprova as mudanças e realiza uma ação de localização e execução de serviços para um ambiente dinâmico. A proposta da arquitetura do Sistema Ciber-Físico para o 
Controle de Casas é descrita em três camadas: i) A Camada Física, ii) Camada de Serviços, iii) Camada de Aplicação. Nesta última camada todos os serviços prestados pelos equipamentos físicos podem ser convertidos para o modelo de serviços para usuários OSGI, através da camada de serviço.

No modelamento dos serviços, na estrutura do middleware, a utilização desnecessária de um componente é um evento comum quando existe uma fraca especificação dos requisitos nos fluxos de execução da aplicação. Em [4] apresenta-se o resumo da proposta de um middleware Framework para monitoramento e controle de sistemas de distribuição de água em grande escala. A proposta destaca um middleware framework representado numa estrutura de camadas que segue um modelo FOSD (Feature Oriented Software Design) [8]. A abordagem categoriza os componentes de forma intrínseca ou extrínseca, de modo que o middleware possa evitar a utilização desnecessária de componentes no fluxo de execução. Cada evento e ação correspondente acontece e utiliza recursos num contexto particular, esta informação é fundamental para saber quais agentes devem ser incluídos no fluxo de ação, de modo que a tarefa desejada é corrigida no próprio contexto sobre as restrições oferecidas.

A utilização do middleware busca, como para muitas aplicações em sistemas distribuídos, criar uma estrutura robusta para tratar e integrar a informação de outras camadas, fornecendo maior integridade entre os serviços e as aplicações. A integração de camadas e serviços acaba sendo muito mais complexa quanto maior é o número de camadas, serviços e aplicações, este é o caso dos CPS. A utilização de técnicas orientadas a serviços para gerenciamento de informação e integração da comunicação entre camadas não é uma tarefa simples; é necessário especificar a forma de comunicação entre as camadas, definir os serviços e quem gerencia a comunicação entre eles, prioridades dos requisitos funcionais ou não funcionais em tempo de execução, considerando requisitos de tempo para evitar situações criticas.

Entre os muitos desafios deste trabalho de tese, está determinar o suporte aos múltiplos protocolos de comunicação por parte do CiberSens, basicamente a diversidade de singlehop e multihop, assim como o gerenciamento de aspectos de escalabilidade resultado da adesão de hardware heterogêneo na aplicação em curso.

Os aspectos comuns a serem considerados em todo middleware, junto aos desafios no desenvolvimento do CiberSens, middleware para redes de sensores em sistemas Ciber-físicos são: i) o controle em tempo real dos dispositivos sensores, ii) definição de parâmetros temporais para atribuir confiabilidade na comunicação dos dispositivos, iii) determinar níveis adequados de abstração para os atores do sistema (usuário e administrador), iv) mecanismos de consulta em tempo real, v) identificação de eventos críticos, vi) ferramentas de integração a outros sistemas, 
vii) reusabilidade e suporte aos módulos do middleware.

O maior dos desafios não reside unicamente em aspectos de integração e abstração e sim na inclusão das características especiais das arquiteturas de redes de sensores sem fio, interfaces de consulta em tempo real exigem um número alto de troca de mensagens demandando recursos de energia e poder de processamento. Por outro lado, a diversidade de arquiteturas e o próprio meio de comunicação sem fio restringem a flexibilidade na criação de serviços e interfaces para configuração dos parâmetros associados à diversidade de ambiente de aplicação do CPS.

Finalmente, em tempo de execução o CiberSens deve permitir gerenciar a organização dos dispositivos sensores iniciando pelo ambiente, seguido pela sua divisão em cenários, características do fenômeno físico ao qual deve ser associado um tipo de sensor, associação e delimitação do numero de dispositivos por redes para um melhor controle de densidade, estatísticas de rede, projeção adequada de camadas e módulos para uma fácil gerenciamento e melhor desempenho da arquitetura.

\subsection{Objetivos do Trabalho}

O objetivo principal deste trabalho é propor um modelo de Middleware em três camadas. O middleware chamado de CiberSens deverá atuar como uma Plataforma de Gerenciamento Para Redes de Sensores em Sistemas Ciber-Físicos. Um dispositivo denominado de módulo integrador - MI realiza a abstração da comunicação do middleware com os dispositivos sensores e atuadores.

\subsubsection{Objetivos Específicos}

- Definir requisitos funcionais, não funcionais e o estudo de conceitos, características e abrangência de um sistema Ciber-Físico.

- Elaborar um padrão de projeto MVC (model-view-controler) de três camadas para implementação do middleware num domínio de redes de sensores e atuadores em sistemas Ciber-Físicos.

- Propor um módulo de gerenciamento (Módulo Integrador) que facilite a abstração de dispositivos de hardware, para controle de sensores e atuadores heterogêneos que façam parte de uma mesma aplicação.

- Especificar uma aplicação-exemplo para implementação do padrão de projeto e conceitos 
do CiberSens. Para a aplicação-exemplo são utilizadas as arquiteturas do TmoteSky, Arduino UNO e Arduino Duemilanove.

- Modelar o fluxo de controle de dispositivos no ambiente da aplicação-exemplo através da ferramenta SysML.

\subsection{Delimitação do Trabalho}

O domínio de aplicação é restrito às redes de sensores e atuadores sem fio na sua integração com um Sistema Ciber-Físico dando ênfases na heterogeneidade das arquiteturas existentes, suas características especiais e à diversidade de protocolos de comunicação singlehop e multihop. O meio de comunicação é sem fio e os dispositivos de hardware utilizados na implantação do caso de estudo trabalham sobre o padrão de comunicação ZigBee, entretanto, é necessário salientar que o módulo de gerenciamento de dispositivos atua sobre as características de um módulo integrador abstraindo comunicação de dispositivos que operem sobre outros padrões de comunicação sem fio.

Na aplicação-exemplo os níveis de abstração para os atores do sistema são determinados na implantação segundo as características e funcionalidades exigidas pela aplicação ao CiberSens. Assim mesmo o tipo de consultas em tempo de execução realizadas pelo middleware à aplicação do CPS são de caráter restrito e especifico para diminuir o impacto no desempenho do CiberSens e da RSSF.

A pesar de que a característica de adaptabilidade é comum a todos os middlewares este trabalho oferece meios para que as adaptações no middleware entre os serviços e o hardware aconteçam de forma quase intuitiva e transparente para o usuário e o administrador do CiberSens.

\subsection{Visão Geral do Texto}

O restante do texto esta organizado em mais 4 capítulos.

No Capítulo 2 são destacados os principais conceitos, características e abrangência dos Sistemas Ciber-Físicos.

No Capitulo 3 são apresentados os principais trabalhos sobre middlewares para Sistemas Ciber-Físicos. 
No Capitulo 4 proposta e metodologia de desenvolvimento, além de algumas justificativas que fundamentam a escolha de algumas técnicas abordadas no modelamento e desenvolvimento do middleware CiberSens.

No Capitulo 5 apresenta-se a validação do middleware CiberSens através da especificação e implantação de uma aplicação-exemplo.

No Capitulo 6 será apresentado as conclusões finais, algumas considerações e discussões, produto da implantação da aplicação-exemplo e finalmente as contribuições alcançadas. 


\section{Referencial Teórico}

Neste capítulo são destacados os principais conceitos, características e abrangência dos Sistemas Ciber-Físicos.

\subsection{Sistemas Ciber-Físicos}

Os Sistemas Ciber-Físicos (Cyber Physical System - CPS) consistem numa rede de elementos que interagem entre o meio físico e as ferramentas computacionais (hardware e software). A maior parte destes elementos é constituída por dispositivos de hardware embarcado (sensores e atuadores) para monitoramento e controle de processos físicos. Em geral, o conceito de sistemas Ciber-Físicos surge como um processo de integração dos elementos computacionais que conhecemos com os elementos físicos, deixando os primeiros de serem totalmente dependentes, porém, sua autonomia e funcionalidade estarão sempre condicionadas a outros sistemas que estendem suas atividades em função dos fenômenos físicos monitorados, e reagem com certa autonomia, exigindo, no processo, a execução de outros sistemas sincronizados e em tempo real.

Os CPS são considerados um sistema distribuído que eventualmente devem lidar com eventos aperiódicos e periódicos com diversos requisitos [6].

Os CPS, apresentam uma ampla complexidade na sua descrição, projeção e implementação, entretanto, prometem mudar a forma como interagimos e percebemos o mundo físico, através da fácil integração e acesso às novas tecnologias de dispositivos de hardware, software e computação móvel que permitiram até mesmo personalizar determinados aspectos do ambiente físico, o qual é comumente fora de nosso alcance.

Como supracitado, os CPS são constituídos em grande parte por dispositivos ou componentes embarcados, os quais possuem comumente ciclos de retro-alimentação nos quais os processos físicos afetam os cálculos predeterminados, diminuindo a confiabilidade do sistema. No mundo físico, os fenômenos naturais, assim como o passar do tempo, são 
inexoráveis e a concorrência entre estes eventos é intrínseca. Isto exige nos atuais projetos das diversas arquiteturas de sistemas embarcados, que estas propriedades sejam consideradas, tanto nas abstrações dos processos informáticos (aplicações e plataformas operacionais), quanto nas arquiteturas de redes de sensores, razão pela qual cada estrutura de software e hardware deverá ser minuciosamente projetada, considerando alguns parâmetros como de variação, adaptação, eficiência, funcionalidade, abstração, sincronização, confiabilidade, segurança e usabilidade em um CPS.

Na elaboração do CiberSens é necessário identificar e definir como os dispositivos de hardware interagem com o ambiente, incluindo características espaciais, de tempo, naturais, produto da interação humana. Nos CPS o conhecimento sobre a abstração do mundo real e a simulação do comportamento humano são apenas duas questões de como a realidade espacial e a experiência humana são ligadas. Para empreender tal análise complexa da ação humana acaba sendo necessário recorrer a conceitos físicos e matemáticos, como auxilio no modelamento de fenômenos que fazem parte do ambiente humano-físico. A necessidade do CiberSens é abstrair características espaciais humanas comuns no mundo real, em suas relações espaciais típicas e em interações espaciais, e determinar como estas atividades podem ser acopladas a uma rede de sensores como parte de um Sistema Ciber-Físico. A especificação de relação fornece uma especificação para as ligações funcionais entre o ser humano e o ambiente e os serviços de uma comunicação de coordenação entre o hardware, nós sensores e o ambiente físico.

\subsubsection{Definições para Sistemas Ciber-Físicos}

As definições apresentadas neste documento sobre os Sistemas Ciber-Físicos são resultado de uma extensa leitura e análise de trabalhos publicados, nos quais cada autor acrescenta sua própria visão proporcionando uma abrangência maior e, em alguns casos, uma definição mais clara para este tipo de sistema.

Os CPS são sistemas que combinam um sistema físico com um sistema de processamento de informação embarcado que resulta em um sistema de capacidades harmoniosas que não poderiam ser alcançadas por entidades físicas e computacionais de forma independente [9].

Em [10], descreve-se um CPS como: "A Integração de Processos Físicos com computação em rede que levou a uma nova geração de sistemas de engenharia (CPS - Cyber-Physical System). Tais sistemas utilizam cálculos e comunicação profundamente enraizada na integração com processos físicos para adicionar novas capacidades aos atuais sistemas físicos. Estes sistemas variam de pequena a grande escala, porque o aumento de computação está em todas as partes e constituem uma fonte de crescimento econômico". Em um artigo publicado pela 
NSF [11], afirma-se que a integração de sistemas físicos e processos com computação em rede levou a uma nova geração de sistemas de engenharia, chamado de Sistemas Ciber-Físicos. Tais sistemas utilizam cálculos e computação embarcada em integração com processos físicos para adicionar novas capacidades aos atuais sistemas físicos, estes CPS variam desde dispositivos com aplicações minúsculas, até dispositivos com aplicações em grande escala.

Para [12], os CPS podem ser considerados como um grupo de sistemas híbridos que interagem e colaboram uns aos outros através de comunicação em rede (incluindo comunicação sem fio), com uma fusão entre a computação e os processos físicos. As plataformas físicas com suporte para CPS oferecem cinco capacidades: computação, comunicação, controle preciso, colaboração remota e autonomia.

Como descrito em [13], muitos dos esforços e estudos relacionados aos sistemas embarcados focados no desafio do ambiente físico trazem as bases cientificas para as redes de informações (Software Embarcado). Sistemas Embarcados são sistemas de processamento de informações embarcadas em produtos eletrônicos. Nesta classificação de componentes eletrônicos é possível associar carros, aviões, trens, equipamentos de telecomunicação, equipamentos de medição, instrumentação etc. Tais sistemas incluem um grande número de características comuns, incluindo restrições de tempo real, confiabilidade, assim como requisitos de eficiência e desempenho. Em [14], se enfatiza a seguinte citação Software Embarcado é Software integrado com processos físicos. O problema técnico é administrar tempo e concorrência nos sistemas computacionais. Na citação utiliza-se o termo Software Embarcado como uma extensão da definição de Sistemas Embarcados. Para [15] a recente ligação destes conceitos com a física da origem há uma nova definição, 'Sistemas CyberFísicos: (CPS) que são integrações de computação e os processos físicos'. O novo conceito enfatiza a ligação de parâmetros físicos como tempo, espaço, energia etc. Para [15], o conceito de Sistemas Cyber-Físicos vem compor a ideia de sistemas embarcados (processamento de informação) a ambientes físicos.

Para [13], a mudança de escopo nos Sistemas Embarcados permitiu a introdução do CPS como um novo ramo da ciência e da tecnologia que proporciona muito mais do que a reestruturação dentro deste domínio. A nova abordagem pode transformar todos os setores industriais em produtores de CPS. Concretamente considera-se em [16], que os CPS são a fusão da computação em rede com sistemas físicos para criar novas capacidades e melhorar a qualidade dos produtos em alguns casos já existentes.

Diversas são as definições descritas para os Sistemas Ciber-Físicos, entretanto, existe um consenso o qual consiste na integração dos sistemas computacionais com os processos físicos, 
assim como a complexidade deste tipo de sistemas e a revolução que apresenta para a engenharia de sistemas embarcados e distribuídos.

\subsubsection{Cenário Atual dos Sistemas Ciber-Físicos}

Nos últimos anos a Internet tem influenciado a forma como conduzimos a pesquisa, os estudos, negócios, serviços, entretenimento etc., entretanto, ainda existem algumas lacunas no espaço em relação a onde e como a informação é trocada no mundo físico em que nós vivemos.

Nesse processo surgem as primeiras aplicações que buscam definir um sistema CiberFísicos, surgindo perspectivas da sua aplicação para controle de energia [17], onde existem conjuntos de componentes heterogêneos difíceis de acompanhar, sendo que nem todos os dispositivos podem ser modelados por causa da sua não uniformidade e da complexidade extrema nos seus diversos tipos de componentes [18]. Ao mesmo tempo em que os CPS procuram aperfeiçoar o consumo de determinados recursos como a energia, é necessário prover métodos que garantam a segurança da informação nos componentes, em alguns casos, sensores que fazem parte do CPS [19] durante este e outros processos algumas soluções propõem o isolamento da segurança através da separação do hardware considerando suas características e limitações de recursos, reforçando os critérios de segurança em função de suas características criticas [20]. Software e segurança é uma sociedade necessária nas atuais aplicações e os CPS não fogem dessas exigências, entretanto, QoS é um parâmetro necessário para garantir a integridade da informação transportada e nos CPS [21] a tarefa é mais complexa, já que a escalabilidade das aplicações pretendem ser maiores, e sua heterogeneidade também. Mesmo com estas exigências a solução ainda são especificas das aplicações não atingindo a diversidade de aplicações que os CPS começam a desenvolver.

Enfim, podemos acrescentar que os CPS constituem uma pesquisa relativamente nova, que se iniciou nos finais de 2006 com o impulso da NSF (National Science Foundation), que organizou nesse mesmo ano o primeiro workshop de Sistemas Ciber-Físicos, realizando posteriormente alguns outros eventos e financiamentos relacionados a CPS em algumas universidades, principalmente na UCLA (University of California, Los Angeles), que anos depois criou o primeiro laboratório para estudos sobre CPS (The Cyber-Physical Systems Laboratory - CyPhyLab).

Apesar de existir uma crescente pesquisa sobre CPS são poucos os resultados alcançados em relação a este novo conceito de sistemas híbridos, pois ainda não contamos com uma ciência madura para suportar as características e exigências de sistemas de engenharia de CPS com alto nível de confiança, sendo as conseqüências desse fato profundas. As atuais ferramentas 
tradicionais de análises são incapazes de lidar com o alto nível de complexidade dos CPS ou ao menos prever adequadamente o comportamento destes sistemas. Um claro exemplo seria os últimos eventos na rede elétrica blackout sobre grandes regiões como resultado de falhas generalizadas no sistema. Isto provavelmente ilustre as deficiências e limitações das atuais tecnologias, o que dificulta a conceituação e projetos de sistemas independentes de engenharia que interajam com o mundo natural, o mundo físico. Ao mesmo tempo as exigências dos atuais governos para desenvolver tecnologias renováveis como a energia, telemedicina, fabricação avançada de materiais inteligentes, veículos movidos a energia elétrica, transporte aéreo, criam oportunidades sem precedentes para repensar muitos dos sistemas existentes.

\subsubsection{Objetivos dos Sistemas Ciber-Físicos}

O objetivo dos Sistemas Ciber-Físicos - CPS é permitir uma visão mais ampla de serviços que transcende à nossa perspectiva atual de como o hardware interage com o mundo físico. A conclusão desta afirmação é que se faz necessário a construção de uma nova ciência de sistemas híbridos, computacional - físico, que forneça uma estrutura unificada e robusta para o tratamento de informação em massa de forma coerente.

Seguindo estas exigências temos como prioridade desenvolver ciência necessária para projetar complexos sistemas computacionais que se integrem de forma harmoniosa e quase intuitiva com o mundo físico e que as pessoas possam depender destes sistemas com um alto nível de confiança.

Os CPS têm também como objetivo integrar princípios científicos e de engenharia que sustentem a integração da cibernética e elementos físicos em todos os setores de aplicação [NSF, 2010]. Para isto, é necessário o desenvolvimento de métodos, ferramentas e componentes de hardware com base nestes princípios transversais, juntamente com a validação destes princípios através de protótipos e ambientes de simulação.

É necessário salientar que os CPS são sistemas de engenharia construídos a partir da sinergia dos componentes computacionais e físicos e sua integração deve ser coordenada, conectada e distribuída através de métodos ágeis e robustos de integração. Seguindo estas afirmações os futuros CPS devem superar em muito os atuais sistemas em termos de capacidade, adaptabilidade, resiliência, usabilidade e segurança. 


\subsection{4 Áreas de Aplicação dos Sistemas Ciber-Físicos.}

Os CPS prometem uma abrangência de aplicações significativa e acredita-se que a tecnologia envolvida pode ser aplicada em uma grande variedade de domínios. Os CPS consideram na sua implementação uma junção de tecnologias de hardware e software embarcado, e na sua interação com o mundo físico considera-se a utilização de grandes estruturas de monitoramento composta por redes de sensores sem fio na sua maioria heterogênea. Considera-se está afirmação, do meio de comunicação sem fio, devido a que a mobilidade é uma potencial característica destes novos sistemas. Seguindo esta linha de raciocínio da relevância das RSSF dentro do contexto dos CPS, a aplicabilidade é ainda maior podendo se iniciar com soluções para a rede elétrica como o Smart Grid, Edifícios Inteligentes, Novas Tecnologias Médicas, Gestão de Tráfego Aéreo, Fabricação avançada do silício etc.

- CPS para Transporte Inteligente; Integração da tecnologia automobilística com sistemas de controle de trânsito em tempo real, veículos com maior desempenho, segurança e menor consumo de energia. Controle de tráfego aéreo, transporte aéreo mais rápido através técnicas de gestão que permitam um melhor e mais eficiente uso do espaço aéreo.

- CPS para Agricultura; Utilização de técnicas mais eficientes de irrigação através da utilização de arquiteturas de RSSF para automação de processos, melhorias na segurança dos produtos alimentares, aprimoramento do impacto ambiental.

- CPS para Saúde e Biomedicina; Sistemas biomédicos interconectados em rede, aplicações para medicina assistiva, novas tecnologias de próteses internas como externas, aplicações integradas de telemedicina etc.

- CPS para Automação Industrial; Novas fontes de energia renovável, um eficiente e menor consumo de energia partindo dos ambientes industriais, empresas geradoras de energia elétrica etc.

Como já citado, a abrangência e aplicabilidade dos CPS é extensa e seguindo este raciocínio pode se afirmar que o projeto de um CPS deverá demandar a utilização de técnicas robustas de engenharia para satisfazer as exigências de projeto, desenvolvimento e implementação destes sistemas. 


\subsubsection{Relevância dos Sistemas Ciber-Físicos}

Os Sistemas Ciber-Físicos são uma tendência emergente em todo o mundo devido a suas bases tecnológicas e força econômica e ao conjunto e junção de tecnologias associadas a estes sistemas. Os CPS constituem hoje uma das principais áreas onde as tecnologias disruptivas emergem e criam novas indústrias, assim como propoem reorganizar o atual status tecnológico e de funcionamento de todos os setores industriais. A relevância destes CPS se reflete em um relatório do Conselho Nacional de Pesquisa dos EUA. Segundo o relatório a TI (Tecnologia da Informação) está à beira de uma outra revolução, na qual sistemas de computadores embarcados interconectados em rede tem o potencial de mudar radicalmente a forma como as pessoas interagem com seu meio ambiente, ao conectar uma extensa variedade de dispostivos de hardaware e sensores que permitam a coleta, compartilhamento, processamento de informações. Estes novos sistemas são os CPS's.

Nos Estados Unidos (EUA), a Fundação Nacional de Ciência (NSF - National Science Foundation) iniciou o apoio à pesquisa sobre Sistemas Ciber-Físicos em 2010 [16], assim mesmo, na Europa, a comissão européia através do CORDIS (Community Research and Development Information Service) iniciou seu apoio na investigação e desenvolvimento de sistemas embarcados. É evidente quão fundamental é para os EUA manter a liderança no projeto de CPS, isto devido ao que seria uma tendência emergente em todo o mundo por causa de forças econômicas fundamentais e tecnológicas associadas a este novo conceito, bem como seu potencial impacto sobre os grandes desafios em uma serie de setores críticos para a segurança da competitividade dos EUA, incluindo setores aeroespaciais, automotivo, produção química, infraestrutura civil, energia, saúde, manufatura, indústria de materiais e transporte. Apesar destas afirmações, a verdade é que a liderança no desenvolvimento de novos sistemas de computação embarcada que consigam interagir de forma inteligente com o ambiente e sistemas físicos possibilitando a integração e otimização de sistemas existentes, assim como a criação de novos sistemas de hardware embarcado que possam reagir em função dos diversos fenômenos associados a um ambiente físico, não é só exclusivo dos EUA e sim uma tendência no mundo todo.

\subsubsection{Características e Propriedades dos Sistemas Ciber-Físicos}

As características são os elementos formadores do conceito de Sistemas Ciber-Físicos, identificam as propriedades e o grau de abstração destes sistemas, entretanto, devido à complexidade dos CPS existe certa dificuldade em determinar de forma concreta as 
características que determinem a abrangência e grau de abstração deste tipo de sistemas. Obedecendo a esta afirmação, as características apresentadas são o resultado de uma exaustiva análise de pesquisas e estudos que procuram definir, caracterizar e propor o exemplo mais próximo de um CPS.

Em [22] [23] [24], é descrito um conjunto de características que evidenciam a abrangência e robustez necessária para os CPS:

- Cyber-Capacidade em Cada Componente Físico e Restrição de Recursos; O Software encontra-se embutido em todos os sistemas embarcados ou componentes físicos e os recursos do sistema, por exemplo: computação e largura de banda de rede, são geralmente limitadas.

- Completamente Integrados; Os CPS evidenciam uma estreita integração da computação com os processos físicos.

- Conexão Em Rede e em Grande Escala; Os CPS incluem meios de comunicação com fio e sem fio, Wi-fi, Bluetooth e GSM, entre outros, caracterizando um sistema distribuído. Assim mesmo a escalabilidade dos sistemas e categorias de dispositivos de hardware apresenta-se bastante heterogênea.

- Complexidade Temporal Múltipla e Escalas Espaciais; Nos CPS, os diferentes componentes possuem, provavelmente, desigual granularidade em tempo e espaço. OS CPS são estritamente limitados pela espacialidade e capacidade em tempo real.

- Organização e Reorganização Dinâmica; Os CPS, como muitos sistemas complexos de grande escala devem contar com uma ampla capacidade de adaptação.

- Controle de Circuito Fechado e Alto Grau de Automação; Uma favorável e conveniente integração homem - máquina e um avançado controle de tecnologias é aplicado a este tipo de sistemas.

- Operação Confiável e em Alguns Casos Certificada; Segurança e confiabilidade são imprescindíveis para um CPS devido a sua extrema complexidade e escalabilidade.

Para os Sistemas Ciber-Físicos é notável a necessidade de integração, controle de hardware, organização e dinamismo, complexidade temporal etc, cada uma destas características com seu próprio nível de profundidade e exigência, segundo seja o cenário de aplicação dos CPS. As características dos CPS não são de caráter exclusivo e são em muitos dos casos, herdadas 
de conceitos como de engenharia de software, sistemas embarcados e arquiteturas de redes. Para [25] as características dos CPS se resumem a exigências de Confiabilidade, Usabilidade, Mobilidade, Privacidade e Segurança, características com alto nível de profundidade e robustez de engenharia. Nos CPS, propriedades físicas e lógicas, como as leis físicas, segurança, ou restrições de energia, recursos, robustez e características de escalabilidade devem ser capturados de uma forma de composição em abstrações de programação, criando-se um modelo ideal e estudando-se a complexidade do sistema em um nível mais alto.

\subsection{Sistemas Ciber-Físicos e os Sistemas Críticos}

Os sistemas críticos são aqueles que evidenciam um impacto direto nos processos e produtos associados a um sistema. Quando estes sistemas falham ao desempenharem seus serviços da forma esperada podem causar graves problemas e perdas relevantes.

Os sistemas críticos são classificados em três principais tipos:

- Sistemas críticos de segurança; são sistemas cuja falha pode resultar em perda de vidas ou danos sérios ao meio ambiente. Um exemplo seria um sistema de monitoramento e automação de plataformas de petróleo.

Sistemas críticos de segurança devem ser sistemas confiáveis e com elevada tolerância a falhas. Estes sistemas devem ser avaliados através de severos métodos de ensaio e simulando as piores condições de funcionamento, já que neste tipo de sistemas um erro oculto e não detectado durante o projeto pode causar um desenlace catastrófico. Concretamente, um único erro de software ou hardware é intolerável, sobre custo e críticidade do sistema.

- Sistemas de missão crítica; são sistemas cuja falha pode desencadear um problema em alguma atividade dirigida a metas. Um sistema de missão critica pode ser visto como um sistema em rede composto por algumas tarefas sub-dependentes umas das outras e com capacidade de se executar em paralelo ou em serie com o objetivo de satisfazer as necessidades dos usuários de serviços.

A continuidade da disponibilidade do serviço é objetivo e requisito em sistemas de missão critica. Atualmente existe um aumento nos ataques de exploração de serviços e de vulnerabilidades de protocolos os quais resultam em falhas e graves problemas à segurança dos sistemas. É necessário argumentar que existe um número extenso de pesquisas que visam resolver os problemas de segurança em sistemas de missão critica 
através de pesquisas em segurança de rede com base em análise de impacto [Li Bingyang, et. al., 2009].

- Sistemas críticos de negócio; o desenvolvimento de sistemas críticos de negócio pode envolver serias dificuldades. O sistema crítico de negócio é um sistema cuja falha pode resultar num alto custo para negócio que utiliza esse sistema.

Os sistemas críticos de negócios é um software ou a associação de hardware e software cujo correto funcionamento é crucial para o negócio ou empresa [26].

\subsubsection{Padrões De Comunicação em Sistemas Criticos e Considerações no CPS}

Os CPS procuram associar um conjunto finito de aplicações e hardware com características e funcionalidades heterogêneas, estas aplicações podem estar ainda em fase de projeto e implementação ou em completo estado de funcionamento em diversos ambientes como domésticos, industriais, empresas provedoras de telefonia, energia elétrica, água, plataformas de petróleo, gás etc.

Em algumas das aplicações mencionadas e em outras muitas são imprescindível a utilização de elementos de hardware que ofereçam alta disponibilidade, mobilidade e um robusto padrão de comunicação sem fio, estes padrões devem na prática evidenciar características de confiabilidade, interoperabilidade e segurança para o sistema em uso. Os sistemas críticos agrupam o conjunto de exigências dos CPS isto devido a sua alta complexidade e necessidade de manter o funcionamento da aplicação sobre qualquer circunstância de erro humano ou fenômeno físico. Alguns padrões como o WirelessHart [27] e o ISA100.11a [28], próprios para aplicações industrias pretendem resolver os aspectos críticos de funcionamento destas aplicações.

\subsubsection{Observações Gerais dos Sistemas Ciber-Físicos e os Sistemas Críticos.}

Os CPS são o resultante de um conjunto de tecnologias emergentes e novos conceitos de engenharia para sistemas distribuídos híbridos, nos quais sistemas com hardware e software heterogêneos fortemente acoplados se integram e reagem aos fenômenos físicos, executando aplicações e protocolos de comunicação que podem sentir e reagir de forma intuitiva a seus ambientes de aplicação. 
Para o nosso contexto os sistemas críticos são resultado da sobreposição da lógica da infra-estrutura de implantação adotada num CPS e as dinâmicas próprias do CPS com o ambiente físico. Estes sistemas críticos atuam como suporte desta matriz computacional biofísica denominada de CPS, incluindo fatores de acessibilidade, disponibilidade, segurança, permeabilidade, integridade para a subsistência dos CPSs.

\subsection{Middlewares}

Para suportar redes e arquiteturas de hardwares heterogêneos e ao mesmo tempo oferecer uma visão de sistema único e coerente para o usuário da aplicação, os sistemas distribuídos são comumente organizados através de uma camada de software entre as aplicações e a plataforma operacional, esta camada de software é denominada de Middleware.

Middlewares proporcionam uma característica de transparência ou abstração de distribuição de processos, isto é basicamente ocultar do usuário cada um dos eventos que desencadeia uma solicitação de serviços na camada de aplicação.

Em [29] afirma-se que um middleware gerencia o ciclo de vida e a comunicação entre os serviços e se define um middleware como uma camada de software que consiste em um conjunto de componentes que colaboram, integram e abstraem o ambiente de execução, assim como implementam funcionalidades comuns e canais de comunicação. No middleware a localização dos serviços não é importante já que o mesmo gerencia sua descoberta, manipula todas as tarefas de transferência como endereçamento, troca de mensagens, empacotamento de dados, entrega, entre outros serviços de comunicação.

Para [30] 'Um middleware é um software que pode gerar a troca de informações entre programas com diferentes protocolos de comunicação, sistemas operacionais e plataformas. $\mathrm{O}$ middleware também fornece uma estrutura de programação mais rica e produtiva, facilitando o desenvolvimento de aplicações distribuídas e a integração de sistemas legados ‘

Em [31], define-se middleware como uma coleção não estruturada de recursos e serviços, localizados entre a camada de transporte e a camada de aplicação, os quais podem ser utilizados individualmente ou de forma conjunta. Middleware pode-se definir como um software distribuído construído junto a um conjunto de recursos e serviços que permitem a múltiplos processos se executarem em um ou mais computadores e se interconectar através de uma arquitetura de rede. Assim mesmo, provê uma interface abstrata que oferece ao programador de aplicações uma visão mais uniforme dos elementos heterogêneos de baixo nível (Sistemas Operacionais e arquiteturas de redes nas camadas subjacentes) [32]. 


\subsubsection{Características de um Middleware}

Os middlewares na sua construção associam um número grande de características e requistos, isto pode mudar de geral a mais especificas segundo seja o tipo de arquitetura de middleware a seguir na etapa de projeto e desenvolvimento. As principais características descritas a seguir são resultado de um extenso estudo realizado sobre trabalhos publicados em [33] [34] [35] [36].

- Interoperabilidade: Define até que ponto duas ou mais implementações de sistemas ou componentes distribuídos de fornecedores diferentes devem trabalhar em conjunto. Esta coexistência com base na simples confiança mútua nos serviços proporcionados por cada um destes sistemas, este processo especificado dentro de um padrão comum. $\mathrm{O}$ middleware deve permitir a troca de informações entre o sistema operacional e o hardware heterogêneo, inclusive entre plataformas de software desenvolvidas por outros fabricantes.

- Transparência: A transparência é quesito relevante em um sistema distribuído e consistem em ocultar os processos e recursos que se encontram fisicamente distribuídos em vários computadores. São identificados alguns tipos de transparência como de Acesso, Localização, Migração, Replicação, concorrência.

- Disponibilidade e Confiabilidade: A disponibilidade trata-se de capacidade dos recursos e serviços de se manterem acessíveis para proporcionar um serviço correto ao sistema distribuído, para manter esta característica é necessário evitar a centralização destes serviços e componentes. Algo que não pode acontecer é que devido a um componente falhar, todo o middleware fique inoperante. O middleware caracteriza-se como confiável quando é capaz de executar, quando requerido, suas funções de abstração baixo determinadas condições, em alguns casos críticas.

- Escalabilidade: Está determinado pela facilidade com que um sistema, seus recursos e serviços, podem se adequar ao crescimento contínuo de processos que influenciem no desempenho e funcionalidade do middleware de uma forma critica.

- Abstração: Abstração de processos. O middleware deve prover um maior nível de abstração que as camadas inferiores, de forma que o desenvolvedor, ao contrario de trabalhar entidades como conexões, as trate como entidades de maior nível como eventos, transações e objetos. 


\subsubsection{Interfaces do Middleware}

Todo middleware, na sua estrutura, prove uma interface de programação de aplicações (API), a qual está formada por um conjunto de entidades que permitem ao desenvolvedor construir aplicações distribuídas sobre o mesmo.

No modelamento e desenvolvimento API, o middleware está sujeito a duas considerações:

A primeira expressa que o middleware permita a construção de um grande número de aplicações inclusive de natureza heterogênea. Para que isto aconteça, é necessário gerenciar múltiplos serviços e recursos os quais incrementariam o tamanho do API enquanto a um maior numero de classes e funções.

A segunda consideração seria o tamanho do API, que é necessário conhecer para acessar os serviços e recursos providos pelo middleware. Esta é uma preocupação dos desenvolvedores de aplicações que sempre desejam trabalhar com ambientes simples e de fácil gerenciamento.

Segundo [31], os APIs dos middlewares devem, no seu desenvolvimento, considerar um conjunto de parâmetros mínimos, expressados a seguir:

- Interface de Execução Remota: Este parâmetro permite a solicitação a serviços e recursos administrados pelo middleware a execução remota de suas funcionalidades. Estes chamados de execução remota podem se resumir à invocação de um método, procedimento ou chamada remota.

- Interface de Administração de dados: Facilita a manipulação de dados entre cachês distribuídos, armazenamento de dados e replicação de sistemas de arquivos.

- Interface de Descoberta de Ambiente: Proporciona o acesso à identificação e descoberta de recursos de hardware, características, capacidades e situação das redes subjacentes, assim como aplicações e serviços remotos incluindo a informação dos usuários do sistema distribuído.

- Interface de Administração de Processos: Implementa a manipulação e movimentação de dados com a execução remota.

\subsubsection{Middleware e Redes de Sensores}

A melhor abordagem, em geral, é considerar fazer sistemas de middleware de modo que sejam simples de configurar, adaptar e personalizar conforme necessário para uma aplicação. Quando 
o assunto é uma Rede de Sensores sem Fio (RSSF) o middleware também deve permitir a geração de comunicação de tarefas de alto nível, assim como a coordenação de tarefas entre os nós, mesmo quando estes nós possuam características heterogêneas [37]. É necessário salientar que o alcance de um Middleware não se restringe unicamente à rede de sensores e sim aos dispositivos e redes conectadas à mesma.

Com o objetivo de atender às restrições de recursos computacionais das RSSF, a qual é propensa a falhas, o middleware deve ser projetado para ser robusto o suficiente para ser tolerante a falhas exigindo pouco processamento e armazenamento, limitando-se sempre a menor troca de mensagens possível.

Os atuais projetos de RSSF evidenciam uma forte dependência entre as aplicações e os protocolos de comunicação utilizados [38], isto devido à necessidade de eficiência em energia por parte da RSSF. As atuais pesquisas fundamentam esta teoria através da necessidade de um forte acoplamento entre as diversas camadas da pilha de protocolos de comunicação, sendo estes últimos bastante diversos e em muitos casos com funcionalidade especifica para alguns cenários de aplicação.

Para [39] o principal objetivo do middleware para RSSF é de apoiar o desenvolvimento, implementação, execução e manutenção de aplicações baseadas em sensores. Entre estes objetivos incluem-se mecanismos para formulação de complexas tarefas como as de comunicação, coordenação, entre outras, as quais facilitam a distribuição de atividades para os nós sensores de forma individual. Assim mesmo, devem ser fornecidos abstrações e mecanismos adequados para lidar com a heterogeneidade dos nós sensores. Todos os mecanismos previstos por um middleware devem respeitar os princípios de projeto e as características de uma RSSF resumidas à energia, escalabilidade e robustez.

O projeto de middlewares parece ser cada vez mais diversificado quando se trata de uma RSSF, arriscando poder de processamento através de um middleware orientado a serviços para redes de sensores e atuadores com comunicação sem fio que propõe uma padronização na comunicação da rede com as aplicações cliente; isto acontece através da utilização de tecnologias de Web Service como o protocolo SOAP e uma sintaxe para a troca de dados e documentos orientados a texto chamado de XML [40]. A proposta apresenta um modelo superficial de camadas, com apresentação de resultados de processos de comunicação obtidos através de simulações.

Outro projeto de Middleware é descrito em [41], os autores propõem um middleware que oferece uma camada entre aplicações e a rede de sensores e oferece um mecanismo padrão para representar consultas, tarefas e dados. Além disso, fornece a escolha automatizada da 
configuração da rede e da estratégia de disseminação de dados usada, permitindo ao usuário acessar a rede sem tomar conhecimento de infra-estrutura e software subjacentes.

Redes de Sensores possuem uma forte integração com o mundo físico, e suas características especiais (limitações computacionais) fazem da sua implementação uma tarefa nada trivial. Para [42] é necessário no projeto de um middleware conter um ambiente de execução que suporte e coordene vários aplicativos e serviços padronizados, tais como a agregação de dados, políticas de gestão de dados, controle e políticas de gestão de adaptação para aplicações e outros mecanismos adaptativos que promovam a utilização eficiente de recursos do sistema para prolongar a vida útil da rede de sensores.

Para [43] projetar um Middleware para RSSF, considerando o reduzido poder computacional e outras características restritivas destes pequenos dispositivos embarcados, não é uma tarefa trivial e, é preciso lidar com muitos desafios ditados pelas características da RSSF, assim como das aplicações. Entre estes, temos: Recursos de hardware, escalabilidade e topologia de rede, heterogeneidade, organização da rede, integração com o mundo real e o conhecimento da aplicação, neste último o middleware deve incluir mecanismos para injetar conhecimento da aplicação na infra-estrutura da RSSF, o que, permitirá que os requisitos de mapeamento de comunicação de aplicativos para os parâmetros de rede permitam um ajuste fino do processo de monitoramento da rede, mantendo ao mesmo tempo padrões mínimos de qualidade de serviço (QoS), como já é característico numa RSSF.

A lista de propostas de middlewares para RSSF é bastante extensa, algumas passam unicamente por estudos baseados em análises bibliográficas dos modelos existentes, outros apresentam resultados baseados em simulação e descrevem modelos de serviços de detecção de eventos em tempo real através de um middleware chamado de DSWare [44]. A proposta argumenta sobre a falta de confiabilidade no serviço de eventos em tempo real, e apresenta uma solução com técnicas de confiabilidade e semântica, a proposta inclui a detecção parcial de eventos críticos. Um levantamento das principais aplicações para RSSF se faz necessário para caracterizar as funcionalidades do mesmo e a necessidade de um middleware que permita aos aplicativos especificar uma política de gestão para as RSSF, já que os atuais não atendem as necessidades especificas de todas as aplicações para redes de sensores [45]. A demonstração é realizada através do middleware MILAN para aplicações de saúde baseada em sensores pessoais. 


\subsubsection{Observações para os Middlewares de Integraçao Redes de Sensores e Sistemas Ciber-Físcos}

Não se pode esquecer que os dispositivos físicos que fazem parte de um CPS, na sua maior parte, são tipicamente limitados pelos seus recursos de energia, processamento e potência de cálculo e nem sempre é possível projetar e executar processos complexos de computação sobre estas arquiteturas, na sua maioria embarcada.

Quando se trata de uma RSSF as características antes mencionadas tornam-se críticas, já que além da limitação de recursos computacionais, devido a sua reduzida fonte de energia, é necessário também considerar a dinamicidade da sua estrutura organizacional enquanto topologias e diversidade de protocolos de comunicação de um único salto (single-hop) e de múltiplos saltos (Multihop). Existe aqui uma grande dificuldade já que para diversas aplicações a escolha do protocolo de comunicação determinará a eficiência no gerenciamento dos recursos e atividades da RSSF. Esta complexidade de características e escolhas se estende até os CPS onde cobram um nível exponencial já que a integração e funcionalidades de uma RSSF dentro de um CPS pretendem ir além de unicamente monitorar ambientes. Na prática estes elementos de hardware com características especiais deverão coletar valores do ambiente físico e associar estes valores a novos parâmetros que permitam acionar e integrar outros sistemas computacionais.

É também necessário ressaltar que o processo de desenvolvimento de um middleware passa por demandar um grande esforço e em muitas ocasiões o projeto e a estruturação progressiva dos eventos de comunicação entre camada superior e as camadas subjacentes é bastante lenta. As etapas de modelamento são trabalhosas e muitas vezes acabam sendo difícil registrar a qualidade do middleware, entretanto, é essencial capturar e registrar todas as etapas do projeto e do desenvolvimento que podem determinar a implementação e utilização bem sucedida do middleware por parte do usuário do CPS. No projeto de middleware para o CPS é necessário considerar alguns requisitos característicos destes sistemas, assim como de muitos sistemas distribuídos, a diferença é que dentro de um CPS alguns requisitos exigem um maior cuidado na sua identificação e descrição para uma posterior codificação, isto devido à alta densidade de componentes de hardware associados, assim como as características de mobilidade e heterogeneidade de protocolos de comunicação e arquiteturas que fazem parte do CPS. Na figura 2.1, são apresentados alguns destes requisitos. 


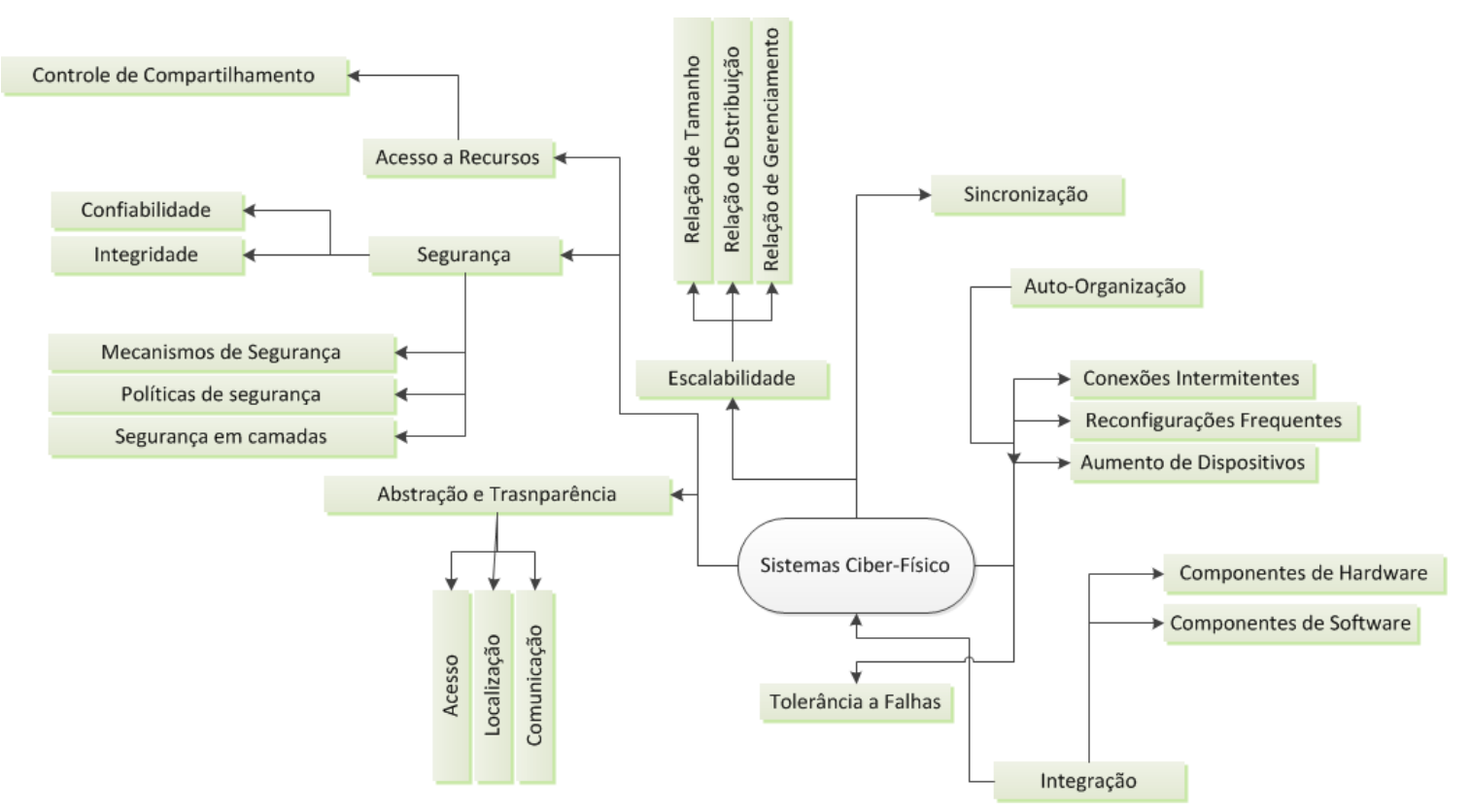

Figura 2.1: Diagrama de Requisitos Globais num Sistema Ciber-Físico.

Os requisitos apresentados (Figura 2.1), não são de caráter definitivo e específico e obedecem unicamente a uma forma de caracterização das funcionalidades que deve atingir um CPS dentro de um pequeno dominio de sensoriamento, controle e atuação.

\subsection{Padrões de Projeto (Design Patterns)}

Os padrões de projeto (em alguns casos chamados de modelos) são soluções estruturadas e validadas, aplicadas na engenharia de software com o objetivo de registrar o conhecimento sobre a implementação de uma arquitetura de forma que possa ser reproduzida em outros contextos de desenvolvimento e aplicação [46].

\subsubsection{Padrão GoF}

Existe um número amplo de padrões de projeto, [47] dos quais o GoF (The Gang of Four) descreve aproximadamente vinte e três padrões e incluem desde as soluções mais genéricas até as mais complexas no desenvolvimento de estruturas de software.

O GoF classifica o conjunto de padrões de projeto seguindo três critérios:

- Criação de classes e objetos

- Alteração da estrutura de um programa 
- Controle de seu comportamento

\subsubsection{Padrão Facade}

O padrão Facade, é um padrão de projeto de estrutura e oferece uma interface simples para um conjunto extenso e complexo de classes para o usuário. O padrão Facade é definido como padrão de projeto e define uma interface de alto nível que integra um conjunto de interfaces de subsistemas fornecendo uma forma de apresentação muito mais consistente [48].

\subsubsection{Padrão DAO}

O padrão DAO (Data Access Object) é um método muito simples de mapear objetos para bases de dados e é comumente implementado junto ao modelo MVC [49].

O que o DAO basicamente faz é proporcionar uma interface comum entre a aplicação e um ou mais repositórios de dados. Utiliza unicamente uma interface de comunicação API do proprio gerenciador de banco de dados ou algum outro substituto com o ODBC entre outros. O padrão DAO é concretamente utilizado em:

- Abstração e encapsulamento de acesso a dados.

- Gerenciador de conexões aos repositórios de dados.

- Obtém e atualiza os dados armazenados nos repositórios estruturados. 


\subsubsection{Padrão MVC (Model-View-Controler)}

O MVC é um modelo de projeto também conhecido como padrão de arquitetura para aplicações de software [49] e permite a implementação de projetos em camadas, separa a lógica de negócios da interface do usuário, assim como facilita a evolução, reutilização e flexibilidade de componentes desenvolvidos para cada uma das camadas do software.

- Modelo; O modelo é predeterminado pelo desenvolvedor e inclui desde o template que utilizará para as interfaces até o modelo para a estrutura dos dados.

- Interface; São as interfaces HTML que permitem ao usuário interagir com os componentes nas camadas subjacentes.

- Controlador; O controlador é o thread principal de tratamento de eventos que captura e transfere os eventos entre o modelo e as interfaces. 


\section{Trabalhos Correlatos}

Neste capítulo são apresentados os principais trabalhos sobre middlewares para Sistemas CiberFísicos.

\subsection{Middlewares e Sistemas Ciber-Físicos.}

No capitulo I, foram descritos de forma sucinta alguns exemplos de middlewares para Sistemas Ciber-Físicos - CPS. Neste capitulo é realizada uma abordagem de caráter mais objetivo, descrevendo detalhes dos trabalhos de maior relevância em relação ao tipo de middleware Cibersens desenvolvido no presente trabalho de teses. As recentes pesquisas em CPS evidenciaram alguns dos desafios na construção de projetos de CPS e entre estes desafios temos a necessidade de investigação de novos projetos de middleware que permitam tratar características como a heterogeneidade, escalabilidade de componentes e aspectos críticos relacionados a sensoriamento, controle e aplicação.

\subsubsection{Arquitetura de Middleware Orientada a Serviços para Sistemas Ciber-Físicos (Service-Oriented Middleware Architectures for Cyber- Physical Systems) [1]}

Em [1] destaca-se a necessidade da construção de novas tecnologias de middleware que se ajustem às características e demandas dos CPS e se propõe um middleware chamado de WebMed, construído sobre uma perspectiva de orientação a serviços para suportar aplicações para CPS. O WebMed facilita o acesso aos dispositivos subjacentes e integra a funcionalidade de um dispositivo especifico com outra aplicação de serviços.

No trabalho destaca-se a necessidade da importância de middlewares mais ágeis e reutilizáveis, aproveitando as características inovadoras das tecnologias web. Na sua construção o WebMed considera cinco componentes sobre os quais repousa sua arquitetura: Nó WebMed, Serviço Web, Serviço de Repositório, Motor e Aplicação de Desenvolvimento. 
No caso de uso, descreve-se um centro comercial com vários prédios com diversos locais de estacionamento e é neste último que se foca a descrição da aplicação. Os locais de estacionamento utilizam-se de uma antiga arquitetura de redes de sensores aparentemente bastante heterogênea. Aqui o WebMed implementa uma camada de Nós WebMed para ocultar a heterogeneidade da camada subjacente existente e proporciona ao administrador do local uma interface flexível para administrar a disponibilidade de vagas no local, assim como também informa aos clientes, via sms, sobre a validade do bilhete do estacionamento.

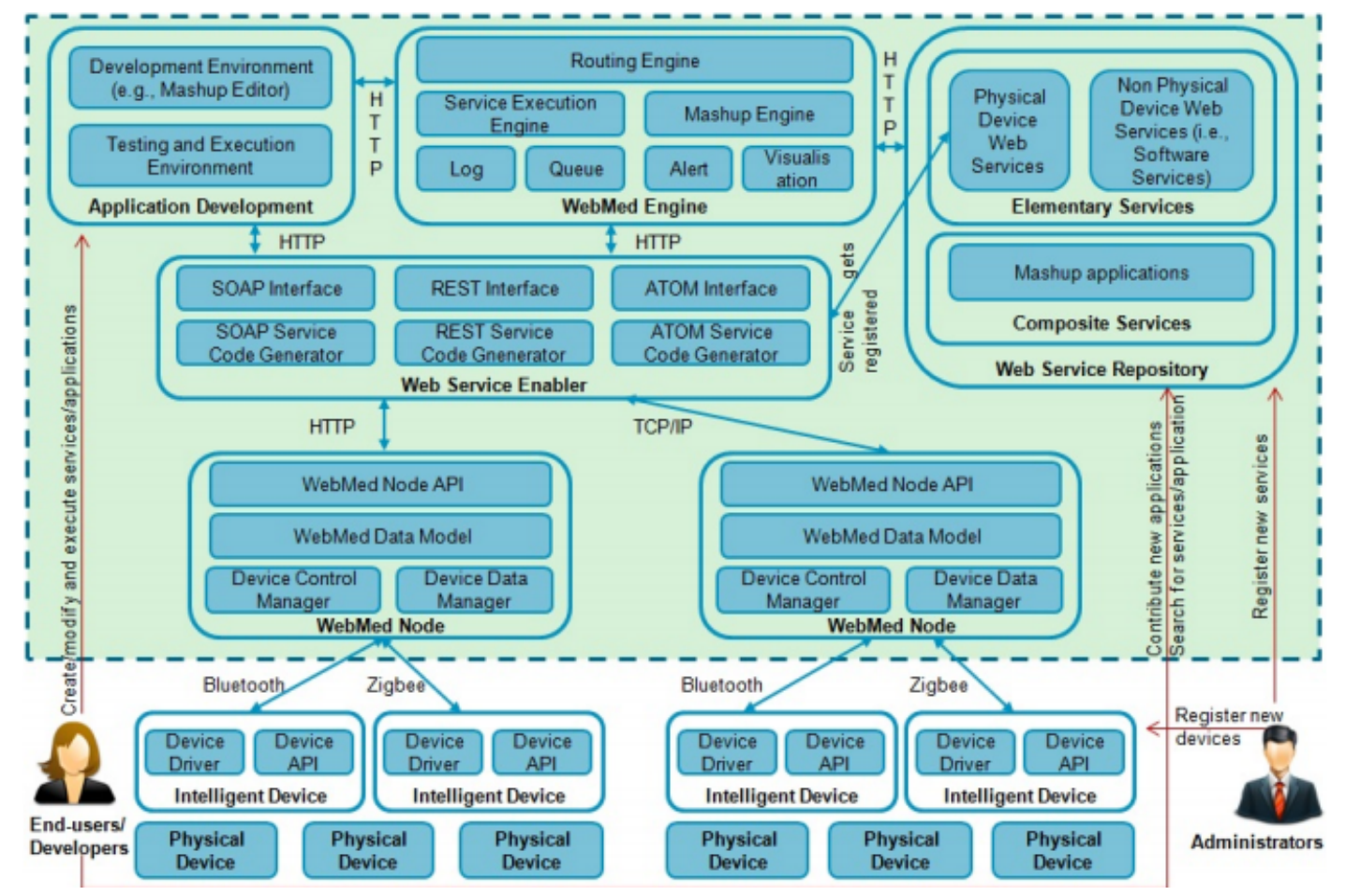

Figura 3.1: Arquitetura do WebMed [1].

A arquitetura do WebMed (Figura 3.1) apresenta-se bastante descritiva e inclui a integração de interfaces de comunicação sem fio ZigBee e Bluetooh, ao mesmo tempo em que considera três tipos de usuários da arquitetura: O Usuário Final, O desenvolvedor das Aplicações e os Administradores da arquitetura. As API para o usuário são construídas utilizando uma linguagem HTTP. Um módulo denominado Serviços Web para dispositivos físicos localizado dentro da camada do Repositório Web Services utilizará uma linguagem SOAP para providenciar um módulo denominado de aplicação de desenvolvimento para o usuário.

- Observações: O trabalho inicia com uma breve referencia às necessidades de middleware para CPS e menciona-se ao mesmo tempo a utilização de tecnologias web para maximizar a flexibilidade dos middleware para CPS. Apesar da ampla descrição da arquitetura (Figura 3.1) a proposta não passa de um modelo teórico sem referência clara de 
implementação de serviços e processos do middleware; assim mesmo menciona-se uma classificação de topologias a qual é comum à classificação de Arquiteturas de Sistemas Distribuídos já existentes (Centralizada, Descentralizada e Híbrida) sobre o qual agrupam-se um numero extenso de trabalhos. Menciona-se na descrição da arquitetura a utilização de um modelo de middleware SOA para CPS, entretanto, excluem-se a descrição das etapas da implantação deste modelo no CPS, assim como sua integração com os dispositivos físicos e o web service e a estrutura e níveis de abstração para a interface de desenvolvimento.

A proposta é sem dúvida interessante, entretanto, fica uma lacuna em relação à estrutura de integração e comunicação dos módulos para as interfaces de desenvolvimento, assim como os processos envolvidos na integração e abstração da pilha de dados dos diversos padrões de comunicação utilizados (ZigBee e Bluetooh).

\subsubsection{Um Middleware de Controle Dinâmico para Sistemas Ciberfisicos para uma Rede Global Baseada em Ipv6 (A dynamic control middleware for cyber physical systems on an IPv6-based global network) [2]}

Em [2] inicia-se a proposta de um middleware de controle dinâmico sobre a possibilidade de integração de um CPSs com outros CPSs e para essa característica de escalabilidade a utilização do IPV6 seria a escolha mais adequada. Os autores propõem um middleware de controle dinâmico (Figura 3.2) para uma pesquisa eficiente de dispositivos em uma rede baseada em IPV6 a partir de qualquer lugar através da utilização de telefones inteligentes (smartphones) junto a um novo mecanismo destinado a reduzir o numero de mensagens gerados por um dispositivo de busca. No DCM (Dynamic control middleware - middleware de controle dinâmico), os dispositivos são classificados em dispositivos de controle (CDs) os quais podem executar funções especificas como de controle de temperatura e controle de outros CDs ou CDMS em uma rede global de comunicação sem fio ou em uma LAN sem fio. Um CDM é um dispositivo de controle que registra e gerencia outros CDs e deve estar posicionado em cada local com o objetivo de fornecer informações sobre os CDs. Na descrição da arquitetura em camadas do DCM (Figura 3.3) se descreve a utilização da sintaxe XML para o módulo de mensagem que pela sua vez está divido em três partes (XML Gerator, XML Parser e XML Analyser). O XML Gerator gera mensagens XML para comunicação entre os CDs e o Parser XML converte-os em objetos de controle de mensagens, que consiste em informações extraídas das mensagens XML. Cada módulo DCM obtêm informações necessárias para seu desempenho a partir das funções dos objetos. 


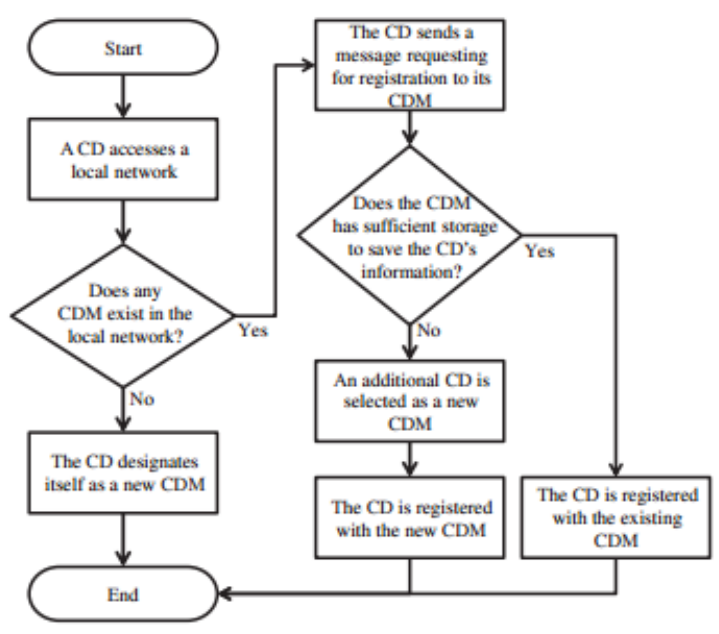

Figura 3.2: Procedimento de seleção de um CDM proposto em [2].

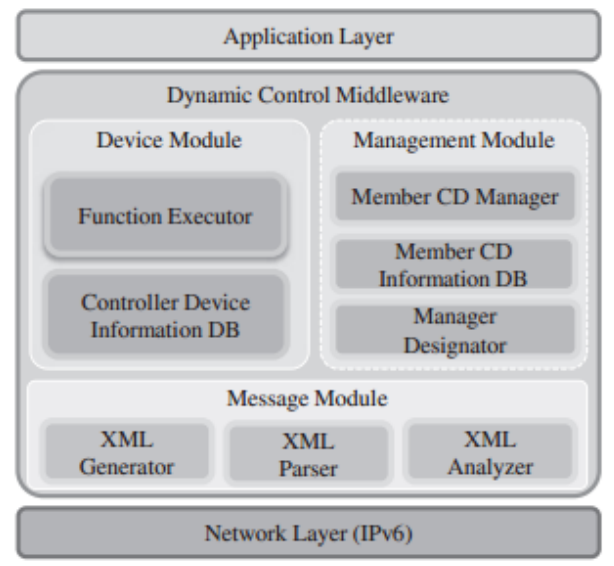

Figura 3.3: Arquitetura em camadas do DCM [2].

A descrição da estrutura apresenta ser bastante consistente, dinâmica e robusta para uma arquitetura de rede de dispositivos sobre IPV6.

- Observações: O trabalho apresenta uma proposta bastante estruturada e ressalta a flexibilidade e dinamicidade do middleware na localização de dispositivos, através de uma técnica de diminuição de troca de mensagens e a descrição de um conjunto de dispositivos comuns CDs e outros de gerenciamento CDMs, os quais compartilham informações para a localização de novos dispositivos, seja em uma rede local ou em uma rede global. Utiliza-se da sintaxe XML para a estrutura de mensagens e funcionalidades dos componentes que abstraem eventos da camada de rede para a camada de aplicação.

A proposta é muito bem detalhada e objetiva na descrição dos processos de implementação, entretanto, a descrição, o cenário de aplicação e os requisitos do 
middleware se restringem a dispositivos de hardware muito mais robustos que uma RSSF.

\subsubsection{Osgi - Arquitetura Baseada em Serviços para Sistemas Ciber- Físicos para Sistemas de Controle de Casas. (OSGi-based services architecture for Cyber-Physical Home Control Systems) [3].}

Em [3] afirma-se a existência de uma variedade de meios de comunicação num ambiente doméstico, tais como WLAN, ZigBee ECHONET e LonWorks, os quais dificultam a interoperabilidade de protocolos nas diferentes redes. Para resolver este problema se propõe uma arquitetura de serviços de controle de métodos. A proposta afirma que os usuários conseguiram controlar aparelhos no ambiente físico através de operações intuitivas que reagem sobre as mudanças dos dispositivos no ambiente físico, o contexto virtual aprova as mudanças e realiza uma ação de localização e execução de serviços para um ambiente dinâmico.

A proposta da arquitetura do OSGI para o Controle de Casas é descrita em três camadas: i) A Camada física, ii) Camada de Serviços, iii) Camada de Aplicação. Nesta última camada todos os serviços prestados pelos equipamentos físicos podem ser convertidos para o modelo de serviços de usuários OSGI, através da camada de serviço, a qual é especificada na Figura 3.4.

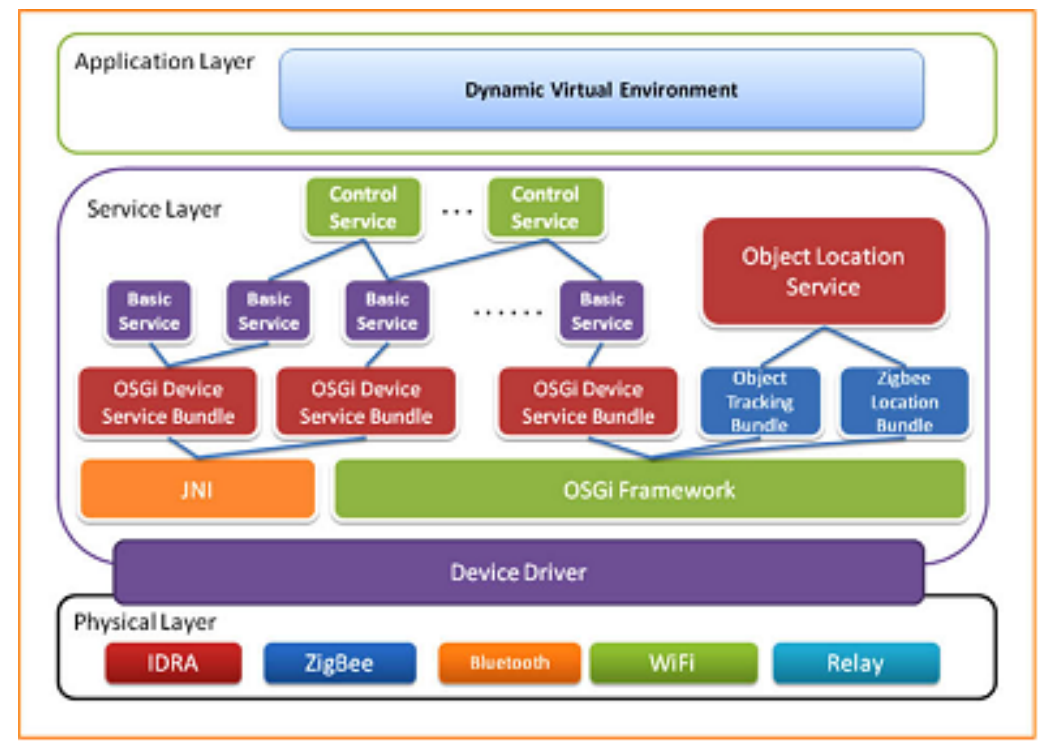

Figura 3.4: Arquitetura em camadas proposto em [3].

A proposta inclui a utilização linguagens como JNI, JAVA, AJAX3D e o suporte a múltiplas plataformas físicas e padrões de comunicação como ZigBee, Bluetooh, Wi-Fi, Relay.

- Observações: A proposta corresponde a um Framework que associa na sua construção 
uma Interface Nativa Java (JNI), assim mesmo inclui a construção de interfaces com AJAX3D (Combinação linguagem JAVA com tecnologia 3D) e Sintaxes XML que permitem implementar técnicas baseadas em serviços para abstrair informações das camadas subjacentes. Os autores não descrevem detalhes de implementação e modelagem, entretanto, representado numa arquitetura em camadas, propõem o gerenciamento da heterogeneidade dos dispositivos que existem num ambiente doméstico. A construção do Framework segue a lógica de tecnologias de middlewares baseados em serviços, porém, alguns métodos e linguagens utilizadas são um tanto restritivos devido a suas exigências de processamento. Na camada de aplicação não é descrito o tipo de barramento, serviço ou técnica de abstração utilizada para gerenciar a alta heterogeneidade dos padrões de comunicação sem fio especificados para essa camada e como esta heterogeneidade será gerenciada pelos módulos de controle na camada de serviços. Considerar um suporte abrangente de padrões de comunicação evidencia uma característica ou exigência de técnicas para gerenciar latência em escalabilidade, isto não é considerado ou descrito no trabalho.

\subsubsection{Middleware Reconfigurável em Tempo Real para Sistemas Distribuídos Ciber-Físicos Com Eventos Aperiódicos (Reconfigurable Real-Time Middleware for Distributed Cyber- Physical Systems with Aperiodic Events) [6]}

Em [6] diferentes sistemas distribuídos Ciber-Físicos devem manipular eventos aperiódicos e periódicos com diversos requisitos. Embora middlewares em tempo real como o CORBA RealTime tenham se mostrado bastante promissores para plataformas de sistemas distribuídos, com restrições de tempo, sua pouca flexibilidade e mecanismos necessários para configuração fim-afim, restringem sua aplicação para a ampla gama de CPS com eventos periódicos e aperiódicos. A proposta baseia sua principal contribuição na concepção, implementação e avaliação de desempenho, primeiro da configuração dos componentes de serviços do middleware para controle de admissão e balanceamento de eventos periódicos e aperiódicos fornecendo uma plataforma de software flexível para sistemas distribuídos ciber-físicos com restrições de tempo fim-a-fim. A chave da abordagem para dar suporte a tarefas aperiódicas e periódicas em diferentes aplicações para CPS é um framework de componentes configuráveis que pode ser utilizado para diferentes conjuntos de tarefas aperiódicas e periódicas. Um dos componentes desenvolvidos denominado de AC (Admission Controller), fornece o controle de admissão de componentes on-line e testes de escalonabilidade para tarefas que chegam dinamicamente em tempo de execução. Um outro componente denominado de IR (relata todas as sub-tarefas 
concluídas em um processador para o componente AC quando o processador fica ocioso (Idle), de modo que o componente AC possa remover as suas contribuições reduzindo assim o pessimismo da análise AUB em tempo de execução, de acordo com a regra de reajuste ocioso. Existem também outros componentes como o LB - Load Balancer e TE - Task Efector associados ao processo. Quando utilizados, estes componentes juntos as suas estratégias de funcionamento, alcançam dez e oito combinações de ações, no entanto, algumas destas não aplicáveis, para isto propôe-se a exclusão de algumas combinações pela sua semelhança na execução.

- Observações: As combinações e métodos utilizados correspondem a um modelo CORBA Real-Time otimizado. O modelo é otimizado na sua interface de comunicação com o objetivo de flexibilizar a configuração e tratamento de eventos aperiódicos e periódicos que resultam das camadas subjacentes; isto resulta em um maior desempenho dada a robusteza da arquitetura CORBA. Os resultados apresentados são fundamentados em referências com resultados empíricos o qual não invalida o método, entretanto, existe uma clara ausência de caracterização de um cenário de testes mais heterogêneo, assim como da descrição das arquiteturas de hardware e o conjunto de protocolos que podem ser associados sobre este middleware. Os controles de escalabilidade e escalonabilidade são necessários para dispositivos de hardware que se sincronizam da rede durante o funcionamento da aplicação assim como a diversidade de eventos gerados pelos dispositivos e aplicações em tempo de execução. As arquiteturas CORBA se caracterizam pela variedade de aplicações que podem ser criadas e integradas sobre esta arquitetura, mesmo assim suas exigências de desempenho, troca excessiva de mensagens entre componentes para conclusão de um processo, ou sua interrupção em tempo de execução, deixam a arquitetura restrita a cenários de aplicação com alta disponibilidade de processamento e recursos de energia.

\subsubsection{Um Middleware Framework Cyber-Físico para Monitoramento Contínuo de Sistemas de Distribuição De Água (A Cyber- physical Middleware Framework for Continuous Monitoring of Water Distribution Systems) [4]}

Em [4] apresenta-se o resumo da proposta de um middleware Framework para monitoramento e controle de sistemas de distribuição de água em grande escala (Figura 3.5)

A figura 3.5 mostra o projeto do middleware framework representado numa estrutura de 


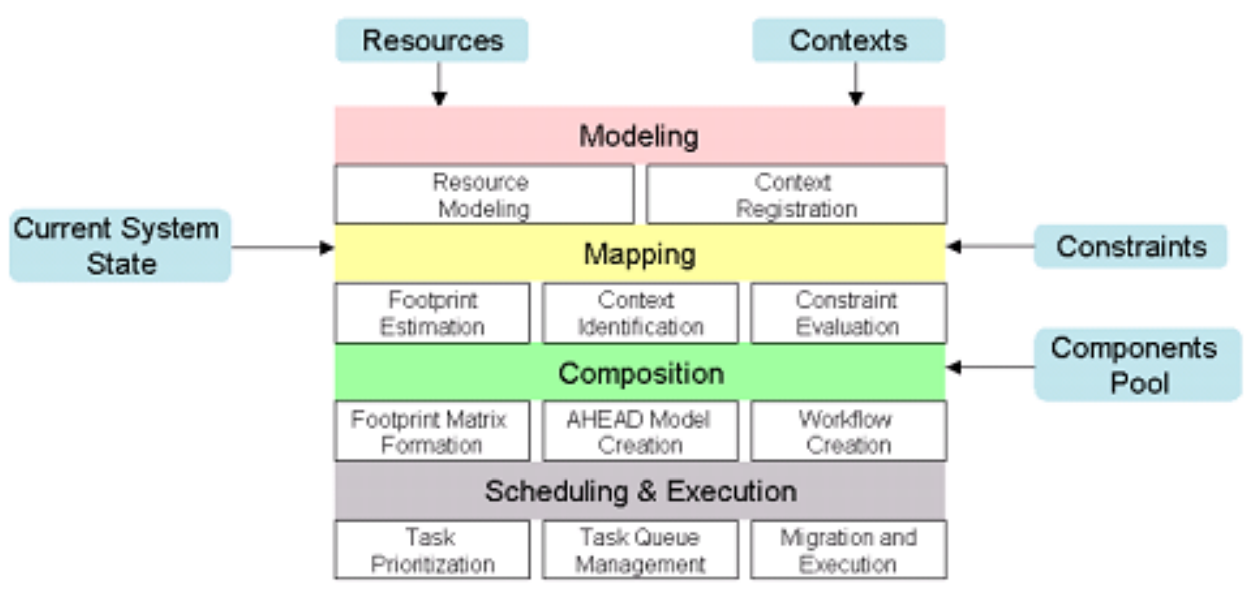

Figura 3.5: Middleware Framework proposto em [4].

camadas seguindo um modelo FOSD (Feature Oriented Software Design) [8]. A abordagem categoriza os componentes de forma intrínseca ou extrínseca, de modo que o middleware possa evitar a utilização desnecessária de componentes no fluxo de execução. Cada evento e ação correspondente acontece e utiliza recursos num contexto particular, esta informação é fundamental para saber quais agentes devem ser incluídos no fluxo de ação de modo que a tarefa desejada seja corrigida no próprio contexto sobre as restrições oferecidas. Como exemplo teríamos um caso de detecção de fugas, onde agentes são utilizados para processar tanto a pressão e os dados acústicos em tempo real para encontrar padrões que caracterizem um vazamento na tubulação. Após a detecção de um padrão, um fluxo de trabalho será criado para localizar o vazamento. O modelamento de mapas para as entidades do sistema e os fluxos de trabalho são formados utilizando princípios de equações hierárquicas algébricas para o desenho do sistema que segue uma implementação FOSD. Já para esta proposta utiliza-se de equações AHEAD que representam a classificação de cada entidade em termos da sua capacidade para participar no fluxo de trabalho em execução. AHEAD oferece uma ferramenta chamada de Origami Matrix para derivar composições do recurso.

- Observações: A descrição da proposta é bastante superficial já que resulta da publicação de um resumo (poster), porém não menos interessante. A proposta segue um modelo FOSD para construção de middleware e atribui a sua contribuição à utilização de equações AHEAD; na matriz as linhas indicam as características procuradas em uma entidade para uma tarefa no fluxo de trabalho e as colunas indicam todos os recursos possíveis e prestados por uma entidade. A proposta restringe-se à utilização de entidades para representar processos em um fluxo de trabalho e associar um evento para cada entidade dentro de um fluxo de trabalho, isto é bastante viável, e melhora significativamente a abstração e comunicação de alguns processo no middleware, entretanto é preciso da 
especificação de limites e classificações rigorosas da entidades e tarefas associadas com o objetivo de proporcionar maior confiabilidade ao sistema.

\subsection{Características e Observações Gerais}

O conjunto de middlewares descritos apresenta propostas com características interessantes, a maior parte destas baseadas em serviços, sejam para aplicações que precisam de um protocolo que facilite a alta densidade como o IPV6 e aplicações mais robustas, ou aplicações mais restritas como sensores e atuadores em ambientes comuns como um estacionamento. Apesar da relevância dos trabalhos, existe uma carência por flexibilidade, especificações para a confiabilidade, adaptabilidade e interoperabilidade dos middlewares (ver tabela 1) sobre e entre novas arquiteturas de hardware e protocolos de comunicação, assim mesmo é adequado observar que não existe especificação de abstração de arquiteturas de hardware que operem sobre mais de um protocolo de roteamento.

A utilização do middleware busca, como para muitas aplicações em sistemas distribuídos, criar uma estrutura robusta para tratar e integrar a informação de outras camadas, fornecendo maior integridade entre os serviços e as aplicações. A integração de camadas e serviços acaba sendo muito mais complexa quanto maior é o numero de camadas, serviços e aplicações; este é o caso dos CPS. A utilização de técnicas orientadas a serviços para gerenciamento de informação e integração da comunicação entre camadas não é uma tarefa simples. É necessário especificar a forma de comunicação entre as camadas, definir os serviços e quem gerencia a comunicação entre eles, prioridades dos requisitos funcionais ou não funcionais em tempo de execução considerando requisitos de tempo para evitar situações criticas. Escolha do protocolo de comunicação mais adequado que ofereça confiabilidade aos serviços e determinar a quantidade certa de abstração pelo middleware, tipos de dispositivos e funcionalidades dentro da estrutura da aplicação, publicar para o administrador do CPS interfaces com características de design flexíveis que permitam o tratamento de novas estruturas de protocolos de roteamento segundo as exigências da aplicação em curso, não são abordadas pelos middlewares descritos nesta seção. 
Tabela 3.1: Características dos middlewares.

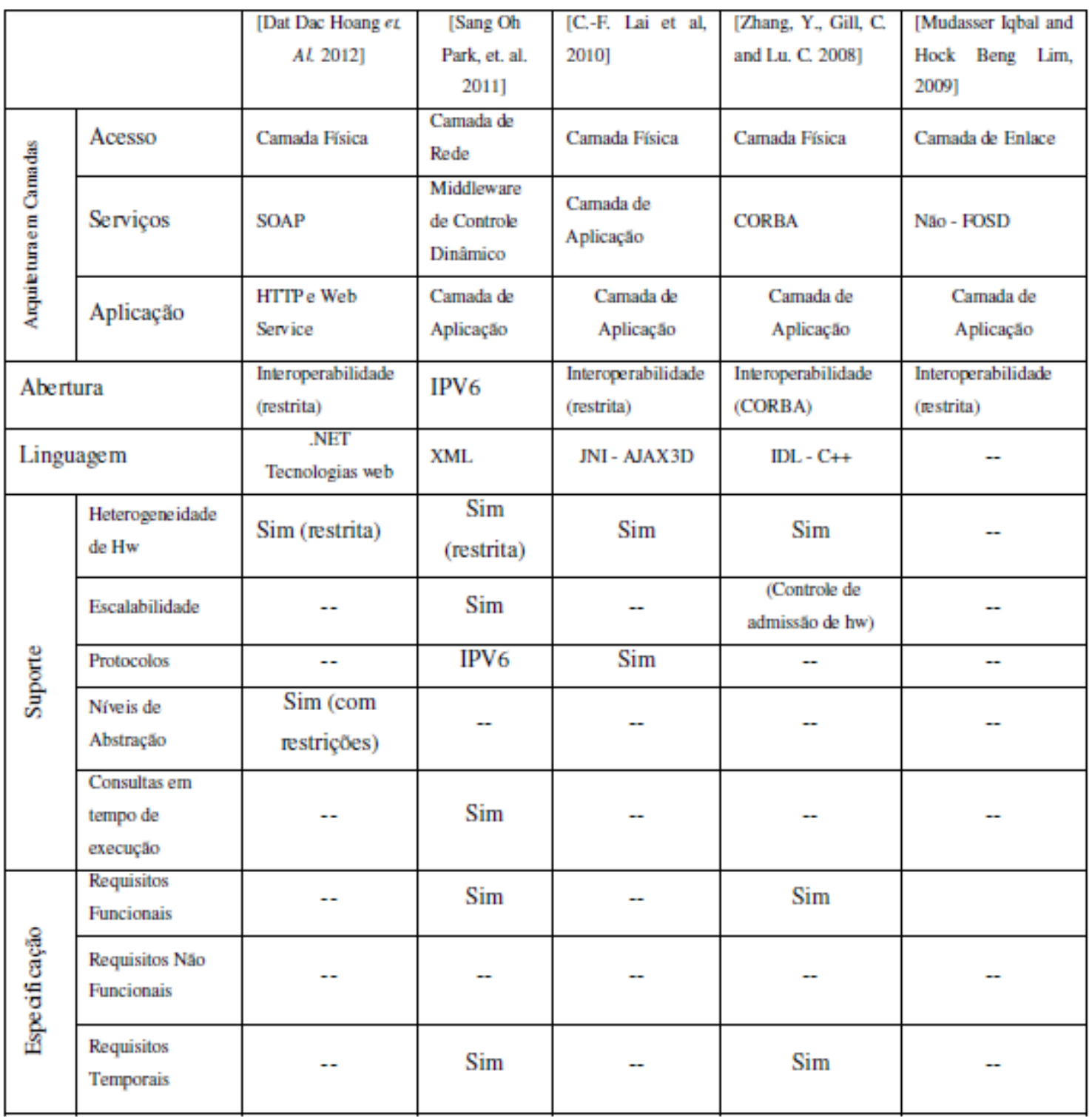

A tabela 3.1, apresenta o conjunto de características e aspectos abordados pelos middlewares descritos e analisados nesta seção. Alguns dos trabalhos analisados estabelecem técnicas de abstração e serviços a partir da camada de enlace e rede, sendo assim variáveis relacionadas ao meio de comunicação são excluídas deixando atrás possibilidade de gerenciamento de eventos críticos como resultado das informações providas por esta camada. Informações de qualidade de enlace - LQI, potência do sinal recebido - RSSI são úteis para determinar o tempo de vida e a confiabilidade em função da disponibilidade do MST na manutenção de processos e rotas dentro de uma aplicação.

A clara especificação de requisitos é tratada de forma bastante superficial e alguns dos trabalhos não são considerados, sendo difícil determinar o alcance das funcionalidades dos 
middlewares propostos. Níveis de abstração para os atores do sistema são relevantes para evitar a divulgação excessiva de informação, lógica do serviço e aplicação para os atores do sistema, em alguns casos isto pode evitar o surgimento de eventos críticos relacionados à segurança da informação provida pelos elementos sensores e atuadores do CPS. Em alguns dos trabalhos descritos são mencionados os atores para os middlewares, entretanto, não se especifica a abrangência dos serviços disponíveis e os níveis de abstração dos mesmos para estes atores.

O CiberSens, diferente dos middlewares descritos nesta seção, flexibiliza a utilização de diversas arquiteturas de hardware de MSTs (Módulos Sensores Transmissores) e MSBs (Módulos Estação Base) em funcionamento no CPS, assim como de diversos tipos de protocolos de comunicação através da identificação dos atributos comuns aos protocolos multihop e singlehop, como origem, destino, numero de saltos, tempo de amostragem, número de amostras, tipo de amostra, parâmetros de RSSI e LQI, etc. O método de processamento e desagregação dos dados e o mesmo para cada protocolo e, para quando partes da estrutura do protocolo muda (inclusão de um novo protocolo) é providenciado o acesso à estrutura do serviços de abstração do protocolo para o administrador (aqui é necessário determinar o nível de abstração para evitar com que o administrador extraia um número excessivo de parâmetros do protocolo, o qual possa influenciar o desempenho e confiabilidade do sistema), de modo que através de uma estrutura XML ele consiga realizar a alteração e identificar os campos que deverão ser armazenados, processados e abstraídos para o próprio administrador e para o usuário do CPS, depois disto a comunicação e abstração da informação deve acontecer de forma intuitiva.

Na camada de comunicação e suporte, o CiberSens gerencia os MSBs e armazena a informação da estrutura completa de dados do monitoramento e roteamento que resultam da aplicação e dos MSTs com o intuito de gerar estatísticas das redes associadas aos ambientes cenários e atividade do MST.

A interoperabilidade e flexibilidade da estrutura de classes, módulos, métodos, atributos e serviços projetados para o CiberSens permite a inclusão de novos módulos e aplicações à estrutura de gerenciamento e abstração.

No projeto do Middleware CiberSens, é necessário considerar que o desenvolvimento de aplicações próprias para RSSF envolve requisitos específicos como; controle no consumo de energia, escalabilidade da rede, otimização da rede (protocolos, sincronização), interfaces para tratamento de dados do nó, entre outros requisitos que deverão ser levados em conta no projeto de todo middleware para CPS, sem deixar de considerar que em determinados ambientes e aplicações esses parâmetros podem ser um obstáculo à implementação da aplicação. Portanto, um processo metódico e sistemático é adotado para mediar o conflito entre requisitos específicos 
que influenciem a implementação do modelo no caso de uso de uma RSSF dentro de um CPS.

Este trabalho de tese procura optar por uma abordagem que considere, além de requisitos básicos, os diversos modelos de entrega de dados (medidas periódicas, requisição-resposta etc), níveis de abstração e suporte a heterogeneidade de dispositivos e protocolos que influenciam e caracterizam fortemente a interação entre as camadas subjacentes do middleware e os serviços associados a cada camada, resultado da alta heterogeneidade de aplicações e dispositivos sensores e atuadores existentes dentro dos sistemas ciber-físicos (CPS). 


\section{Proposta e Metodologia}

Os sistemas distribuídos proporcionam os meios necessários para que os componentes de uma única aplicação distribuída se comuniquem uns com os outros.

\subsection{Fundamentação}

Nos últimos três anos têm sido desenvolvidos no Grupo de Computação Pervasiva e Alto desempenho - PAD, no Laboratório de Sistemas Integráveis - LSI da Escola Politécnica da Universidade de São Paulo, projetos que integram computação visual, redes de sensores sem fio, Sistemas de Radar UWB. Esses projetos prevêem a automatização de determinados processos e a possibilidade de serem inseridos como parte do próprio ambiente, de forma quase transparente para o usuário final. Como exemplo, temos a integração de computação visual com comunicação sem fio. Tal integração constituí-se numa Rede de Sensores Visuais a qual realiza a leitura dos medidores de água e coleta os dados da imagem adquirida, fazendo uso de um software para reconhecimento de caracteres (OCR) embutido em cada um dos módulos sensores [50]. Um estudo caracteriza a integração de uma rede de sensores sem fio em ambientes veiculares [51] prevendo e adquirindo informação útil para o piloto sobre o ambiente transitado. Óculos para deficientes com ELA, utilizam a aquisição de sinais EOG/EMG/EEG para executar comandos que facilitem a interação do paciente com seu ambiente. Em [52] desenvolve-se uma metodologia que facilita e direciona a implementação de aplicações de realidade aumentada (RA) em dispositivos móveis (p.ex. telefones celulares) que utilizem recursos como; câmera integrada, GPS, sensores integrados etc. O sistema de Radar UWB utiliza o padrão para detectar objetos através de obstáculos [53] como paredes. Se observarmos de uma forma mais abstrata como estas aplicações interagiram com o ambiente, concluiremos que acabarão sendo parte de um Sistema Ciber-Físico - CPS, porém, a dificuldade aparece quando se deseja integrar essas soluções para que possam interagir quase de forma imperceptível com o ambiente físico, e as informações adquiridas sirvam para modificar, alterar ou até mesmo antecipar e reprogramar algumas atividades ou processos no ambiente físico. 
Neste trabalho de tese o middleware proposto é chamado de CiberSens 4.1 o qual deve prever a capacidade de integração das diversas aplicações as quais incluam na sua composição arquiteturas de redes de sensores sem fio. É necessário salientar que os CPSs definem um alcance teórico bastante extenso difícil de ser representado num ambiente real de sensoriamento, atuação e controle. Este trabalho de tese restringe-se a pequenos domínios de controle com o objetivo de representar de forma mais clara e objetiva a alta complexidade existente dentro da heterogeneidade de dispositivos e aplicações que compõem os Sistemas Ciber-Físicos.

O trabalho identifica as características heterogêneas dos Sistemas Ciber-Físicos e procura atender às exigências de suporte a heterogeneidade para RSSF, flexibilidade na abstração de protocolos de comunicação através de um módulo integrador. Níveis de abstração de serviços para os atores do sistema, aspectos temporais, módulos de consulta à aplicação em tempo de execução, através do ambiente supervisório do CiberSens. Este trabalho de tese considera três aspectos relevantes em aplicações de CPS com RSSF, as quais são sensoriamento, controle e aplicação. O trabalho de tese apresenta estes aspectos relevantes através da descrição das camadas do Middleware e representação em uma aplicação-exemplo. O Trabalho inclui uma segunda aplicação exemplo que consiste na formalização de um processo de sensoriamento, atuação e controle através da utilização da ferramenta SysML.

Os middlewares oferecem um conjunto de vantagens como permitir a comunicação entre componentes de hardware e software heterogêneo, abstração de processos, transparência na comunicação entre o sistema e o usuário, entre outras características relevantes. Apesar das vantagens citadas sobre sua utilização, são poucos os projetos de RSSF que tem explorado esta tecnologia de integração denominada de middleware. Já o recente surgimento dos CPS exige a criação de camadas de software que facilitem a integração de arquiteturas heterogêneas, escaláveis com características altamente dinâmicas, é aqui que encaixam os middlewares, entretanto, é necessário maximizar as características tecnológicas desta camada de software agregando confiabilidade, integridade e robustez nos seus processos de integração e comunicação dentro das aplicações para CPS.

\subsection{O CiberSens}

O middleware CiberSens (figura 4.1) facilitará a extração de dados do mundo físico e os transformará em dados representados de forma padronizada e que possam ser incluídos em trabalhos de computação em diversas aplicações de CPS e RSSF.

No projeto do CiberSens segue-se um estilo arquitetônico de implementação em camadas, 
assim como uma estrutura de implementação e comunicação orientada a serviços a qual procura ser o suficientemente flexível para integrar um número extenso de aplicações, hardwares e protocolos de comunicação heterogêneos.

Diferente de outros middlewares descritos em capítulos anteriores, o CiberSens abstrai a comunicação dos MSTs (Módulo Sensor Transmissor) que fazem parte da aplicação e que utilizam diversos protocolos de comunicação com o intuito de maximizar o desempenho e a confiabilidade através da utilização de um módulo integrador - MI. Estes MSTs podem responder a arquiteturas de hardware heterogêneo com estruturas de pacotes e amostragem própria de cada arquitetura e protocolo utilizado.

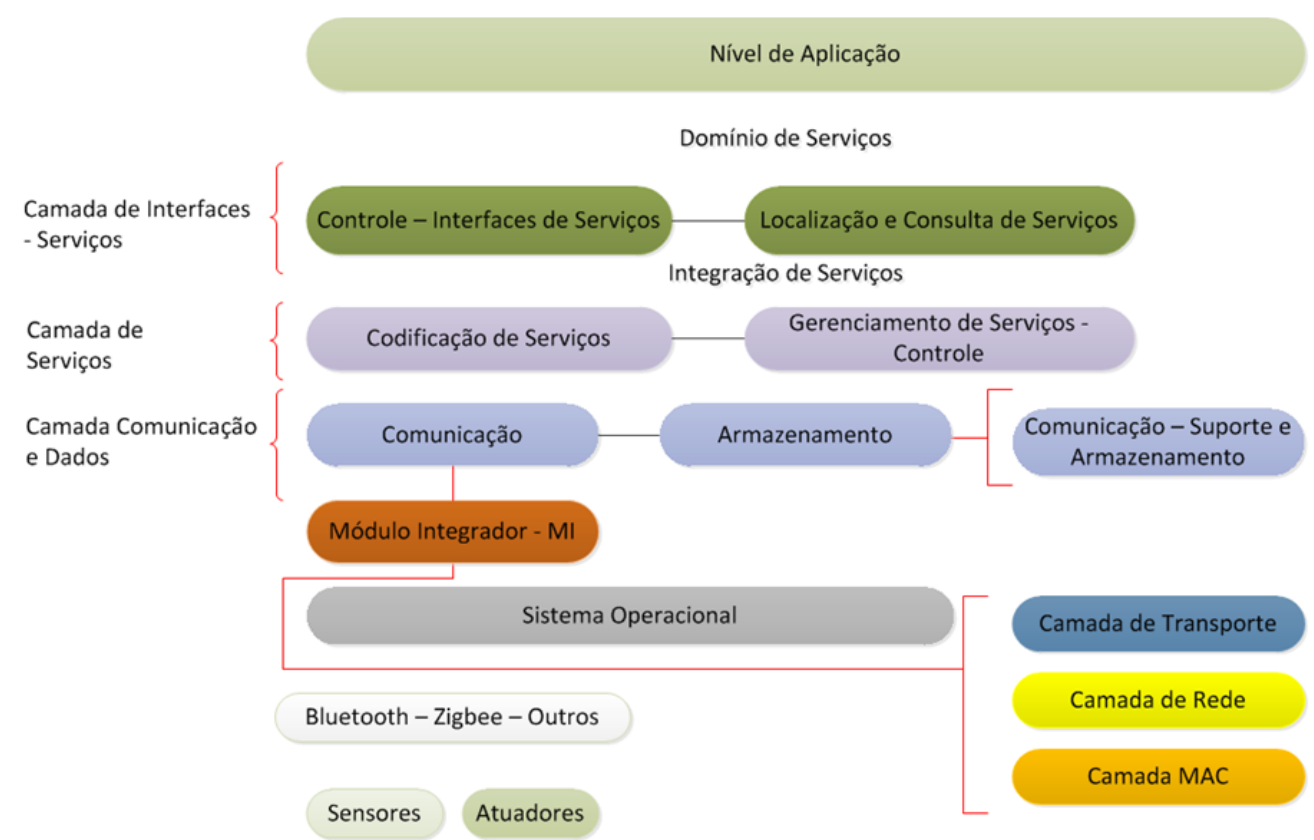

Figura 4.1: Modelo de Camadas do Middleware CiberSens.

O conjunto de serviços e processos associados que compõem o CiberSens (figura 4.1) são detalhados em cada uma das camadas (Secção 4.4, Descrição de Camadas). Na aplicaçãoexemplo (Capítulo 5), descreve-se o desenvolvimento do modelo de middleware com maior nível de detalhes procurando facilitar a identificação e associação das técnicas, linguagens e protocolos mais adequados para sua implementação em cada camada do middleware, assim como a manipulação das estruturas de dados e serviços, tanto pelo usuário como pelo administrador do CPS.

No projeto do middleware é necessário seguir uma metodologia de desenvolvimento semelhante ao das aplicações, incluindo no processo fases de análises de requisitos, modelagem lógica dos dados, e outros processos formais padronizados para facilitar a compatibilidade na 
comunicação entre as aplicações e as camadas subjacentes ${ }^{1}$. No projeto do CiberSens, inclui-se aspectos espaciais, aspectos temporais, espaço temporais dos elementos físicos que constituem a realidade do ambiente físico, diferente de outros middlewares. O Cibersens deve ser capaz de capturar todos esses parâmetros característicos do CPS, com o intuito de facilitar o posterior projeto de novas aplicações e sua integração com arquiteturas heterogêneas.

\subsection{Especificações do Middleware}

Nesta seção, é descrita uma breve e importante classificação dos requisitos Funcionais e Não Funcionais existentes em uma Rede de Sensores sem Fio num ambiente Ciber-Físico. Alguns destes requisitos serão considerados como variáveis de entrada no CiberSens, imediatamente depois é realizada uma descrição das camadas apresentadas na figura 4.1.

Ao contrário dos sistemas embarcados convencionais que trabalham com arquiteturas de dados centralizados, os CiberSens é concebido para coordenar a parte física e computacional de um CPS no qual incluia atividades de sensoriamento, controle e aplicação em pequenos dominios de atuação.

\subsubsection{Requisitos e considerações para o CiberSens}

Os requisitos obedecem a características de funcionamento das RSSF na sua interação com o ambiente físico, e são consideradas no modelamento, uma das etapas mais importantes do futuro sistema, sendo classificados em:

- Requisitos Não-Funcionais: São as exigências de qualidade impostas ao sistema. Os requisitos não funcionais consideram métricas e variáveis que tem relação com a caracterização do sistema, como: escalabilidade, confiabilidade, segurança, indicadores de desempenho, suporte de linguagens, entre outros etc.

Descrever o conjunto de requisitos não funcionais não é uma tarefa trivial, já que da precisão na descrição destes requisitos dependerá drasticamente a qualidade do sistema. Os requisitos não funcionais são determinados de acordo com as funcionalidades primárias do middleware.

- Requisitos Funcionais: São as características requeridas do sistema em função dos seus objetivos (estabelecem o comportamento do sistema), identificam a capacidade de ação

\footnotetext{
${ }^{1}$ Em alguns casos o modelo de trabalho e disposição de ambientes e ferramentas pré-definido pelo middleware corresponde a tecnologias e critérios padronizados para sua fácil transição a um ambiente de aplicação.
} 
operacional, ambiente da aplicação, e outras funcionalidades que especificam como os casos de uso serão levados à prática.

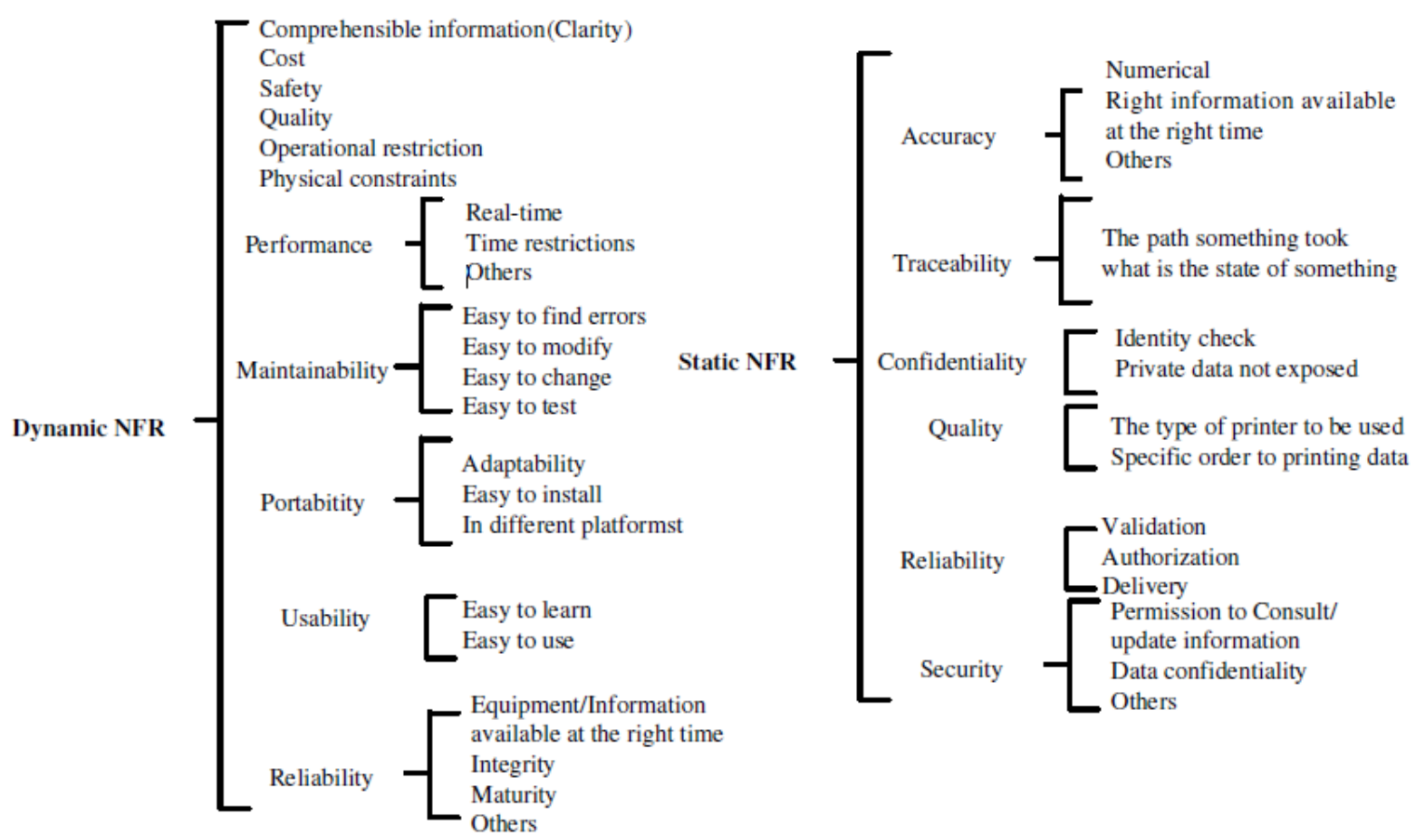

Figura 4.2: Especificação de Requisitos para Middleware [5].

O conjunto de padrões ISO/IEC relacionados a qualidade de software orienta a utilização de três normas ISO a 9126 [54], 14598-1 e 14598-4 [5]. As normas descrevem modelos de qualidade de software, sendo especificamente a norma ISO 9126 que descreve um conjunto de seis características de nível superior para qualidade de software, as quais são: funcionalidade, confiabilidade, usabilidade, eficiência, manutenção e portabilidade. Assim mesmo um anexo desta norma fornece um modelo de qualidade que descreve um conjunto de requisitos não funcionais num middleware agrupados em duas categorias, dinâmicos e estáticos (Figura 4.2)

\subsubsection{Requisitos Funcionais e Não Funcionais para um Sistema Ciber- Físico}

O conjunto de requisitos descritos a seguir são independentes uns dos outros. Os Funcionais servem para determinar as principais características dos CPS em função da aplicação. Os Não Funcionais são descritos e explorados com o intuito de melhorar e aperfeiçoar a arquitetura de RSSF desenvolvida para o contexto do CPS, considerando a diversidade de aplicações. 


\section{Requisitos Funcionais}

Os requisitos funcionais (Figura 4.3) definem de forma concreta o que o CiberSens deve fazer e dependerá das características da aplicação para as quais esteja sendo desenvolvida.

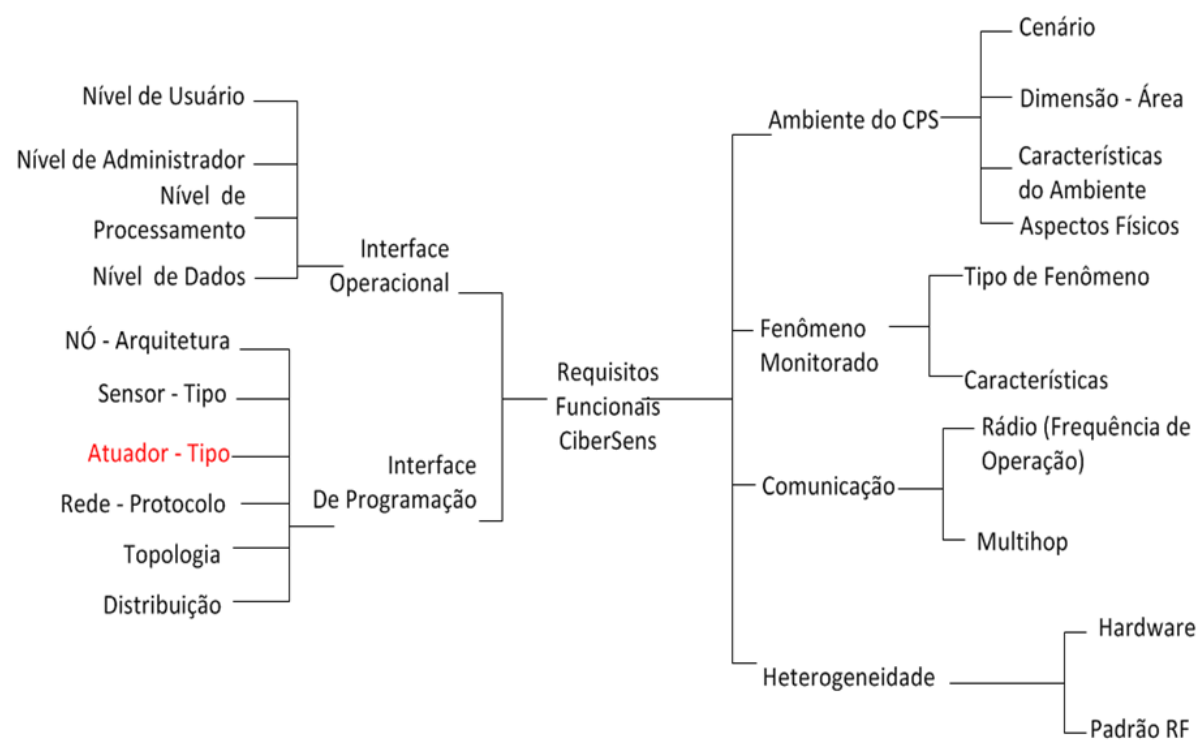

Figura 4.3: Especificação de Requisitos Funcionais para o CiberSens.

\section{Requisitos Não Funcionais}

Os requisitos não funcionais (figura 4.4) são as restrições sobre os serviços oferecidos pelo sistema e aplicam-se ao sistema como um todo. Na prática os requisitos não funcionais podem mudar durante a vida útil do sistema

Antes de determinar o conjunto de requisitos não funcionais que fazem parte de uma aplicação para CPS é relevante identificar o conjunto de elementos que fazem parte da interface operacional (Figura 4.3) da arquitetura de hardware associada à aplicação. Para nosso caso uma rede de sensores sem fio, a identificação deste conjunto de parâmetros permite identificar de forma mais clara os requisitos não funcionais que resultam da associação do hardware e a aplicação. 


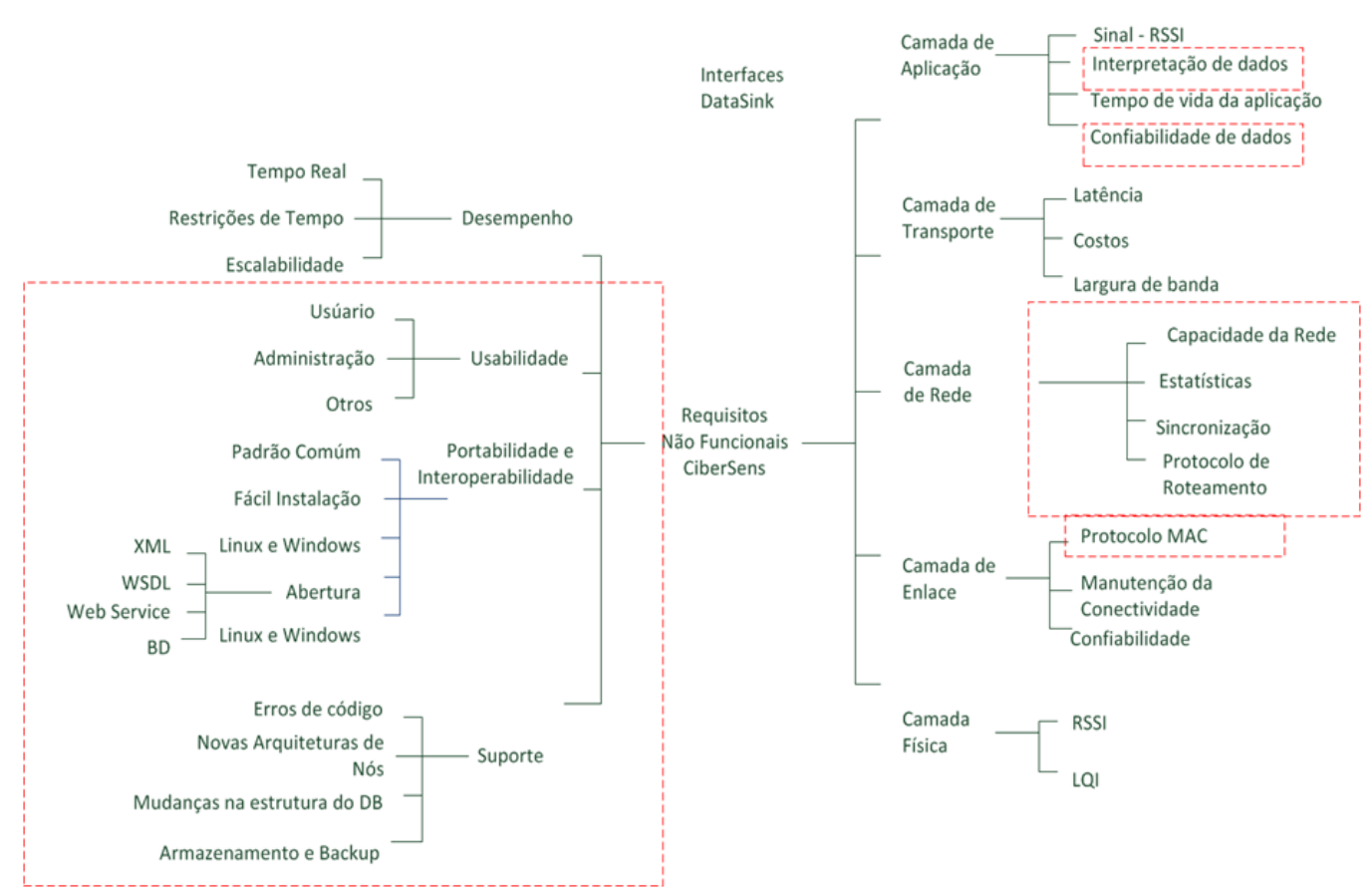

Figura 4.4: Especificação de Requisitos Não Funcionais para o CiberSens.

No contexto do caso de estudo para aplicação do CiberSens a especificação e gerenciamento de requisitos é bastante rígida. No entanto, é necessário considerar a possibilidade de um cenário no qual algum dos requisitos não funcionais, associados a um determinado objetivo no processo de execução na aplicação pode mudar de meta em termos de flexibilidade e pode ser considerado um requisito não funcional sem restrições. Dentro de um CPS a escalabilidade e flexibilidade das aplicações devem ser os requisitos não funcionais mais relevantes a ser considerada em um modelamento, esta última característica deve permitir que quando um requisito não funcional não alcance seu objetivo associado, então o nível de exigência deve ser baseado em uma análise do melhor esforço.

\section{Requisitos Não Funcionais Temporais}

O correto funcionamento do sistema depende não só do resultado dos processos lógicos de computação, mas também do momento em que se produzem esses resultados. Num CPS esta característica acaba sendo critica devido ao grande numero de aplicações integradas que interagem em tempo real. O conjunto destas aplicações e os componentes de hardwares devem ter a capacidade de se sincronizar com o entorno para obter um funcionamento adequado. Os CPSs associam um conjunto grande de sensores com características heterogêneas que exigem a especificação de requisitos temporais que proporcionem confiabilidade à aplicação em execução, estes requisitos providenciam o monitoramento permanente dos sensores, processamento oportuno da informação recebida, monitoramento dos pontos de armazenamento 
de informação e dos eventos que desencadeiam processos em outras aplicações.

No CiberSens as operações executadas através dos componentes das camadas subjacentes são representadas como eventos, por exemplo, quando um novo MI (Módulo Integrador), associado a uma arquitetura especifica de hardware, é iniciado junto ao middleware executase um evento de conexão, o evento é gerenciado por um "thread de conexão"que associa outros threads os quais operam como um conjunto de funções que para o nosso caso gerenciam as interfaces de conexão para os novos dispositivos, identifica a estrutura do frame e invoca o serviço que realizará a decodificação. A informação é armazenada no nível de dados e acessada pela camada de serviços.

Cada evento associa um conjunto de requisitos não funcionais espaço-temporal, seguindo esta afirmação concluímos que um evento é definido como uma combinação de uma ou mais condições de eventos, que são restrições em termos de atributos, tempo, localização. Seguindo o modelo descrito em [55], é possível representar um evento como:

$$
P E_{i d}\left\{t_{E i d}, l_{E i d}, V_{E i d}\right\}
$$

Onde $P E_{i d}$ é o identificador do evento físico, $t_{E i d}$ e $l_{E i d}$ são as ocorrências espaço temporais e $V_{E i d}$ são os atributos do evento físico.

O fenômeno observado é representado como:

$$
\text { PO }(\text { MTid }, \text { SRid }, i)\left\{t_{0}^{o}, l_{0}^{o}, v_{0}\right\}
$$

Onde $P O$ é o fenômeno físico observado, SRid é o tipo do sensor instalado sobre o MTid e $i$ é o fenômeno observado e $t_{O}^{o}\left({ }_{M T i d, S R i d, i}\right), l_{O}^{o}\left({ }_{M T i d, S R i d, i}\right), v_{O}^{o}\left({ }_{M T i d, S R i d, i}\right)$ são as ocorrências da observação física hora, local e atributos, respectivamente.

O evento sensor [55] serve como o primeiro nível para observações no modelo de eventos no CPS:

$$
S E(M T i d, S R i d, i)\left\{t_{S E}^{g}, l_{S E}^{g}, t_{S E}^{e o}, l_{S E}^{e o}, V_{S E}, p s\right\}
$$

MTid é o mote sensor que gera o evento com base na identificação de evento do sensor, $S i d$ na instância do evento $i$. Além disso a 6-tupla propriedade utilizada, onde $t_{S E}^{g}\left({ }_{M T i d, S R i d, i}\right)$ e $l_{S E}^{g}(M T i d, S R i d, i)$ são o tempo e local relacionado com a ocorrência de eventos e mote sensor, respectivamente, $t_{S E}^{e o}(M T i d, S R i d, i), l t_{S E}^{e o}(M T i d, S R i d, i)$, e $V_{S E}^{e o}(M T i d, S R i d, i)$ são o tempo estimado da ocorrência do evento, local e atributo de acordo com o mote sensor e ps (MTid,SRid,i) é o evento 
de confiança do mote sensor em relação ao evento sensor.

Simplificando a representação particular de um evento com a formula 4.1, por exemplo, o monitoramento do aquecimento do servidor $\mathrm{x} 1$ denotado como SCServer ${ }_{x 1}$, no instante $t_{\text {SCServer }} 1$, localizado na posição $l_{S C \text { Server }_{x}}$, detectado por meio dos atributos Temperatura $V_{S C S e r v e r}$ emp $_{x} 1$ e Umidade relativa $V_{S C S \text { Sever }_{U}}$ Ii $_{x} 1$, pode-se expressar por meio de:

$$
\operatorname{SCServer}_{x 1}\left\{t_{\text {SCServer }_{x} 1}, l_{\text {SCServer }_{x} 1},\left[V_{\text {SCServer }_{T} \text { emp }_{x} 1}, V_{\text {SCServer }_{U}} i_{x} 1\right]\right\}
$$

Desta maneira, o evento Aquecimento no servidor x1, pode-se ser detectado por meio da avaliação dos atributos Temperatura e Umidade relativa de sensor próximo dele (x1), além de estar associado com os atributos de outros eventos definidos para o sistema, os quais podem ser representados seguindo as formulas 4.2 4.3.

Os CPS apresentam uma alta complexidade e heterogeneidade de componentes de hardwares e aplicações as quais devem interagir com o ambiente físico observando, processando e reagindo a fenômenos externos, tudo isto em tempo real. Seguindo estas exigências é necessário considerar requisitos temporais como: i) segundo o esquema de ativação e ii) segundo o prazo de execução.

\section{- Requisitos temporais segundo Esquema de Ativação}

Estes requisitos podem ser de Ativação Periódica ou Aperiódica. Os requisitos de ativação periódica são acionados uma vez por cada período T, e exatamente cada período T. (Figura 4.5).

Dentro do CPS a RSSF precisa utilizar técnicas de amostragem para oferecer uma maior eficiência e principalmente confiabilidade dos dados coletados durante o monitoramento. No CiberSens entre os requisitos temporais temos um número diferenciado e fixo de coleta de amostras por sensor. Por exemplo, considerando a utilização de dois protocolos de roteamento, singlehop e multihop para equilibrar a eficiência e a confiabilidade dos dados adquiridos do ambiente físico os sensores transmitem o resultado de 5 e 10 leituras num único frame em exatamente cada T. Na prática teríamos 5 ou 10 leituras a cada $100 \mathrm{~ms}$, este último parâmetro pode ser alterado pelo administrador segundo as características da aplicação. Poder alterar o ciclo de transmissão é interessante para algumas aplicações, contudo, quando já se tem um conjunto alto de amostras por frame não é necessária uma transmissão com alta periodicidade. 

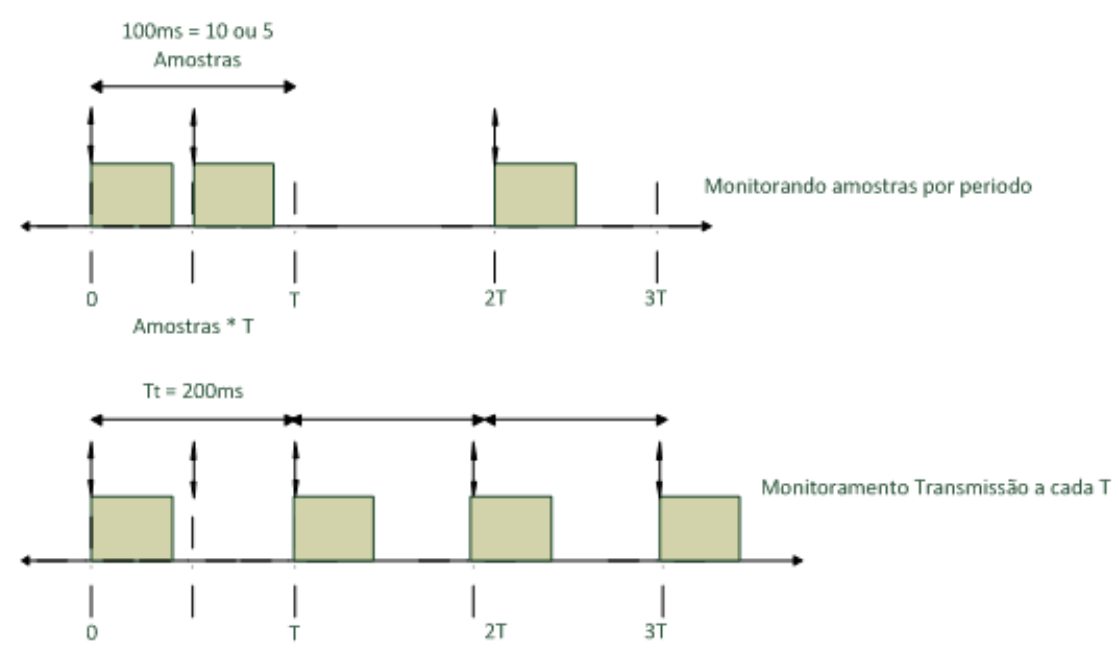

Figura 4.5: Representação de requisitos de ativação periódica.

Como mencionado, algumas aplicações no CPS, como o controle de eventos, pode exigir nós sensores para realizar observações e transmissões periódicas das características dos eventos detectados. No CPS o grau de correlação entre as medições consecutivas do nó sensor pode variar de acordo com as características de variação temporal do fenômeno físico.

No projeto do CiberSens, e mesmo dentro do CPS é necessário flexibilizar a execução de alguns requisitos, deixando que os objetivos de cada um destes seja alcançado também em função do melhor esforço. É aqui que é necessário considerar a aplicação de requisitos temporais segundo o prazo de execução.

Para isto é possível utilizar algumas combinações de requisitos, como periodicidade, tempo de execução e validade, assim mesmo a junção de requisitos temporais e funcionais que exijam um nível menor de precisão, porém permitam a conclusão do processo. Em algumas aplicações o importante e a entrega e recepção do dado e não o tempo que leva no percurso de transmissão e recepção.

$\mathrm{Na}$ figura 4.6, é representado o processo de um requisito temporal segundo o prazo de execução. 


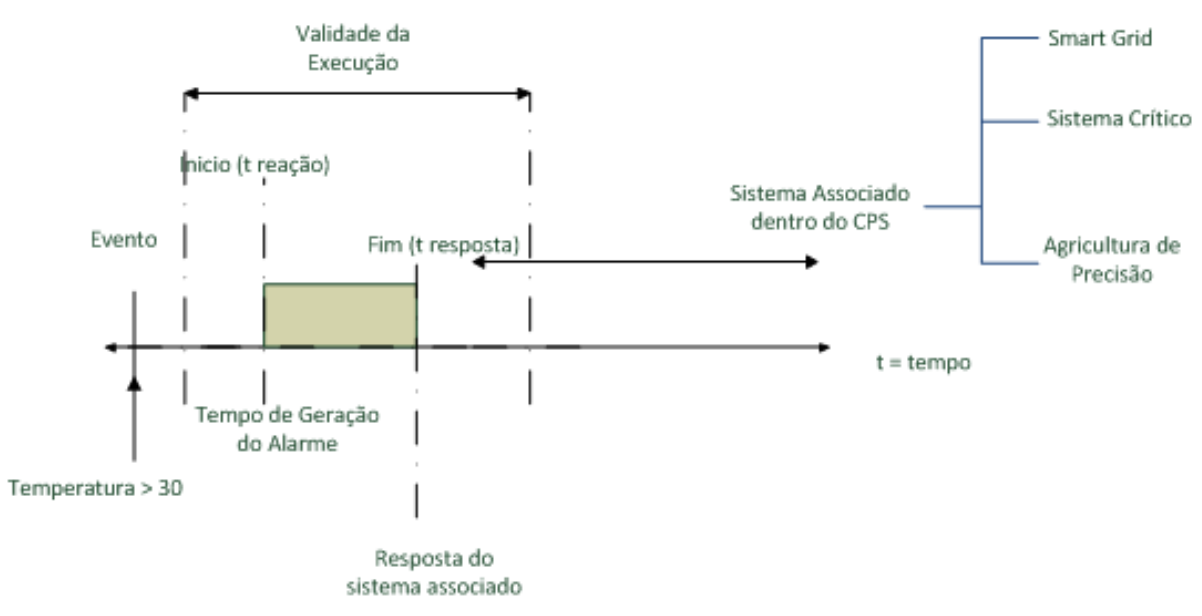

Figura 4.6: Representação de requisito segundo o prazo de execução.

$\mathrm{Na}$ aplicação de requisitos temporais segundo o prazo de execução é necessário salientar que existem aplicações como a de sistemas críticos que não admitem sobre nenhuma circunstancia a violação do prazo de execução do evento.

Os requisitos funcionais e não funcionais apresentados são resultado de um cuidadoso estudo das características dos CPS e a estrutura de funcionamento de uma RSSF, a escolha e determinação de cada requisito passa por uma avaliação especifica e detalhada das atuais arquiteturas de redes de sensores, características espaciais e físicas de integração e iteração com o ambiente físico as quais são comuns a todos os CPS.

\subsection{Descrição de Camadas}

A ideia básica para implementação de componentes seguindo uma arquitetura em camadas segue uma lógica bastante simples; os componentes definidos como uma unidade modular com interfaces requeridas e fornecidas são organizados em camadas e, os componentes de camadas superiores se comunicam com componentes de camadas subjacentes, para o nível de atuação, e das camadas subjacentes para as camadas superiores, no nível de sensoriamento. Isto quer dizer que basicamente o controle da comunicação flui de camada para camada mantendo uma hierarquia, quando uma solicitação acontece esta resulta da camada superior $\mathrm{C} 1$ para a camada inferior C1-1 e a resposta flui na vertical, para cima (figura 4.7). 


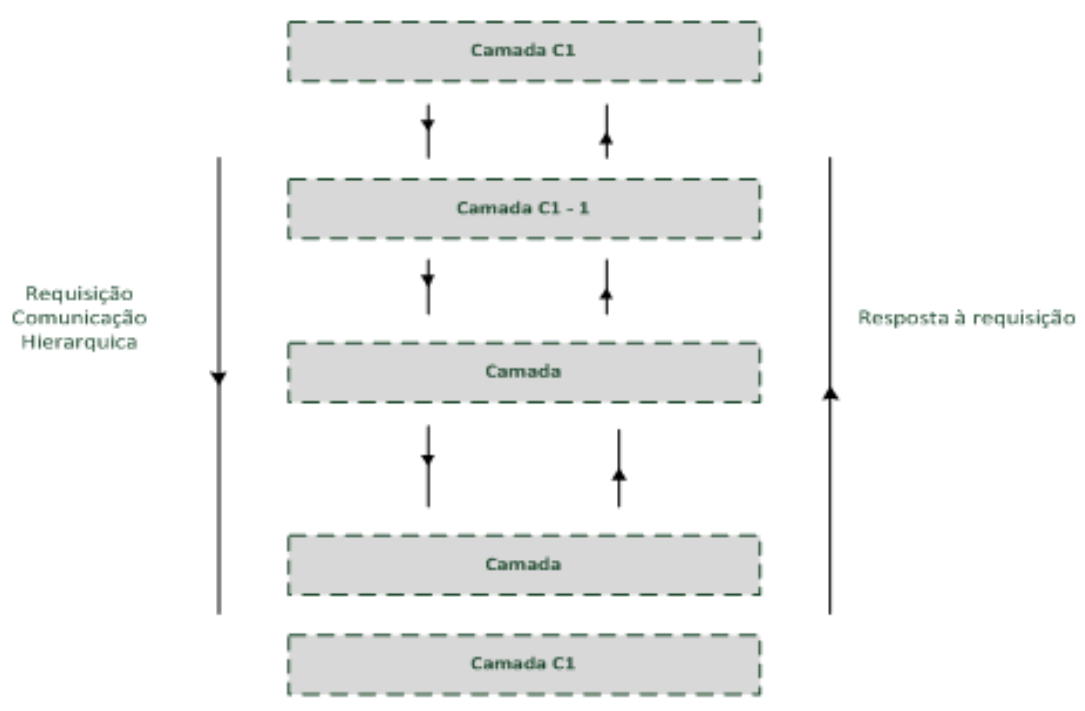

Figura 4.7: Estilo Arquitetônico em camadas - hierarquia de comunicação.

Esta forma de implementação e comunicação de componentes em camadas (Figura 4.7) segue a lógica de modelo de projetos MVC (Secção 4.4.5., Modelo de Projeto para o CiberSens), onde requisições de serviços seguem uma hierarquia, mais claramente descem pela hierarquia, o usuário solicita um serviço a camadas inferiores e resultados seguem um fluxo vertical, de baixo para cima.

\subsubsection{Camada de Comunicação e Suporte}

Nesta camada (Figura 4.8) deve-se garantir o acesso à informação, dependendo do papel que está exercendo o usuário durante a requisição. Assim mesmo, na elaboração deste módulo consideram-se alguns parâmetros citados em [21], como topologia dinâmica, plataformas heterogêneas, tráfego misto, gerenciamento de energia e protocolos de comunicação. Para atingir a qualidade destes parâmetros, serão necessários padronizar a utilização de topologias e protocolos para as aplicações a serem suportadas pelo CiberSens. 


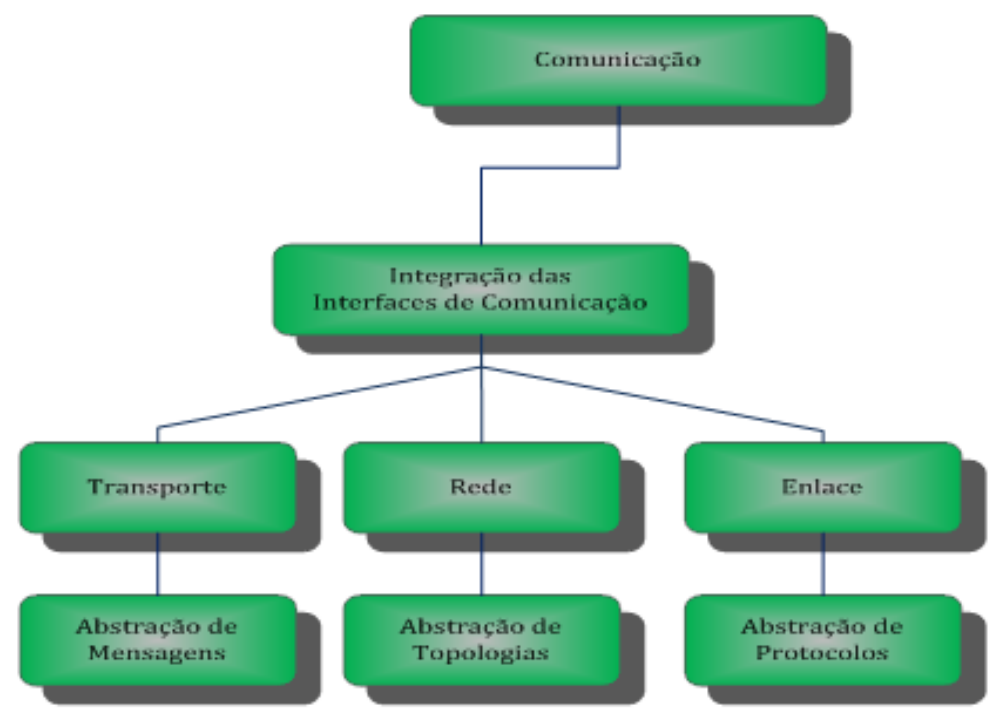

Figura 4.8: Diagrama da camada de Comunicação e Suporte - Módulo Integrador (MI).

\section{Módulo Integrador MI}

O elemento mais importante para nosso Middleware é o chamado MI, considerado a principal contribuição do CiberSens o MI atua como um elemento de integração entre os dispositivos sensores, atuadores (MST e MSB) e o middleware. Basicamente o MI realiza o controle de captura do tráfego da rede, executa a inserção e remoção de módulos de hardware, abstração de protocolos de roteamento e controle de interfaces. As características de topologia são atendidas de forma intuitiva pelo CiberSens através do MI já que os parâmetros de organização e roteamento são transportadas no encapsulamento do protocolo na camada de rede e enlace (Figura 4.9).

Para flexibilizar o acesso e configuração do MI é preciso o desenvolvimento de uma API que permita a configuração de valores dos novos MSTs na rede, valores como tamanho total do pacote, tamanho do pacote de roteamento e do payload ${ }^{2}$ de dados.

\footnotetext{
${ }^{2} \mathrm{~A}$ informação do payload corresponde à informação do fenômeno observado e número de amostras por pacote. Está informação pode variar segundo as características do hardware dos MSTs.
} 


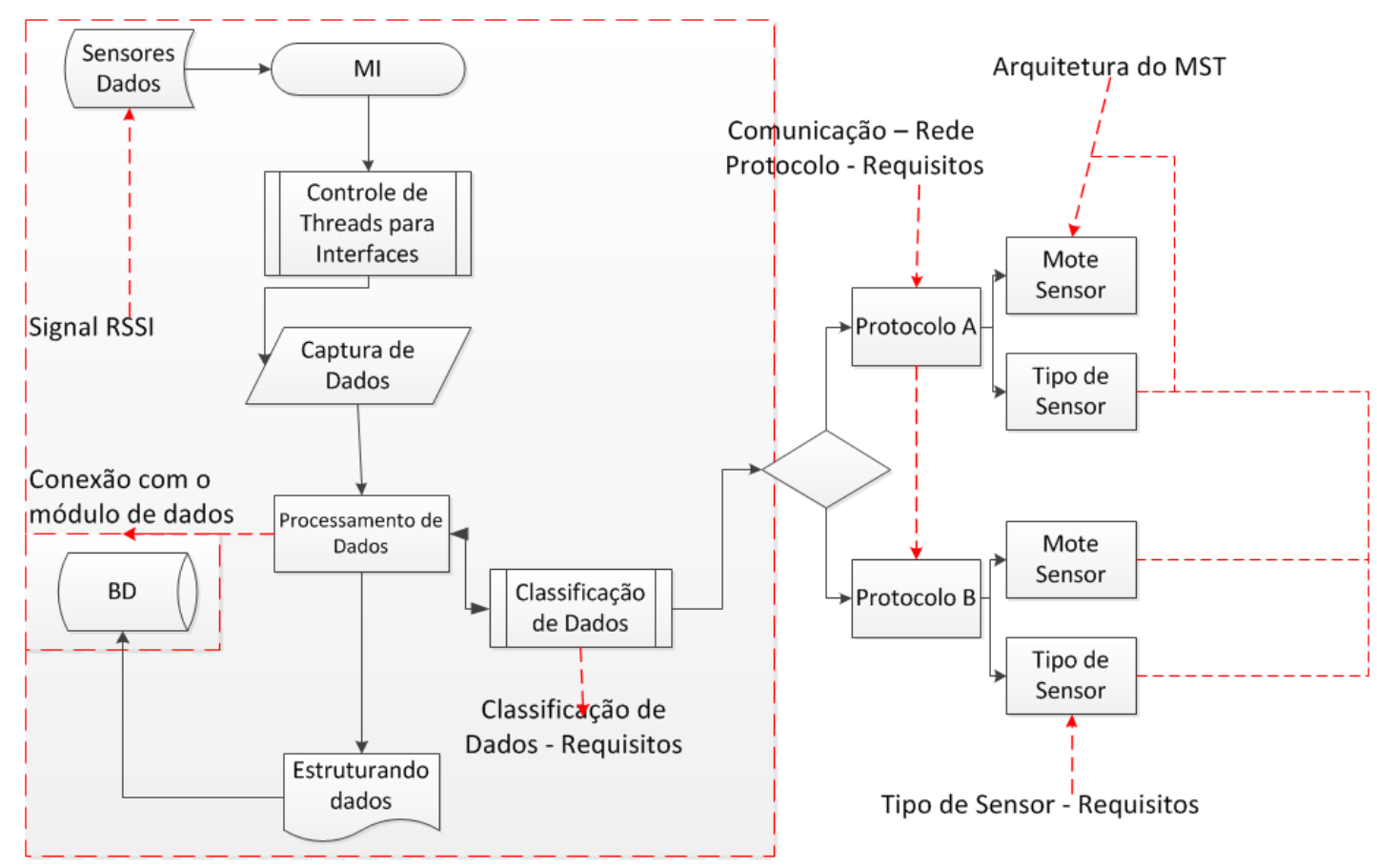

Figura 4.9: Diagrama de Operação do Módulo Integrado - MI.

O Diagrama procura especificar a lógica de abstração do MI, basicamente o módulo constitui a principal etapa do CiberSens. No MI, é realizado o gerenciamento das interfaces de comunicação, abstração de protocolos de comunicação, abstração de topologias e padrões de comunicação. No processo de inicialização do MI um thread inicia o controle das interfaces e um segundo thread inicia a captura baseada em controle de eventos (Figura 4.10).

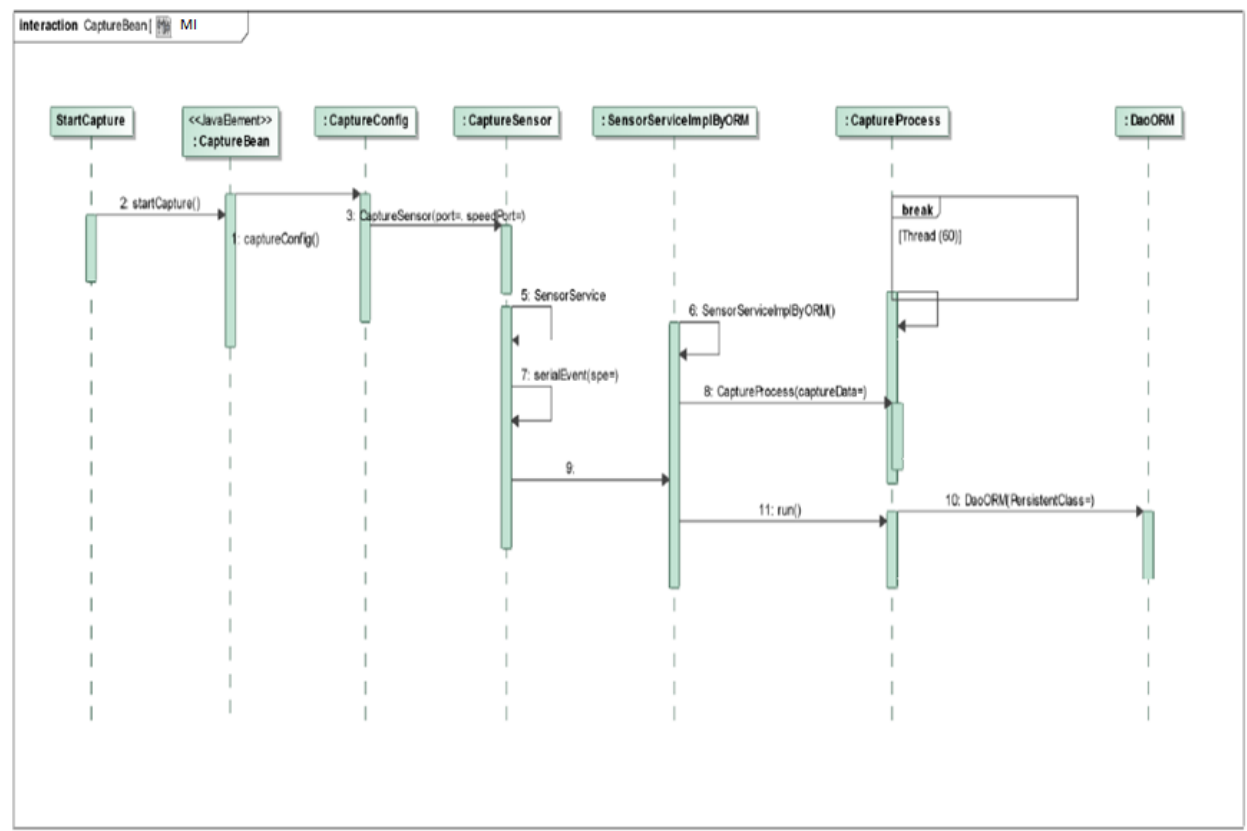

Figura 4.10: Diagrama de Sequência do Módulo Integrado - MI.

O MI pode ser iniciado tanto desde a interface do middleware como de forma independente 
no dispositivo de hardware, operando sobre a lógica de controle de um data sink, é claro que com um maior nível de funcionalidade e abstração.

No nível de interface do middleware o MI inicia-se com um botão "start", o qual da inicio ao método "StartCapture".

Na Interface (view) o botão "Start (do método "StartCapture") realiza um "request"para o nível de controle representado na classe "CaptureBean", enviando as informações dos inputs (Figura 4.11).

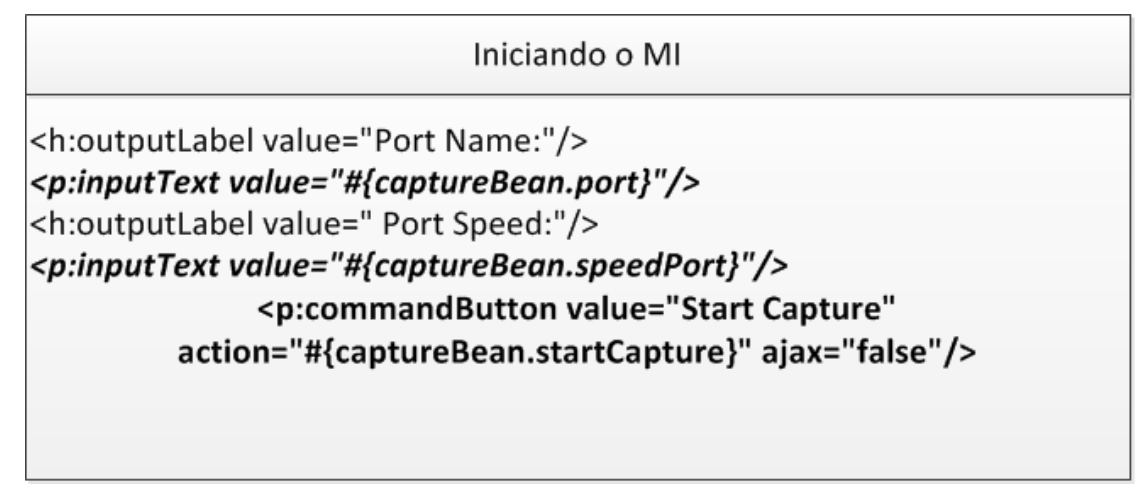

Figura 4.11: Código de Inicialização do MI.

Pode-se observar na figura 4.12 que no método "startCapture"da classe de controle "CaptureBean"é instanciado a classe "CaptureSensor"e a mesma é iniciada na chamada do método "captureConfig.getCaptureSensor().Start();"'onde concretamente é iniciada a captura.

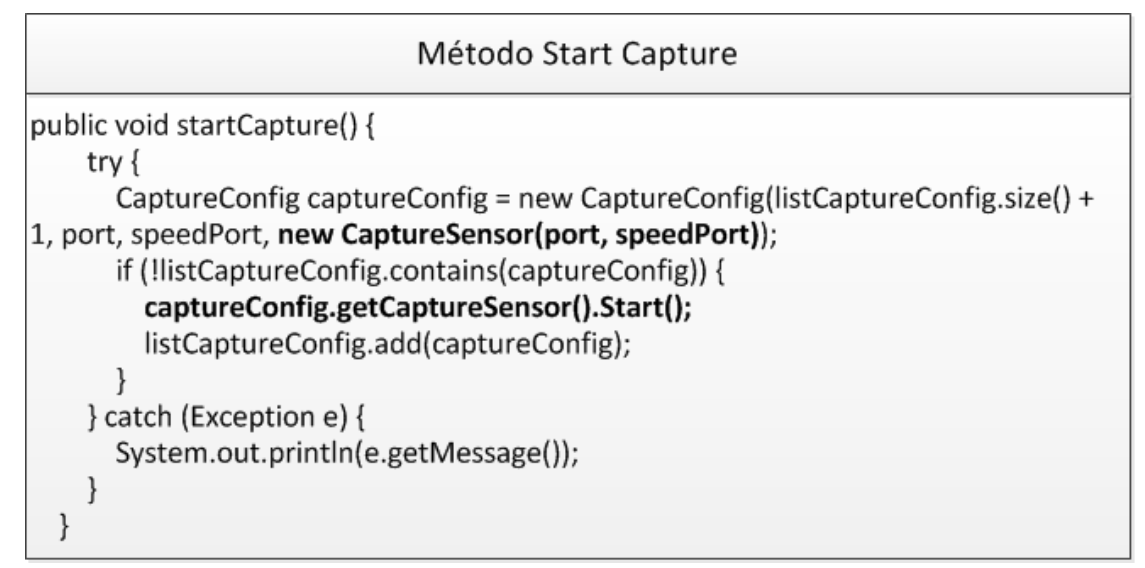

Figura 4.12: Código do método StartCapture do MI.

Na figura 4.13 a classe CaptureSensor é declarada a interface do service (padrão facade), isto possibilita criada a instancia no construtor, selecionando a implementação desejada. 


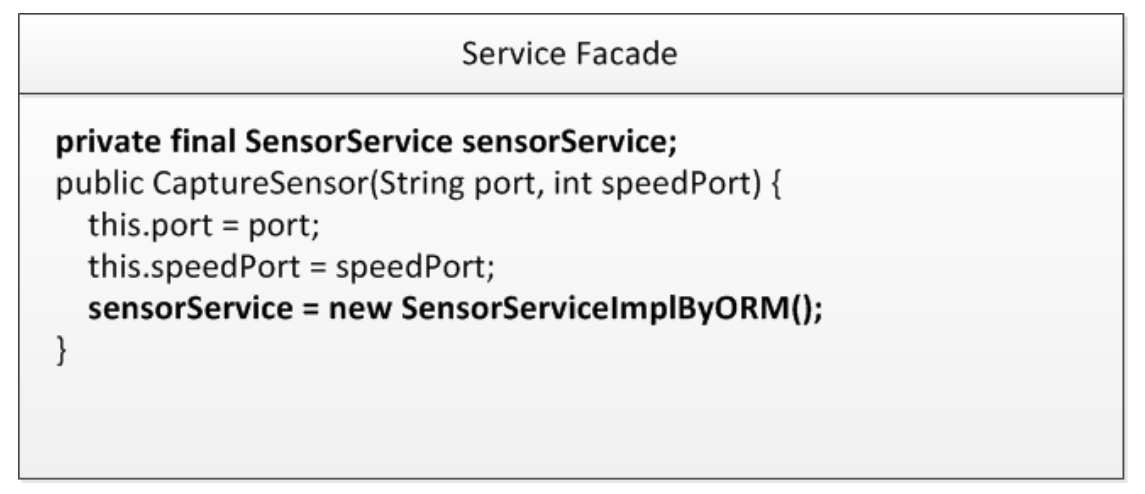

Figura 4.13: Código do Service facade do MI.

Ainda na classe "CaptureSensor"temos a implementação do método "serialEvent (figura 4.14)"que é uma implementação da interface "SerialPortEventListener", esse método é adicionado como "Listener", e toda vez que ocorre alguma ação na porta ele é executado. E com isso ele chama o método "Capture"e envia como parâmetro um clone do "buffer".

\begin{tabular}{|c|}
\hline Método SerialEvent \\
\hline $\begin{array}{l}\text { @Override } \\
\text { public void serialEvent(SerialPortEvent spe) \{ } \\
\text { try \{ } \\
\text { Thread.sleep(60); } \\
\text { int a = inputStream.available(); } \\
\text { byte[] readBuffer = new byte[a]; } \\
\text { while (inputStream.available() > 0) \{ } \\
\quad \text { inputStream.read(readBuffer); } \\
\quad \text { \} } \\
\text { sensorService.Capture(readBuffer.clone()); } \\
\text { \} catch (Exception e) \{ } \\
\text { System.out.println(e.getMessage()); } \\
\text { \} } \\
\text { getSerialPort().addEventListener(this); }\end{array}$ \\
\hline
\end{tabular}

Figura 4.14: Código do método serialEvent.

No método Capture da classe SensorServiceImplByORM é instanciada a classe CaptureProcess é chamado o método start(), que é a classe herdada do thread principal, e com isso é iniciando uma nova thread para processar o pacote. 


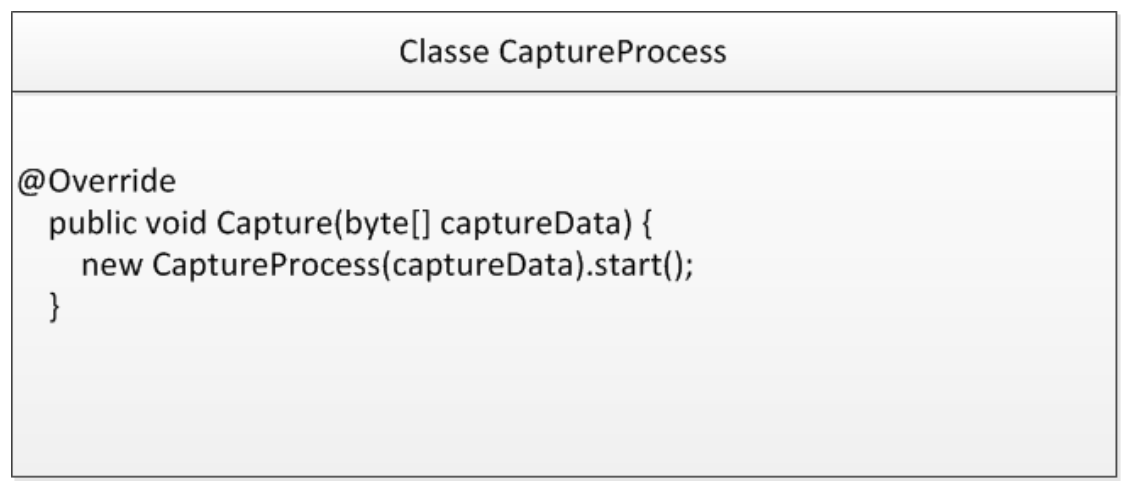

Figura 4.15: Código da classe CaptureProcess.

Na classe CaptureProcess, é iniciado todos os DAO para realizar as tarefas de persistência, tais como consulta, gravar e deletar dados no banco de dados.

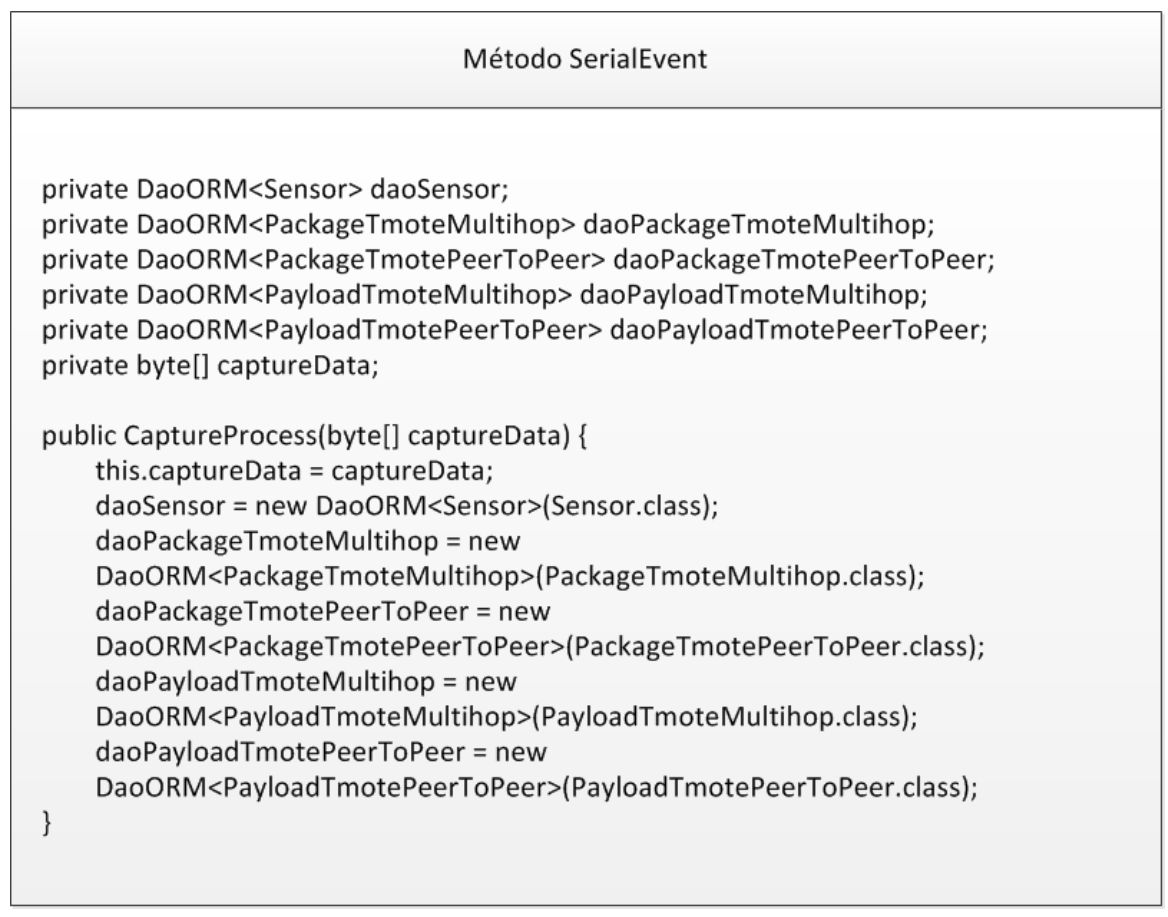

Figura 4.16: Código de inicialização do DAO na classe CaptureProcess .

A informação abstraida da rede através do módulo MI é armazenada de forma estruturada no banco de dados existente em uma arquitetura remota. O MI estabelece comunicação com módulo de dados através de um método run, o qual é um método sobrescrito da classe thread, ele executa toda vez que uma thread é iniciado com o start(). No método run os pacotes são processados e persistidos no banco. No script apresentado da figura aparecem em vermelho os pontos onde se identificam as iterações com o módulo de dados (figura 4.17). 


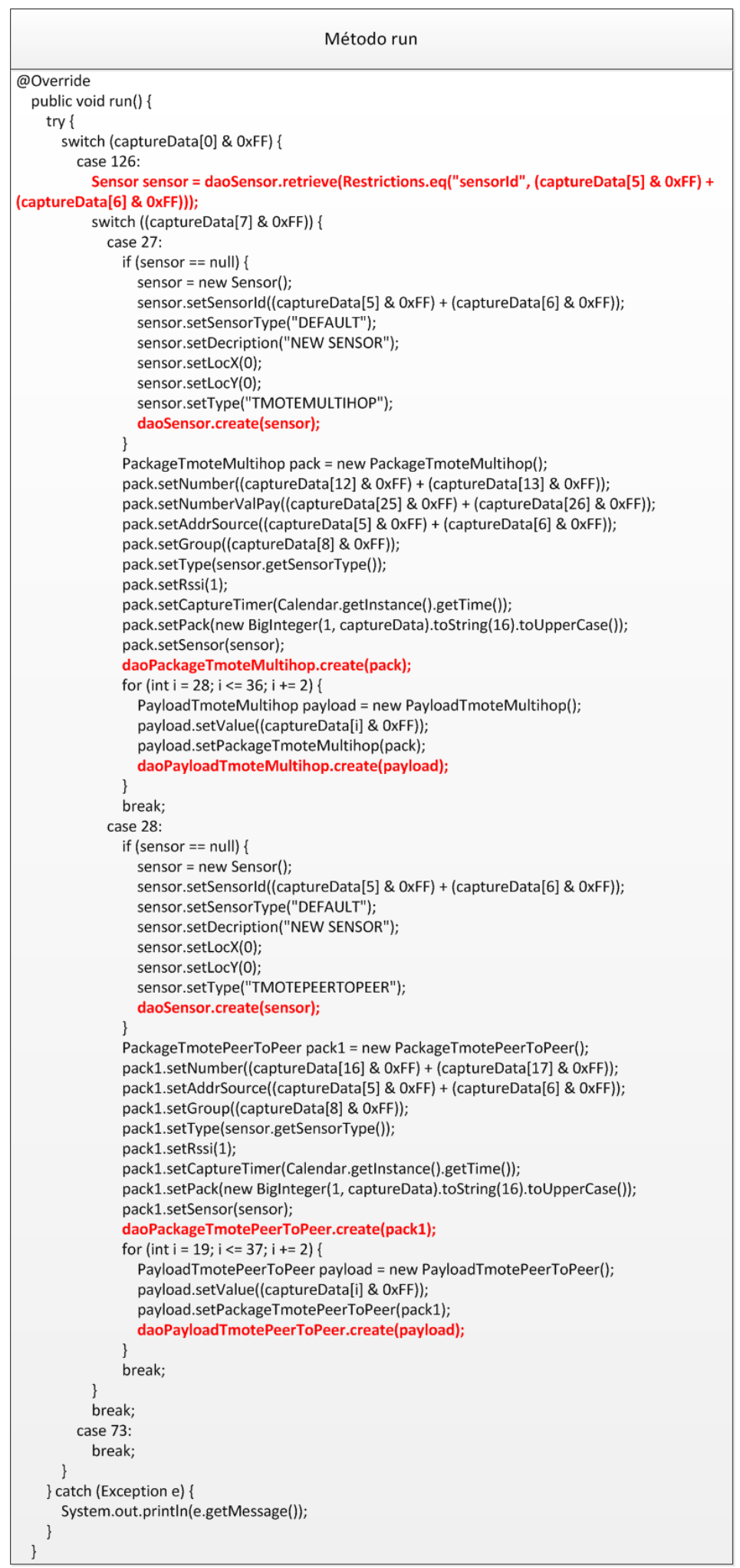

Figura 4.17: Código de método run. 
Algumas das classes como PackageTmoteMultihop e PackageTmotePeerToPeer são fortemente acopladas e evitam uma fácil alteração ou atualização da sua estrutura de componentes e serviços isto é importante devido a que partes da estrutura dos protocolos de comunicação utilizados como os singlehop e multihop possuem características únicas na sua estrutura e sua estabilidade depende da forma como os serviços extraem e armazenam a informação de roteamento e dados. Esta característica de forte acoplamento é necessária para evitar que o usuário ou próprio administrador do CPS tente extrair um numero excessivo de informações dificultando o desempenho da aplicação em tempo de execução.

Num CPS são utilizadas diversas arquiteturas de hardwares e protocolos de comunicação, sendo assim, os serviços na camada de comunicação devem implementar e iniciar componentes e métodos que abstraiam essa diversidade de protocolos e topologias criando um ambiente comum para todos estes elementos. Quando uma nova rede se conecta ao CPS o CiberSens deve iniciar na camada de comunicação um processo de abstração da interface do MI e do protocolo de comunicação que a rede de MST associada ao MI está utilizando, armazenando o conjunto de informações da rede num buffer para que possa ser tratado em tempo de execução pelo módulo de armazenamento na camada de comunicação.

O MI abstrai a informação da rede e dos MSTs e guarda a informação do pacote no módulo de armazenamento (processado). O pacote do MST proporciona informações de roteamento e amostragem de fenômenos físicos que acionam outros transdutores e sistemas integrados ao CPS, algumas destas informações são tratados em tempo de execução e disponibilizados para o usuário do CPS e outros são mantidas no módulo de armazenamento caso o administrador ou usuário do CPS possa precisar das mesmas.

A complexidade do módulo de suporte a comunicação e armazenamento (figura 4.18) resulta da diversidade de protocolos de comunicação, cuja demanda poderia estar em função da arquitetura do nó, da aplicação e do tipo de roteamento que esta última demanda, como; $i$ ) roteamento plano (flat), ii) roteamento hierárquico (hierarchical), iii) roteamento baseado na localização (location-based) e $i v$ ) roteamento baseado em multi-caminho (multi-path). Neste módulo concentra-se toda a informação necessária para o gerenciamento com o intuito de otimizar o acesso à maior parte das informações de gerenciamento e estatísticas da rede. 


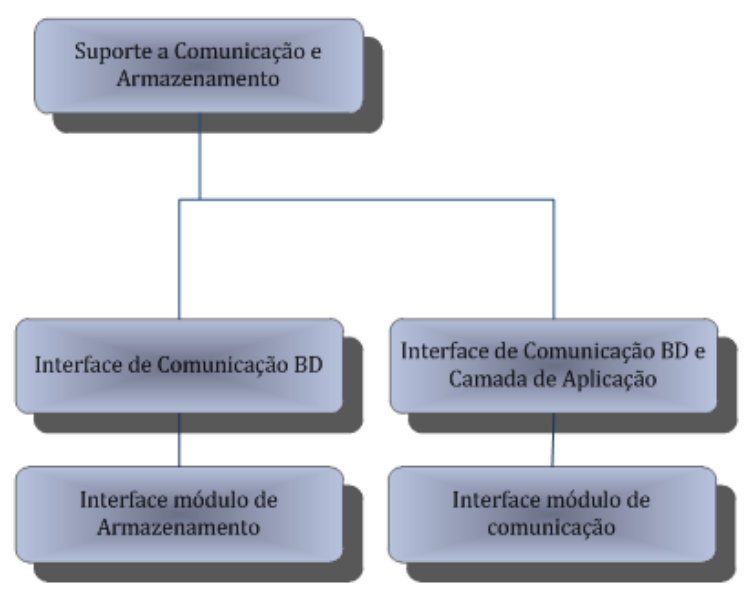

Figura 4.18: Diagrama de blocos do Módulo de Comunicação.

O módulo de suporte (figura 4.18) providencia a utilização a manutenção e controle de acesso às interfaces dos MI, conexão do MI com o módulo de armazenamento e da interface de comunicação, modulo de dados, com a camada de aplicação do middleware . O MI captura as informações da rede e os resultados do ambiente físico monitorado, e os disponibilizam através do CiberSens, num formato compreensível para o usuário e também para outras aplicações que façam parte do CPS. No CPS deve ser comum a utilização de diversas arquiteturas de hardware e protocolos de comunicação motivo pelo qual os MI devem ser capazes de capturar a transmissão de dados dos MSTs que utilizem os diversos tipos de protocolos singlehop e multihop e diversos padrões de comunicação sem fio resultado da exigência da aplicação em funcionamento no CPS, na prática seria possível ter MSTs de temperatura e umidade que possuam a mesma arquitetura de hardware, porém, como uma exigência ao tamanho do cenário e da aplicação utilizem de diferentes protocolos e padrões de comunicação para realizar o roteamento dos dados (Figura 4.19).

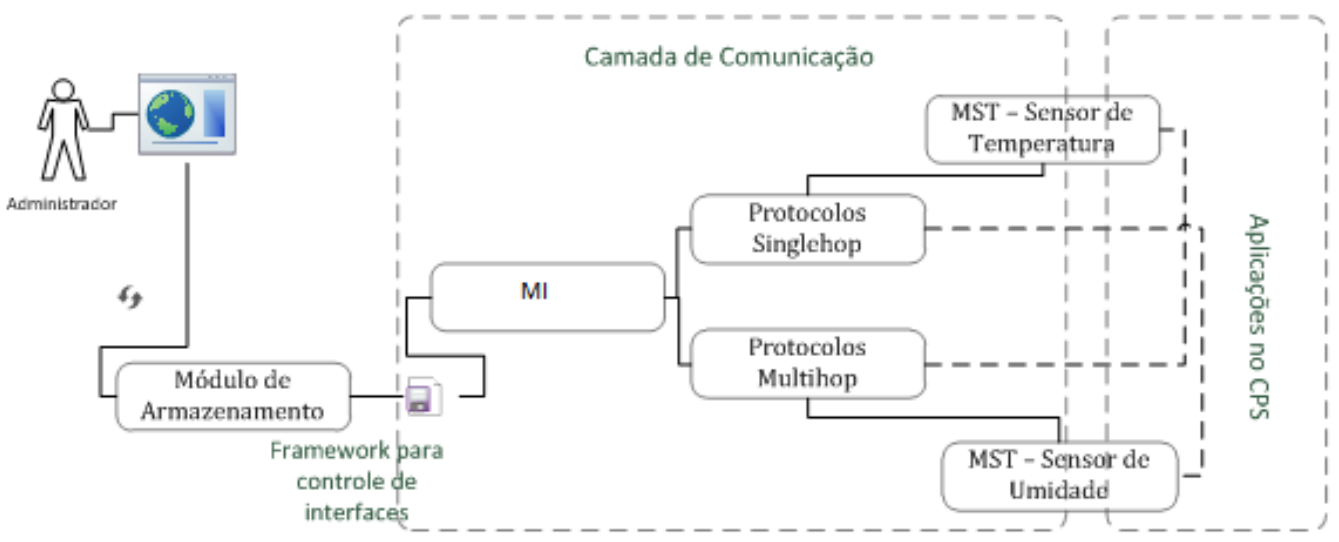

Figura 4.19: Cenário de comunicação heterogênea (Singlehop - Multihop).

No abstração do módulo de armazenamento(Figura 4.20) é determinado o tipo de informação que será apresentada para o usuário e quais informações devem ser preservadas 
pelo sistema. É necessário salientar que no CiberSens serviços e interfaces são projetados para delimitar informações deixando para o usuário só aquilo que lhe é necessário e funcionalmente útil. O excesso de informações pode permitir ao próprio usuário consumidor dos serviços ou administrado fazer julgamentos sobre a existência, funcionalidade e eficiência de um serviço o qual não é adequado para a preservação da lógica da arquitetura e dos detalhes de projeto do serviço. Na desagregação os dados são distribuídos segundo sua hierarquia, funcionalidade e objetivo passando de níveis inferiores para níveis superiores, dados que correspondem unicamente a roteamento se distribuem entre os serviços da camadas inferiores, e dados resultados do parâmetro monitorado são encaminhados para as camadas superiores seguindo uma ordem estruturada previamente em função da carga útil do dado.

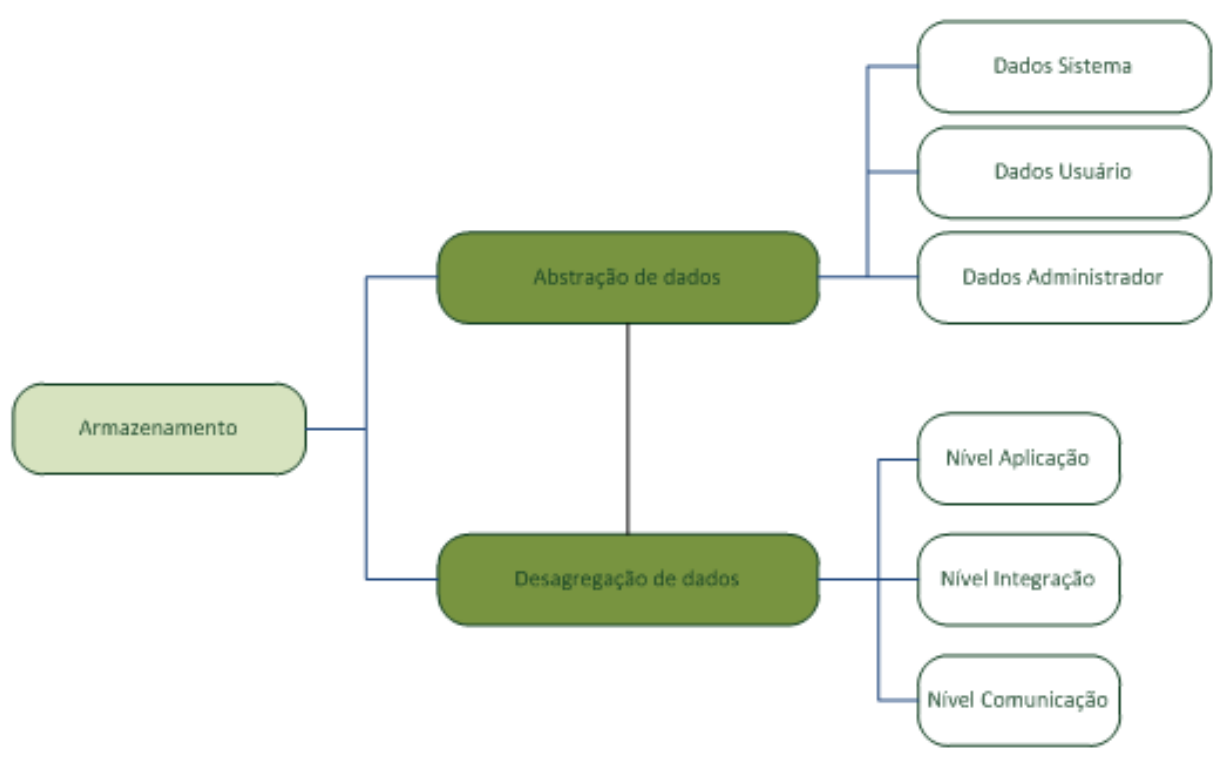

Figura 4.20: Diagrama do Módulo de Armazenamento.

As tabelas 4.1, 4.2 descrevem cada um dos serviços da camada de comunicação e suporte, específicamente ao módulo de armazenamento. Os serviços descritos abstraem a informação transportada pelo MI a qual é disponibilidada para o CiberSens através da conexão com o módulo de armazenamento. 
Tabela 4.1: Classes do Ambiente - Modelo

\begin{tabular}{|l|l|}
\hline Serviço & Descrição \\
\hline Environment & $\begin{array}{l}\text { Define os métodos de acesso a dados do ambiente para o } \\
\text { módulo de armazenamento e desde a camada de interfaces. }\end{array}$ \\
\hline Map & $\begin{array}{l}\text { Define os métodos de acesso a dados do mapa para o } \\
\text { módulo de armazenamento e desde a camada de interfaces. }\end{array}$ \\
\hline Scenario & $\begin{array}{l}\text { Define os métodos de acesso a dados do cenário para o } \\
\text { módulo de armazenamento e desde a camada de interfaces }\end{array}$ \\
\hline
\end{tabular}

Tabela 4.2: Descrição de Classes

\begin{tabular}{|l|l|}
\hline Serviço & Descrição \\
\hline Sensor & $\begin{array}{l}\text { Esta classe define o acesso ao módulo de armazenamento } \\
\text { do CiberSens e inicia a captura de informação dos MSTs } \\
\text { através MI }\end{array}$ \\
\hline Network & $\begin{array}{l}\text { Esta classe define os métodos de acesso e abatração de } \\
\text { dados da rede }\end{array}$ \\
\hline Query & $\begin{array}{l}\text { Define os métodos de acesso a dados para realização das } \\
\text { consultas ao módulo de armazenamento }\end{array}$ \\
\hline PackageTmotePeerToPeer & $\begin{array}{l}\text { Define os métodos de acesso a dados no módulo de } \\
\text { armazenamento para os pacotes de roteamento de origem } \\
\text { SingleHop }\end{array}$ \\
\hline PayloadTmotePeerToPeer & $\begin{array}{l}\text { Define os métodos de acesso a dados no módulo de } \\
\text { armazenamento para os payload de origem SingleHop }\end{array}$ \\
\hline PackageTmoteMultihop & $\begin{array}{l}\text { Define os métodos de acesso a dados no módulo de } \\
\text { armazenamento para os pacotes de roteamento de origem } \\
\text { Multihop }\end{array}$ \\
\hline PayloadTmoteMultihop & $\begin{array}{l}\text { Define os métodos de acesso a dados no módulo de } \\
\text { armazenamento para os payload de origem Multihop }\end{array}$ \\
\hline
\end{tabular}

As classes desta camada são disponibilizadas e implementadas na camada de integração de serviços. As classes que resultam da camada de comunicação e suporte correspondem à camada do modelo de projeto MVC (ver secção 4.4.5 - Modelo de Projeto para o CiberSens) no nível de implementação e são resultado de uma criteriosa análise do cenário de aplicação. Cada uma das classes descritas associam um conjunto de requisitos funcionais, não funcionais e espaço temporais, por exemplo; a classe Network, associa topologia e localização dentro do ambiente (Environment), cenário (Scenario) e abstrai informações de temporalidade e atributos de arquitetura, elemento monitorado, protocolo, arquitetura do mote etc, junto à classe Sensor. 


\subsubsection{Camada de Integração de Serviços}

A construção de aplicações divididas em módulos de comunicação e aplicação e, residentes em diversos ambientes de computação, tem sido, dúvida um grande passo para a computação distribuída. Na camada de integração de serviços (Figura 4.21) é determinada a flexibilidade na integração com as aplicações da rede de sensores dentro de um CPS, para o qual é necessário que seja desenvolvido com tecnologias padronizadas que ofereçam recursos para o desenvolvimento de novas aplicações.

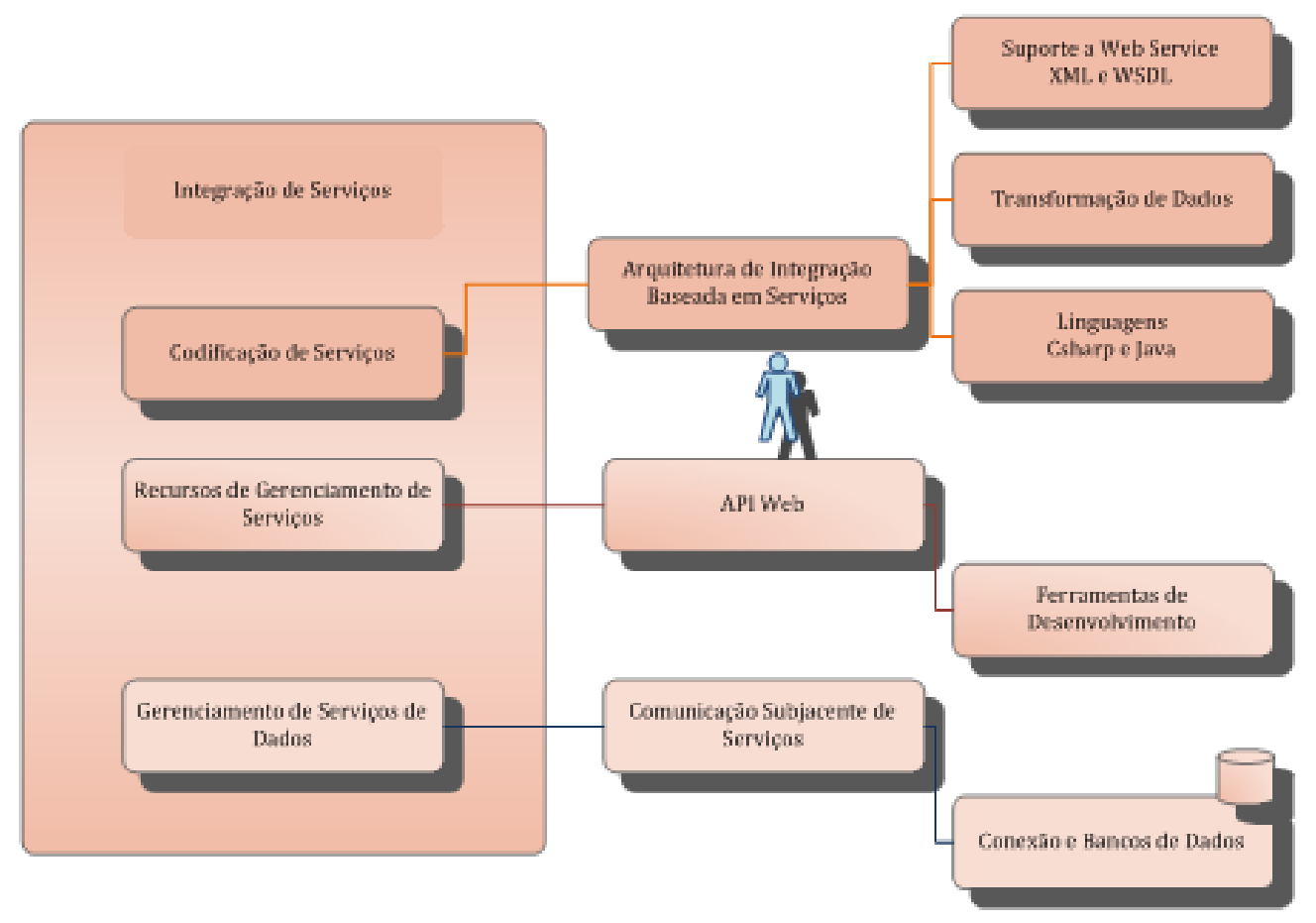

Figura 4.21: Diagrama de blocos da Camada de Integração e Serviços).

A integração de tecnologias de computação utilizando interação de serviços não é uma tarefa trivial, assim como tratar de problemas como a integração de sistemas heterogêneos, o qual na maior parte dos casos são pouco flexíveis.

No projeto e implementação desta camada são considerados alguns dos parâmetros mais relevantes para a integração dos serviços associados aos componentes computacionais. Os elementos de integração obedecem a um conjunto de ferramentas de software necessárias para a conclusão efetiva deste processo, estas ferramentas são associadas a determinadas características de integração:

- Análise do Cenário: Esta característica é de caráter imprescindível devido a que permite, junto a uma analise de requisitos, determinar a linguagem, ferramentas e técnicas mais 
adequadas para a abstração de processos das camadas subjacentes que possam satisfazer os requisitos do aplicativo.

- Classificação de Requisitos: Na análise inicial de requisitos o conjunto total é classificado e considerado obrigatório, aplicável e não aplicável. Seguindo esta forma pouco estruturada de classificação é atribuída a relevância de cada requisito na integração dos componentes computacionais com as aplicações através de uma estrutura que seja uma lógica de serviços.

- Complexidade Tecnológica: A seleção da tecnologia de integração mais adequada é bastante complexa em função da diversidade de interfaces e recursos de programação que podem ser utilizados. Uma escolha inadequada pode produzir efeitos sérios na maneira como os serviços irão se comportar finalmente. O modelo MVC flexibiliza esta escolha, onde cada camada pode ser implementada seguindo diferentes logicas de programação.

- Padronização: O usuário recebe o acesso à informação de forma consistente e fácil de entender os serviços.

- Definição de Processos: Definição da estrutura de cada etapa de processo com o intuito de ter uma melhor classificação dos requisitos do aplicativo para o middleware de integração, para nosso o caso um middleware baseado em serviços. 
Os serviços desta camada (tabela 4.3) são resultado da camada de comunicação (módulo de armazenamento - Modelo). Os serviços que resultam da camada de comunicação e suporte correspondem à camada do modelo (MVC), no nível de implementação cada classe é representada como um serviço.

Tabela 4.3: Serviços na camada de Integração

\begin{tabular}{|l|l|}
\hline Serviço & Descrição \\
\hline ScenarioService & $\begin{array}{l}\text { Interface que define os métodos de acesso a dados e } \\
\text { processo de captura para o MST (Sensor Atuador). }\end{array}$ \\
\hline PayloadTmotePeerToPeerService & $\begin{array}{l}\text { Interface que define os métodos de acesso a dados para o } \\
\text { payload do pacote Singlehop. }\end{array}$ \\
\hline PayloadTmoteMultihopService & $\begin{array}{l}\text { Interface que define os métodos de acesso a dados para o } \\
\text { payload do pacote multihop }\end{array}$ \\
\hline PackageTmotePeerToPeerService & $\begin{array}{l}\text { Interface que define os métodos de acesso a dados para o } \\
\text { pacote Singlehop. }\end{array}$ \\
\hline PackageTmoteMultihopService & $\begin{array}{l}\text { Interface que define os métodos de acesso a dados para o } \\
\text { pacote multihop. }\end{array}$ \\
\hline NetworkService & $\begin{array}{l}\text { Interface que define os métodos de acesso a dados para a } \\
\text { informação da rede. }\end{array}$ \\
\hline MapService & $\begin{array}{l}\text { Interface que define os métodos de acesso a dados para o } \\
\text { mapa. }\end{array}$ \\
\hline EnvironmentService & $\begin{array}{l}\text { Interface que define os métodos de acesso a dados para o } \\
\text { ambiente de sensoriamento e atuação. }\end{array}$ \\
\hline QueryService & $\begin{array}{l}\text { Interface que define os métodos de acesso a dados para as } \\
\text { consultas. }\end{array}$ \\
\hline
\end{tabular}

Cada um dos serviços descritos associam um conjunto de requisitos funcionais, não funcionais e espaço temporais que resultam do MI e do ambiente de aplicação, por exemplo; o serviço NetworkService, associa informações de topologia e localização dentro do ambiente (EnvironmentService) e cenário (ScenarioService), no processo de abstração de dados abstrai informações de temporalidade e atributos de arquitetura, elemento monitorado, protocolo, arquitetura do mote etc, junto à classe SensorService. 


\subsubsection{Camada de Domínio de Controle de Serviços}

Nesta camada (Figura 4.22) se encontram e se agrupam todos os parâmetros do software que automatizam ou apóiam os processos que realizam os usuários na camada de aplicação. Estes parâmetros ou aspectos tipicamente incluem cada uma das tarefas que formam parte dos processos, assim como as regras e restrições que associadas.

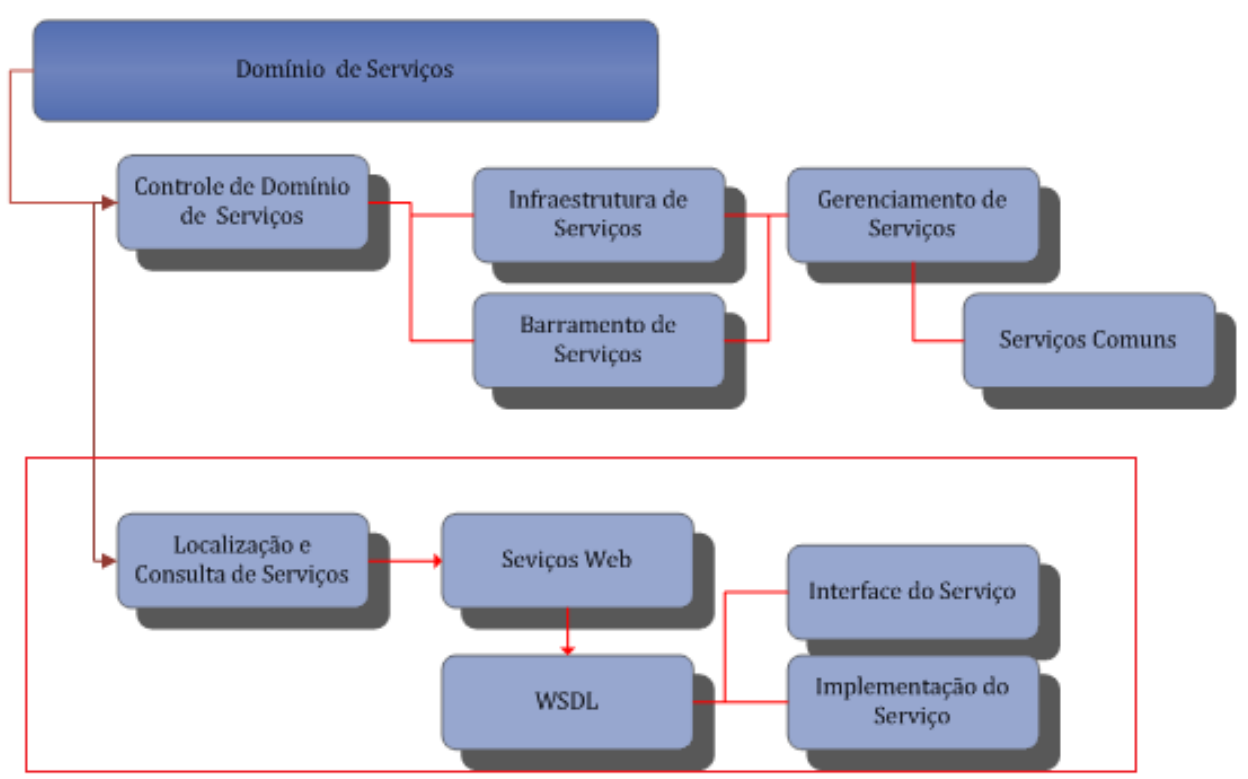

Figura 4.22: Diagrama de blocos da camada de Domínio de Serviços).

Os módulos demarcados na figura 4.22 (WebService - WSDL) não fazem parte da implementação na aplicação-exemplo, com exceção do módulo de consulta 
Na camada de Dominio os serviços e classes que são implementados efetivamente para a aplicação-exemplo do CiberSens (Capítulo 5) são descritos na tabela 4.4:

Tabela 4.4: Serviços e Classes na camada de Controle

\begin{tabular}{|l|l|}
\hline Serviço & Descrição \\
\hline SensorServiceImplByORM & $\begin{array}{l}\text { O serviço implementa o acesso a dados do } \\
\text { network utilizando o daoORM (Hibernate) e } \\
\text { utiliza a classe CaptureProcess para delegar o } \\
\text { serviço de processamento de captura em uma } \\
\text { nova thread iniciada ao chamar o método start. }\end{array}$ \\
\hline ScenarioServiceImplByORM & $\begin{array}{l}\text { implementa o acesso a dados do scenario } \\
\text { utilizando o daoORM (Hibernate). }\end{array}$ \\
\hline PayloadTmotePeerToPeerServiceImplByORM & $\begin{array}{l}\text { É implementação de acesso a dados } \\
\text { do payloadTmotePeerToPeer utilizando o } \\
\text { daoORM (Hibernate). }\end{array}$ \\
\hline PayloadTmoteMultihopServiceImplByORM & $\begin{array}{l}\text { Implementação do acesso a dados para o } \\
\text { payloadTmoteMultihop utilizando o daoORM } \\
\text { (Hibernate). }\end{array}$ \\
\hline PackageTmotePeerToPeerServiceImplByORM & $\begin{array}{l}\text { Implementa o acesso a dados para o } \\
\text { packageTmotePeerToPeerService utilizando o } \\
\text { daoORM (Hibernate). }\end{array}$ \\
\hline PackageTmoteMultihopServiceImplByORM & $\begin{array}{l}\text { Implementa o acesso a dados para o } \\
\text { packageTmoteMultihopService utilizando } \\
\text { o daoORM (Hibernate). }\end{array}$ \\
\hline EnetworkServiceImplByORM & $\begin{array}{l}\text { Implementa o acesso a dados do network } \\
\text { utilizando o daoORM (Hibernate). }\end{array}$ \\
\hline MapServiceImplByORM & $\begin{array}{l}\text { Implementa o acesso a dados do Map utilizando } \\
\text { o daoORM (Hibernate). }\end{array}$ \\
\hline $\begin{array}{l}\text { Implementa o acesso a dados para o } \\
\text { environment utilizando o daoORM (Hibernate). }\end{array}$ \\
$\begin{array}{l}\text { Está classe implementa o módulo de } \\
\text { processamento para o pacote capturado. } \\
\text { A classe CaptureProcess é herdeira da classe } \\
\text { thread e sobrescreve o método run, o qual é } \\
\text { executado quando se inicia uma nova thread } \\
\text { (Herança, CaptureProcess). }\end{array}$ \\
\hline Eaprocess
\end{tabular}




\subsubsection{Camada de Interface de Abstração de Programação}

A camada de aplicação oferece uma interface dinâmica que permite a edição. A edição deve permitir a adição e remoção de serviços para a aplicação em uso, isso inclui interfaces de conexão, configuração, restrições de acesso a serviços.

Entre a camada de aplicação e o middleware temos uma camada de abstração de programação, a qual faz parte propriamente do middleware e é nesta camada que se oferece o suporte à funcionalidade da aplicação para o usuário, a flexibilidade imposta através da linguagem de alto nível utilizada nesta camada, assim como os tipos de meta-abstração de serviços utilizada determinará a facilidade de uso das aplicações para o usuário assim como um maior nível de abstração dos processos das camadas subjacentes (Figura 4.23).

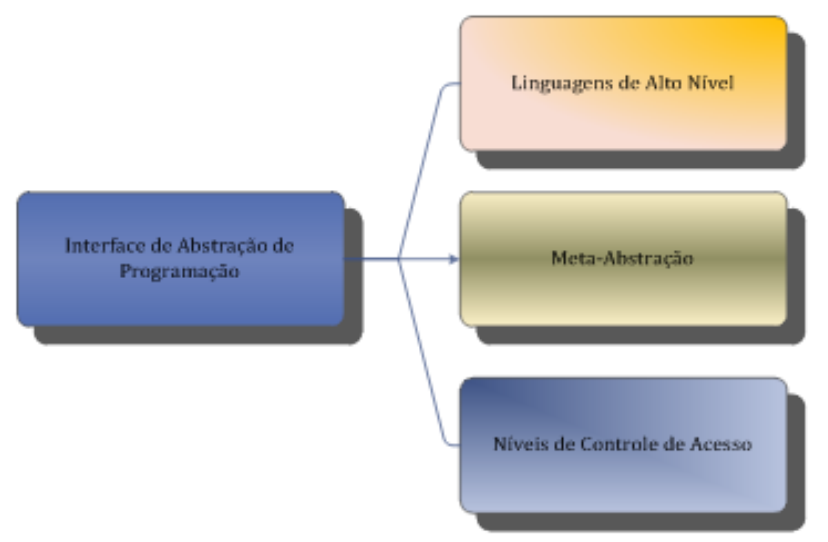

Figura 4.23: Diagrama de blocos da camada de abstração de programação.

A linguagem determina a riqueza da API e muito provavelmente o nível de abstração proporcionada à aplicação, entretanto, o domínio é sempre restrito ao perfil e à preferência do programador sem deixar de lado as exigências do modelo de middleware, ou seja para o caso do CiberSens as características de um modelo baseado em serviços.

Nesta camada a definição de abstração pode parecer bastante vaga se não se define o tipo de informação ou processo que precisa ser abstraído das camadas subjacentes para a camada de aplicação. Seguindo este raciocínio são considerados três tipos de abstração apresentadas no diagrama da figura 4.24 . 


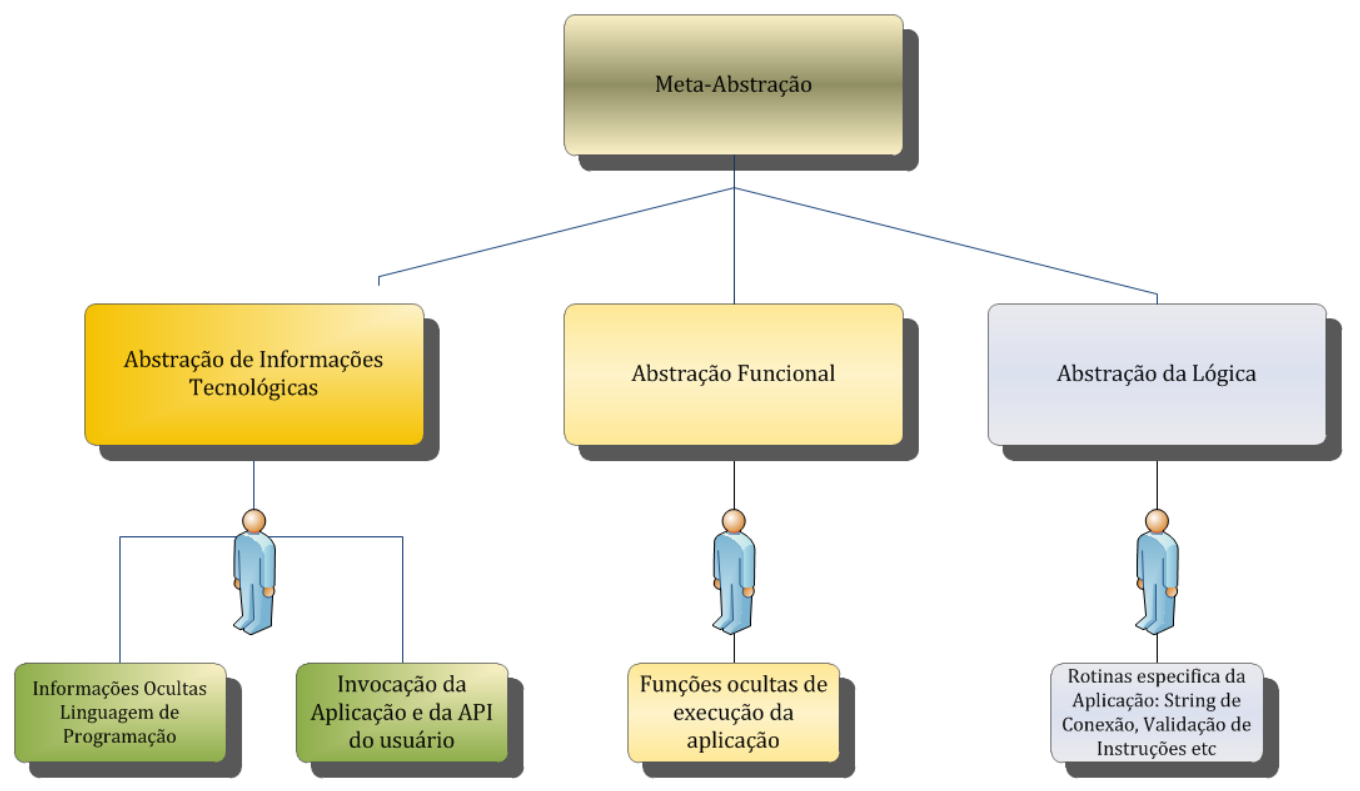

Figura 4.24: Diagrama de tipos de abstração de informações no middleware.

Na abstração de tecnologia é necessário manter um determinado nível de flexibilidade já que o middleware é desenvolvido como plataforma aberta para integração de arquiteturas de redes de sensores heterogêneas dentro de um Sistema Ciber-Físico. Na abstração funcional, considera-se um nível real de funcionalidades da aplicação basicamente são disponibilizadas um conjunto de funções genéricas, para interagir com o usuário. Já os detalhes internos da aplicação de nível mais baixo fazem parte da abstração lógica, aspectos de projeto, rotinas de código, lógica de tratamento de dados, exceções e validação de instruções, para estas é imposto um nível de acesso restrito determinado por interfaces com um nível mais alto de abstração funcional. 


\subsubsection{Modelo de Projeto para o CiberSens}

A implementação de um novo, ou reutilização de um existente, Modelo de Projeto (Design Pattern) para a construção de middlewares para CPS resulta num extenso levantamento de novas questões, devido à alta complexidade do cenário de aplicação que este novo conceito de sistemas apresenta. A construção dos CPS segue uma lógica distribuída, como consequência, a estrutura proposta para gerenciar a diversidade de componentes e serviços que existem dentro de um CPS, não pode ser diferente.

A estrutura inicial do middleware deve seguir um modelo de projeto que permita uma abrangente descrição e expressão dos requisitos funcionais do cliente do CPS e a representação do comportamento previsível da aplicação em tempo de execução. O objetivo da utilização do MVC e facade é explorar vantagens de modelos de projeto existentes para produzir uma estrutura de middleware reutilizável e de fácil manutenção para um CPS no nível de sensoriamento. O modelo MVC Model View Controller adotado esta organizado em três camadas (Figura 4.25), no qual a camada intermediaria exerce o controle dos serviços, e nesta se determina o comportamento da aplicação.

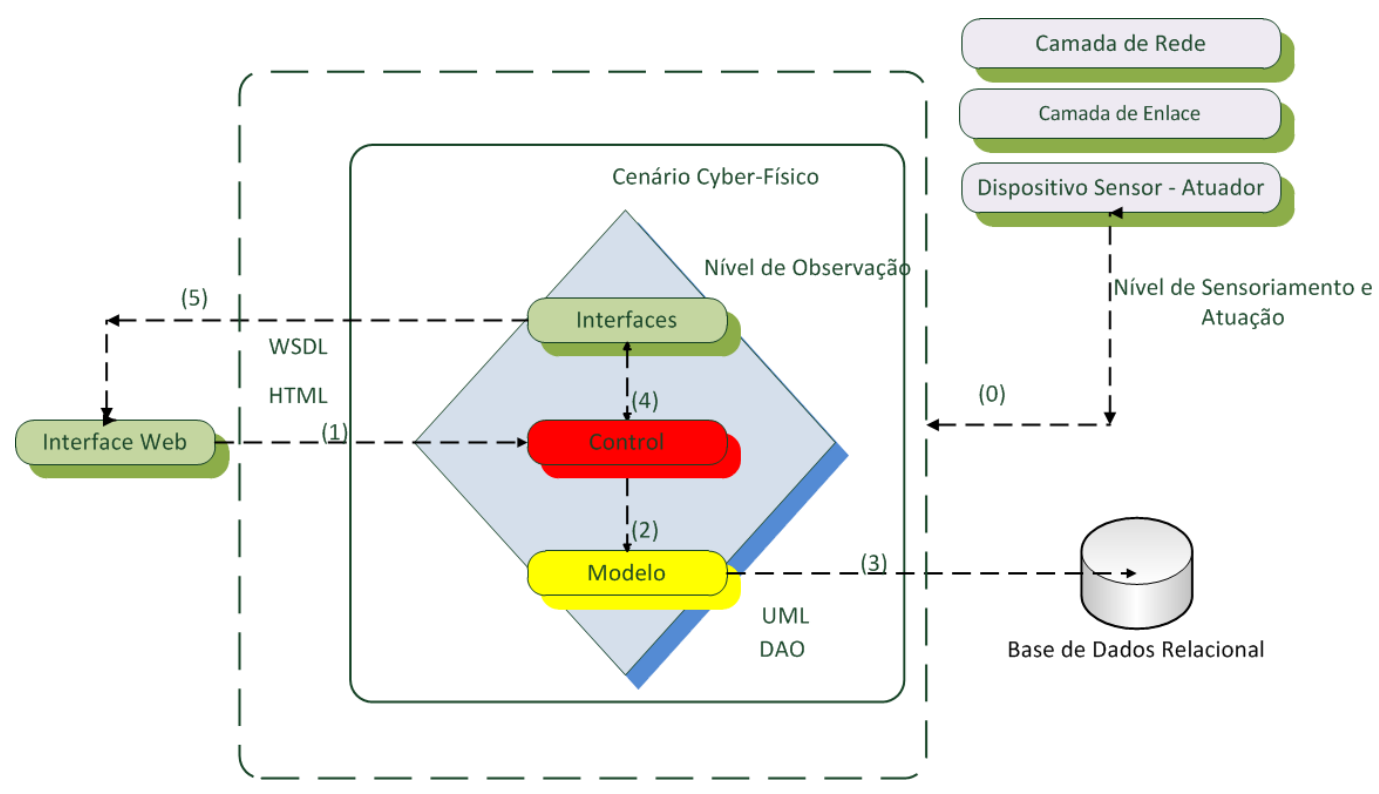

Figura 4.25: Modelo Arquitetônico em camadas - hierarquia de comunicação.

Afigura 4.25, apresenta o modelo MVC de três camadas que integra o padrão Facade o qual atribui ao middleware importantes características de abstração, e junto ao padrão de acesso a dados (DAO - Data Access Object), ambos modelos orientados a objetos, atribuem maior flexibilidade e menor complexidade na realização de alterações na estrutura das classes. $\mathrm{O}$ padrão ou modelo de projeto MVC permite a modelagem modular de cada um dos componentes do middleware, os quais serão associados em seu conjunto através de uma camada de serviço, 
proporcionando características de reutilização e fácil manutenção. A figura 4.27, apresenta a modelagem macro da arquitetura que descreve o Modelo (Model), os Serviços (Services), as Interfaces (View) inclui também o padrão DAO utilizado para determinar as regras de acesso ao módulo de estruturado de armazenamento.

O padrão Facade qual atua como um padrão estrutural de projeto e facilita a associação entre classes e objetos. O padrão permite criar um maior nível de abstração para cada um dos processos e diminuir o acoplamento entre as classes, objetos e métodos nas camadas de comunicação, integração e domínio de serviços.

A figura 4.26, apresenta o modelo de camadas para o CiberSens descrito na figura 4.1 e a relação de camadas no nível de implementação dentro do modelo de camadas MVC.

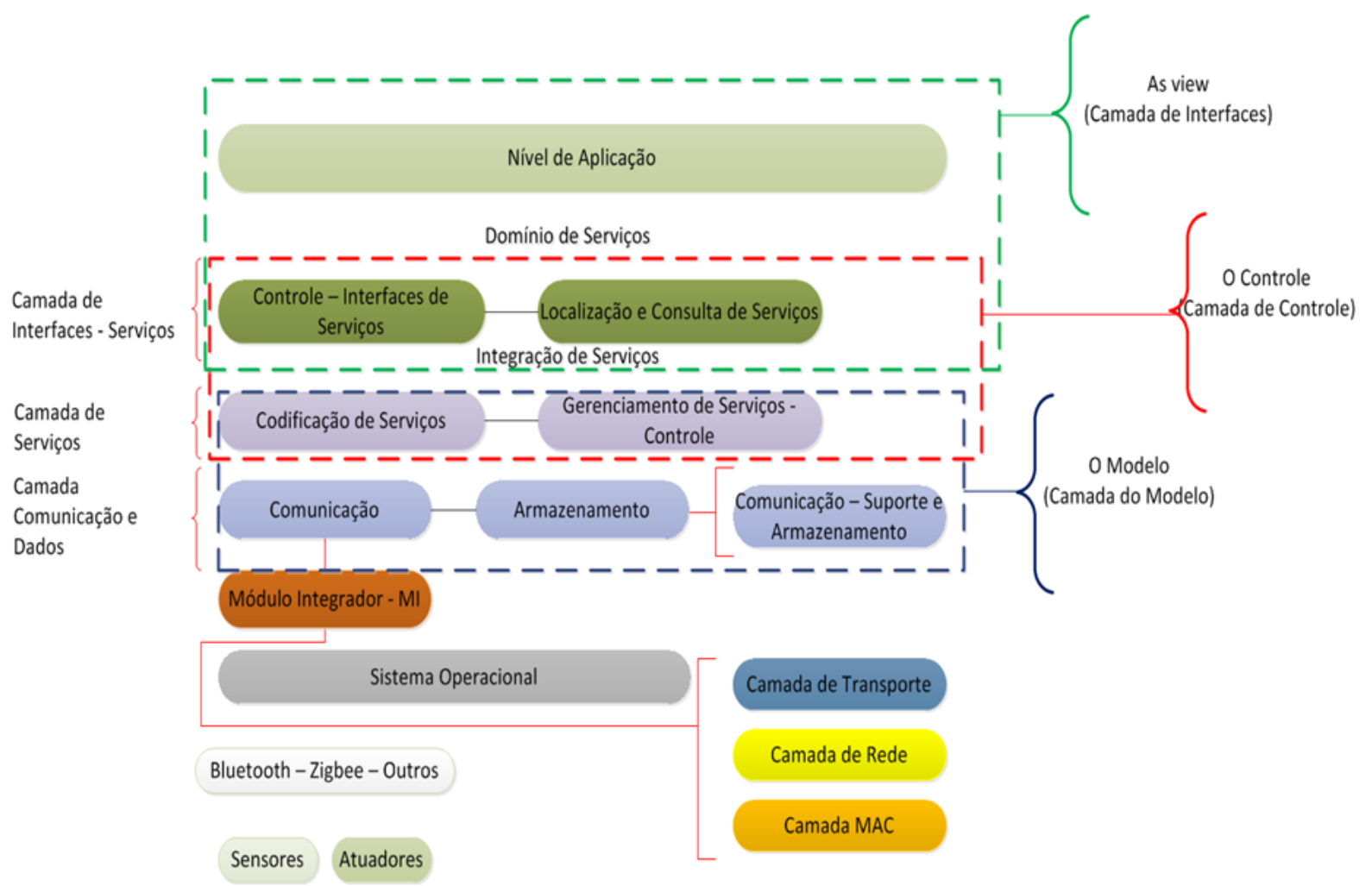

Figura 4.26: Diagrama do Middleware - Modelo MVC para Implementação.

Os modelos de projeto utilizados constituem uma excelente opção para gerenciar os componentes de um middleware nas camadas mais baixas, proporcionando uma modelagem bastante estruturada e flexível de ser reutilizada pela camada de serviços no nível mais alto do middleware (Figura 4.27). 


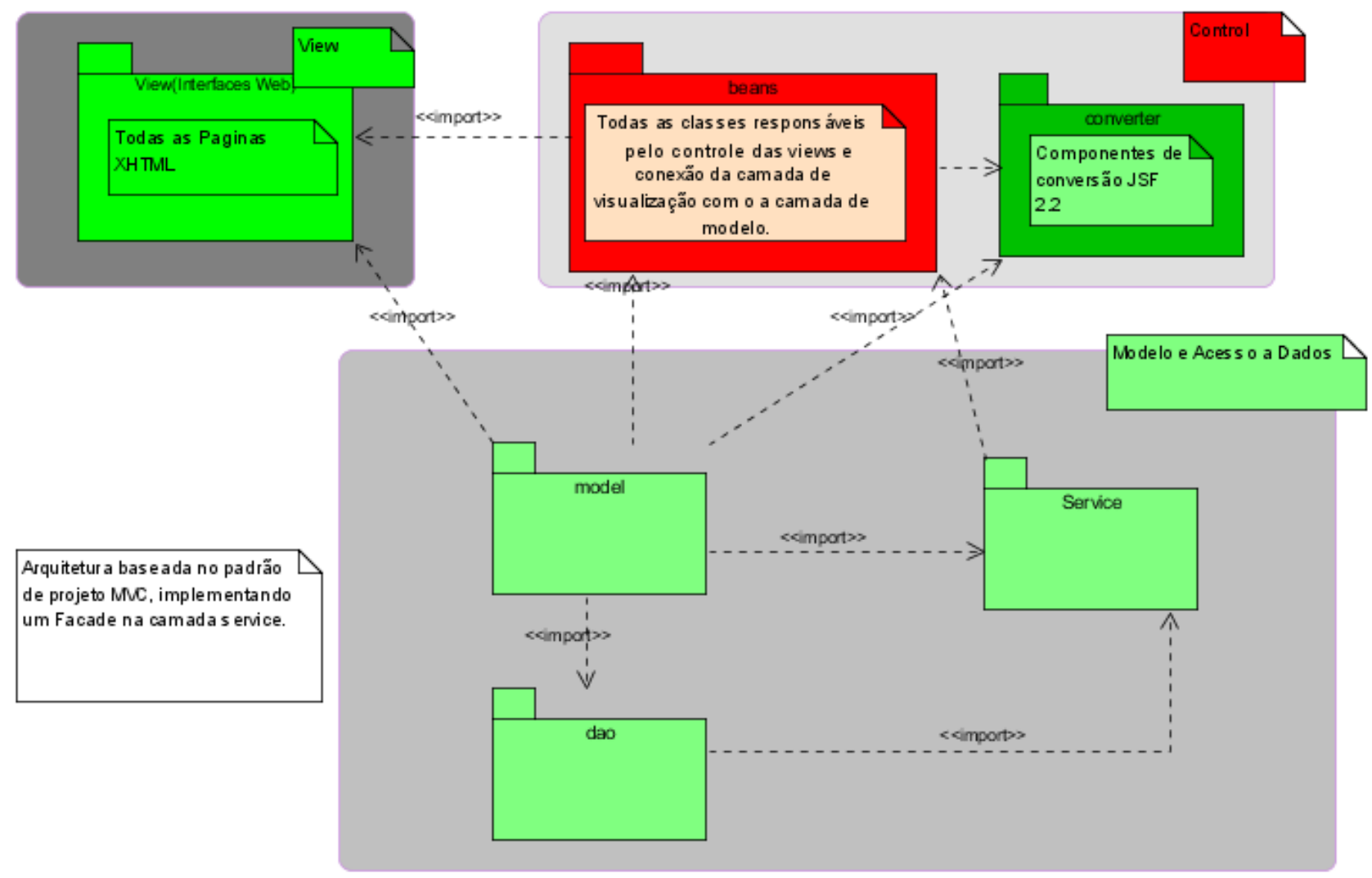

Figura 4.27: Diagrama do Middleware / Aplicação-Exemplo.

Define-se a dependência entre os componentes como resultado do modelo utilizado. Os modelos orientados a objetos exigem um maior nível de acoplamento entre os componentes, isto é ideal para os componentes que realizam a abstração de dados e comunicação nas camadas subjacentes, e que resultam da diversidade de arquiteturas e protocolos que fazem parte do CPS. A forte dependência nas camadas mais baixas do middleware favorecem a robustez do sistema, necessária pela alta granularidade de dados que resultam destas camadas.

O acoplamento nas camadas superiores é associado ao modelo na camada de serviços, permitindo determinar alguns níveis de acoplamento de serviços mais adequados para determinados componentes, especificamente aqueles necessários para favorecer a confiabilidade e disponibilidade do sistema, posicionando o serviço como um recurso altamente disponível e acessível, sendo inclusive necessário pela alta disposição a eventos críticos no CPS. 
No diagrama da Figura 4.28 é apresentado o modelo de serviços para o CiberSens, a composição de classes são descritas ao detalhes no capítulo 5.

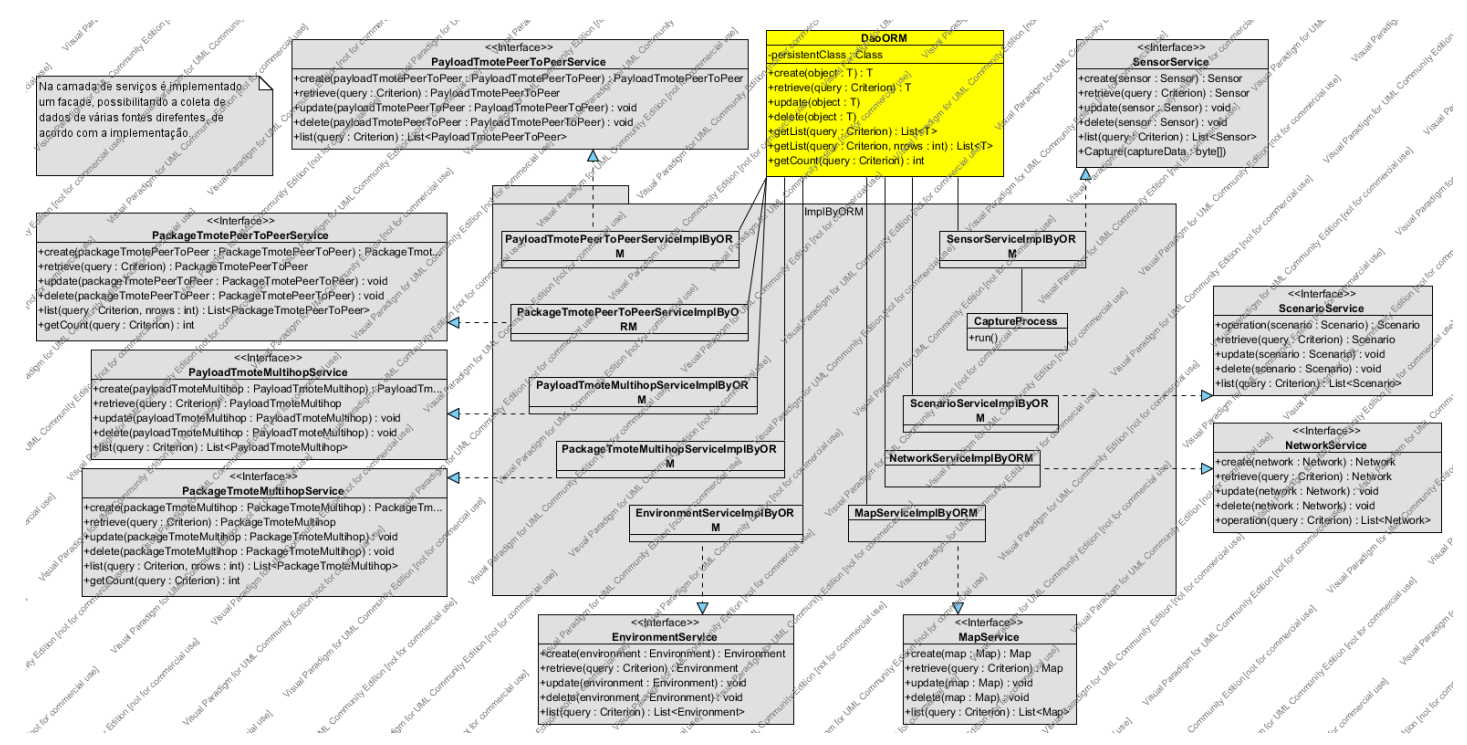

Figura 4.28: Diagrama do Modelo de Serviços para o CiberSens.

O modelo MVC permite gerar aplicações de fácil manutenção, reusabilidade e permite atribuir a característica de flexibilidade ao CiberSens permitindo que cada um dos seus módulos sejam alterados pelo administrador de forma que não influenciem o funcionamento de outros módulos e componentes associados, uma filosofia de implementação por camadas. 


\section{Descrição da Aplicação-Exemplo}

O middleware para um CPS é fundamental uma vez que integra computação com processos físicos para melhorar a cofiabilidade, coordenação, distribuição de serviços, maior precisão e eficiência assim como melhor controle autônomo dos processos e aplicações de um CPS.

Ao contrario de middlewares convencionais para sistemas embarcados centrados sobre os dispositivos físicos o CiberSens é concebido para coordenar partes física e computacional de um sistema devido a que os dispositivos (RSSF) associados ao CPS têm tipicamente recursos limitados de processamento, energia e poder de cálculo, sendo que nem sempre é possível projetar ou executar computação e processos complexos sobre estas arquiteturas.

Para lidar com este desafio dos CPS e as características especiais das RSSF, este trabalho implementa, através do caso de estudo, um middleware utilizando o modelo proposto de três camadas junto a um módulo integrador (MI), todo recriado no espaço restrito de uma Casa Ecológica Inteligente (Smart Green House). O caso de estudo descreve um conjunto de eventos associados a atividades da Casa os quais associa e gerencia através de uma lógica de controle. $\mathrm{O}$ formalismo destes processos resulta da utilização da ferramenta SysML [56]. O SysML permite representar e verificar processos do fluxo de controle da Casa Ecológica Inteligente com alto nível de detalhes.

O middleware proposto pretende demonstrar sua viabilidade e eficiência atingindo os seguintes critérios:

- Oferecer aos usuários um sistema unificado.

- Fácil acesso a informação através de um elemento integrador de arquiteturas.

- Fácil gerenciamento de Protocolos de comunicação com elementos físicos e elementos de software.

- Facilitar a construção flexível de sistemas, preservando a eficiência e confiabilidade fundamentada na lógica de controle dos processos envolvidos para cada elemento sensor 
e atuador.

\subsection{Aplicação Exemplo - I}

Na primeira aplicação exemplo (Figura 5.1) procura-se representar o conjunto de eventos dentro do ambiente supervisório do CiberSens.

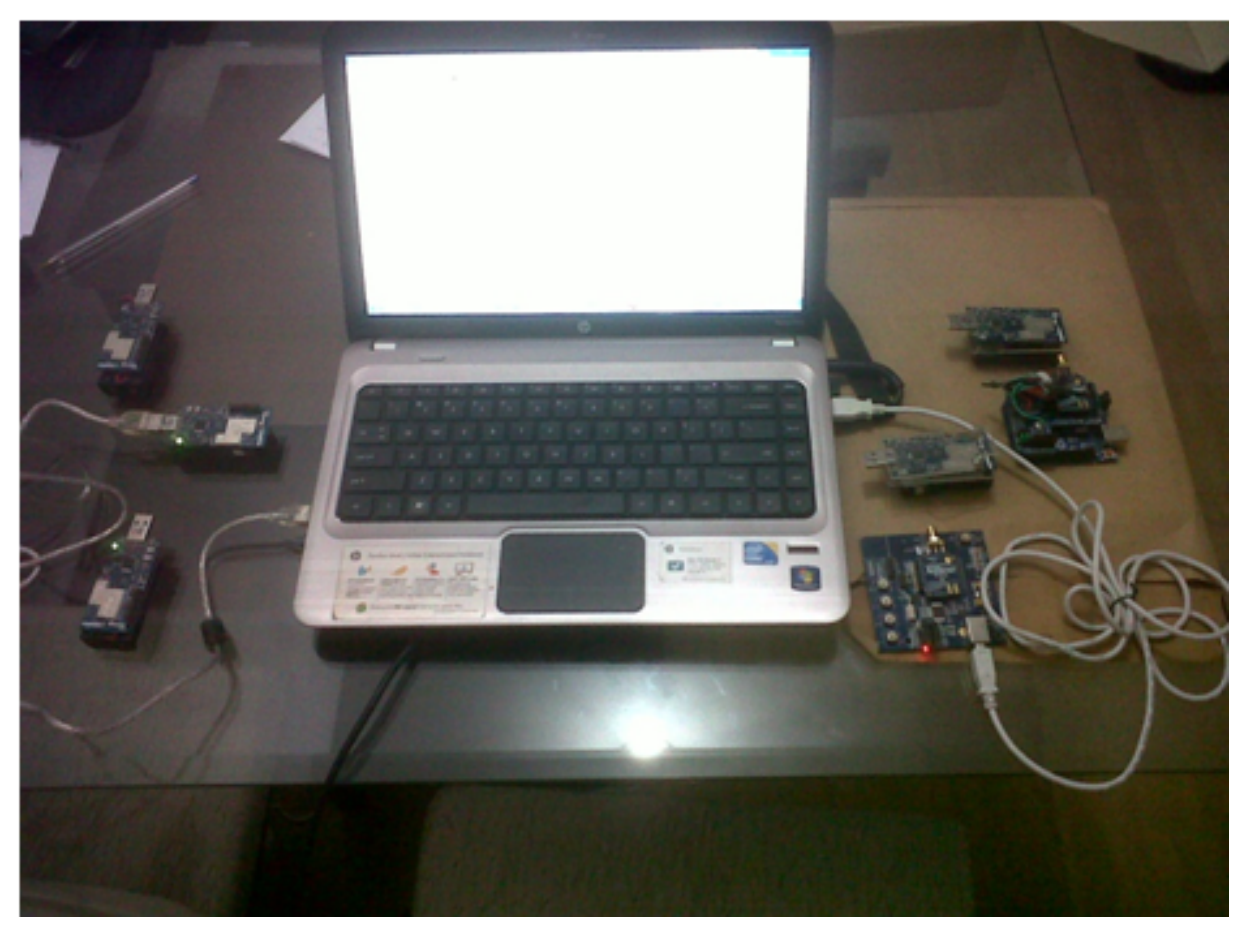

Figura 5.1: Dispositivos de Hardware - Ambiente Experimental

O conjunto de processos são descritos no caso de uso da figura 5.2, nesta fase inicial é definido um único ator para o sistema e um único nível de abstração para todos os processos.

A aplicação-exemplo procura representar a modelagem inicial de um ambiente de sensoriamento, especifica um conjunto de processos os quais são representados posteriormente como classes as quais consideram um ambiente de aplicação, o ambiente dividido em cenários de monitoramento, sensores organizados por redes, informações de monitoramento e interfaces de consulta. As informações do cenário e monitoramento são representadas de forma visual. 


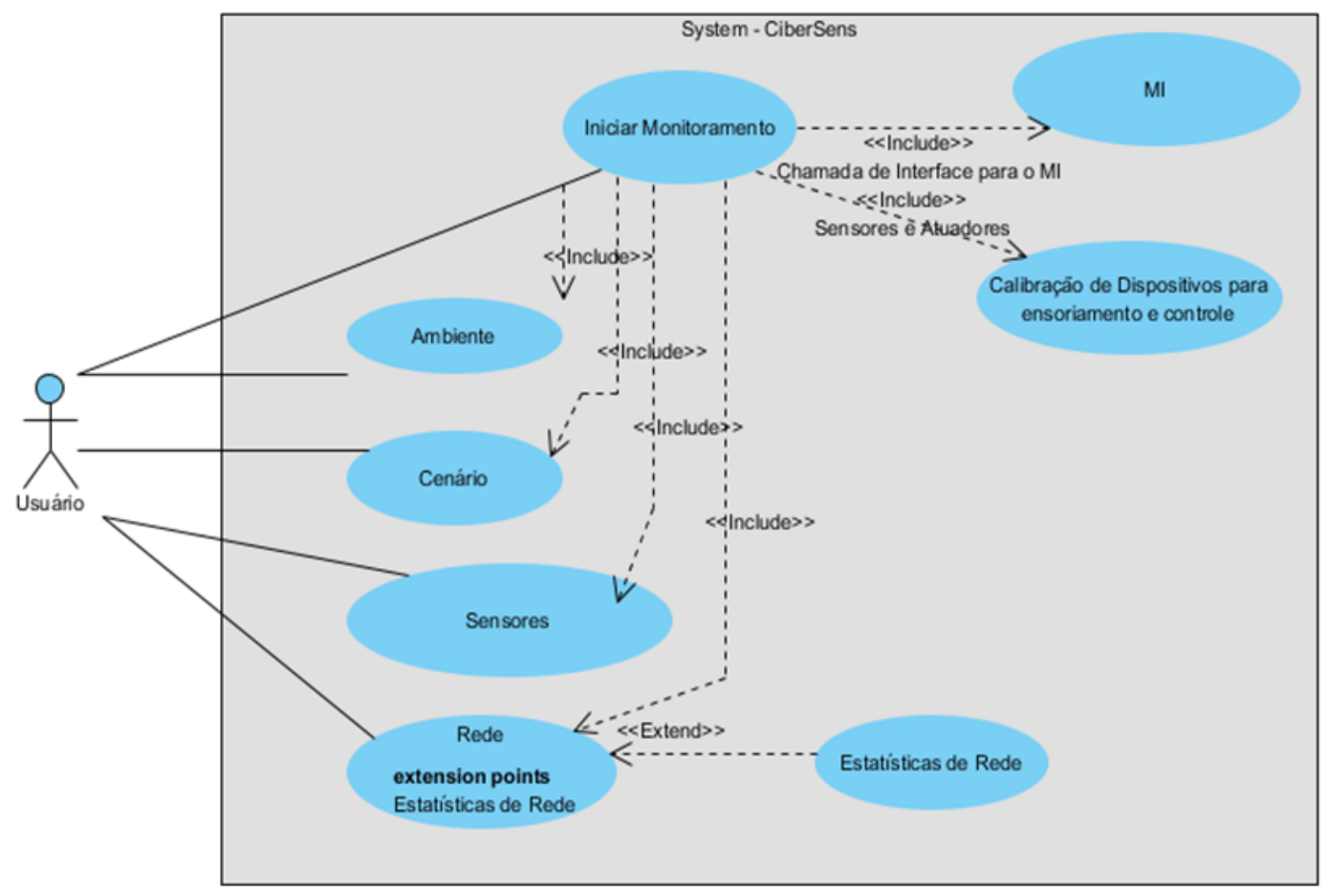

Figura 5.2: Diagrama simplificado de Caso de Uso, Ambiente CiberSens

O seguinte caso de uso apresentado na figura 5.3 descreve as formas de consulta aos serviços e repositorios de dados do modelo, o conjunto de informações podem ser salvas em formato XML para seu posterior processamento pelo CiberSens ou outras aplicações, podendo gerar eventos de atuação, controle e auxilio na toma de decisão na execução de novos eventos.

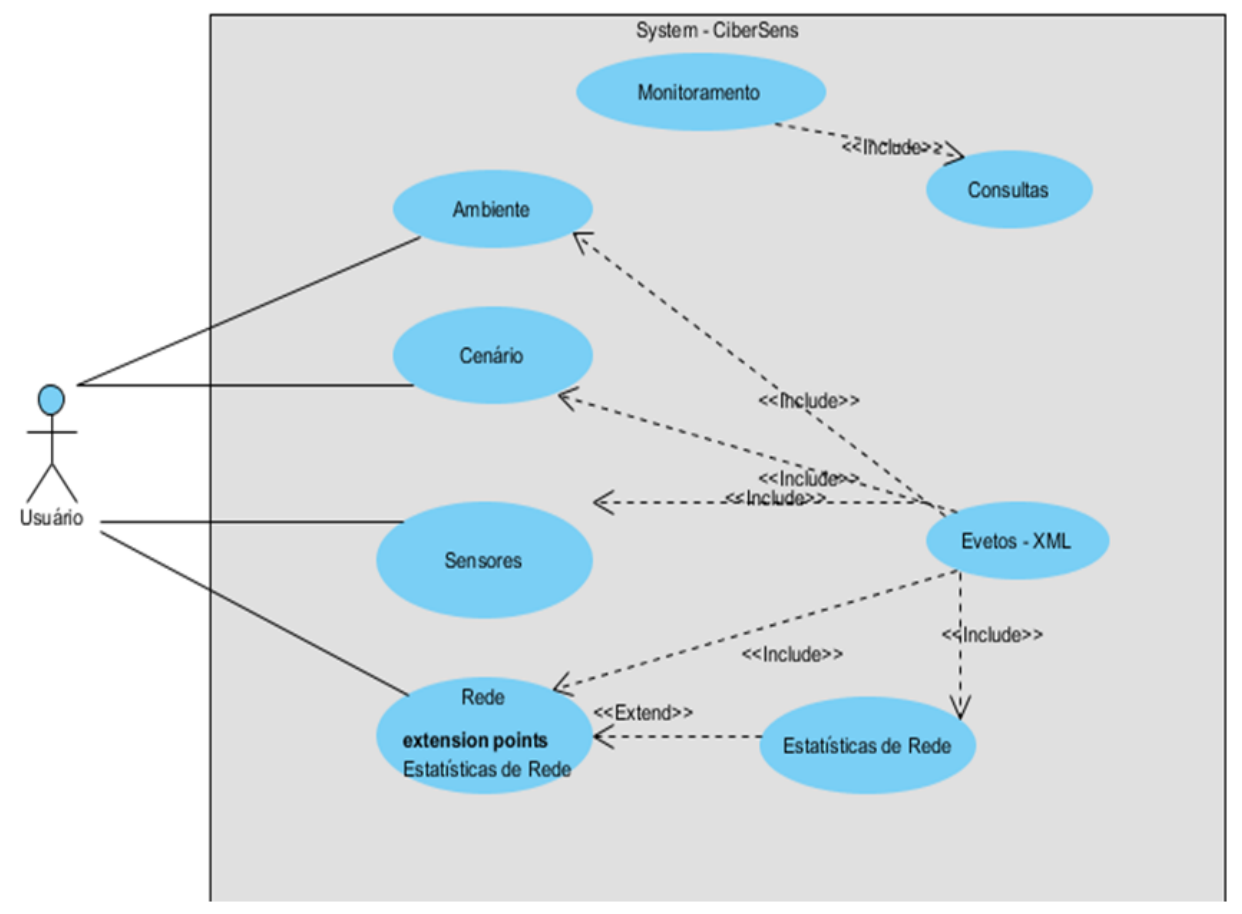

Figura 5.3: Diagrama simplificado de Caso de Uso Eventos e Consultas 
Os requisitos funcionais e de usuário são facilmente observados na interface do CiberSens (Figura 5.4).

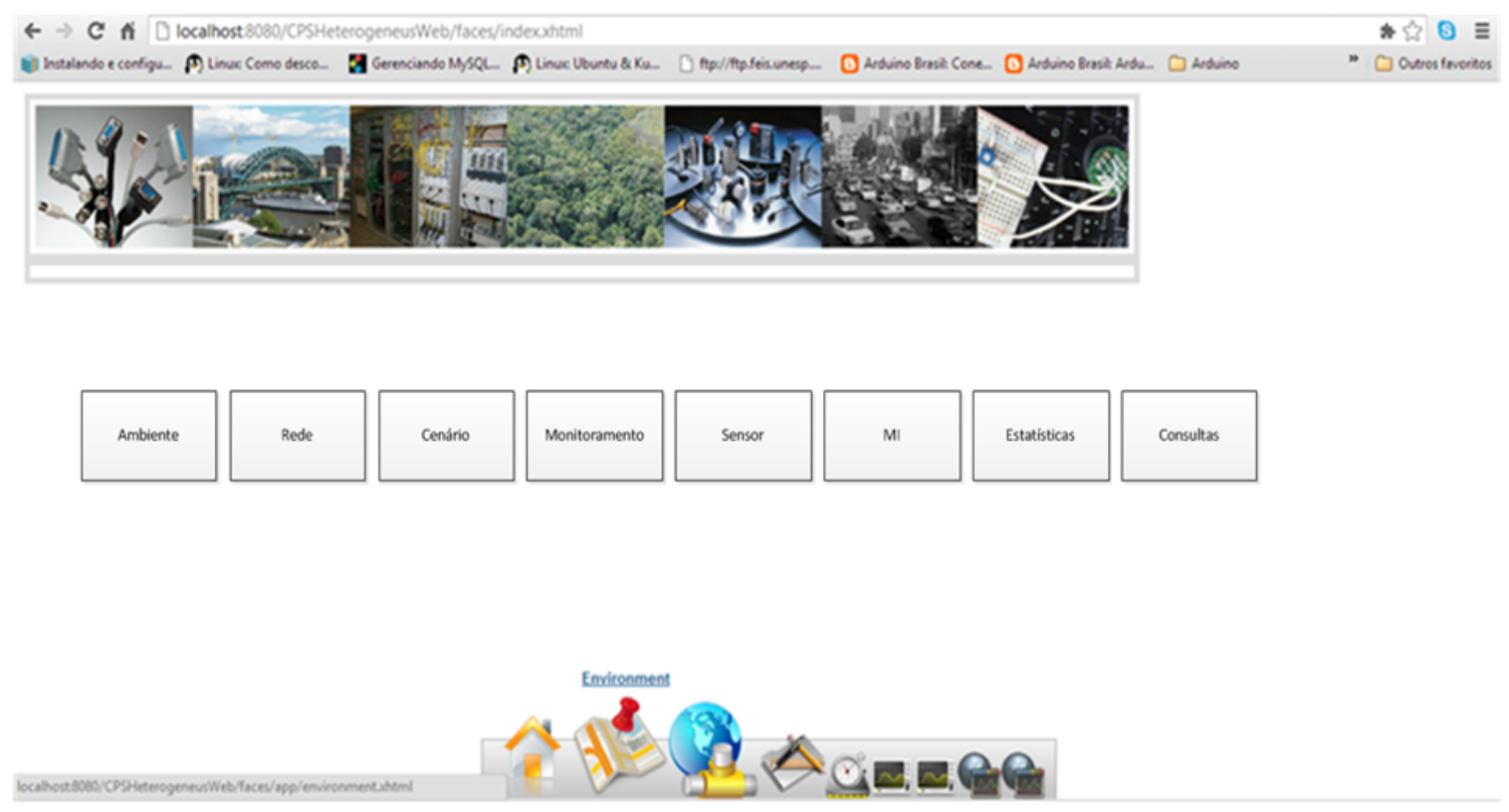

Figura 5.4: Interface Principal do CiberSens

\subsection{CiberSens - Descrição do Módulo Integrador - MI - Implementação}

A figura 5.5 apresenta a modelagem do MI dentro do middleware. O MI conecta ao servidor central e inicia um thread de conexão com o middleware. Quando estabelecida a conexão com a interface do servidor (na camada de dados) inicia-se um segundo thread. O segundo thread atua como um thread servidor que invoca um ou mais threads operários: os threads operários gerenciam as interfaces para cada data sink conectado ao MI (na prática o MI exerce ambas funções). Quando inciados os dois primeiros threads, um terceiro é iniciado e permite o controle e classificação de tráfego, classificando o fluxo de pacotes pelo protocolo de comunicação (multihop e singlehop) utilizado pelo nó sensor (MT) assim como pelo tipo de informação que este transporta no payload de dados, aplicando 5.2 e 5.3. Na classificação consideramse alguns requisitos não funcionais, não funcionais espaço-temporais e atributos extraídos da estrutura dos dados ingressados por meio do data sink para o MI, aplicando 5.1.

$$
S E(M T i d, \operatorname{Sid}, i)\left\{t_{S E}, l_{S E}, V_{S E}\right\}
$$

Informações da estrutura de dados de cada sensor são representados como eventos que 
incluem requistos não funcionais espaço-temporal, para atribuir confiabilidade ao sistema. $\mathrm{O}$ conjunto de eventos é gerenciado pela camada de serviços. A representação destes eventos e atributos de sensor são representados através de uma simplificação da proposta em [55], resultando em 5.1.

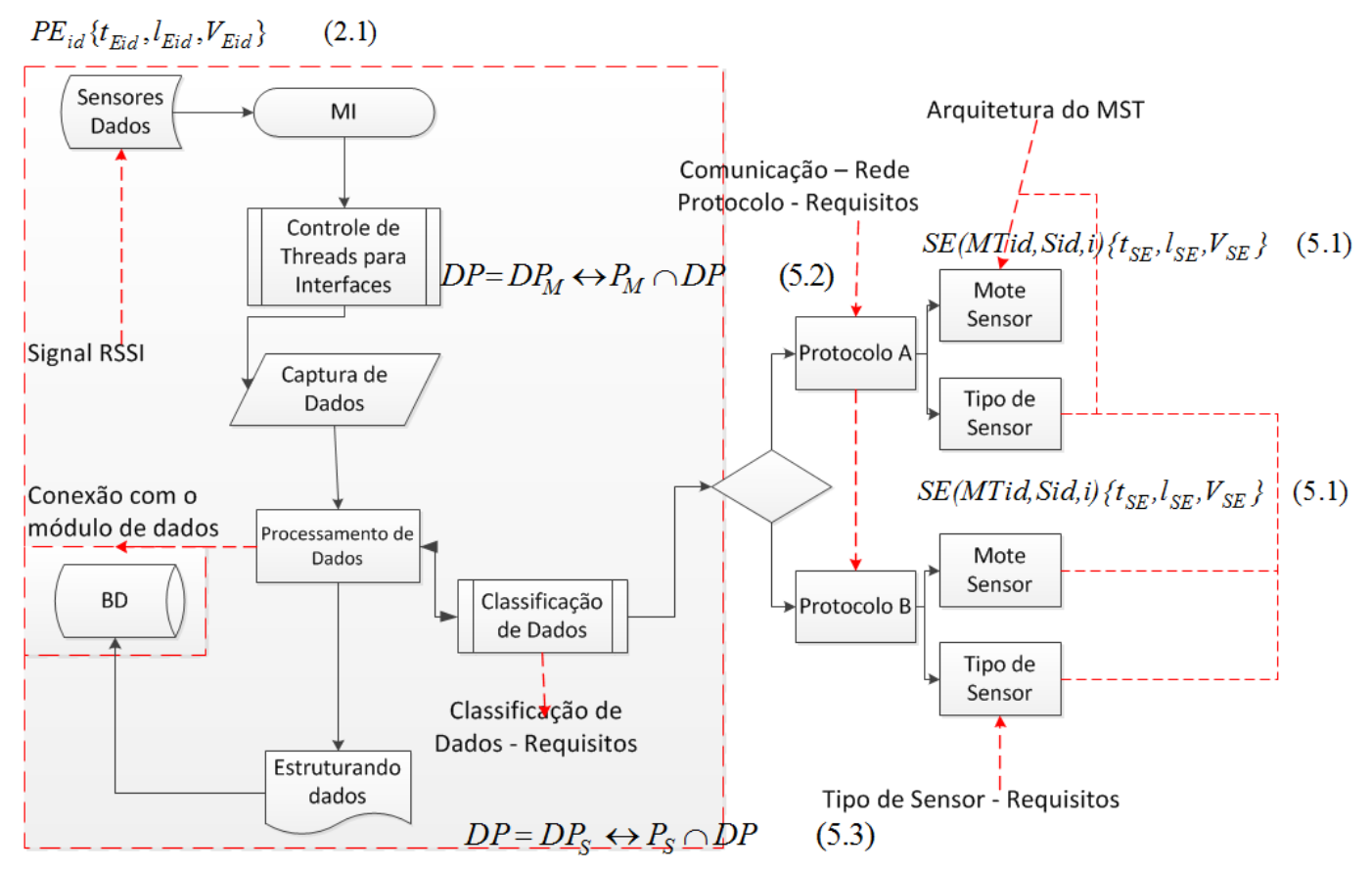

Figura 5.5: Diagrama do MI - Eventos e Requisitos

Onde SE é o evento sensor, MTid corresponde à arquitetura do mote, Sid o tipo de sensor sobre a arquitetura do mote, $i$ é o evento observado pela arquitetura e correspondem a requisitos de tempo, espaço e atributos, respectivamente. O processo de classificação de dados é realizado determinando variáveis comuns na estrutura dos protocolos multihops; esse conjunto de variáveis é representado como $P_{M}$, para esse caso o pacote de dados de entrada $D P$ é classificado como um pacote multihop $D P_{M}$ quando na sua estrutura inclui o conjunto de valores $P_{M}$. A mesma lógica se aplica para os dados singlehop $D P_{S}$.

$$
\begin{aligned}
& D P=D P_{M} \longleftrightarrow P_{M} \cap D P \\
& D P=D P_{S} \longleftrightarrow P_{S} \cap D P
\end{aligned}
$$

Na figura 5.6 apresenta-se o diagrama SysML de descrição de blocos para o MI, diferente de um diagrama UML convencional o diagrama de descrição de blocos SysML permite recriar e associar código para verificação do fluxo de processo de controle. 


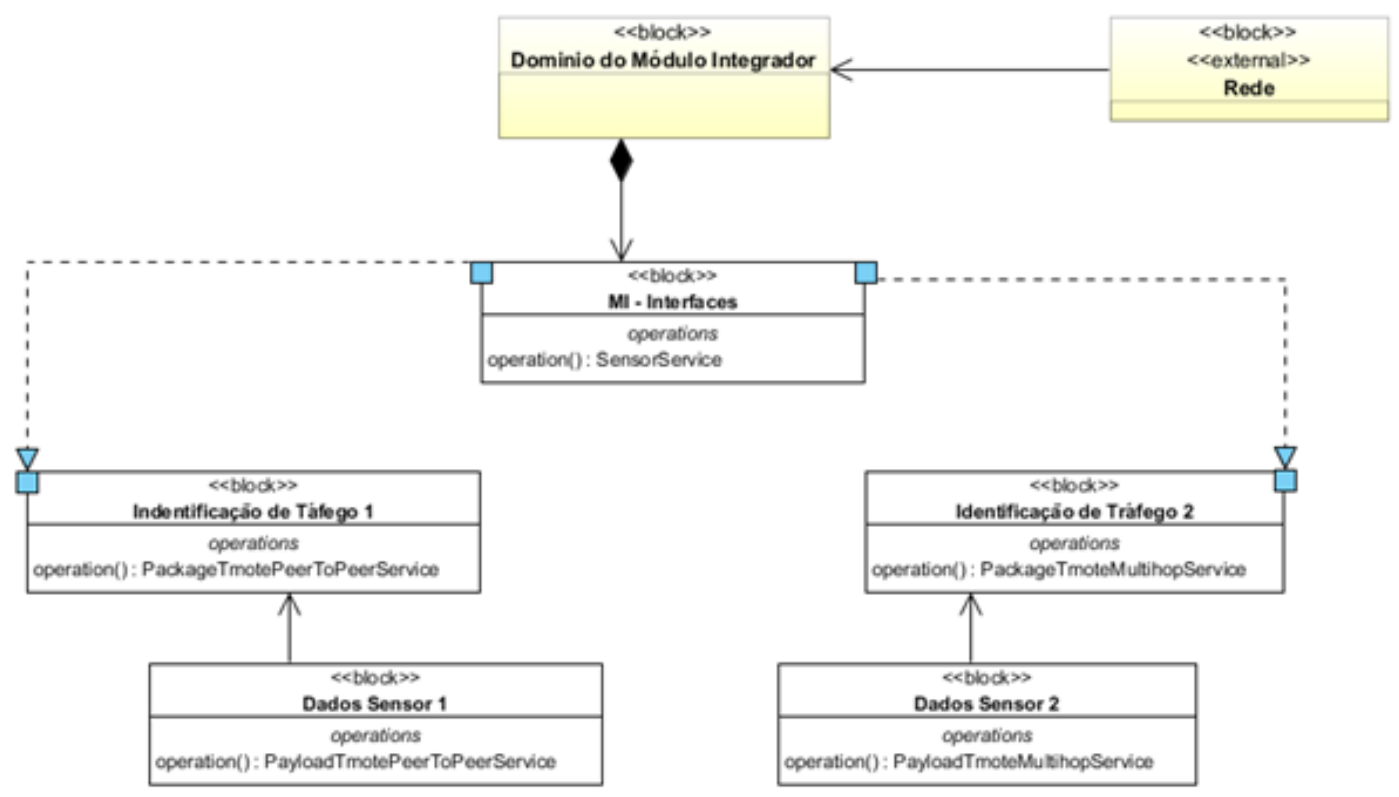

Figura 5.6: Diagrama SysML de Descrição de Blocos - MI

Toda a informação abstraida pelos MIs é controlada pelo ambiente supervisório constituida na prática pelo middlleware, a informação é processada e apresentada nas interfaces do ambiente supervisório.

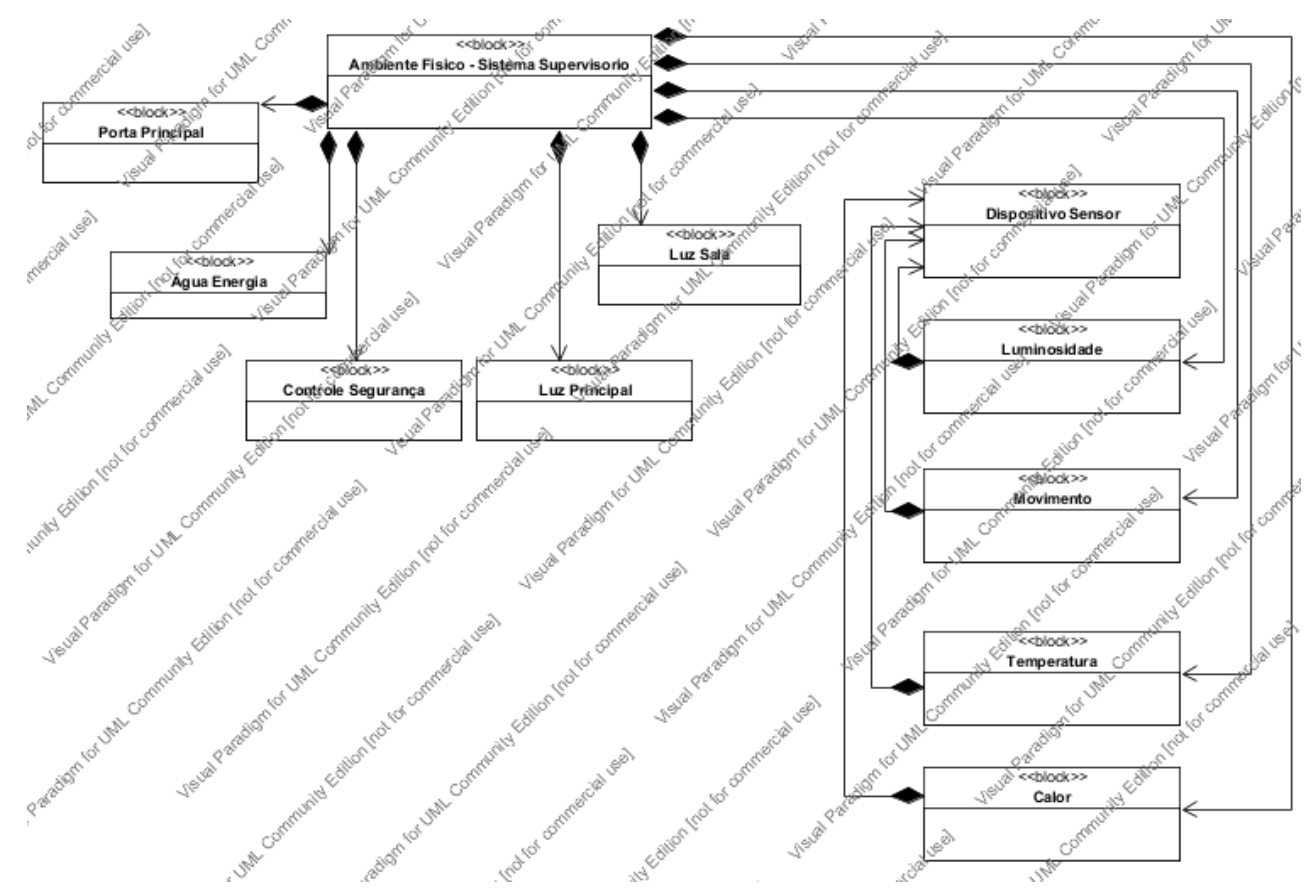

Figura 5.7: Diagrama SysML de Descrição de Blocos do Ambiente Supervisório

A figura 5.7 apresenta o fluxo de relação e controle dos dispositivos sensores para o ambiente supervisório, o ambiente supervisório concluí na atuação dos dispositivos como resultado das variáveis de saida que resultam do ambiente físico da casa. O SysML entende 
que cada bloco associa um conjunto de eventos físicos do ambiente, eventos coletados pelos sensores que quando transmitidos ao bloco supervisório (figura 5.8) será tomada uma decisão de atuação.

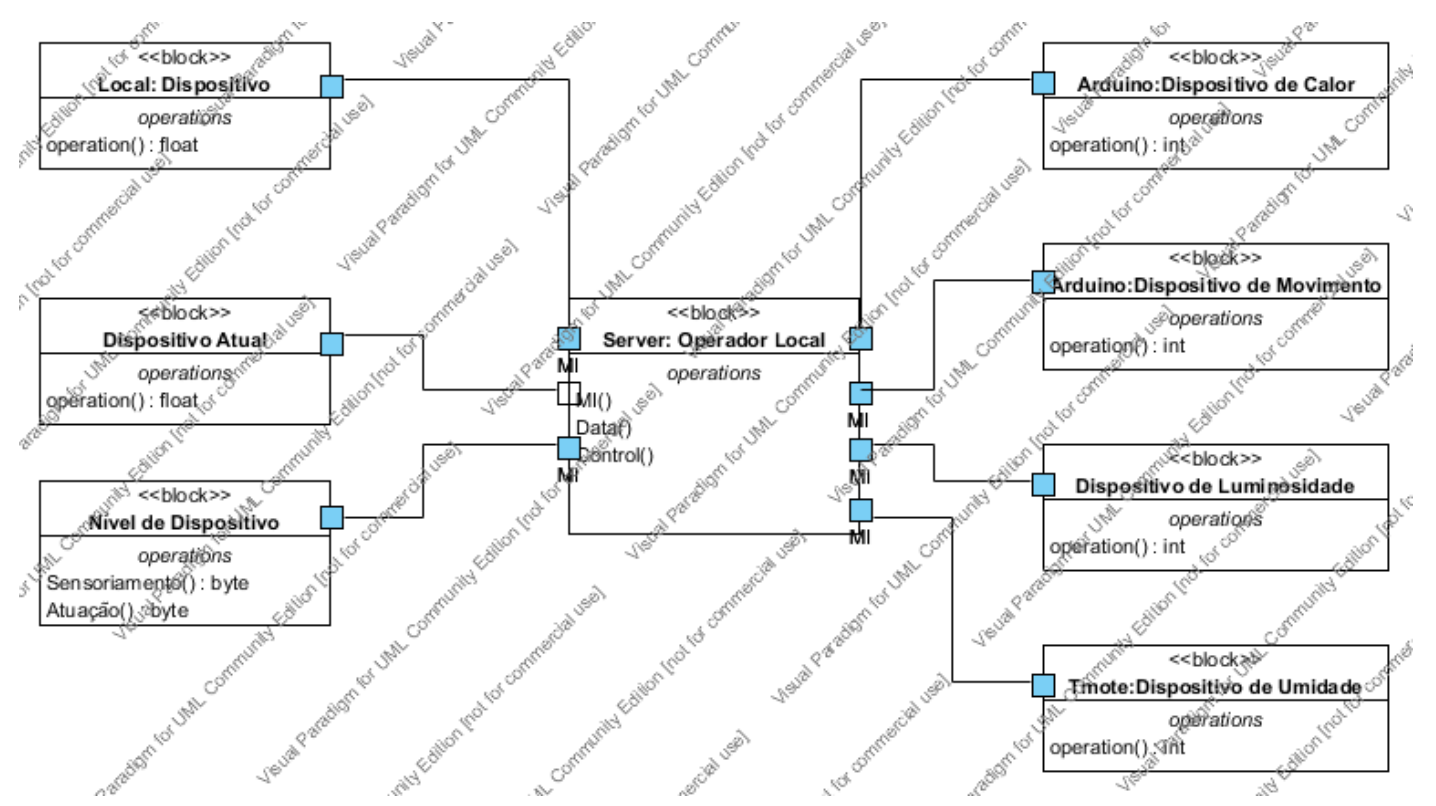

Figura 5.8: Diagrama SysML de Descrição de Blocos do Controle Supervisório

\subsubsection{Resumo do Fluxo de Eventos}

- Na primeira etapa acontece a captura de fenômenos do ambiente físico (Casa), variáveis de temperatura, movimento, calor e umidade. Os dispositivos MST transmitem utilizando protocolos de comunicação multihop e singlehop para o MI.

- O MI recepciona e desagrega a informação dos protocolos, processa a informação válida enviada pelos MSTs (O payload, o qual transporta a informação das leituras).

- Na interface web do usuário a informação é desagregada seguindo a estrutura: ambiente do CPS, cenário (divisão dos espaços do ambiente), informações de monitoramento, informação de monitoramento no cenário (localização do sensor no mapa), estatísticas de rede e uma interface de consulta.

- A segunda etapa da inicio com a geração de um evento de atuação.

Observações:

1. Disponibiliza acesso à configuração da estrutura de novos protocolos multihop ou singlehop para o administrador do CiberSens. 
2. As informações coletadas do ambiente físico podem serem salvas em estruturas de dados XML preservando a possibilidade de serem integradas ou tratadas por outros sistema.

\subsection{Ferramentas para o Caso de Estudo}

Nesta seção são descritas as ferramentas de software e hardware utilizadas para modelagem e desenvolvimento do caso de uso.

\subsubsection{Sistema Operacional TinyOS}

Desenvolvido pela Universidade de Berkeley [57]. É um S.O baseado em componentes e orientado a eventos. O TinyOs é um dos S.O mais usado para RSSF e possui módulos de programação de propósito geral para as redes de sensores, aliás, nos seus módulos de programação inclui diferentes plataformas de nós sensores como: os nós sensores da família Mica Motes, Telos, TmoteSky. O TinyOs proporciona entre seus muitos módulos de programação a aplicação do TosBase . Originalmente o S.O. TinyOS oferece uma interface de operação através do emulador de Linux chamado Cygwin, o qual proporciona uma janela de comandos para a programação e monitoramento da rede. Porém, o Cygwin oferece uma interface de programação pouco flexível, sendo usada em alguns casos a interface do Eclipse para a programação e configuração dos nós da rede.

A utilização de um Middleware para integrar novas aplicações ao TinyOS para tecnologias de sensores atualmente existente pode tornar-se um processo bastante complexo, considerando que o TinyOS não dispõe de mecanismos que associem prioridades à execução de novas tarefas, e que a linguagem de programação NesC impõe uma sintaxe bastante peculiar baseada em conceitos emergentes de engenharia de software dificultando a integração e criação de novas aplicações sobre este sistema operacional. Em geral, não utilizam multiprogramação porque cada nó sensor oferece apenas uma única funcionalidade para uma aplicação. Oferece pouco controle nas aplicações e não facilita a troca de aplicação em tempo real. Estas características demandam uma maior análise na estruturação do módulo de integração do middleware com o sistema operacional (S.O.), sendo necessário em muitos casos optar por outro S. O. com maior flexibilidade na sua estrutura de programação, por ser considerado um grande desafio o aumento de transparência no acesso às configurações internas dos nós sensores e da rede.

A utilização do S. O. TinyOS complica-se quando os módulos contidos no código do sistema operacional consideram unicamente arquiteturas restritas a uma família de nós sensores 
(mica, micaz, telosB etc), todos desenvolvidos pela universidade de Berkeley.

\subsubsection{Interface de Programação Arduino}

Arduino é uma plataforma open-source de computação baseada em uma placa e um ambiente de desenvolvimento IDE, a linguagem utilizada é C com algumas restrições. Arduino pode ser usado para desenvolver objectos autónomos ou interactivos. As placas podem ser reproduzidas a mão e o código fonte é totalmente aberto, bastante adequado para a elaboração de novos projetos de automação.

\subsubsection{Nível de Acesso - Sensoriamento - Descrição}

Na implementação do caso de uso serão utilizadas duas das mais novas gerações de nós sensores ZigBee, porém não iguais. A primeira rede (A) corresponde aos módulos Xbee Serie 2 [58]. O módulo de rádio possui uma potência de transmissão de $1 \mathrm{~mW}$ TX current $45 \mathrm{~mA}$, RX currente $50 \mathrm{~mA}$, supply voltage 2.8 - $3.4 \mathrm{VDC}$, banda de frequência $2.4 \mathrm{GHz}$ and Antenna Options Integrated Whip, Chip or U.FL Connector, RPSMA Connector. O módulo de rádio é instalado no Arduino UNO [59] e Arduino Dueilanove [60] utilizando um Shield XBee.

A segunda rede (B) é composta pelos módulos TmoteSky [61], com uma taxa de transmissão de $250 \mathrm{kbps}$, operam numa banda de frequência de $2.4 \mathrm{GHz}$, com baixo consumo de energia, taxa elevada de transmissão de dados e aplicações para RSSF projetadas com tolêrancia a falhas e de fácil desenvolvimento. 


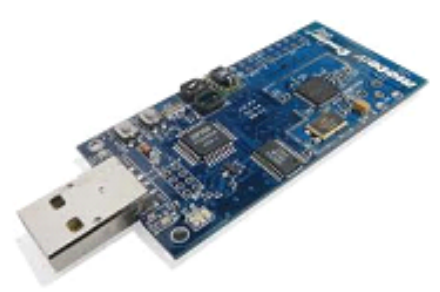

Tmotesky

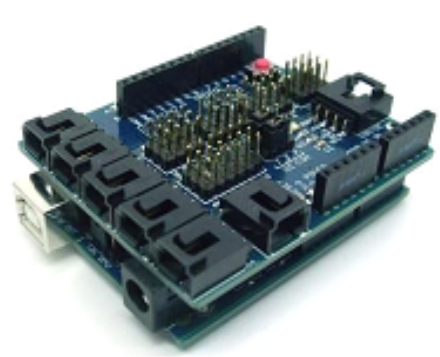

Arduino $\mathrm{l} / \mathrm{O}$

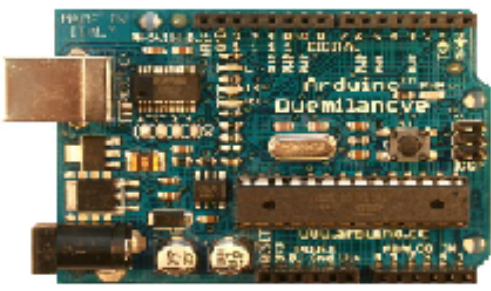

Arduino Duemilanove

Figura 5.9: TmoteSky - Arduino Duemilanove - Hardware para o Caso de uso

No nível de acesso são utilizados dois protocolos: o primeiro é um protocolo singlehop baseado em beacon, o tamanho do pacote é de 36 bytes dos quais 16 correspondem a informações de roteamento e os outros 20 ao payload de dados. O segundo é um protocolo multihop-LQI [62]: este protocolo proporciona o nível de qualidade de enlace por cada salto entre o MST origem e o MST destino. O tamanho do pacote é de 35 bytes sendo 10 para o payload de dados.

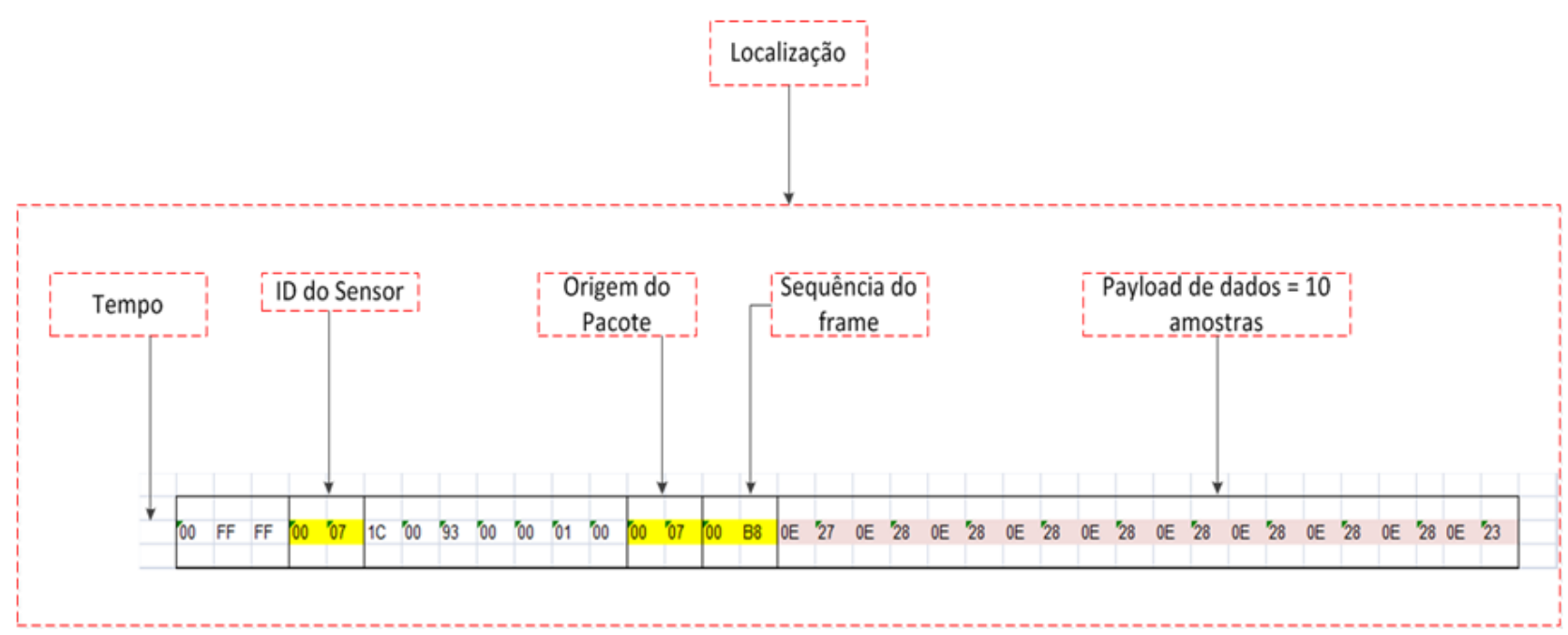

Figura 5.10: Descrição da Estrutura do Frame - Atributos 
A confiabilidade é um fator determinante para aplicações de RSSF e CPS, sendo assim é necessário atribuir estratégias que permitam manter o sistema funcionando como resultado da confiabilidade e disponibilidade do elemento transmissor e dos recursos que este transporta para que o sistema alcance seu objetivo. Seguindo esta lógica o protocolo singlehop é configurado para realizar 10 e transmitir as 10 leituras (Figura 5.11) em único frame até o MI. Já para o Multihop, considerando a limitação do payload, é atribuido uma carga de 5 leituras (Figura 5.12) por transmissão (Figura 5.10).

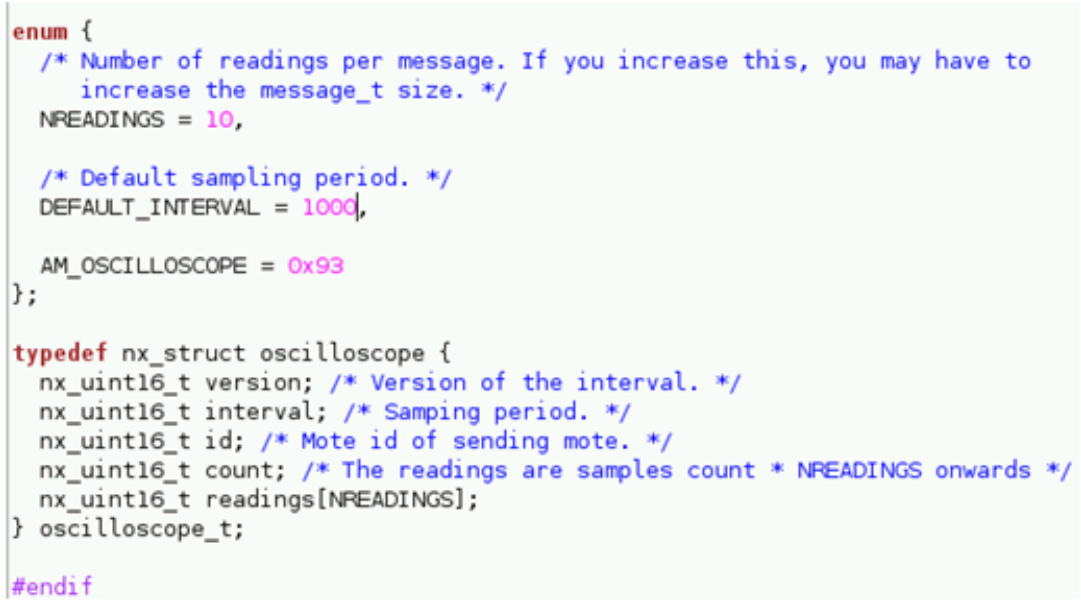

Figura 5.11: Código de configuração para o payload do Singlehop.

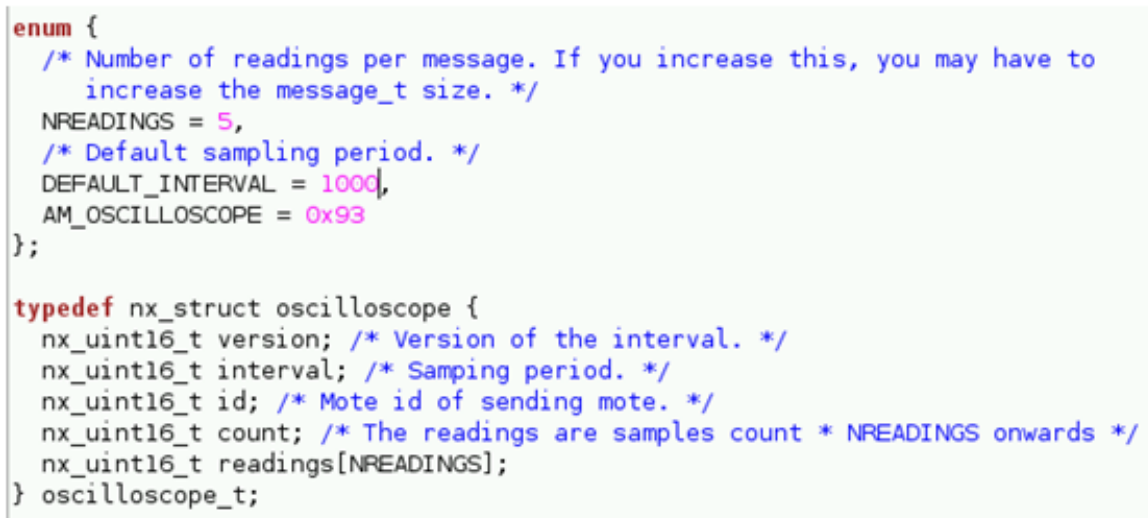

Figura 5.12: Código de configuração para o payload do Multihop. 
Para o módulo de armazenamento é modelada uma base de dados relacional (Figura 5.13).

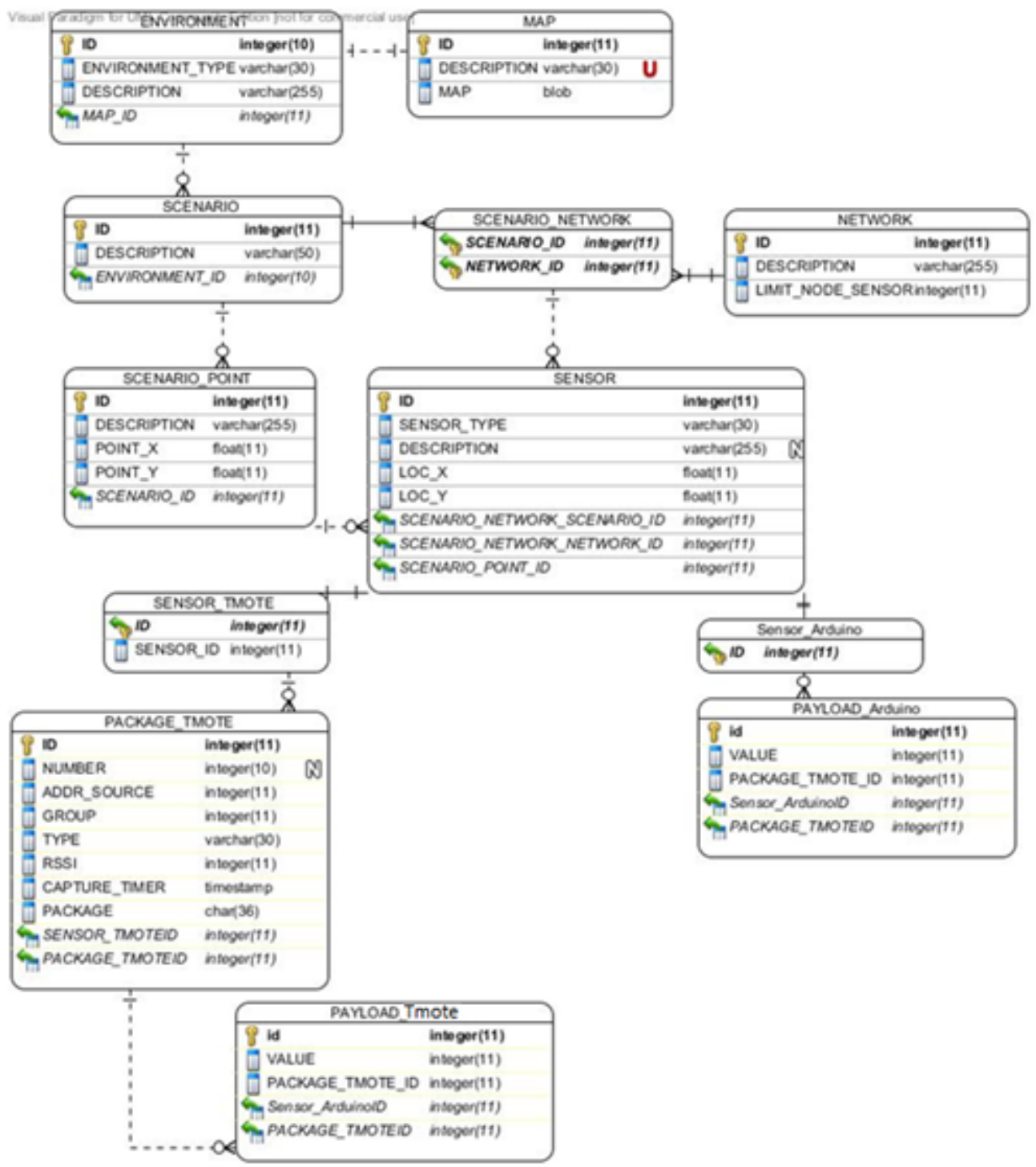

Figura 5.13: Diagrama de Classes - Armazenamento.

Na figura 5.13 são apresentadas as classes e atributos de um ambiente de aplicação de CPS, mais claramente a Casa Ecologica Inteligente. Um Ambiente e um mapa por ambiente, divisão dos espaços do ambiente em cenários, hardware utilizando mais de um protocolo de roteamento por ambiente e cenário etc.

No diagrama é apresentada uma classe PackageData, esta classe abstrai atributos comuns a ambos tipos de protocolos, como informação da taxa de perda do pacote, taxa de transferência de pacotes, o atributo timer, este atributo me permite encapsular um valor de tempo para cada pacote. Quando a leitura do bit de sequência de cada pacote falhar o cálculo de taxa de perda de pacotes será realizada através da verificação do atributo timer encapsulado em cada pacote. A soma do atributo timer deve ser proporcional à soma do timer do pacote anterior mais o send 
rate de disparo entre pacotes, este valor pode ser especificado entre $300 \mathrm{~ms}$ a $1000 \mathrm{~ms}$.

\subsubsection{Nível de Serviço - Controle - Descrição}

Na figura 5.14 é apresentado o diagrama UML, gerado a partir do código da aplicação, de especificação do modelo de controle de serviços.

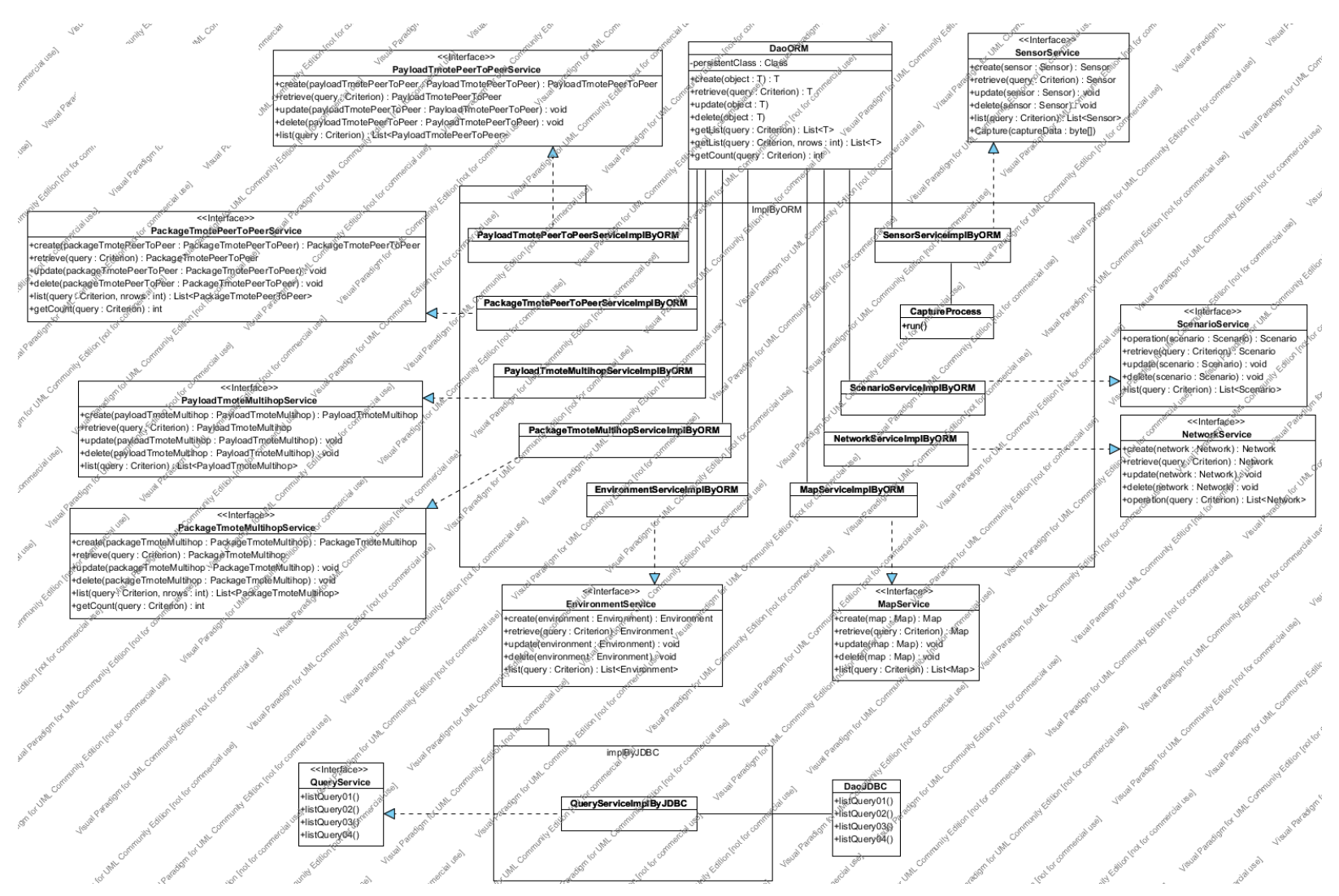

Figura 5.14: Diagrama de Especificação - Nível de Serviços.

Na parte de controle (Figura 5.14) o pacote view representa todas as API disponibilizadas das camadas subjacentes para a camada de aplicação, estas são contruidas utilizando as linguagens HTML e Java. 
No pacote beans estão contidas todas as classes responsáveis pelo controle das view e os métodos de conexão das camadas de acesso e serviços com a camada de aplicação (Figura 5.15).

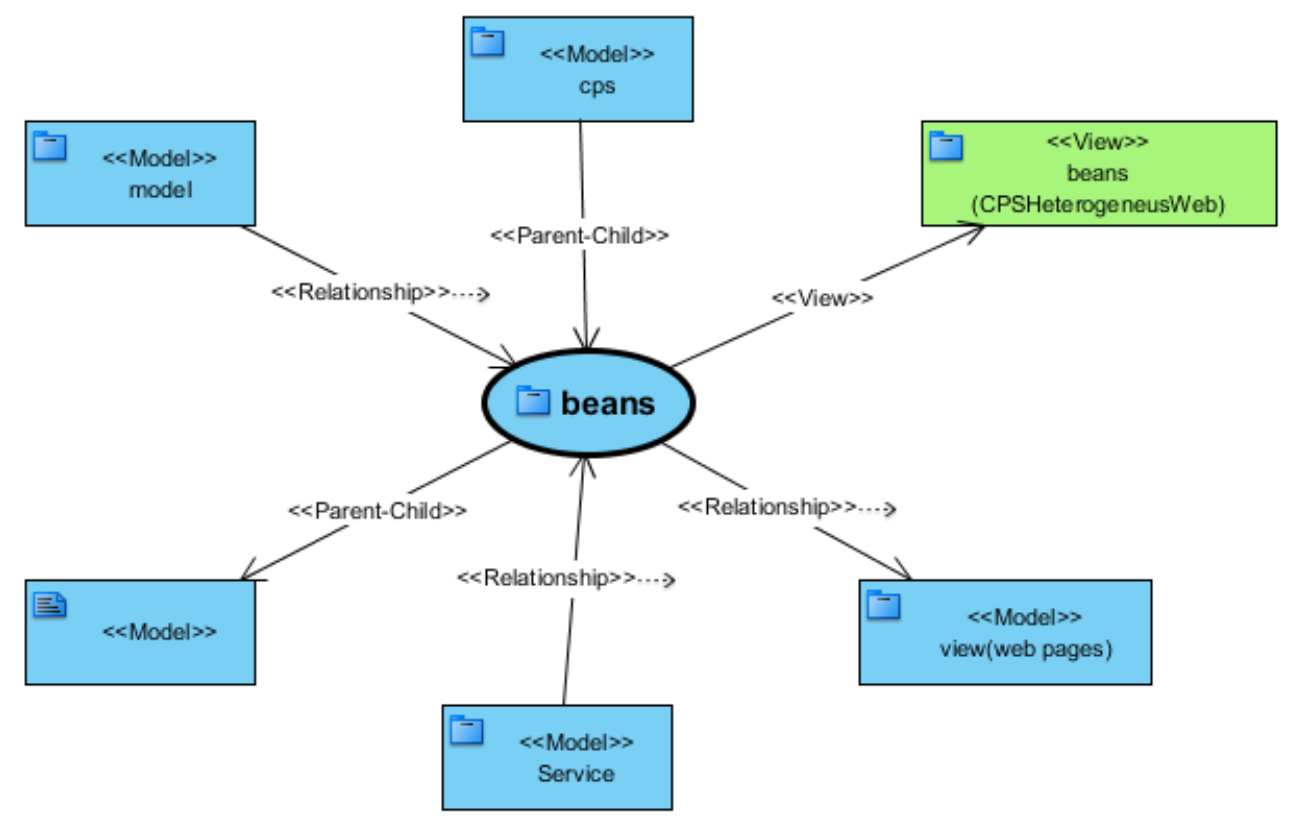

Figura 5.15: Diagrama UML - Nível de Controle.

O pacote DAO (classe DAO), implementa um objeto DAO (Data Access Object) que é o resposável pelo acesso a dados no módulo de armazenamento, criar, salvar, deletar, recuperar etc. Na interface de aplicação do usúario (view) um botão dispara um método especificado no controller que acessa um DAO para recuperar e armazenar os dados para ser tratados na mesma view ou em outra view da aplicação. A DAO implantada na modelagem e implantação do módulo de armazenamento é resultado da utilização do modelo MVC (model - view controller). O Modelo proporciona uma estrutura mais robusta ao modelamento nas camadas superiores e subjacentes.

O pacote converter, contêm os métodos utilizados para o tratamento e conversão dos dados das camadas subjacentes, especificamente de acesso.

\subsubsection{Nível de Aplicação}

No nível de aplicação, é considerada uma divisão em três camadas funcionais:

- Interface

- Processamento 
- Dados

A camada de Interface, na qual temos as view, é determinado o tipo de informação a ser exposta considerando níveis de abstração para os atores usuário e administrador, assim, na figura 5.16 é apresentada a composição das classes (camada de modelo - MVC) e serviços abstraidas nesta camada.

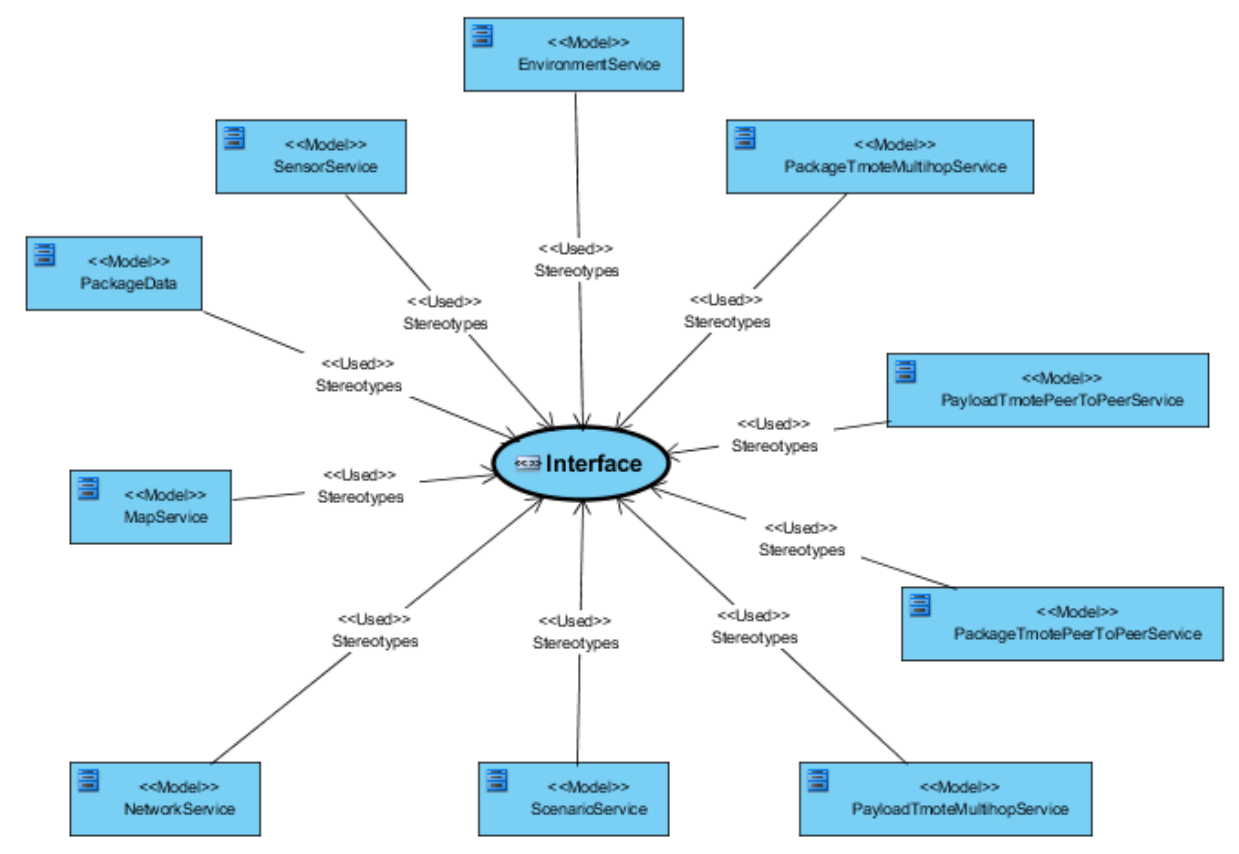

Figura 5.16: Diagrama de Análises da Interface.

As classes e serviços resultam das camadas subjacentes, comunicação (PackageData), comunicação e serviços (PackageTmoteMultihop.Service, PayloadTmotePeerToPeer.Service, Sensor.Service) e de serviços e aplicação (Enviroment.Service, Map.Service, Scenario.Service)

O processo de abstração não é uma tarefa trivial e está sempre fundamentado no tipo de requisitos funcionais especificados para o contexto de aplicações dos CPS. O conjunto de interfaces descritas a seguir é resultado de requisitos e níveis de abstração especificados para o ator usuário do CiberSens.

\section{Interfaces de Ambiente do CiberSens}

Esta é a primeira das interfaces ou views, aqui o usuário do CiberSens determina o ambiente de aplicação de sensoriamento e cadastra alguns atributos como Mapa (plano em formato png), descrição do Mapa e do ambiente (Figura 5.17). 


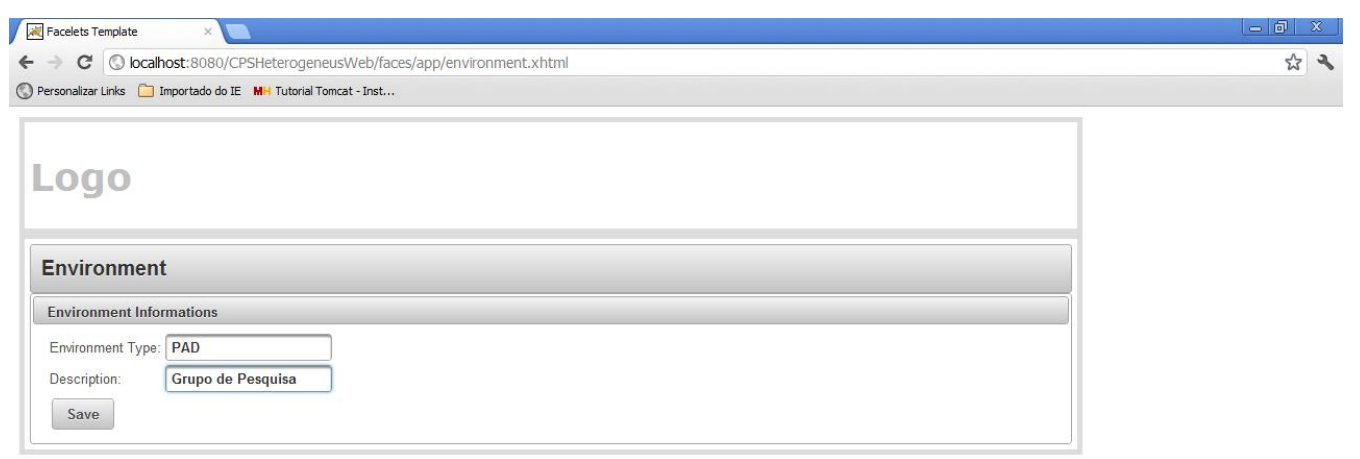

Figura 5.17: Interface de Cadastro de Ambiente e Mapa.

A interface da figura 5.18 corresponde à etapa de seleção do ambiente (o acesso a esta etapa acontece só após o usuário ter cadastrado e realizado o upload do mapa do ambiente de aplicação.

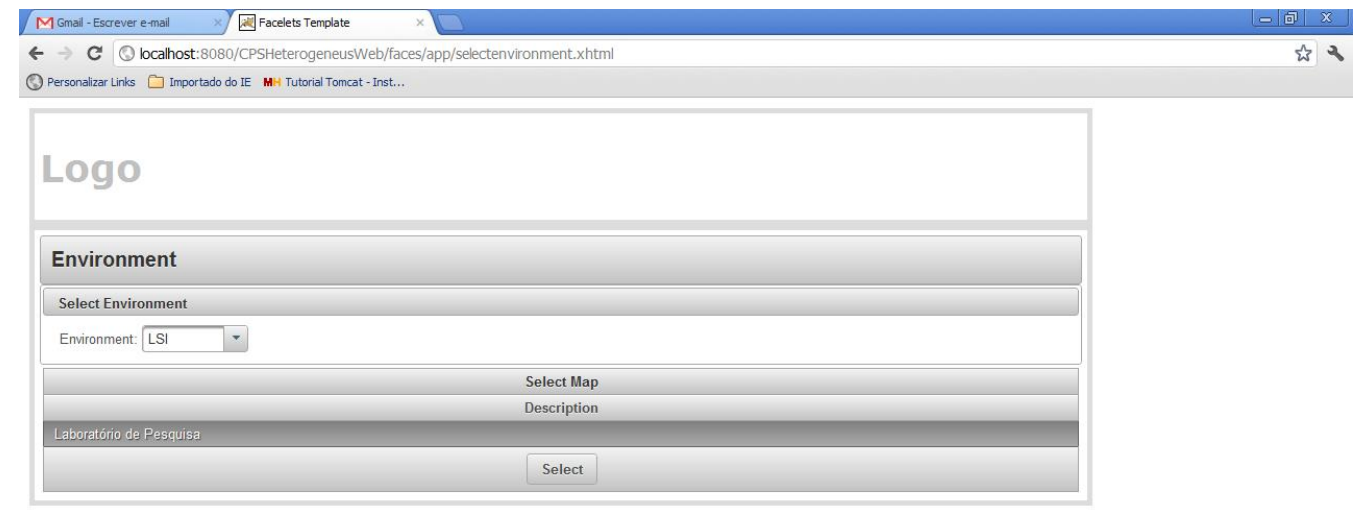

Figura 5.18: Interface de Seleção de ambiente.

A interface da figura 5.19, permite decompor o ambiente em cenários, o usuário atribui uma descrição e pode identificar no mapa do ambiente qual é a área que corresponde a cada cenário, pode ser um corredor, um laboratório etc. Esta informação é armazenada e reapresentada posteriormente na interface monitoramento.

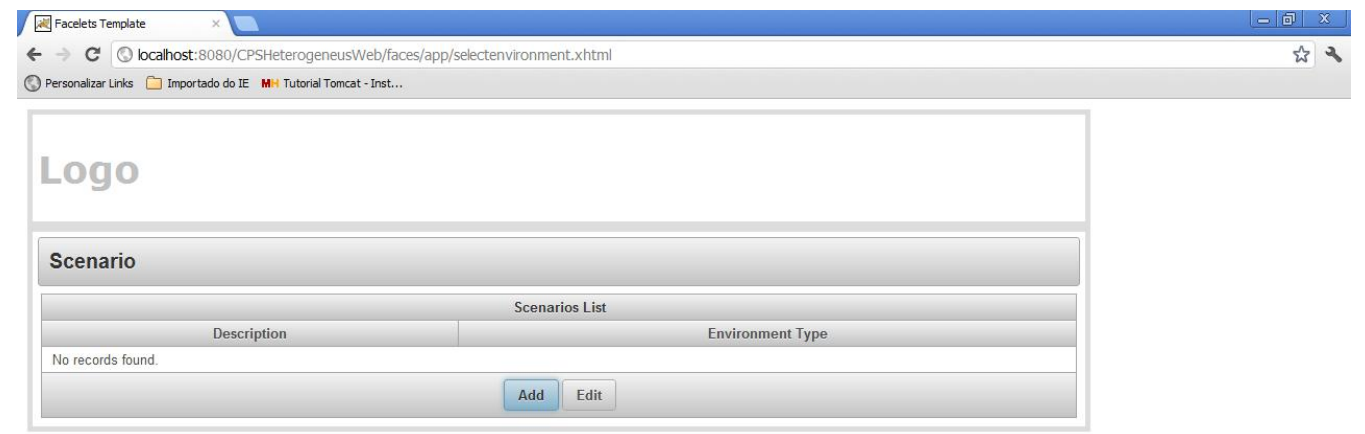

Figura 5.19: Decomposição do Ambiente em Cenários da Aplicação. 


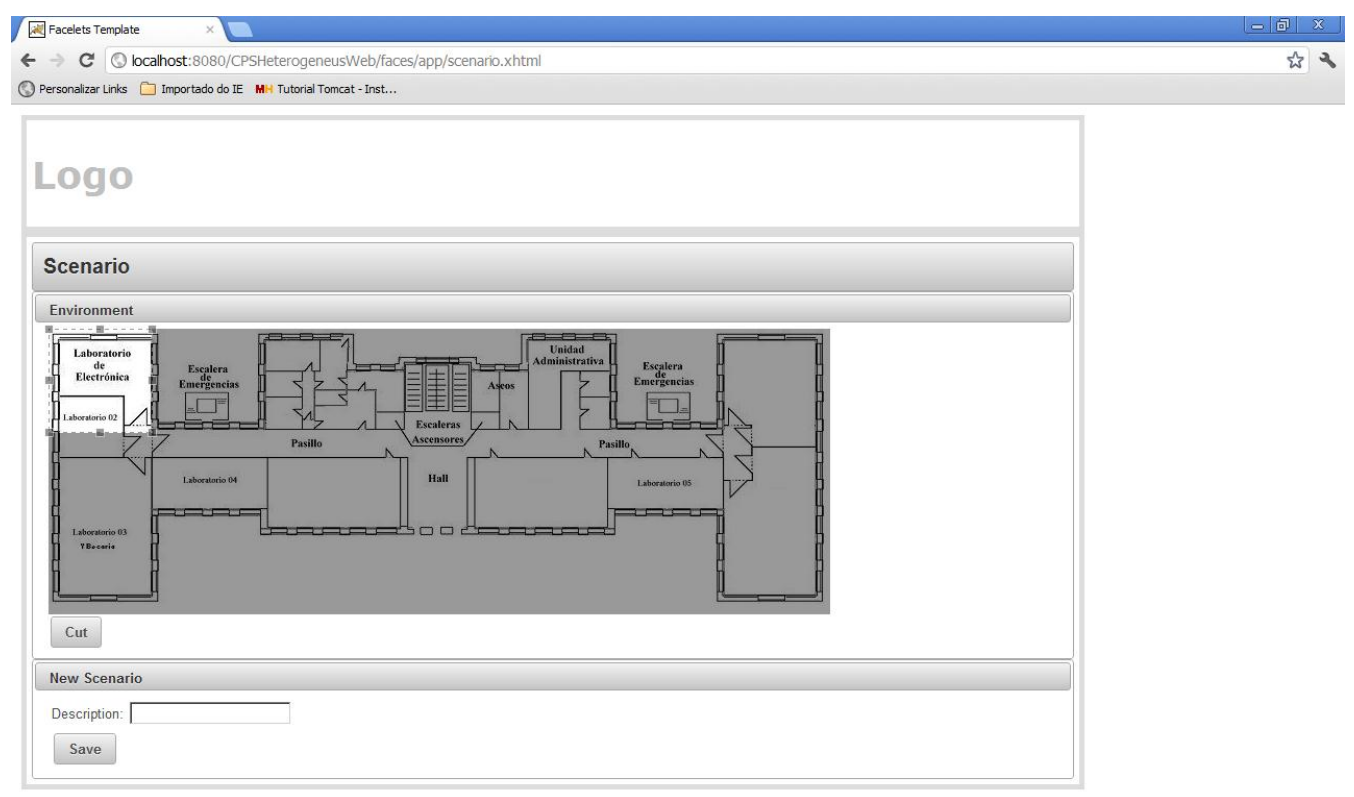

Figura 5.20: Identificação da área do cenário no Mapa.

Quando o método na camada de captura é iniciado e a informação e abstraída, através das camadas de comunicação e serviço, é necessário associar os MSTs que fazem parte de cada ambiente e cenário de aplicação. Como este processo não pode ser executado de forma totalmente intuitiva um serviço disponibiliza a informação dos MST (atributos de rede e sensoriamento) que foram detectados pelo CiberSens, através de uma interface sensor (figura 5.21) na qual apresenta os MST em estado default. Aqui o usuário deverá realizar uma associação manual dos MST segundo o ambiente e cenário da aplicação a qual pertencem.

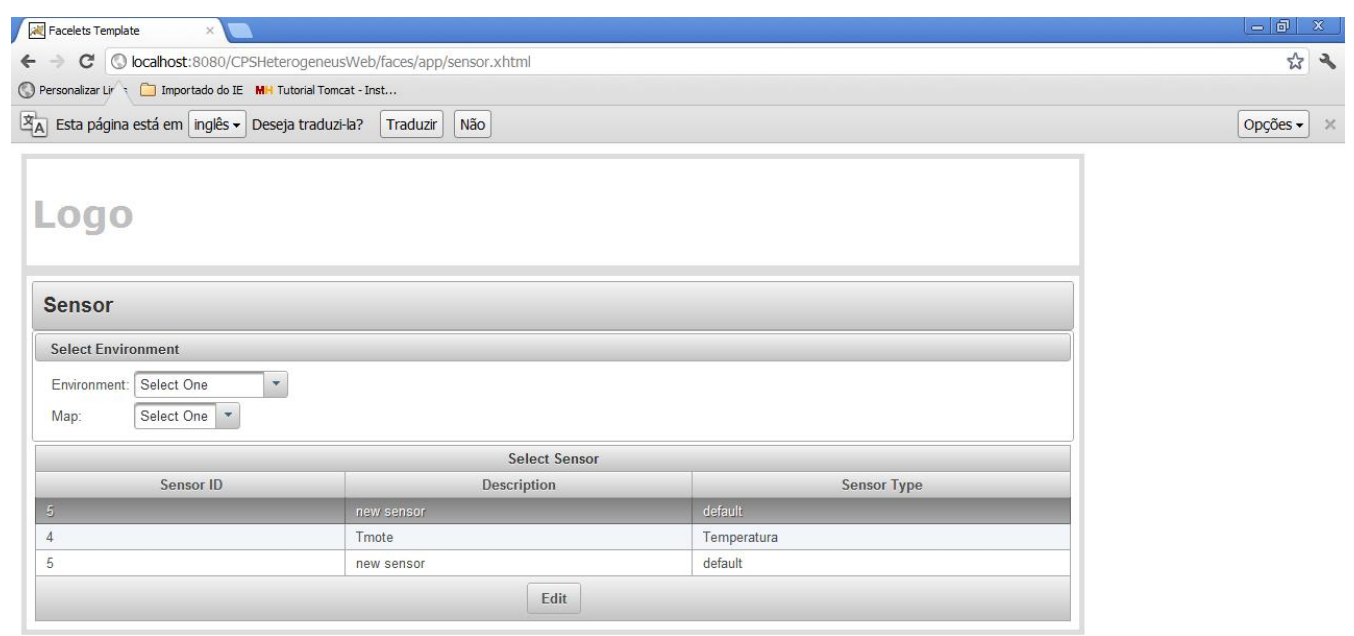

Figura 5.21: Interface Sensor - Cadastro MST.

Após a associação manual ser confirmada a interface sensor permite visualizar os MSTs sincronizados no CiberSens associados por ambiente e cenário de aplicação.

Ao finalizar esta etapa a nova interface é acessada, esta é chamada de monitoramento, aqui é 
apresentada a relação ambiente - cenário de aplicação e os MST que fazem parte desse contexto (Figura 5.22).

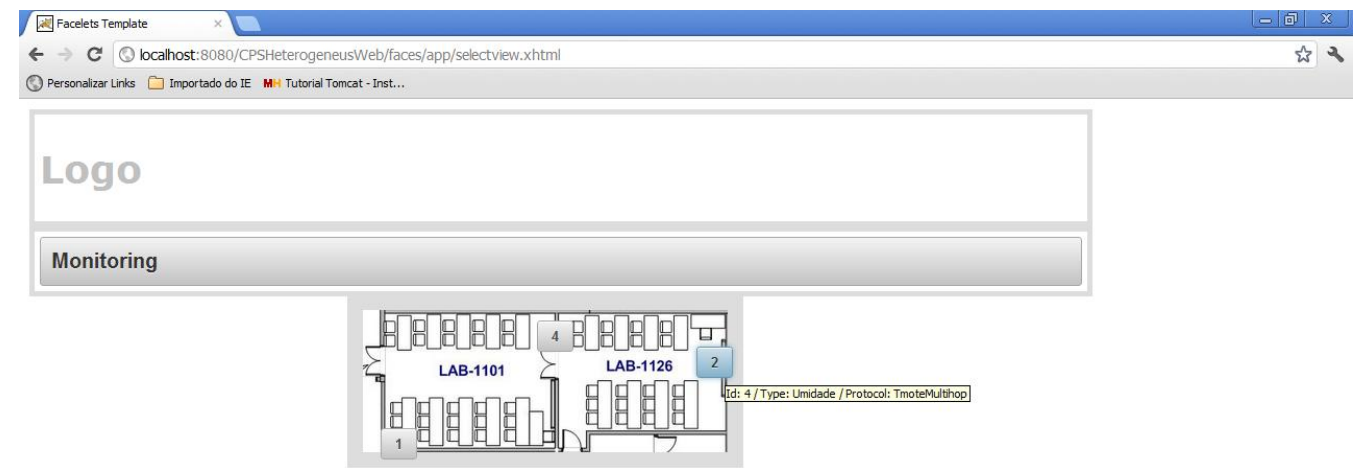

Figura 5.22: Interface Monitoramento - Relação Ambiente - Cenário - MSTs.

Os processo de modelagem e construção de interfaces responde a uma análise especifica de requisitos funcionais mínimos segundo o nível de abstração para o perfil do ator usuário. O modelo propõe ser bastante flexível e dinâmico para atingir as exigências do usuário e proporcionar um maior nível de abstração aos processos das camadas subjacentes para os atores do sistema. 


\subsection{Aplicação-Exemplo - II (Casa Ecológica Inteligente)}

A segunda aplicação-exemplo é uma Casa Ecológica Inteligente, a escolha deste cenário resulta do conjunto de características de sensoriamento necessárias para a apreservação de recursos de energia e controle do ambiente. Entre as principais características deste tipo de ambientes temos:

- Dispositivos Sensores e atuadores,

- Controle de operação de dispositivos,

- Gerenciamento local e remoto.

- Sistema Distribuído

\subsubsection{Definição:}

Definição: As Casas Ecológicas Inteligentes (Smart Green House) constituem um novo conceito de construção de ambientes domésticos que buscam a utilização eficiente dos recursos energéticos, e o controle de poluição e desperdício que resulta da utilização destes recursos. Para atingir estes objetivos utiliza-se de combinações de hardware e software projetados para coordenar todas as necessidades tecnológicas e recursos energéticos de um ambiente doméstico.

Nesta aplicação-exemplo procura-se representar de forma incial o conjunto de eventos necessários para o controle efetivo dos processos da Casa, posteriormente inclui-se o controle de eventos de atuação associados aos dispositivos sensores de temperatura e movimento para controle do sistema de ar condicionado. Para a formalização dos eventos utiliza-se da ferramenta SysML.

Descrição das Atividades de Controle para a aplicação-exemplo, fase inicial:

- Controle de Segurança

Detecção de Controle de Acesso

Controle de Janelas

- Controle de Água

Controle de Vazamentos (Bware - Contador de Água) 
- Controle de Energia

PLC

Tomadas (Power Meter Socket)

- Controle de Ambiente

Temperatura (Arduino)

Umidade (TmoteSky)

Movimento

Luminosidade (Arduino)

A figura 5.23 apresenta os ambientes da Casa Ecológica Inteligente e as arquiteturas de hardware associadas ao monitoramento de eventos para atuação e controle, alguns dos dispositivos como o Bware e o Power Meter Socket, são utilizados como referência na modelagem do cenário da casa, não sendo implementadas no ambiente real do middleware CiberSens. O cenário se restringe a uma casa de três andares, dentros dos quais é possível monitorar eventos de forma simultanea. 


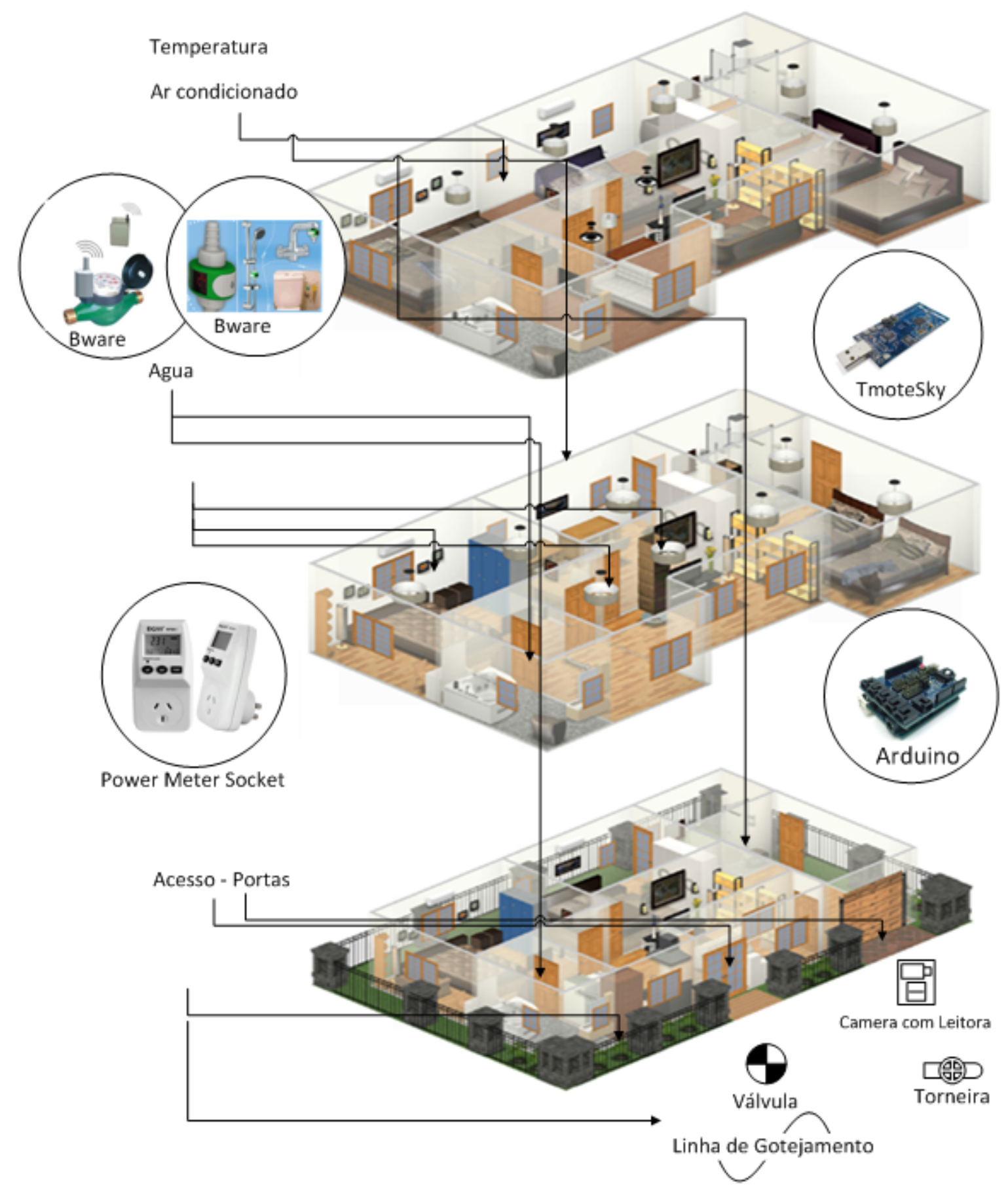

Figura 5.23: Casa Ecológica Inteligente (Cenário de controle, sensoriamento e atuação)

\subsection{Modelo de distribuição - Infraestrutura e Processos}

Neste estudo de caso consideram-se três principais blocos de controle com os quais o sistema se torna funcional. Blocos os quais também podemos chamar de níveis de controle, estes são definidos como; nível de sensoriamento (sensores), nível de controle (controlador), nível de atuação (atuadores) (Figura 5.24). 
- Sensor: Informa as variáveis de saída do ambiente físico, as quais são utilizadas para a lógica de modelagem e controle.

- Controlador: O controlador é identificado como o elemento de software que gerencia a saída real do ambiente junto à saída desejada para o sistema de sensoriamento ou atuação.

- Atuador: Entre ambos níveis de sensoriamento e controle se encontra o atuador.

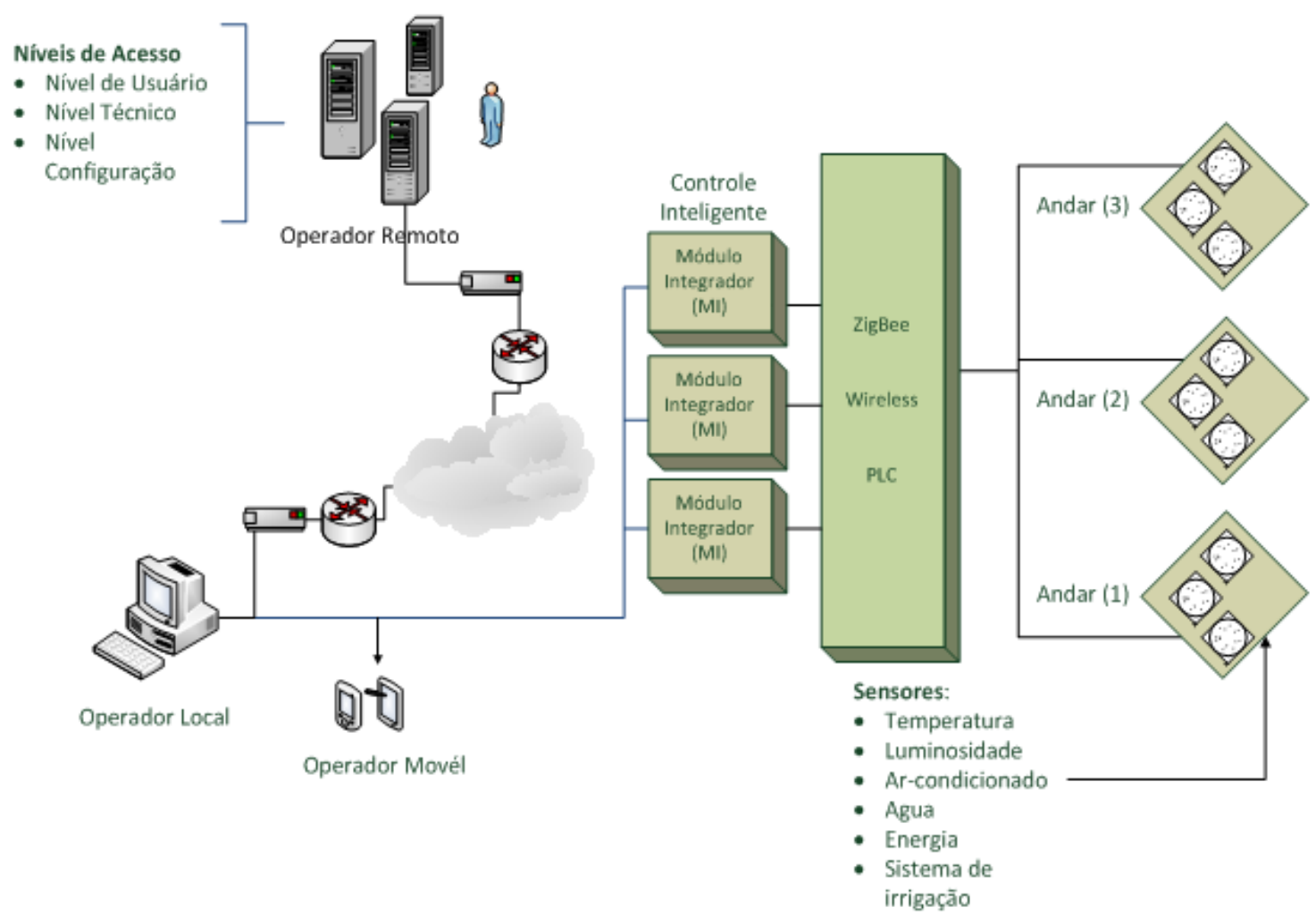

Figura 5.24: Diagrama da Infraestrutura de operação)

\subsection{Descrição dos Principais Estados para Controle da Casa Ecológica Inteligente}

Nesta seção são descritos os principais estados do ambiente que definem o fluxo dos eventos dentro da casa ecológica inteligente, eventos que permitem acionar o monitoramento remoto e a segurança do ambiente quando as pessoas da casa se encontram ausentes por um período curto ou longo por ferias.

- Pessoas Casa: Define se existe ou não uma pessoa nos ambientes da casa.

- Ausente: Define se o individuo deixou o ambiente da casa por um período curto (compras ou trabalho). 
- Ferias: Define que a pessoa está ausente do ambiente da casa por um tempo maior (Neste estado é preciso especificar quais seriam os critérios para acionamento dos serviços básicos para manutenção dos ambientes da casa) Figura (5.25).

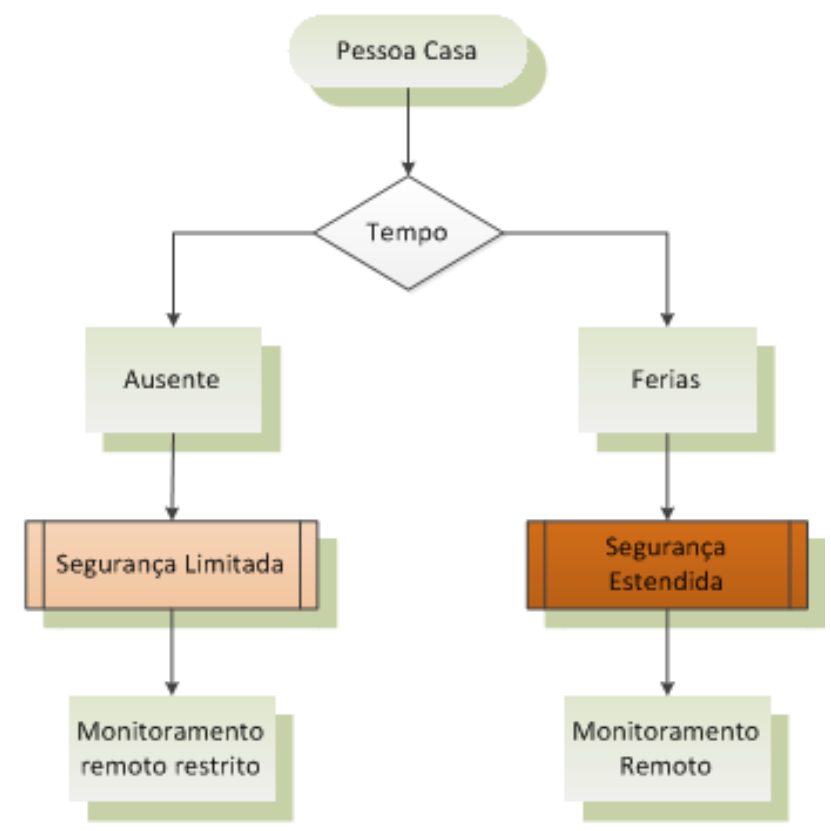

Figura 5.25: Exemplo da lógica dos estados Pessoa Casa - Ausente - Ferias

Como mostra a figura 5.25, quando o sistema se encontra em funcionamento em todos seus níveis é possível ativar o estado "Ausente"para o qual teremos como pré-requisito que o estado "Pessoa Casa"esteja em funcionamento, considerando que o tempo de ausência é curto e os recursos de monitoramento podem ser restritos. Para o estado "Ferias"o critério é o mesmo tendo em conta que teremos um maior nível de segurança acionado, monitoramento remoto completo e para que os critérios se cumpram devemos ter o estado "Ausente"inativo.

\subsection{Ambiente Externo}

\subsubsection{Controle de Segurança}

O controle de segurança pode ser implementado sobre a lógica dos Sistemas Inteligentes de detecção de intrusão (Smart ID System) [63], os quais utilizam de um conjunto de dispositivos sensores gerenciados através de um módulo de controle. O módulo de controle atua sobre a informação obtida dos eventos programados em cada módulo sensor e pode determinar na maior parte dos casos o acionamento de outros eventos dentro ou fora do ambiente da casa, especificando apenas dois estados "ATIVO"e "INATIVO". O estado "ATIVO"pode dar inicio a 
outros sistemas que verificam a existência de pessoas autorizadas dentro do ambiente da casa. $\mathrm{O}$ estado "INATIVO"segue a mesma lógica e permitiria a execução de alguns processos de forma "MANUAL", como ascender as luzes de entrada da casa até verificar a violação dos acessos da casa por pessoas não autorizadas ou inclusive verificar se outros sistemas e ambientes são seguros antes de ficar totalmente ativo.

Para nosso modelo os estados "ATIVO"e "INATIVO"especificam ou iniciam os eventos na segurança da casa descritos na tabela 5.1:

Tabela 5.1: Eventos e Condições - Segurança

\begin{tabular}{|l|l|l|l|l|l|}
\hline \multirow{2}{*}{$\begin{array}{l}\text { Sistema de } \\
\text { Ventilação }\end{array}$} & Ativo & Pessoa Casa & Ativo & Temperatura & Ativo \\
\cline { 2 - 6 } & Inativo & Ausente Ferias & Inativo & Movimento & Inativo \\
\hline Alarme & Ativo & Ausente / ferias & Ativo & & \\
\cline { 2 - 6 } & Inativo & Pessoa Casa & Ativo & Janelas & Inativo \\
\hline Janelas & Ativo & Pessoa Casa & Inativo & Movimento & Ativo \\
\hline & & & & Calor & \\
\hline & Inativo & Ausente / Ferias & Ativo & & \\
\hline
\end{tabular}

\section{- Análises Textual}

A análise textual é uma técnica UML (figura 5.26) para geração de Casos de Uso a partir do detalhamento textual dos processos que constituem o sistema. O processo permite uma identificação mais objetiva dos atores e sua realação com o fluxo de ações, tarefas, classes, sub-processos que fazem parte do sistema que será projetado. 


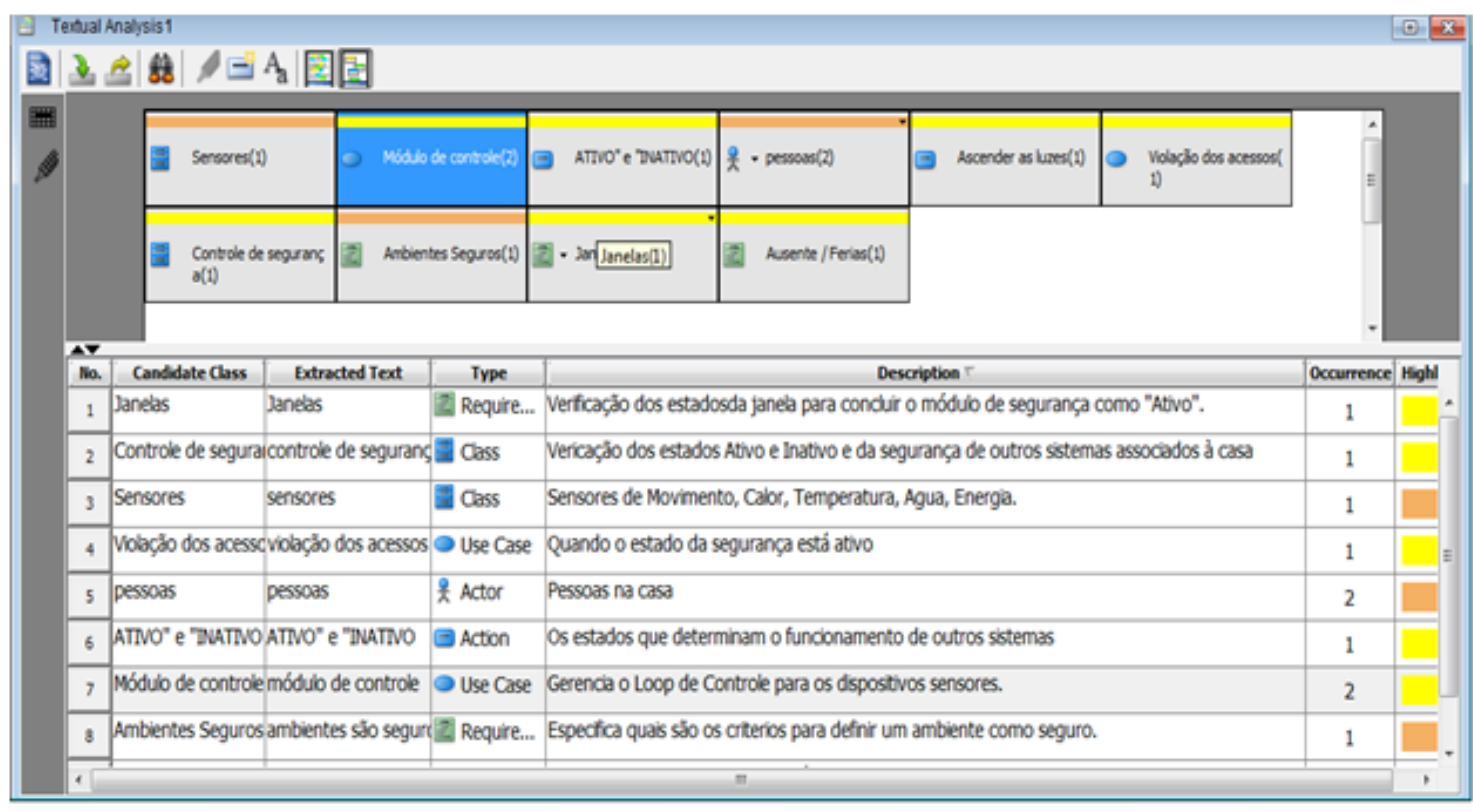

Figura 5.26: Interface da Aplicação de Analises Textual para Caso de Uso

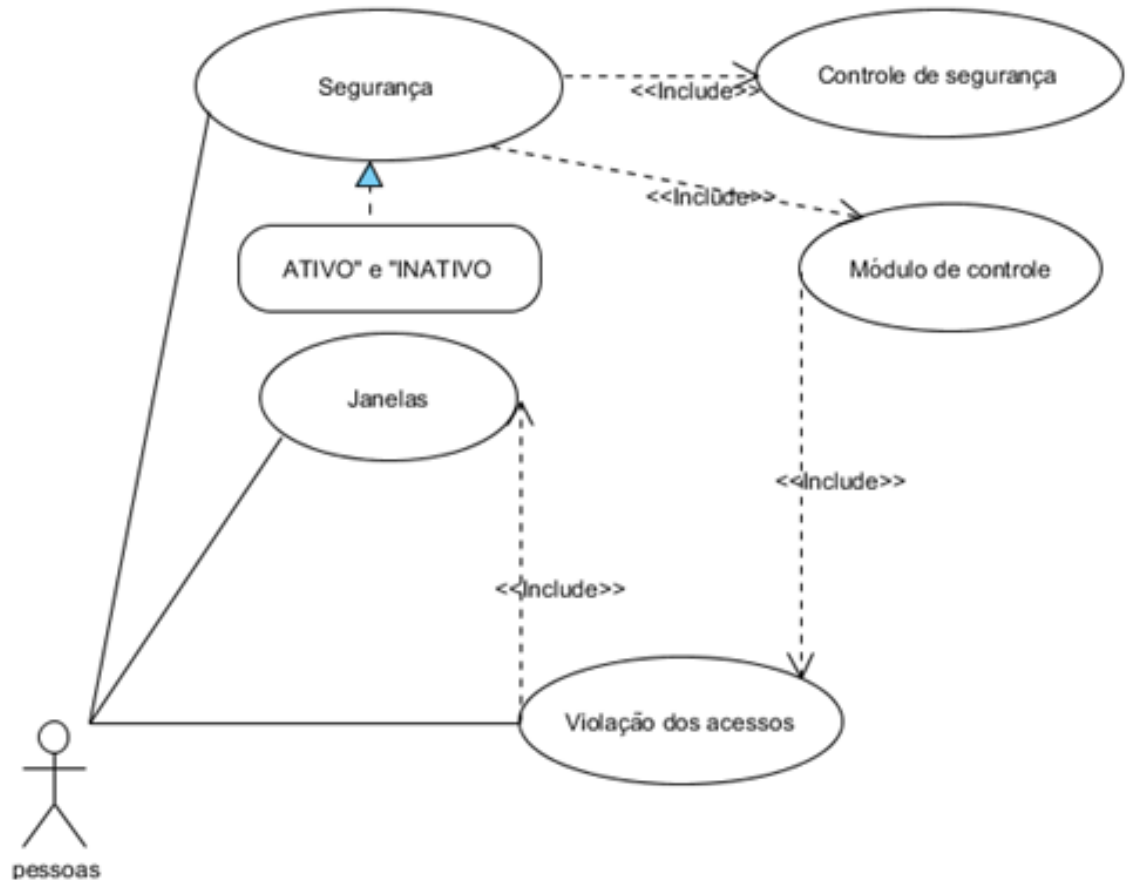

Figura 5.27: Caso de Uso - Segurança

\subsubsection{Estado - Ocupado}

Este estado permite estabelecer a existência de uma pessoa dentro dos ambientes da casa e o acionamento de outros estados e eventos. O estado ocupado associa sensores de calor e movimento, quando estes sensores se encontram ativos existe uma pessoa no ambiente e quando estiverem inativos indica a ausência. O estado "Ocupado"também permite determinar a lógica de segurança na porta de acesso principal, porta posterior e controle de janelas para quando 
existe uma pessoa na casa (ver tabela 5.2.

Tabela 5.2: Eventos e Condições - Estado Ocupado - Ambientes

\begin{tabular}{|l|l|l|l|}
\hline $\begin{array}{l}\text { Sensor de } \\
\text { Movimento }\end{array}$ & Ativo & Ambiente Ocupado & \\
\cline { 2 - 3 } & Inativo & Ambiente Vazio & \multirow{2}{*}{$\begin{array}{l}\text { Sensores de movimento e } \\
\text { calor trabalham em conjunto. }\end{array}$} \\
\hline Sensor de Calor & Ativo & Ambiente Ocupado & \\
\cline { 2 - 3 } & Inativo & Ambiente Vazio & \\
\hline
\end{tabular}

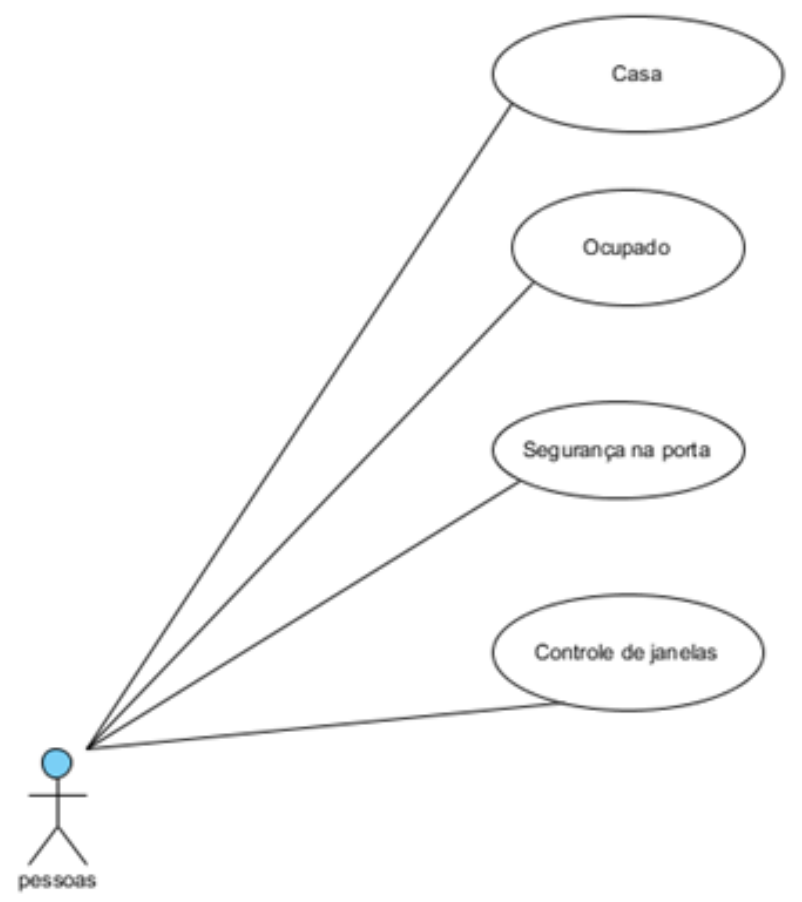

Figura 5.28: Caso de Uso - Estado Ocupado e os eventos na Casa

\subsubsection{Porta Principal - Entrada}

A lógica de controle para "Abrir a Porta Principal"(tabela 5.3), está associada à lógica de segurança (Ativo / Inativo) a qual denota para o resto do sistema que alguém esta na casa (Processo "Pessoa Casa") ou se está ausente por um período curto (Processo "Ausente") ou longo (Processo "Ferias"). Os processos descritos definem a forma de acesso ou saída pela porta principal, como: 
- Forma Manual (Executada pela pessoa)

- Forma Automática (executada pelo sistema)

Tabela 5.3: Eventos e Condições - Entrada Principal - Porta

\begin{tabular}{|l|l|l|l|}
\hline \multirow{3}{*}{ Sensor de Movimento } & Ativo & Abre - Manual & Ativo \\
\cline { 2 - 4 } & Inativo & Abrir e fechar (Sistema) & Inativo \\
\hline \multirow{3}{*}{ Sensor de Calor } & Ativo & Acesso Principal - Manual & Ativo \\
\cline { 2 - 4 } & Inativo & Abrir e Fechar (Sistema) & Inativo \\
\hline \multirow{3}{*}{ Luz Principal } & & Luminosidade (verificar) & Ativo \\
& Ativo & Movimento & Inativo \\
\cline { 2 - 5 } & & Pessoa Casa & \\
\cline { 2 - 5 } & Inativo & & \\
\hline
\end{tabular}

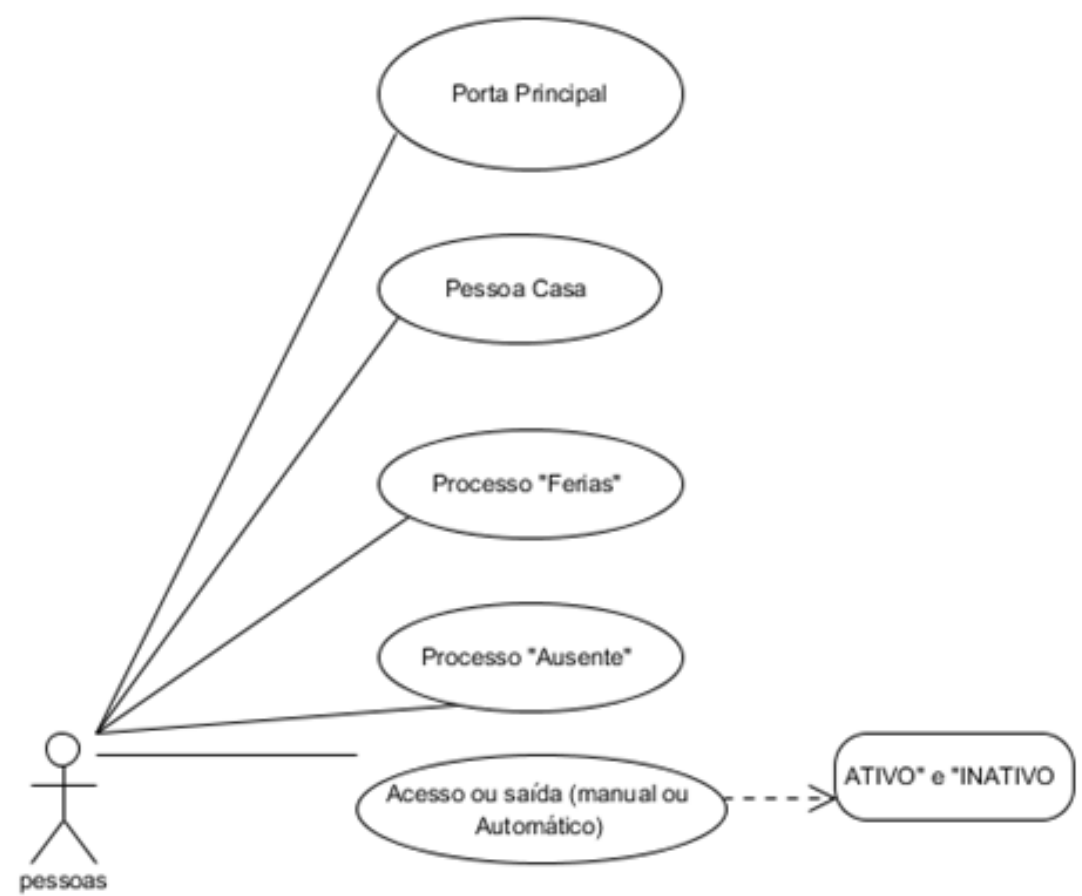

Figura 5.29: Caso de Uso - Eventos e Condições - Entrada Principal - Porta

\subsubsection{Luz Principal - Entrada}

A lógica de controle da Luz Principal (Entrada) está associada ao estado "ATIVO"e "INATIVO"de outros processos, como a presença de pessoas na casa, nível de luminosidade 
externa, sensores de movimento e calor "ATIVO", a porta principal em modo "MANUAL"ou "SISTEMA". A tabela 5.4 descreve os estados dos processos associados para acender a Luz de entrada:

Tabela 5.4: Entrada Principal - Luz

\begin{tabular}{|c|c|c|c|c|c|}
\hline Luz Principal & & & & & \\
\hline \multirow{2}{*}{ Sensor Movimento } & Ativo & $\begin{array}{c}\text { Pessoa Casa } \\
\text { Ocupado }\end{array}$ & Ativo & Porta Manual & \multirow{2}{*}{ Ativo } \\
\cline { 2 - 7 } & Inativo & Ausente / Ferias & Ativo & Abrir / fechar (sistema) & Inativo \\
\hline Sensor de Calor & Ativo & Pessoa Casa & Ativo & & \\
\hline & Inativo & Ausente / Ferias & Ativo & & \\
\hline \multirow{3}{*}{ Sensor de Luminosidade } & Ativo & Tempo & Ativo & & \\
\cline { 2 - 7 } & Inativo & Tempo & Inativo & & \\
\hline
\end{tabular}

\subsubsection{Luz Sala}

A lógica de controle da Luz da Sala depende do estados de outros processos, como de controle de seguraça, ocupado e pessoa casa. Diversos níveis de Intensidade de Luz da sala pode ser especificado quando o sensor de movimento e calor detectem uma pessoa próxima a uma das lampadas da casa. Os principais estados são descritos na tabela 5.5:

Tabela 5.5: Eventos e Condições - Luz Sala

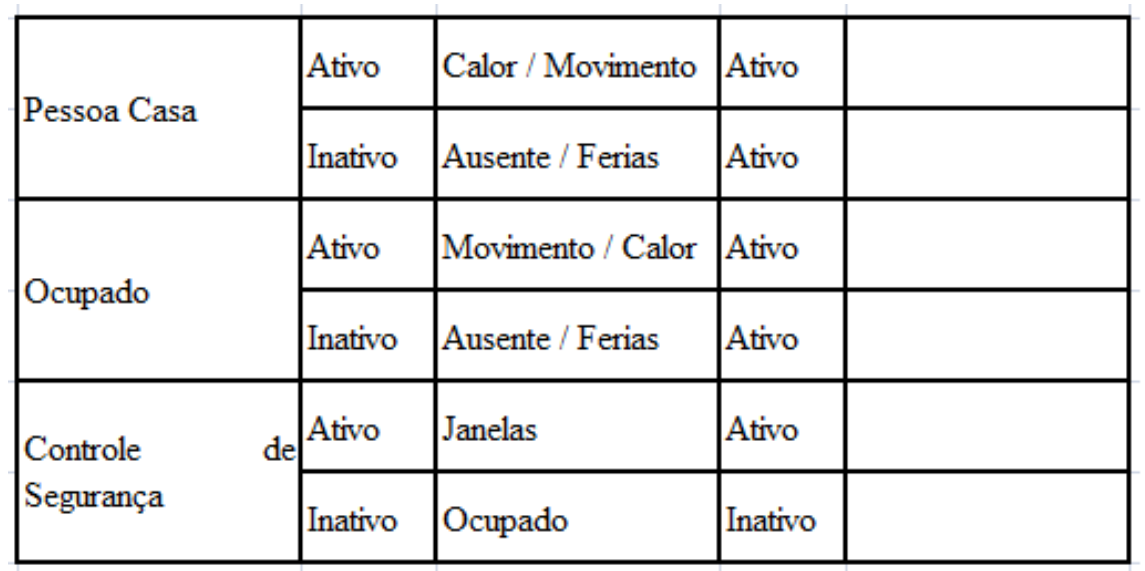

\subsection{6 Água e Energia}

O controle dos recursos de água e energia são altamente importantes dentro dos eventos da casa ecológica inteligente, e com o intuito de simplificar a lógica de controle à aplicação restringe- 
se à utilização de dispositivos proprietários que podem acionar o controle da água quando os estados "Pessoa Casa"estiver "ATIVO"(nos estados ausente ou ferias) e o controle de energia quando o estado "Tomada"estiver "ATIVO". O estado tomada "ATIVO"é determinado pela existência de algum dispositivo eletrônico ou luminárias conectadas (tabela 5.6).

Tabela 5.6: Eventos e Condições - Água e Energia

\begin{tabular}{|l|l|l|l|}
\hline \multirow{3}{*}{ Pessoa Casa } & Ativo & Bware & Inativo \\
\cline { 2 - 4 } & Inativo & Bware & Ativo \\
\hline \multirow{3}{*}{ Tomada } & Ativo & Power Meter & Ativo \\
\cline { 2 - 4 } & Inativo & Power Meter & Inativo \\
\hline
\end{tabular}

\subsubsection{Aplicação-Exemplo - II (segunda fase)}

SysML foi desenvolvido a partir da UML 2.0 em cooperação com Object Management Group (OMG) e o Conselho Internacional de Engenharia de Sistemas (INCOSE). O SysML permite representar e verificar processos do fluxo de controle da Casa Ecológica Inteligente com alto nível de detalhes.

- Diagrama de Caso de Uso

- Diagrama de Blocos

- Diagrama de Descrição de Blocos

- Diagrama de Parametrização

Requisitos:

- Elementos de Hardware

- Sensor de Temperatura

- Sensor de Movimento

- Evento Principal

- Controle do Sistema de Ar Condicionado 
O conjunto de processos representados no diagrama de caso de uso (Figura 5.30) são formalizados através da ferramenta SysML. A formalização de um caso de uso utilizando a ferramenta SysML exige a pre-definição das classes que representam os processos ou eventos no futuro sistema.

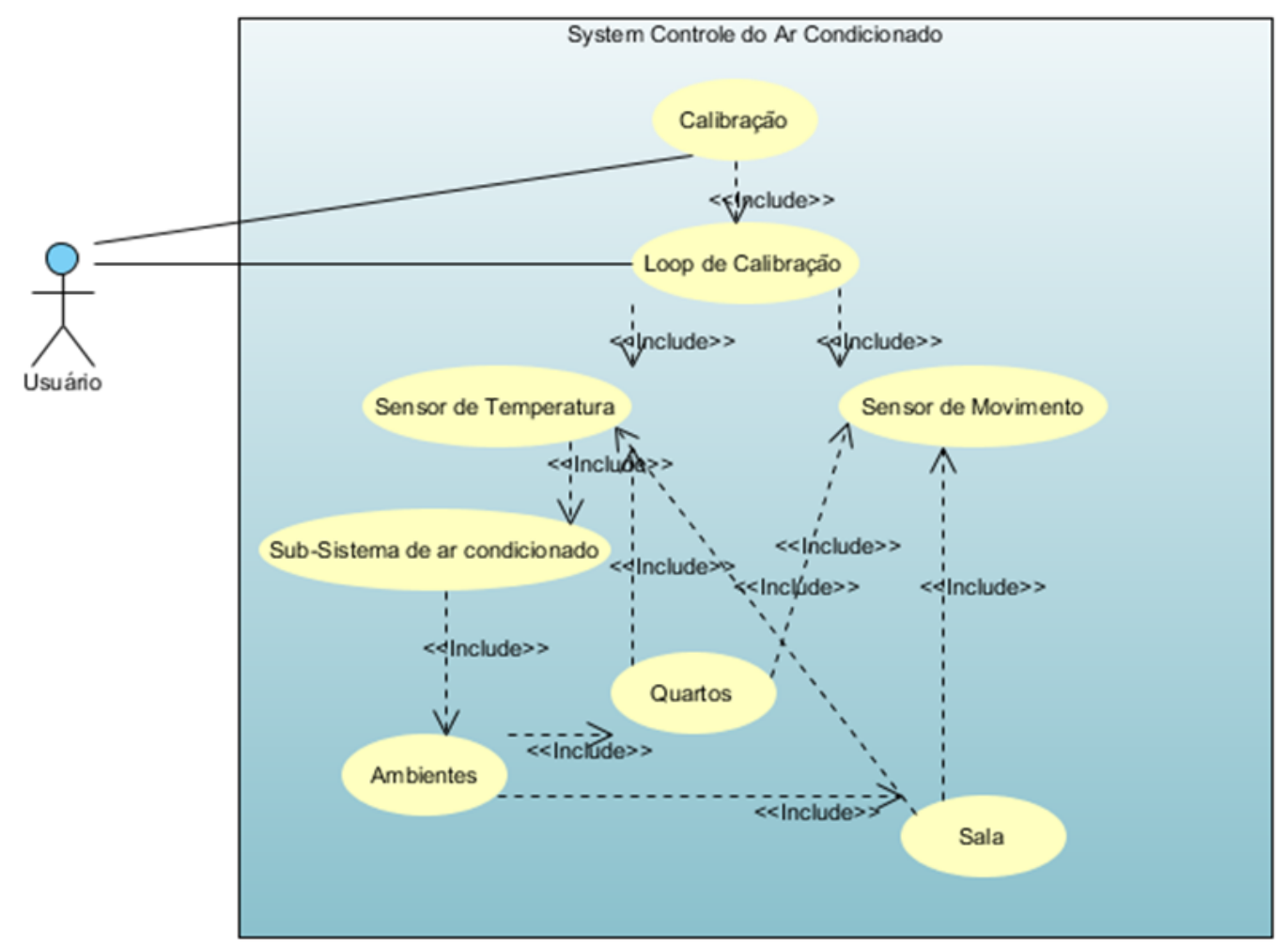

Figura 5.30: Diagrama simplificado de Caso de Uso Casa Ecológica Inteligente

Na sequência apresenta-se o conjunto de eventos devidamente detalhados e formalizados através de casos de uso (Figuras 5.31, 5.32), o fomalismo aplica-se para cada um dos processos associados aos dispositivos sensores e os eventos de atuação que serão gerados como resultado da definição da definição das condições para cada dispositivo. 


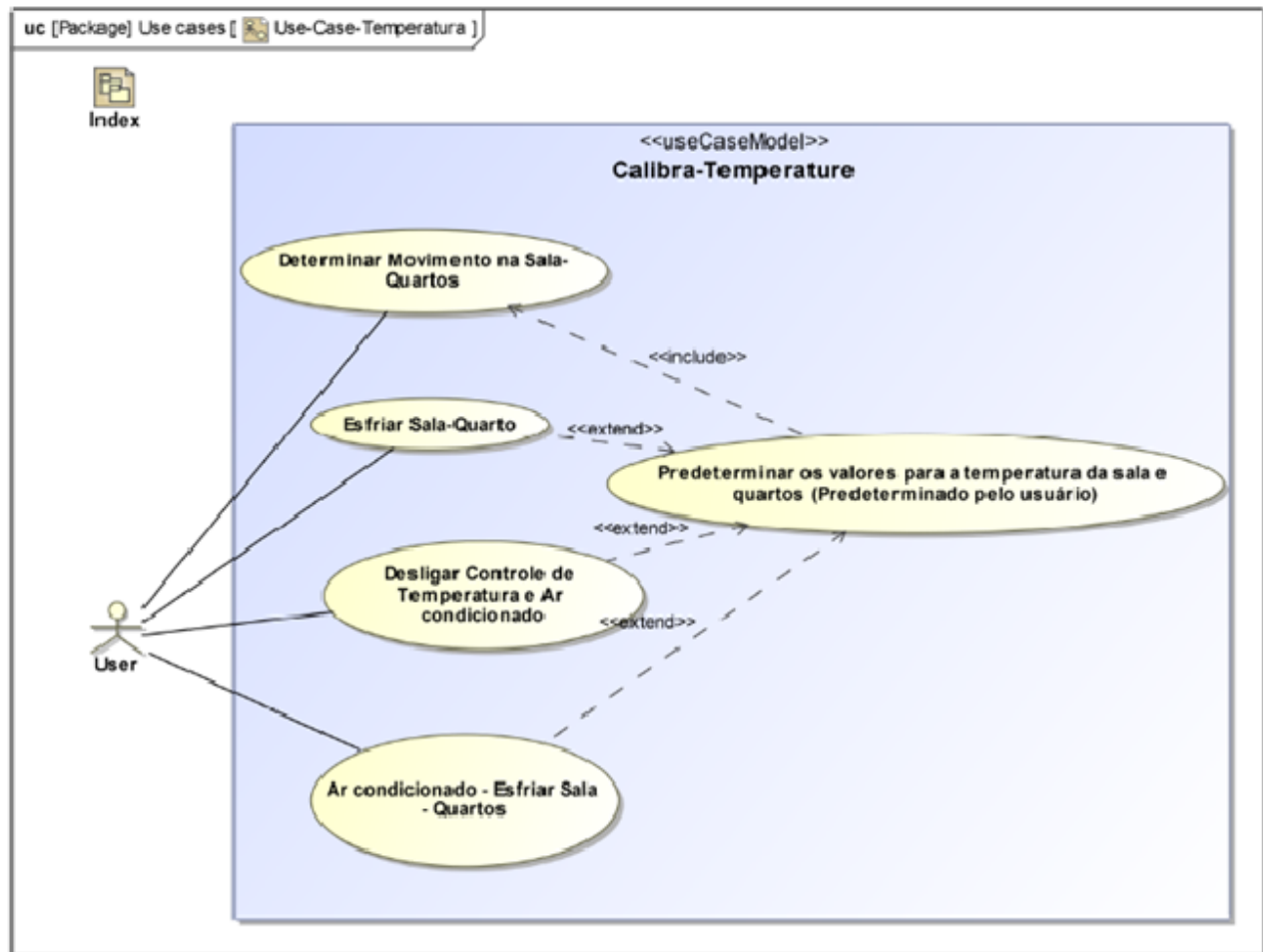

Figura 5.31: Diagrama de Caso de Uso - Sensor de Temperatura

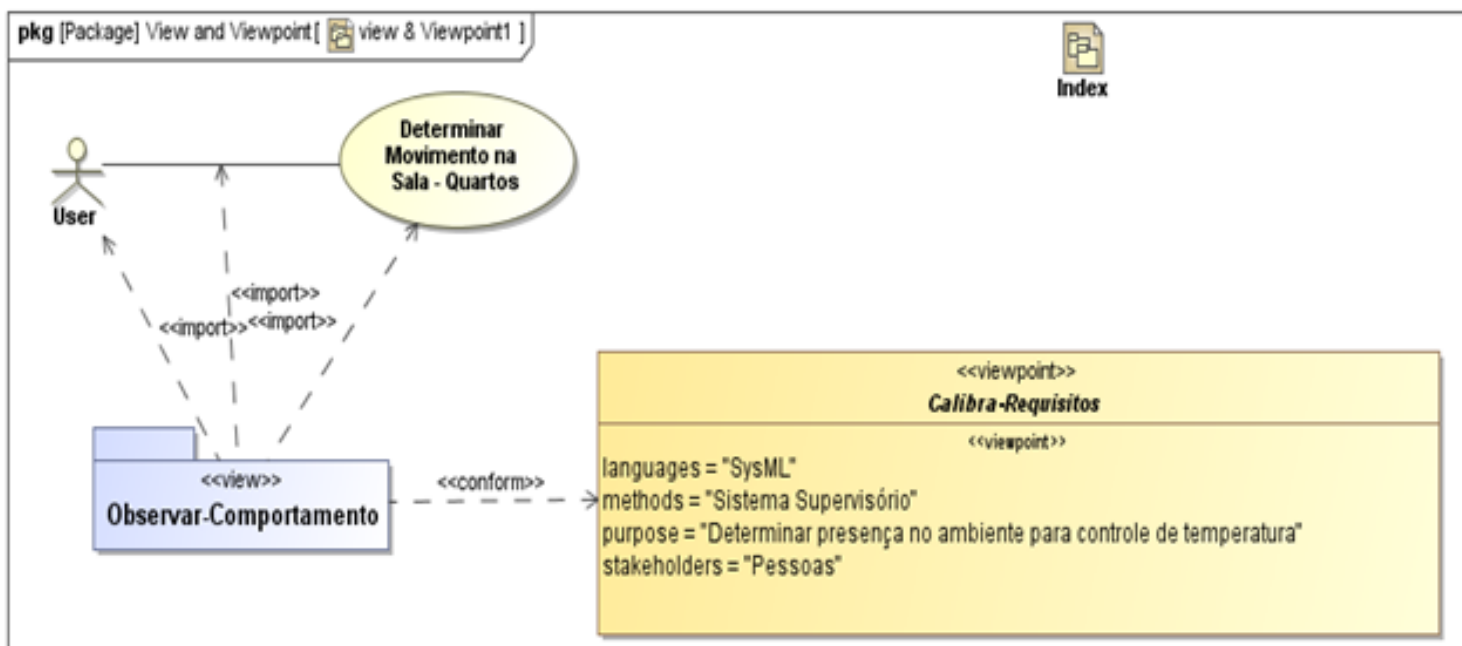

Figura 5.32: Diagrama de Caso de Uso - Sensor de Temperatura - Evento Principal

Os casos de uso das figuras 5.33 e 5.34 descrevem os eventos para o sensor de movimento seguindo o mesmo formalismo apresendado nos diagramas anteriores. 


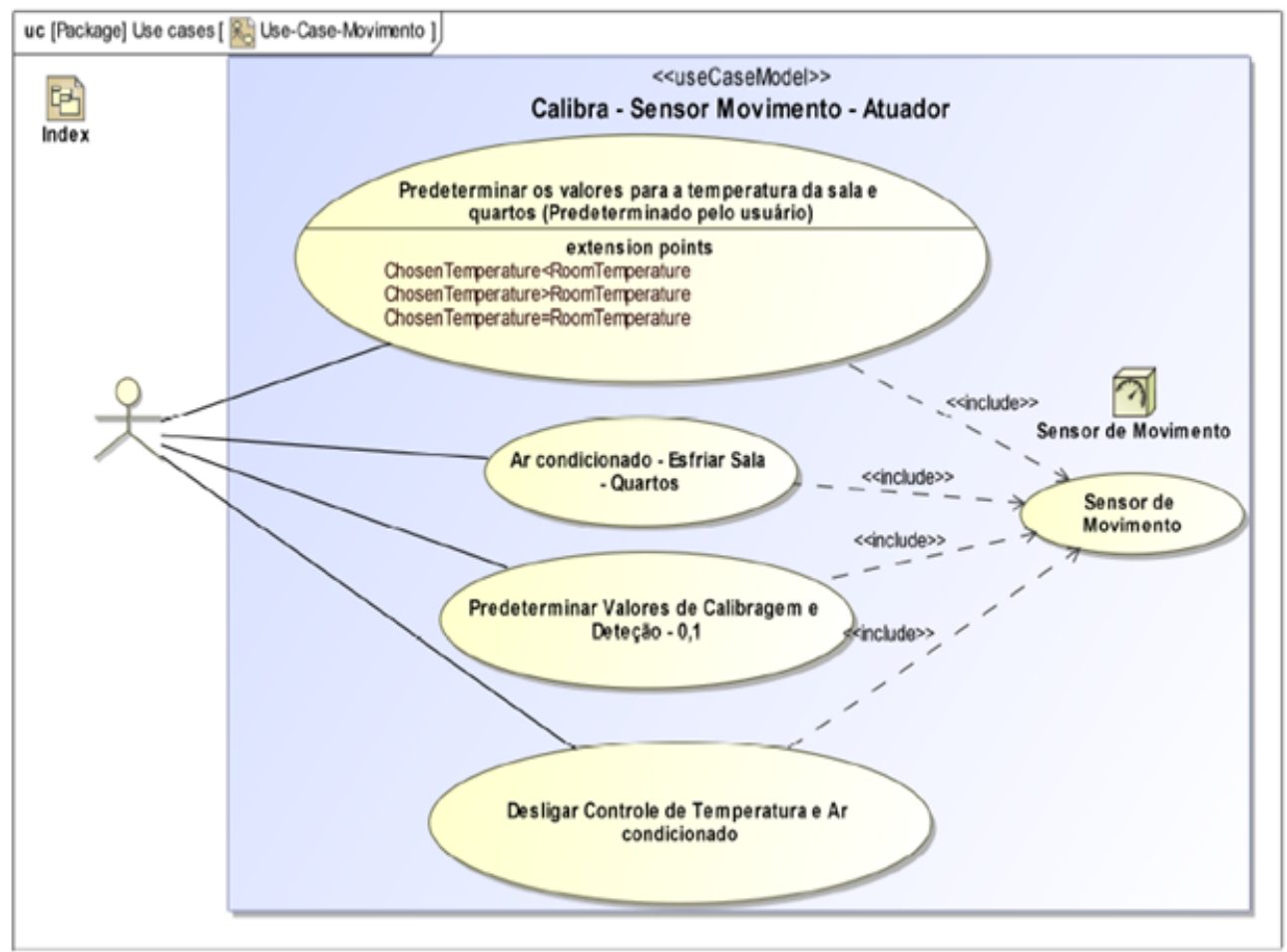

Figura 5.33: Diagrama de Caso de Uso - Sensor de Movimento

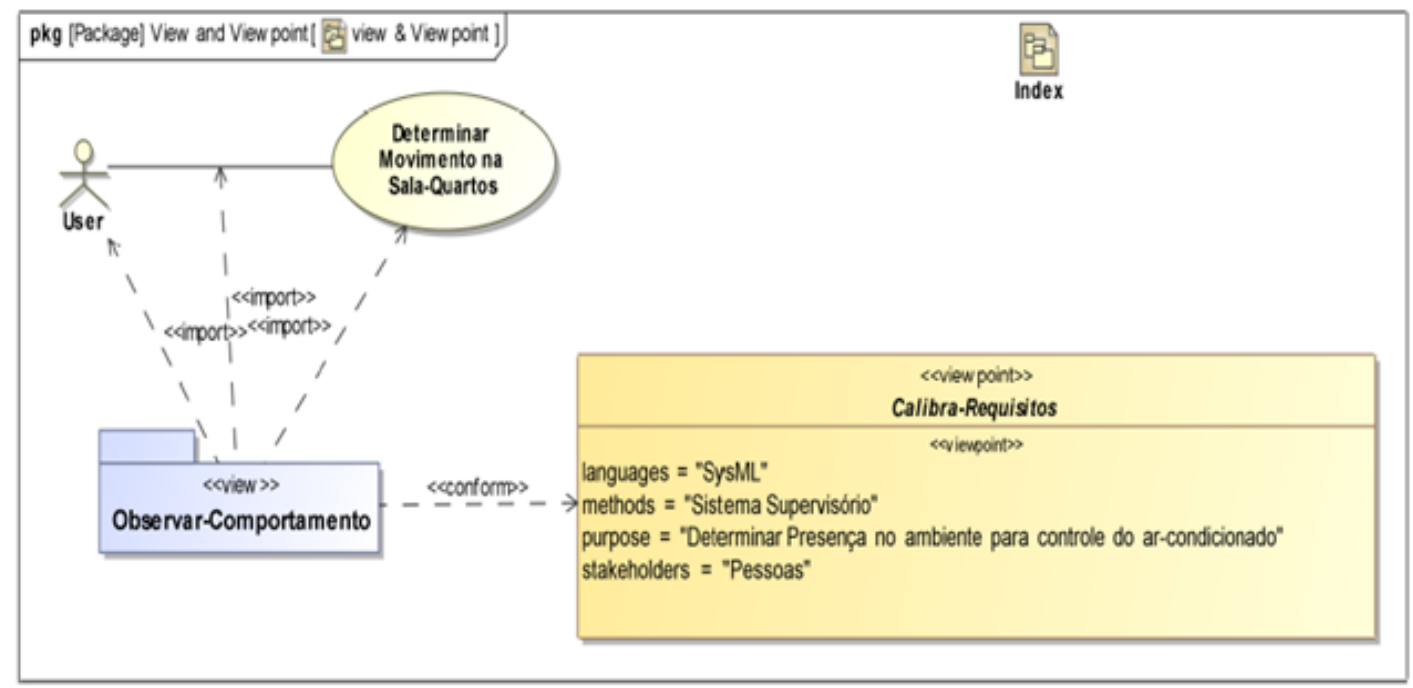

Figura 5.34: Diagrama de Caso de Uso - Sensor de Movimento - Evento Principal 
A Figura 5.35 apresenta o índice do conjunto de classes, pacotes, diagramas formalizados e padronizados para o evento de atuação no ambiente da Casa Ecológica Inteligente.

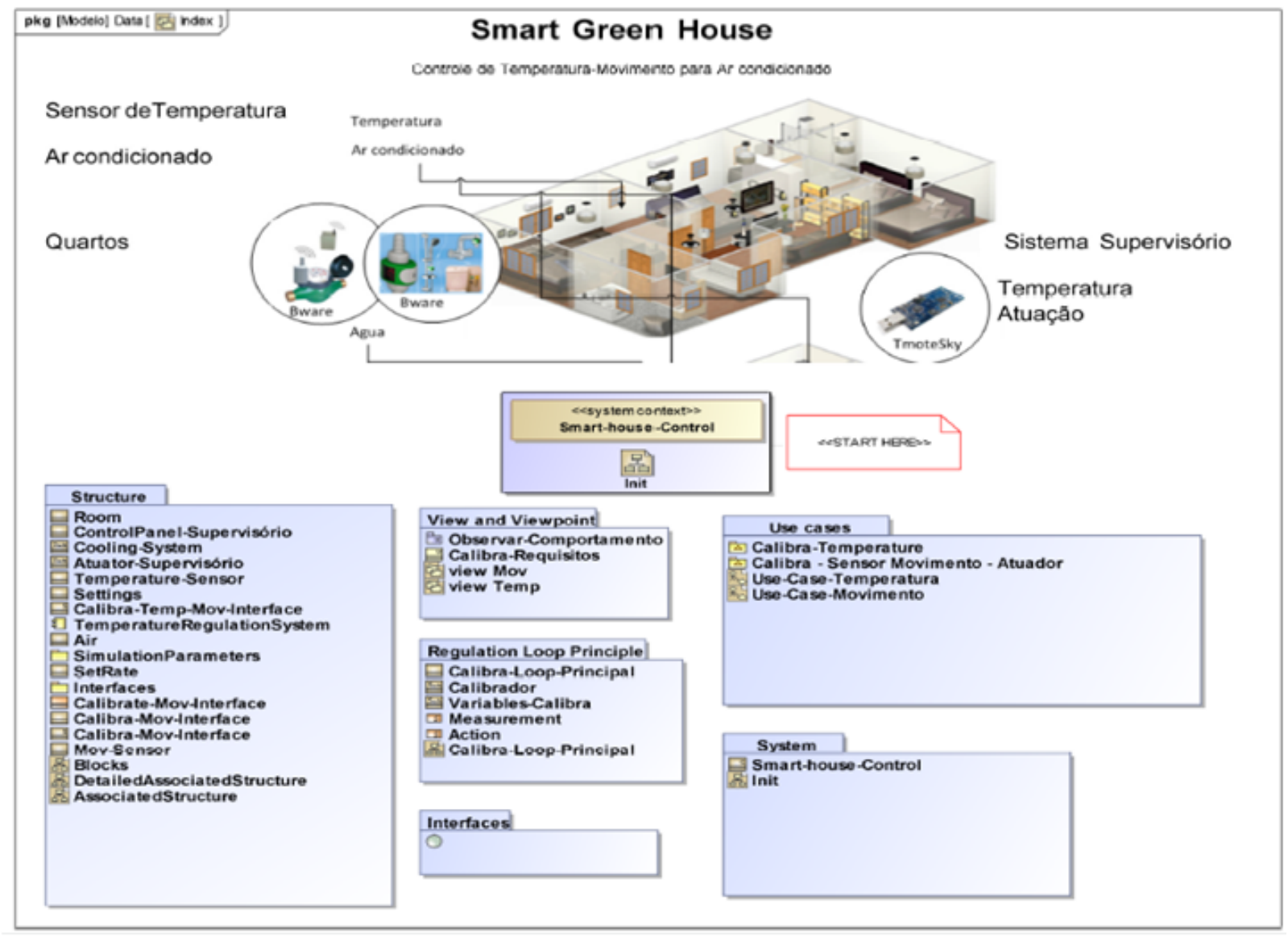

Figura 5.35: Diagrama de Indice - Classes e Blocos 


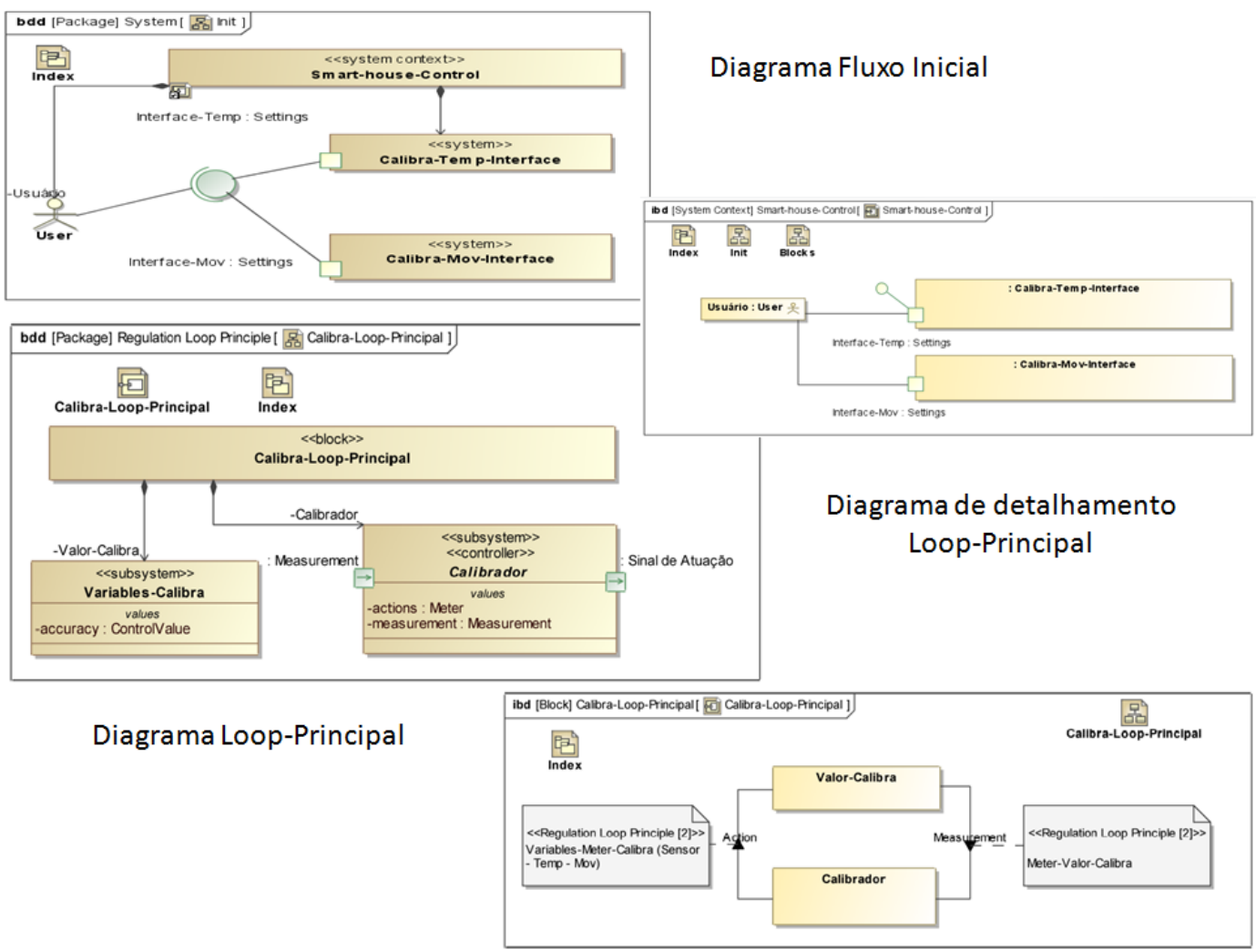

Figura 5.36: Diagrama SysML de Descrição de Bloco - Fluxo e Loop Principal

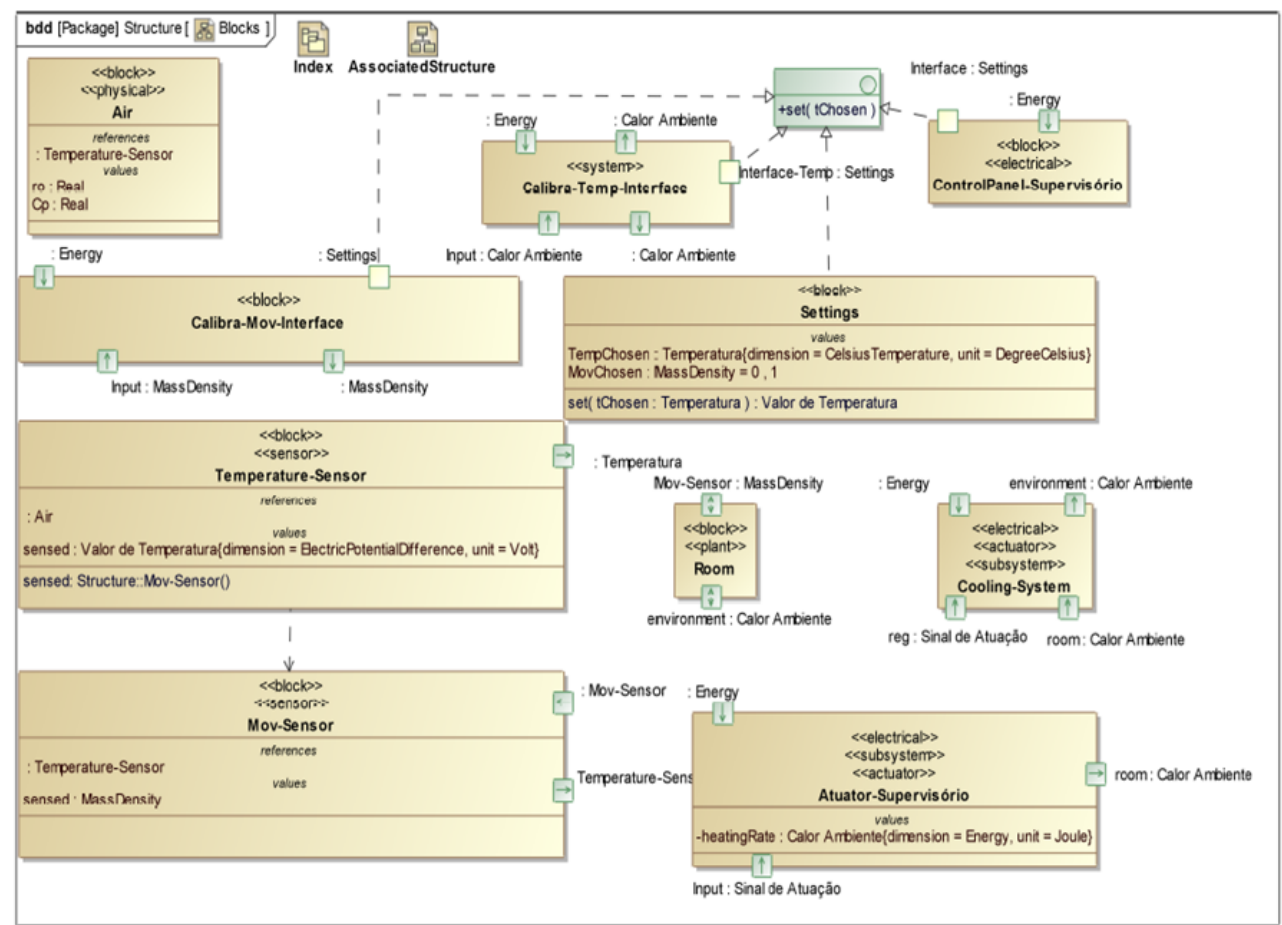

Figura 5.37: Diagrama SysML de Descrição de Bloco - Detalhamento de Blocos 
O diagrama da figura 5.38 apresenta o detalhamento do fluxo de comunicação dos blocos descritos nas figuras 5.36, 5.37.

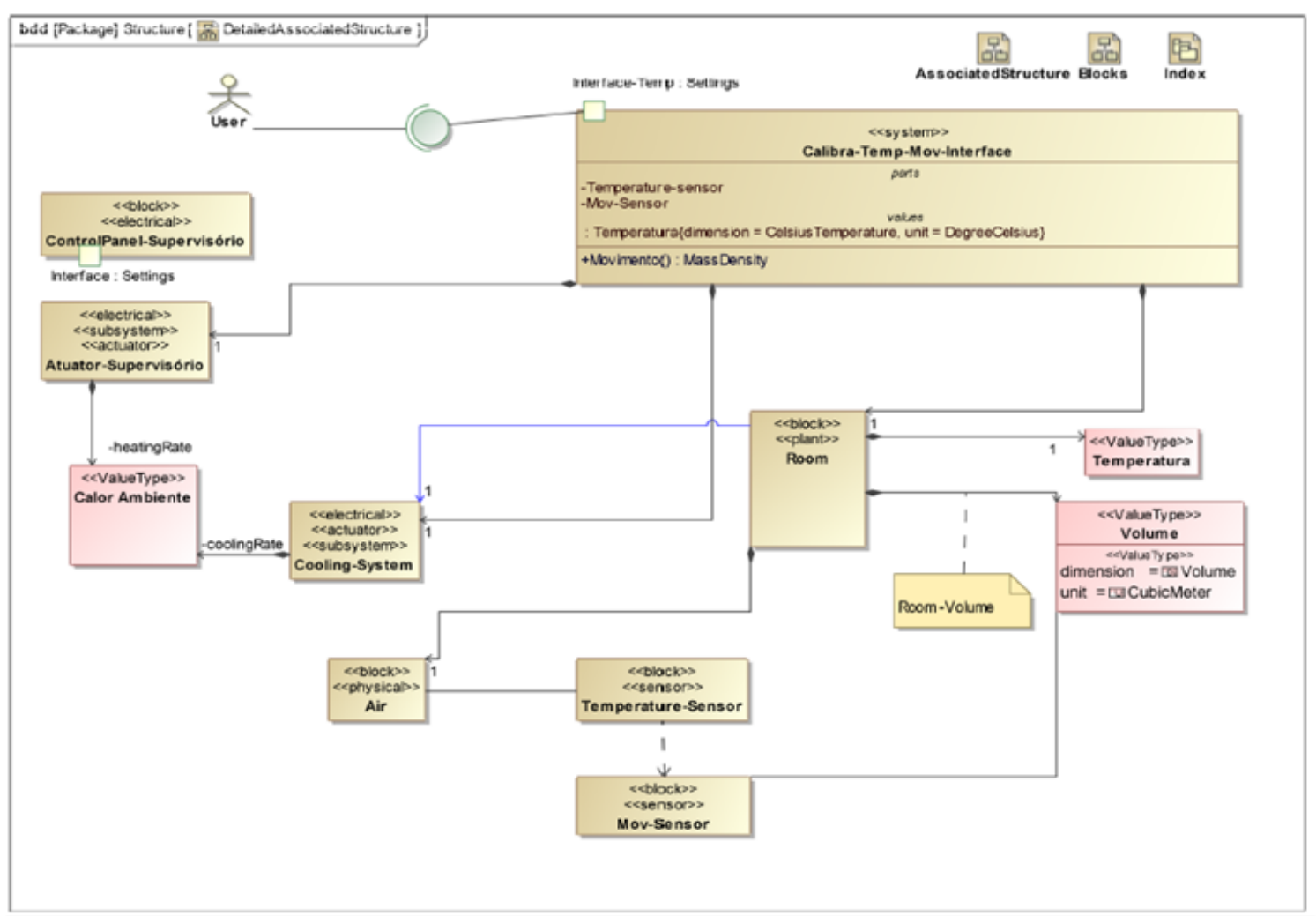

Figura 5.38: Diagrama SysML de Descrição de Bloco - Detalhamento do Pacote da Estrutura do Loop Principal de Controle

Os eventos e formalização de processos para cada um dos blocos que compõem o cenário de atuação para controle de ar condicionado, na Casa Ecológica Inteligente, são resultado de um cuidadoso e detalhado estudo da ferramenta SysML. Algumas etapas da modelagem apresentada correspondem a uma compilação de exemplos de atuação, como resultado cada etapa apresenta um alto nível de formalismo para os eventos de sensoriamento, atuação e loop de controle. 


\section{Resultados - Conclusões - Contribuições}

O trabalho envolve uma proposta de definição de um middleware chamado de CiberSens representando sua viabilidade através de um modelo de caso de estudo. O trabalho de teses espera alcançar a mudança de um paradigma que limita a integração de diversas aplicações de redes de sensores, marcadas por definições conceituais e modelos de programação complexos que acabam resultando em estruturas de sistemas proprietários, como é o caso de vários sistemas operacionais, plataformas de integração e gerenciamento existentes.

Os CPS incluem a diversidade de dispositivos embarcados, sensores e atuadores, a estrutura de dados para cada um destes dispositivos é diversa, sendo assim a separação do padrão MVC iniciando pela camada de dados permite que a heterogeneidade de dados seja abstraída pelo CiberSens independente da camada de interfaces.

O modelo de projeto adotado para a implementação da aplicação-exemplo do middleware CiberSens apresenta ser bastante eficiente e flexível, altamente portável e favorece a reutilização, otimização de código e escalabilidade em cada uma da suas camadas de forma independente.

O MI desenvolvido, apresentou ser suficientemente funcional para o ambiente do CiberSens, abstraindo as características de topologia da rede, diversidade de protocolos e favorecendo o pré-processamento das informações coletadas para favorecer a toma de decisão dentro do ambiente supervisório do CiberSens.

O MI pode ser controlado desde a interface do CiberSens ou executado de forma independente dentro do dispositivo de hardware que realizará o processo de abstração para cada rede e padrão de comunicação.

A especificação de requisitos funcionais e não funcionais para o CiberSens respondem às características dos dispositivos sensores, atuadores enquanto ao cenário de aplicação, topologias, protocolos de comunicação, tipos de eventos monitorados e sua relação de 
localização, e tempo. As bases dos resiquisitos seguem a especificação para middlewares exposta na norma ISSO 9126.

Na primeira parte da aplicação-exemplo, a implementação do CiberSens para o ambiente de monitoramento da casa caracteriza o nível funcional do middleware e do módulo integrador.

Na segunda parte da aplicação-exemplo, na modelagem do fluxo de controle do sistema de ar condicionado, a formalização dos eventos é realizado através do SysML

O SysML permitiu a representação e formalização de eventos com alto nível de detalhes, especificando dependências, comportamento das classes, representação dos valores de entrada e saída, modelagem do subsistema.

Quando comparado com os principais trabalhos correlatos apresentados, neste trabalho o CiberSens atua nas camadas de enlace e rede, é flexível na criação de interfaces e na estrutura do modelo devido ao padrão MVC adotado para implementação. A escalabilidade é a principal característica das aplicações para CPS e o CiberSens deve proporcionar a flexibilidade e robusteza necessária no modelo de implementação.

Existem vários trabalhos que formalizam o fluxo de controle de eventos de sensoriamento e atuação utilizando o SysML [64]. A ferramenta apresenta ser bastante robusta e completa atribuíndo lógicas complexas e formais de representação de eventos que uma ferramenta convencional de modelagem como UML2 não conseguiria fazer.

Pretende-se dar continuidade na formalização de eventos de controle utilizando a ferramenta SysML como exigência que resulta da diversidade e complexidade na construção de aplicações para Sistemas Ciber-Físicos.

Um outro objetivo futuro é concentrar o fluxo de processos do MI em uma arquitetura mais robusta, como a do RaspBerry [65], devendo atuar simultaneamente como data-sink e MI.

A validação do middleware através da aplicação-exemplo é totalmente relevante, já que no modelamento, desenvolvimento e implantação deverá se demonstrar as funcionalidades necessárias, níveis de abstração, serviços e requisitos funcionais de interface para que o usuário possa intervir no sistema quando julgar pertinente. O CiberSens para o caso de estudo, opera sobre as características de um sistema supervisório administrando informação suficiente para se tornar cada vez mais autônomo e eficiente na sua interação com o meio físico.

Continuando com o pensamento anterior, é possível afirmar que os sistemas atuais não oferecem ferramentas que possibilitem ao usuário final e outros modificarem o funcionamento do sistema. Este trabalho de teses modela e desenvolve pequenas interfaces que facilitem 
essa interação, mudando a necessidade de conhecimentos avançados para interagir com a aplicação. As classes e o bom comportamento de abstração dos métodos na camada de acesso (comunicação) determinará a eficiência dos serviços e a confiabilidade da informação acessada pelas camadas superiores.

As arquiteturas de hardware do Arduino e TmoteSky utilizadas, com seus sensores de temperatura e umidade apresentam-se bastante eficientes em termos de comportamento de comunicação para o módulo integrador e de atuação no ambiente do CiberSens. As características de cada arquitetura confirmam a lógica de abstração do MI no ambiente do CiberSens. Arquiteturas de nós sensores como a do TmoteSky são restritas à coleta de fenômenos sem possibilidade de atuação, assim, também a estrutura do pacote não é processada antes de ser encaminhada para o MI, sendo assim o middleware deve dar suporte a esse tipo de dados não estruturados. O Arduino é uma arquitetura muito mais robusta capaz de exercer funções de sensoriamento e atuação, e também realizar o processamento local da informação antes de ser transmitida para o MI e depois para o ambiente supervisório do CiberSens. 
Tabela 6.1: Tabela de Resultados de contribuições - CiberSens)

\begin{tabular}{|c|c|c|c|c|c|c|c|}
\hline & & $\begin{array}{c}\text { [Dat Dac Hoang } e L \\
\text { AL. 2012] }\end{array}$ & $\begin{array}{c}\text { [Sang Oh } \\
\text { Park, et. al. } \\
\text { 2011] }\end{array}$ & $\begin{array}{l}\text { [C-F. Lai et al, } \\
\text { 2010] }\end{array}$ & $\begin{array}{l}\text { [Zhang, Y., Gill, C } \\
\text { and Lu. C. 2008] }\end{array}$ & $\begin{array}{l}\text { [Mudasser lqbal and } \\
\text { Hock Beng Lim, } \\
\text { 2009] }\end{array}$ & CiberSens \\
\hline \multirow{3}{*}{ 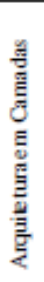 } & Acesso & Camada Física & $\begin{array}{l}\text { Camada de } \\
\text { Rede }\end{array}$ & Camada Física & Camada Física & Camada de Enlace & MI-Enlace \\
\hline & Serviços & SOAP & $\begin{array}{l}\text { Middleware } \\
\text { de Controle } \\
\text { Dinâmico }\end{array}$ & $\begin{array}{l}\text { Camada de } \\
\text { Aplicaçăo }\end{array}$ & CORBA & Năo - FOSD & Modelo MVC \\
\hline & Aplicaçã̃o & $\begin{array}{l}\text { HTTPe Web } \\
\text { Service }\end{array}$ & $\begin{array}{l}\text { Camada de } \\
\text { Aplicaçấo }\end{array}$ & $\begin{array}{l}\text { Camada de } \\
\text { Aplicaçáo }\end{array}$ & $\begin{array}{l}\text { Camada de } \\
\text { Aplicaçáo }\end{array}$ & $\begin{array}{l}\text { Camada de } \\
\text { Aplicaçăo }\end{array}$ & HTTP - Web \\
\hline \multicolumn{2}{|c|}{ Abertura } & $\begin{array}{l}\text { Interoperabilidade } \\
\text { (restrita) }\end{array}$ & IPV6 & $\begin{array}{l}\text { Intercperabilidade } \\
\text { (restrita) }\end{array}$ & $\begin{array}{l}\text { Interoperabilidade } \\
\text { (CORBA) }\end{array}$ & $\begin{array}{l}\text { Interoperabilidade } \\
\text { (nestrita) }\end{array}$ & Interoperabilidade \\
\hline \multicolumn{2}{|c|}{ Linguagem } & $\begin{array}{c}\text {.NET } \\
\text { Tecnologias web }\end{array}$ & $\mathrm{XML}$ & JNI - AJAX3D & $\mathrm{IDL}-\mathrm{C}++$ & - & $\begin{array}{l}\text { C+H-Java-HTML - } \\
\text { Ajax }\end{array}$ \\
\hline \multirow{5}{*}{ 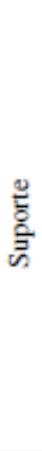 } & $\begin{array}{l}\text { Heterogeneidade } \\
\text { de } \mathrm{Hw}\end{array}$ & Sim (restrita) & $\begin{array}{c}\text { Sim } \\
\text { (restrita) }\end{array}$ & Sim & Sim & - & Sim (Não Restrita) \\
\hline & Escalabilidade & $\cdots$ & Sim & - & $\begin{array}{c}\text { (Controle de } \\
\text { admissáo de hw) }\end{array}$ & - & Sim \\
\hline & Protocolos & $\cdots$ & IPV6 & Sim & - & - & MAC \\
\hline & $\begin{array}{l}\text { Niveis de } \\
\text { Abstraçăo }\end{array}$ & $\begin{array}{l}\text { Sim (com } \\
\text { restriçôes) }\end{array}$ & - & - & - & - & Sim (Não Restrita) \\
\hline & $\begin{array}{l}\text { Consultas em } \\
\text { tempo de } \\
\text { execução }\end{array}$ & $\cdots$ & Sim & - & - & - & Sim \\
\hline \multirow{3}{*}{ 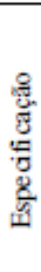 } & $\begin{array}{l}\text { Requisitos } \\
\text { Funcionais }\end{array}$ & $\cdots$ & Sim & - & Sim & & Sim \\
\hline & $\begin{array}{l}\text { Requisitos Năo } \\
\text { Funcionais }\end{array}$ & $\cdots$ & - & - & - & - & Sim \\
\hline & $\begin{array}{l}\text { Requisitos } \\
\text { Temporais }\end{array}$ & $\cdots$ & Sim & - & Sim & - & Sim \\
\hline
\end{tabular}

Na tabela 6.1, são apresentadas as contribuições do CiberSens quando comparadas com outras arquiteturas de middleware propostas para os ambientes Ciber-Físicos.

As especificações para a aplicação-exemplo enquanto aos eventos e condições a serem executados, correspondem a uma análises mínima de variáveis necessárias para validar o fluxo de controle de informação dentro do ambiente Ciber-Físico da Casa Ecológica Inteligente (Smart Green House). Este conjunto de eventos geram informações as quais devem ser comuns no ambiente Ciber-Físico e devem ser abstraídos através de um módulo integrador e gerenciadas no ambiente supervisório do middleware CiberSens. 


\section{ANEXO A - Códigos}

\section{A.1 Código da Classe Captureconfig}

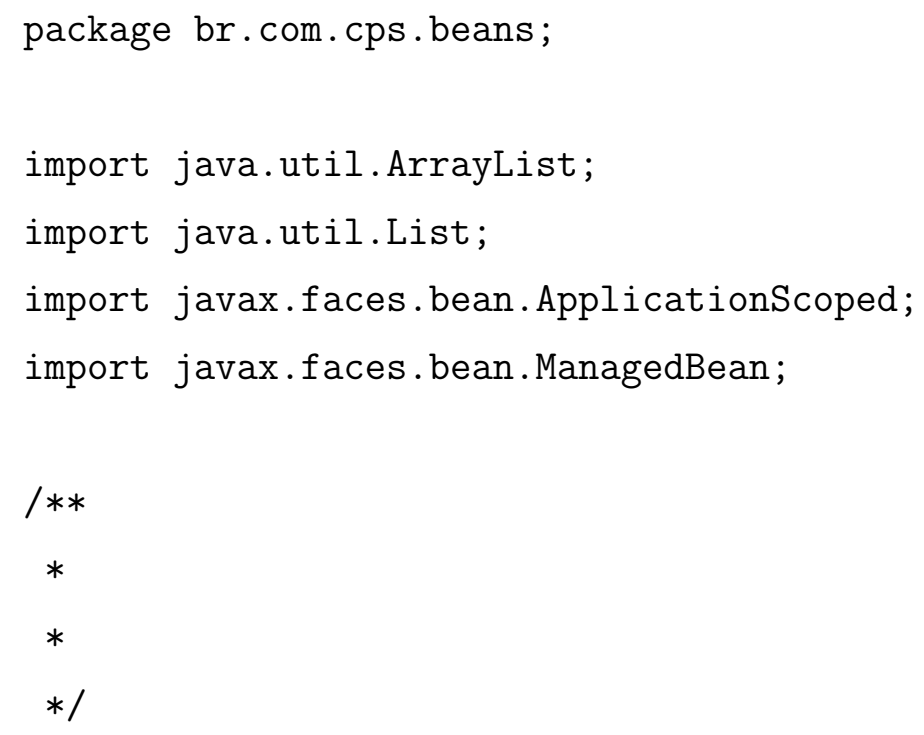




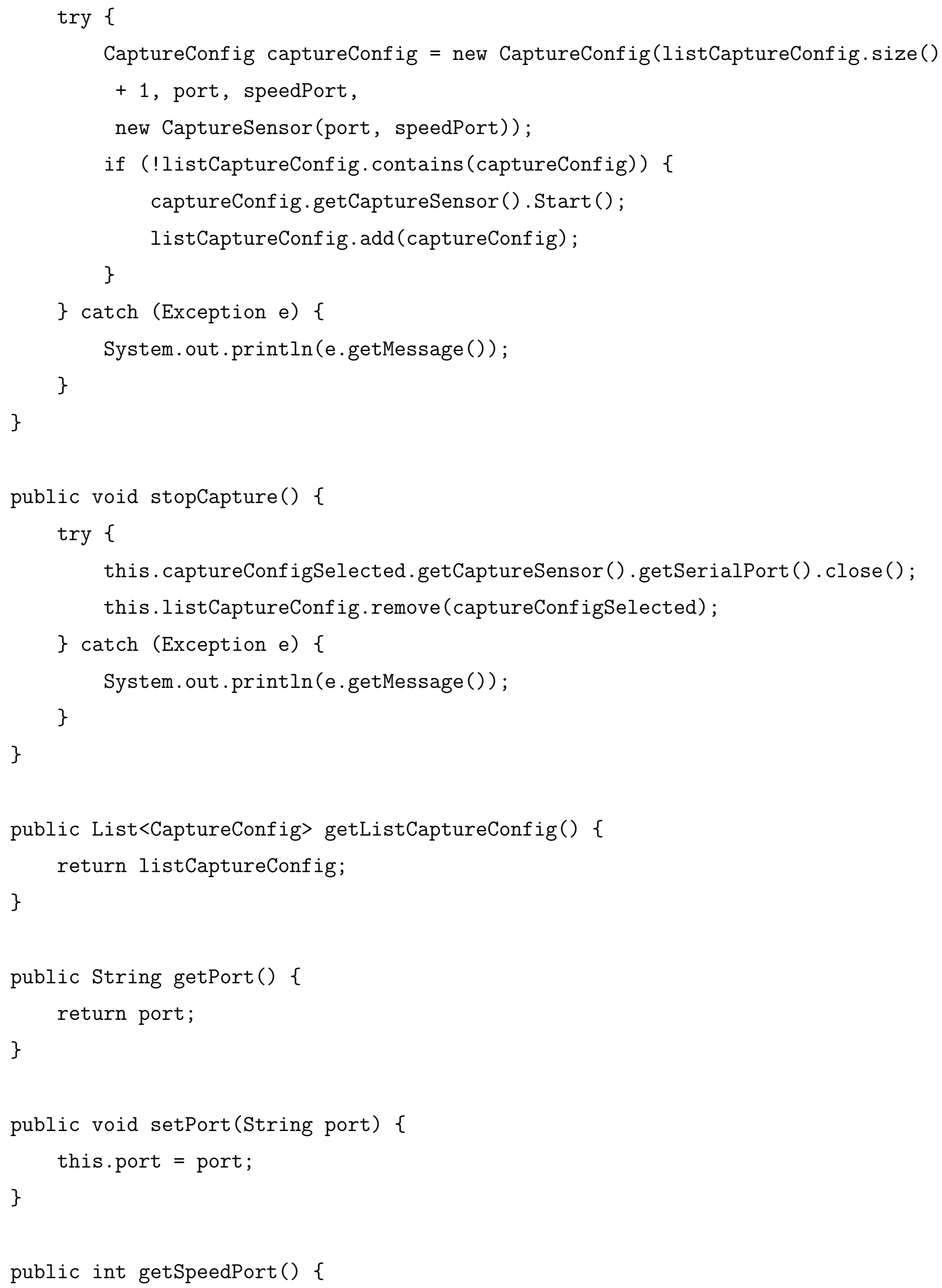


return speedPort;

\}

public void setSpeedPort(int speedPort) \{

this.speedPort $=$ speedPort;

\}

public CaptureConfig getCaptureConfigSelected() \{

return captureConfigSelected;

\}

public void setCaptureConfigSelected(CaptureConfig captureConfigSelected) \{ this. captureConfigSelected = captureConfigSelected;

\}

\} 


\section{A.2 Código da Classe Capturebean}

package br.com.cps.beans;

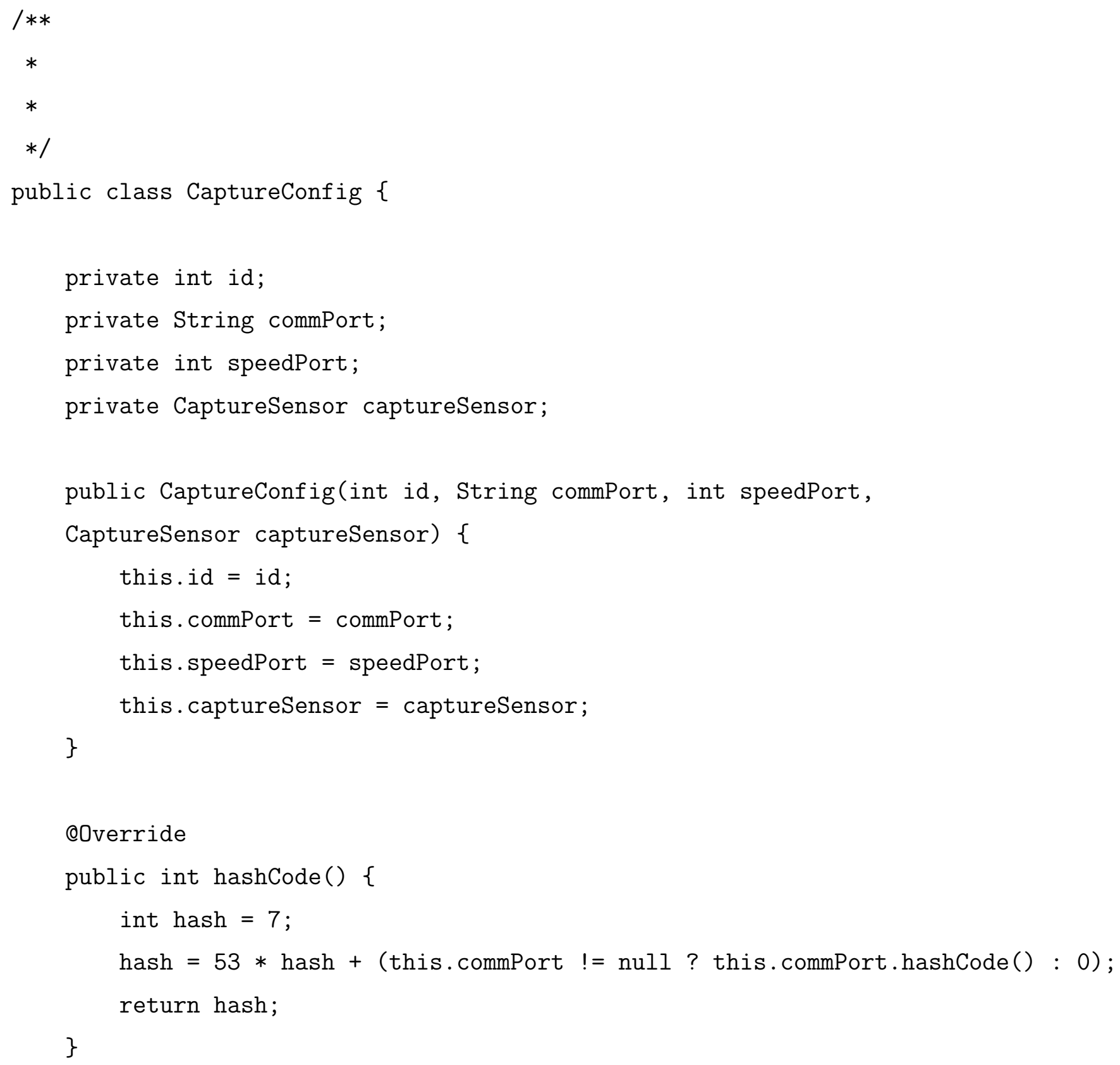




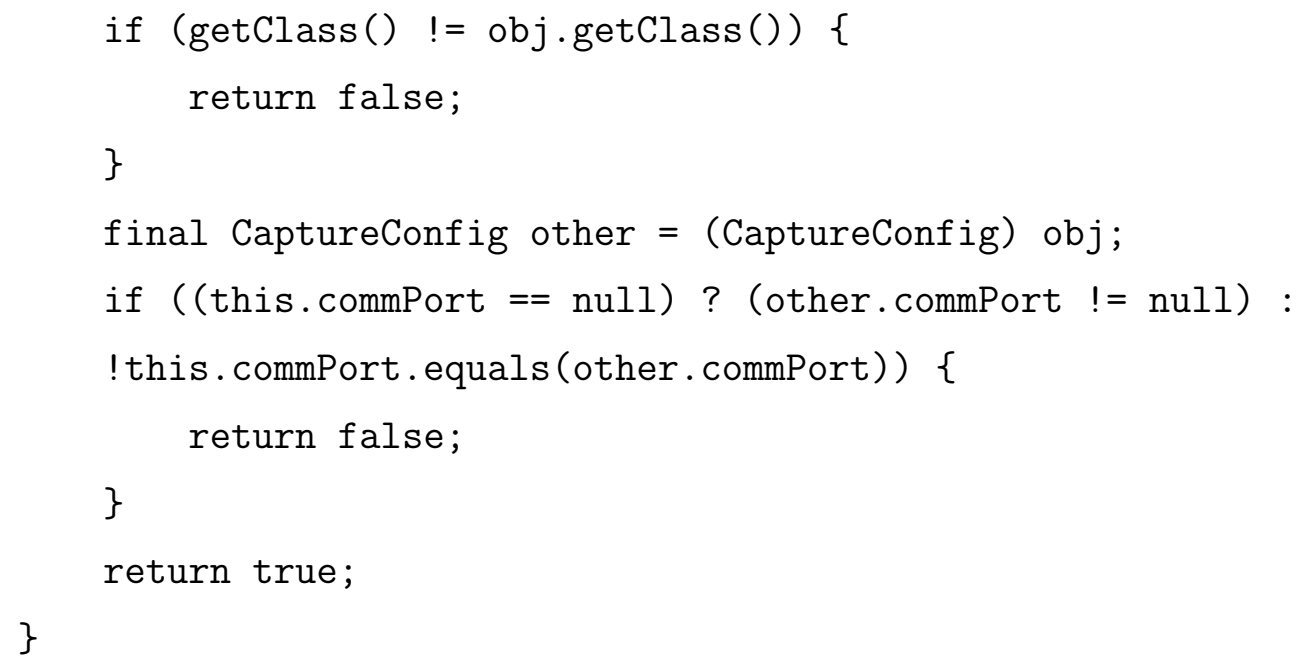


this. speedPort $=$ speedPort;

\}

public CaptureSensor getCaptureSensor() \{

return captureSensor;

\}

public void setCaptureSensor(CaptureSensor captureSensor) \{ this. captureSensor = captureSensor;

\}

\} 


\section{A.3 Código da classe Capturesensor}

package br.com.cps.beans;

import br.com.cps.service. ImplByORM. SensorServiceImplByORM;

import br.com.cps.service.SensorService;

import gnu.io.CommPortIdentifier;

import gnu.io.SerialPort;

import gnu.io.SerialPortEvent;

import gnu.io.SerialPortEventListener;

import java.io.InputStream;

import java.math.BigInteger;

import java.util.Enumeration;

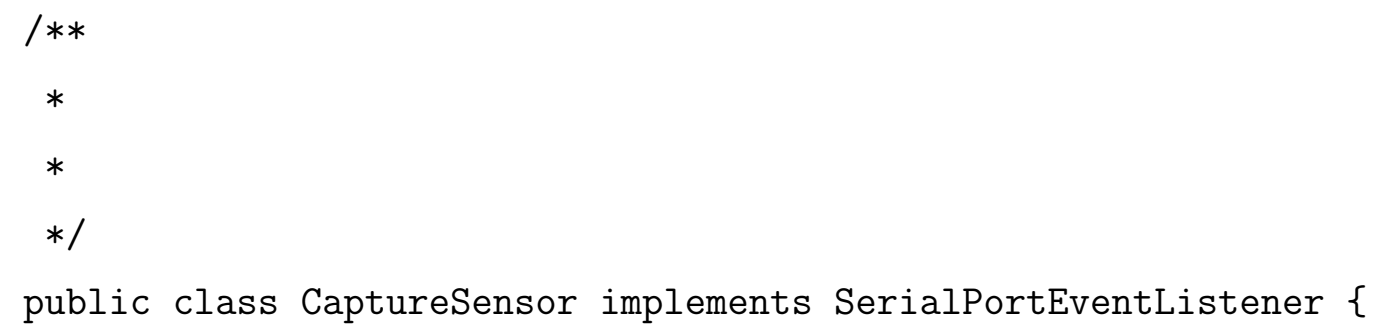

private String port;

private int speedPort;

private SerialPort serialPort;

private InputStream inputStream;

private final SensorService sensorService;

public CaptureSensor(String port, int speedPort) \{

this $\cdot$ port $=$ port;

this. speedPort $=$ speedPort;

sensorService $=$ new SensorServiceImplByORM();

\}

private CommPortIdentifier getPortIdentifier(String portName) \{

Enumeration portList $=$ CommPortIdentifier getPortIdentifiers () ; while (portList.hasMoreElements()) \{ 


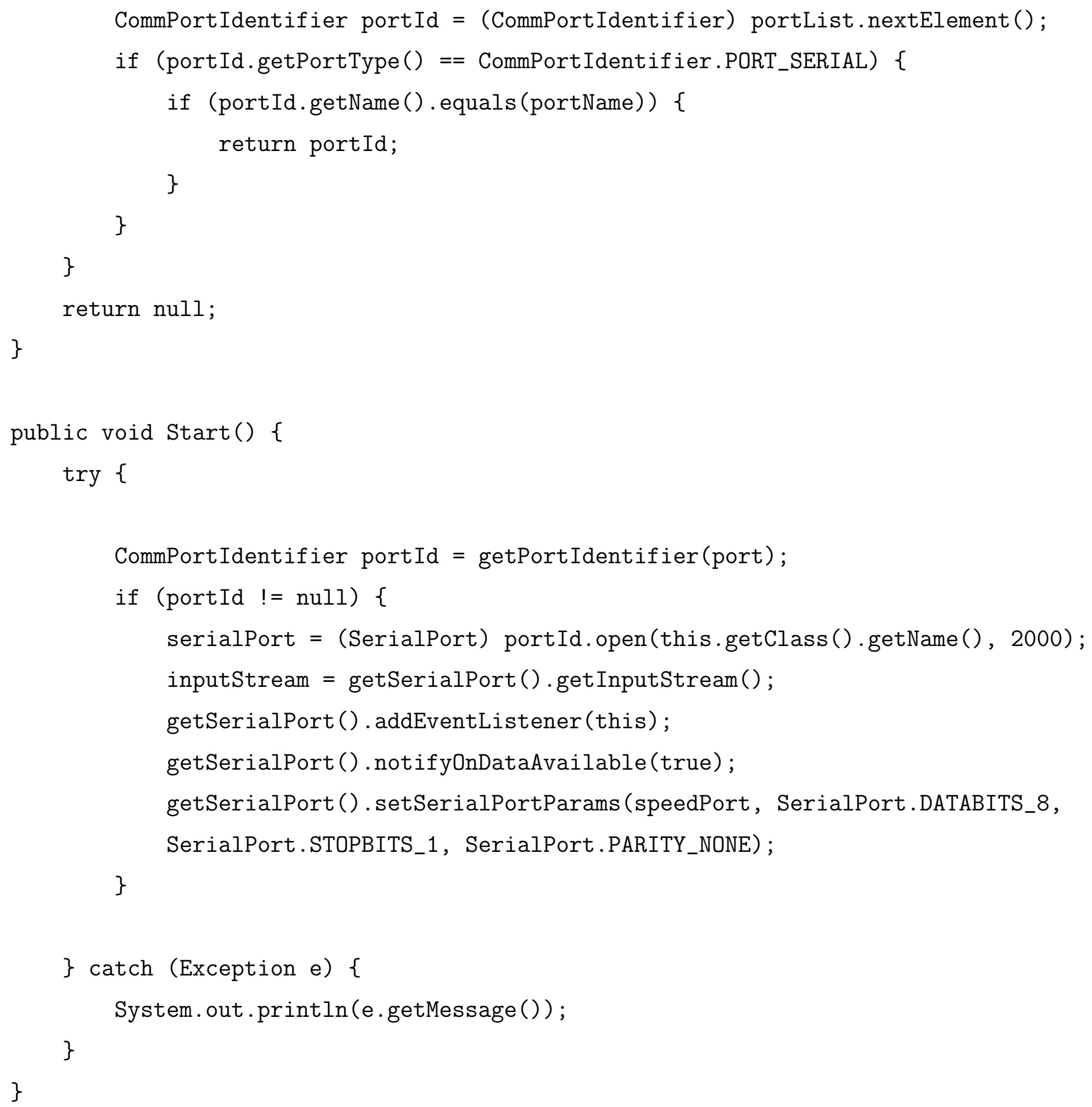




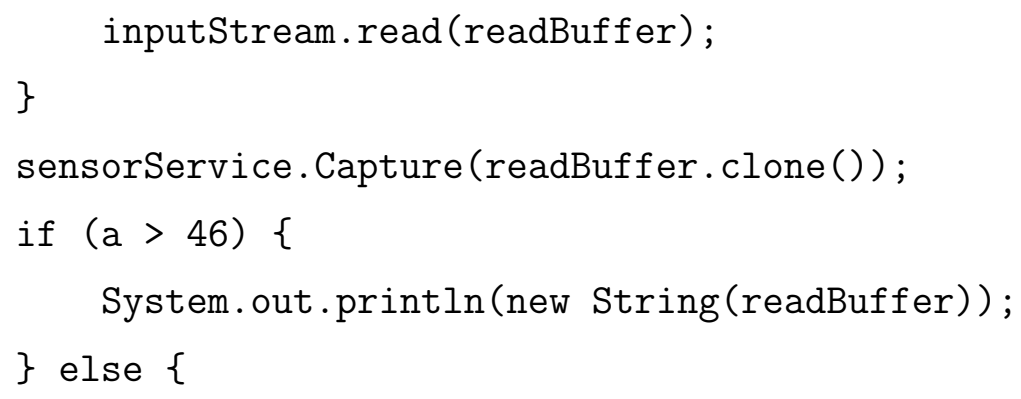




\section{A.4 Código da classe CaptureProcess do Módulo de Integração MI}

package br.com.cps.service. ImplByORM;

import br.com.cps.dao.DaoORM;

import br.com.cps.model. PackageTmoteMultihop;

import br.com.cps.model.PackageTmotePeerToPeer;

import br.com.cps.model.PayloadTmoteMultihop;

import br.com.cps.model.PayloadTmotePeerToPeer;

import br.com.cps.model.Sensor;

import java.math.BigInteger;

import java.util.Calendar;

import org.hibernate.criterion. Restrictions;

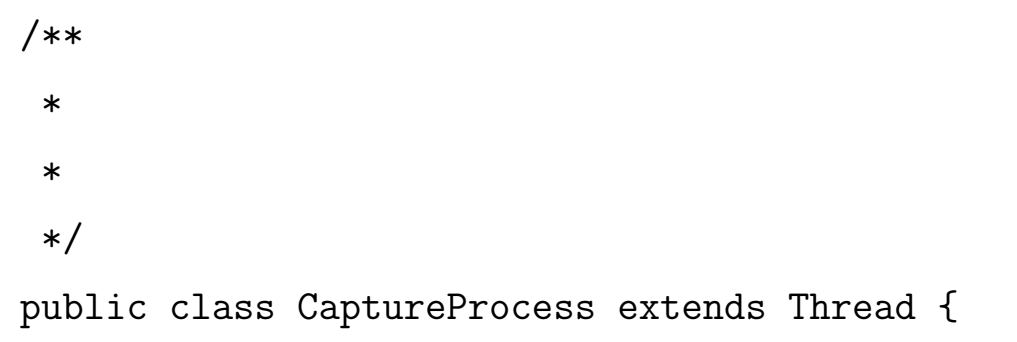

private DaoORM<Sensor $>$ daoSensor;

private DaoORM<PackageTmoteMultihop> daoPackageTmoteMultihop;

private DaoORM<PackageTmotePeerToPeer > daoPackageTmotePeerToPeer;

private DaoORM<PayloadTmoteMultihop> daoPayloadTmoteMultihop;

private DaoORM<PayloadTmotePeerToPeer> daoPayloadTmotePeerToPeer;

private byte[] captureData;

public CaptureProcess (byte [] captureData) \{

this . captureData $=$ captureData;

daoSensor $=$ new DaoORM $<$ Sensor $>$ (Sensor.class);

daoPackageTmoteMultihop $=$ new DaoORM $\langle$ PackageTmoteMultihop $>$

(PackageTmoteMultihop.class);

daoPackageTmotePeerToPeer $=$ new DaoORM<PackageTmotePeerToPeer $>$

(PackageTmotePeerToPeer.class); 


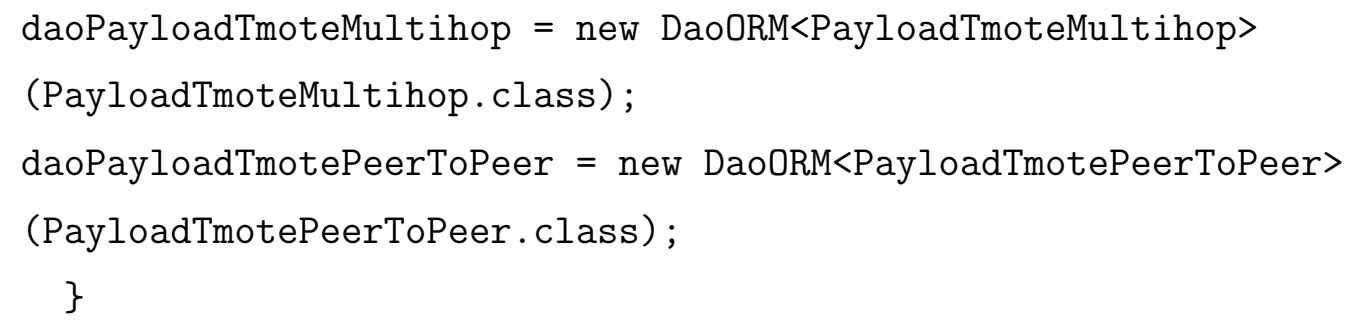

PackageTmoteMultihop pack $=$ new PackageTmoteMultihop();

pack.setNumber ((captureData[12] \& OxFF) + (captureData[13] \& 0xFF)) ;

pack.setNumberValPay ( captureData[25] \& 0xFF) + (captureData[26] \& 0xFF));

pack.setAddrSource ((captureData[5] \& OxFF) + (captureData[6] \& 0xFF));

pack.setGroup ((captureData[8] \& OxFF));

pack.setType (sensor.getSensorType());

pack.setRssi (1);

pack.setCaptureTimer (Calendar.getInstance().getTime());

pack.setPack (new BigInteger(1, captureData).toString(16). toUpperCase()); pack.setSensor (sensor); 


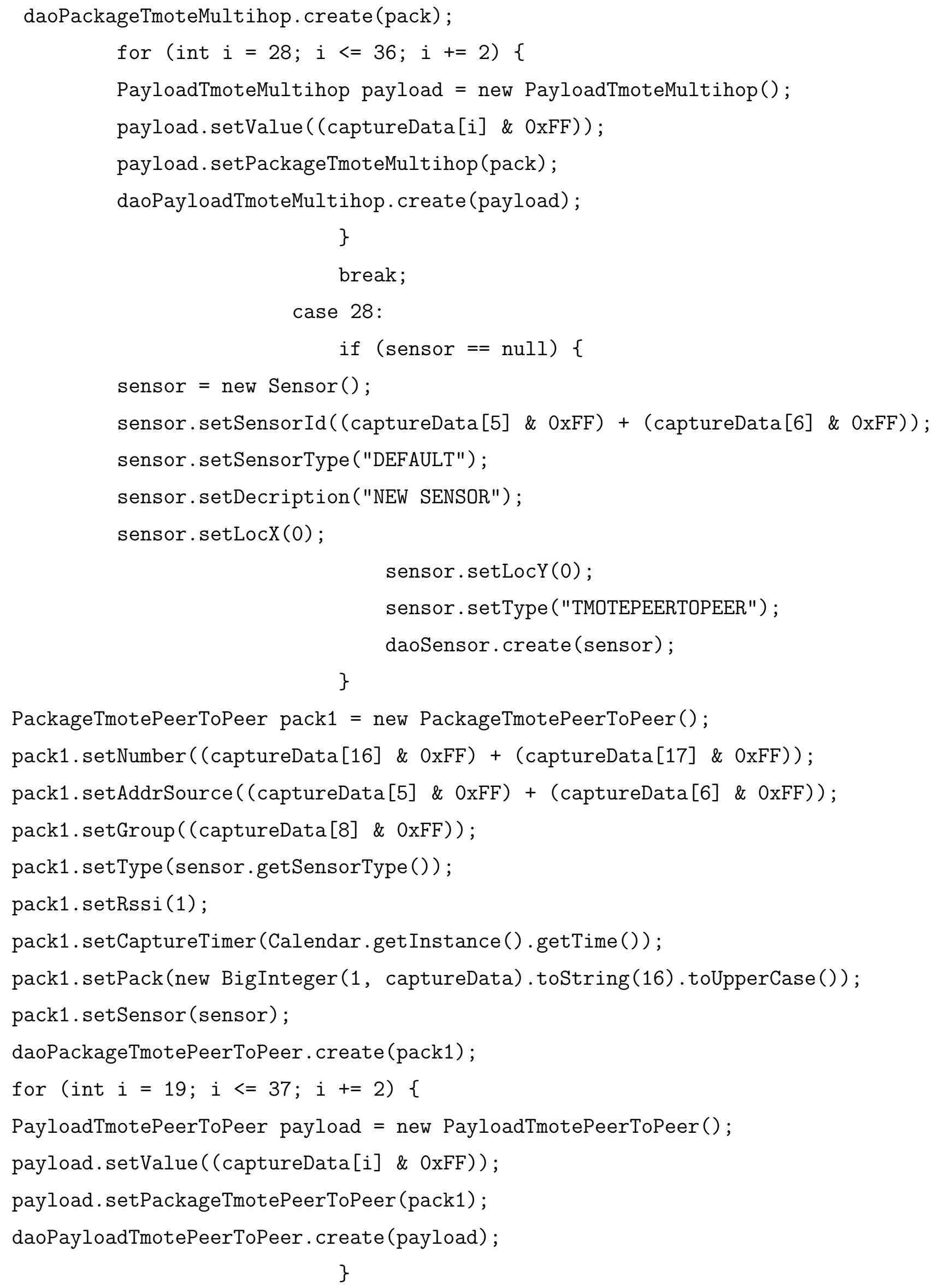




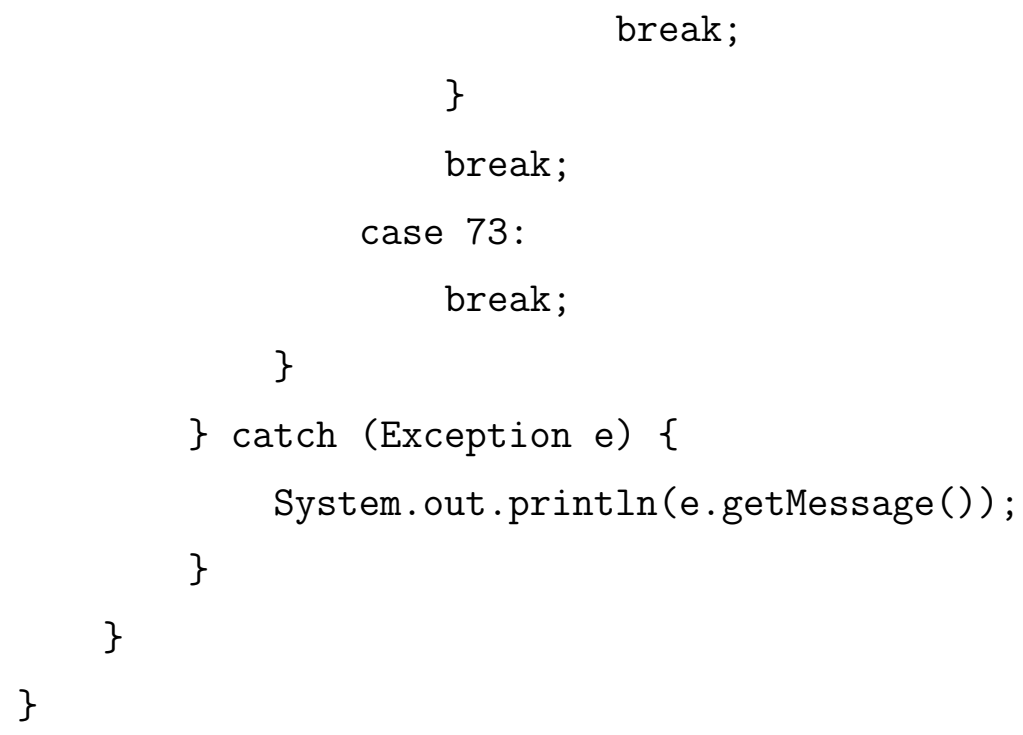




\section{A.5 Código do Sensor de temperatura}

\#include <OneWire.h>

\#include <DallasTemperature.h>

//Especificar pino de entrada de dados

\#define ONE_WIRE_BUS 3

//Preparando instacia OneWire

OneWire oneWire(ONE_WIRE_BUS);

//Epecificando referencia OneWire para a Biblioteca DallasTemperature DallasTemperature sensor(\&oneWire);

//Array para armazenar os endereços dos sensores DeviceAddress insideThermometer;

void $\operatorname{setup}()$

\{

//inicia porta serial

Serial.begin(9600);

//inicia a instancia sensor

sensor.begin();

//localiza os dispositivos de entrada no barramento de dados

Serial.print (sensor.getDeviceCount(), DEC);

Serial.println("devices.");

if (! sensor.getAddress (insideThermometer, 0));

// Serial.println("Unable to find address for Device 0"); 
//Imprime os endereços para ambos dispositivos Serial.println("ID");

printAddress (insideThermometer);

Serial.println();

Serial.println();

\}

//Função imprimir endereço

void printAddress (DeviceAddress deviceAddress)

\{

for (int $i=0 ; i<8 ; i++$ )

\{

//Preenche os endereços com zeros, se necessário

if (deviceAddress[i] < 16) Serial.print("0");

Serial.print (deviceAddress [i], HEX);

\}

\}

//Função para imprimir a Termperatura

void printTemperature(DeviceAddress deviceAddress)

\{

float tempC = sensor getTempC(deviceAddress);

Serial.print("Temp C:");

Serial.print (tempC);

Serial.print("Temp F:");

Serial.print (DallasTemperature: : toFahrenheit(tempC));

\}

//Função Principal para imprimir dados do dispositivo

void printData(DeviceAddress deviceAddress) 


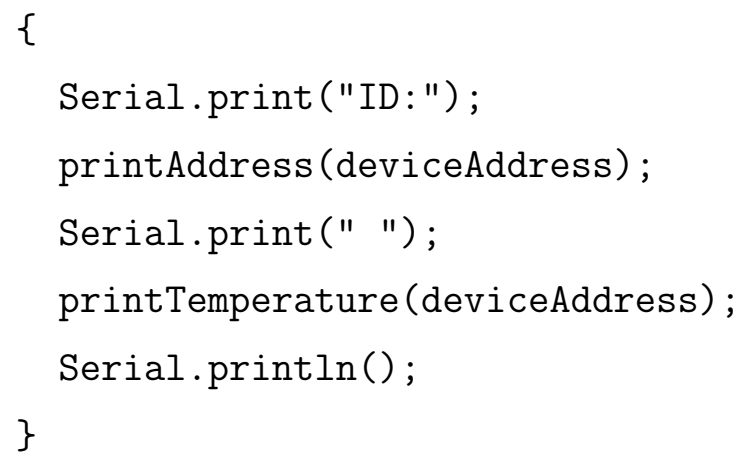




\section{Referências Bibliográficas}

[1] HOANG, D. D.; PAIK, H.-Y.; KIM, C.-K. Service-oriented middleware architectures for cyber-physical systems. IJCSNS International Journal of Computer Science and Network Security, v. 12, n. 1, p. 79-87, 2012.

[2] PARK, S. O.; DO, T. H.; JEONG, Y.-S.; KIM, S. J. A dynamic control middleware for cyber physical systems on an ipv6-based global network. International Journal of Communication Systems, John Wiley and Sons, Ltd, p. n/a-n/a, 2011. ISSN 1099-1131. Disponível em: <http://dx.doi.org/10.1002/dac.1382>.

[3] LAI, C.-F.; MA, Y.-W.; CHANG, S.-Y.; CHAO, H.-C.; HUANG, Y.-M. Osgi-based services architecture for cyber-physical home control systems. Computer Communications, v. 34, n. 2, p. 184 - 191, 2011. ISSN 0140-3664. Special Issue: Open network service technologies and applications.

[4] MUDASSER, I.; BENG, L. H. A cyber-physical middleware framework for continuous monitoring of water distribution systems. In: Proceedings of the 7th ACM Conference on Embedded Networked Sensor Systems. New York, NY, USA: ACM, 2009. (SenSys '09), p. 401-402. ISBN 978-1-60558-519-2.

[5] ISO. ISO/IEC Standard 9126: Software Engineering - Product Quality. [S.1.]: Normas ISO, USA, 2004.

[6] ZHANG, Y.; GILL, C.; LU, C. Reconfigurable real-time middleware for distributed cyberphysical systems with aperiodic events. Distributed Computing Systems, International Conference on, IEEE Computer Society, Los Alamitos, CA, USA, v. 0, p. 581-588, 2008. ISSN 1063-6927.

[7] EUGSTER, P. T.; FELbER, P. A.; GUERRAOUI, R.; KERMARREC, A.-M. The many faces of publish/subscribe. ACM Comput. Surv., ACM, New York, NY, USA, v. 35, n. 2, p. 114-131, jun. 2003. ISSN 0360-0300. Disponível em: $<$ http://doi.acm.org/10.1145/857076.857078>.

[8] DON, B.; NEAL, S. J.; AXEL, R. Scaling step-wise refinement. In: Proceedings of the 25th International Conference on Software Engineering. Washington, DC, USA: IEEE Computer Society, 2003. (ICSE ’03), p. 187-197. ISBN 0-7695-1877-X.

[9] GABOR, K.; JANOS, S. Model-integrated development of cyber-physical systems. In: Proceedings of the 6th IFIP WG 10.2 international workshop on Software Technologies for Embedded and Ubiquitous Systems. Berlin, Heidelberg: Springer-Verlag, 2008. (SEUS '08), p. 46-54. ISBN 978-3-540-87784-4.

[10] GROUP, C. S. Cyber-physical systems - executive summary. v. 1, 2008. 
[11] KROGH, B. H. Cyber physical systems: The need for new models and design paradigms. Presentation Report, Carnegie Mellon University, v. 1, 2008.

[12] WAN, K.; HUGHES, D.; MAN, K. L.; KRILAVICIUS, T.; ZOU, S. Investigation on composition mechanisms for cyber physical systems. INTERNATIONAL JOURNAL OF DESIGN, ANALYSIS AND TOOLS FOR CIRCUITS AND SYSTEMS, v. 2, n. 1, p. 30 $-40,2011$.

[13] SVEDA, M.; VRBA, R. A cyber-physical system design approach. In: Proceedings ICONS 2011, The Sixth International Conference on Systems. St. Maarten, The Netherlands Antilles: [s.n.], 2011. (ICONS '11), p. 12-18. ISBN 978-1-61208-114-4.

[14] LEE, E. A. The future of embedded software. ARTEMIS 2006 Annual Conference, v. 1, 2006.

[15] LEE, E. A. Computing foundations and practice for cyberphysical systems: A preliminary report - technical report no. ucb/eecs-2007-72. University of California at Berkeley, v. 1, 2007.

[16] NSF. National science foundation, cyber-physical systems program solicitation. v. 1, 2010.

[17] FRANK, M. Cyber-physical aspects of energy systems for the 21st century: A perspective from the nsf erc freedm project. v. 1, 2009.

[18] ILIC, M.; XIE, L.; KHAN, U.; MOURA, J. Modeling future cyber-physical energy systems. In: Power and Energy Society General Meeting - Conversion and Delivery of Electrical Energy in the 21st Century, 2008 IEEE. [S.1.: s.n.], 2008. p. 1-9. ISSN 1932-5517.

[19] ANAND, M. et al. Security challenges in next generation cyber physical systems. In: In Beyond SCADA: Networked Embedded Control for Cyber Physical Systems. [S.l.: s.n.], 2006. p. 1-4.

[20] KIRKPATRICK, M.; BERTINO, E. Restricted authentication and encryption for cyberphysical systems. In: . [S.1.: s.n.], 2009. p. 1-4.

[21] XIA, F.; MA, L.; DONG, J.; SUN, Y. Network qos management in cyber-physical systems. In: Proceedings of the 2008 International Conference on Embedded Software and Systems Symposia. Washington, DC, USA: IEEE Computer Society, 2008. (ICESSSYMPOSIA '08), p. 302-307. ISBN 978-0-7695-3288-2. Disponível em: $<$ http://dx.doi.org/10.1109/ICESS.Symposia.2008.84>.

[22] RAJKUMAR, R. Cps briefing. In: . [S.1.]: Carnegie Mellon University, 2007.

[23] HUANG, B. X. Cyber physical systems: A survey. In: . [S.1.]: Presentation Report, 2008.

[24] KROGH, B. et al. Cyber-physical systems: Executive summary. In: . [S.1.]: CPS Steering Group - Presentation Report, 2008.

[25] SHA, L.; GOPALAKRISHNAN, S.; LIU, X.; WANG, Q. Cyber-physical systems: A new frontier. In: Sensor Networks, Ubiquitous and Trustworthy Computing, 2008. SUTC '08. IEEE International Conference on. [S.1.: s.n.], 2008. p. 1 -9. 
[26] AUgusto, J. et al. In: In, System Testing and Validation Workshop, The , Netherlands, IEEE. [S.1.]: Software Technology and Engineering Practice, 2003, 2003. p. $225-233$.

[27] HART-COMMUNICATION-FUNDATION. Standard WirelessHart. USA, 2009. Disponível em: <http://www.hartcomm.org/protocol/training/resources/wiHARTresources/wirelesshart-brochure.pdf $>$.

[28] ISA-STANDARD. ISA-100.11a-2011 Wireless systems for industrial automation: Process control and related applications. USA, 2011. Disponível em: $<$ http://www.isa.org/ $>$.

[29] LOPEZ, P. R.; PASTOR, E.; BARRADO, C.; SANTAMARIA, E. A middleware architecture for unmanned aircraft avionics. ACM/IFIP/USEUNIX 8th Int. Middleware Conference, n. 1, 2007.

[30] FRANçA, C. L. Web services como middlewares para interoperabilidade em sistemas. v. 1, n. 1, 2010. Disponível em: <http://www.uece.br/mpcomp/index.php/dissertacoes/47dissertacao/129-dissertacoes- $>$.

[31] AIKEN, B. et al. Rfc 2768, network policy and services: A report of a workshop on middleware.

[32] SUN, X. he; BLATECKY, A. R. Middleware: the key to next generation computing. Journal of Parallel and Distributed Computing, v. 64, p. 689-691, 2004.

[33] KELKAR, A.; GAMBL, R. Understanding the architectural characteristics behind middleware choices. In: in the Proceedings of the 1 st Int 1 Conference in Information Reuse and Integration. [S.1.: s.n.], 1999. p. 1 -6.

[34] GIESECKE, S. Middleware-induced styles for enterprise application integration. In: Software Maintenance and Reengineering, 2006. CSMR 2006. Proceedings of the 10th European Conference on. [S.1.: s.n.], 2006. p. 4 pp. -340. ISSN 1052-8725.

[35] KJAER, K. E. A survey of context-aware middleware. In: Proceedings of the 25th conference on IASTED International Multi-Conference: Software Engineering. Anaheim, CA, USA: ACTA Press, 2007. (SE’07), p. 148-155. Disponível em: $<$ http://dl.acm.org/citation.cfm?id=1332044.1332069>.

[36] JINGYONG, L.; YONG, Z.; LICHEN, Z.; YONG, C. Aspect-oriented middleware-based real-time and embedded systems software process. In: Services Science, Management and Engineering, 2009. SSME '09. IITA International Conference on. [S.l.: s.n.], 2009. p. $531-534$.

[37] DEliCATO, F. C.; PIRES, P. F.; PIRMEZ, L.; CARMO, L. F. R. da C. A flexible middleware system for wireless sensor networks. In: Proceedings of the ACM/IFIP/USENIX 2003 International Conference on Middleware. New York, NY, USA: Springer-Verlag New York, Inc., 2003. (Middleware '03), p. 474-492. ISBN 3-54040317-5. Disponível em: <http://dl.acm.org/citation.cfm?id=1515915.1515947>. 
[38] A, C. L. H.; MACEDO, D. F.; L, D. S. A.; MARCOS, N. J.; LOUREIRO, A. A. F. A taxonomy for medium access control protocols in wireless sensor networks. Intl Journal of Communications Network and System Sciences, v. 60, n. 4, p. 944-969, 2005. ISSN 19133715. Disponível em: <http://dx.doi.org/10.4236/ijens.2009.28080>.

[39] ROMER, K.; KASTEN, O.; MATTERN, F. Middleware challenges for wireless sensor networks. SIGMOBILE Mob. Comput. Commun. Rev., ACM, New York, NY, USA, v. 6, n. 4, p. 59-61, out. 2002. ISSN 1559-1662. Disponível em: $<$ http://doi.acm.org/10.1145/643550.643556>.

[40] COSTA, G. A. da; KLEINSCHMIDT, J. H. Uma proposta de arquitetura de middleware para redes de sensores e atuadores sem fio utilizando web services. In: XXIX SIMPÓSIO BRASILEIRO DE TELECOMUNICAÇÕES. CURITIBA, PR, Brasil: SBrT 11, 2011. p. $1-2$.

[41] DELICATO, F.; PIRES, P. F.; LAGES, A.; REZENDE, J. F. de; PIRMEZ., L. Middleware orientado a serviços para redes de sensores sem fio. In: Anais do Simpósio Brasileiro de Redes de Computadores e Sistemas Distribuídos. [S.1.: s.n.], 2004. p. 1 -7. ISBN 8588442-81-7.

[42] HADIM, S.; MOHAMED, N. Middleware: middleware challenges and approaches for wireless sensor networks. Distributed Systems Online, IEEE, v. 7, n. 3, p. 1, march 2006. ISSN 1541-4922.

[43] HADIM, S.; MOHAMED, N. Middleware for wireless sensor networks: A survey. In: Communication System Software and Middleware, 2006. Comsware 2006. First International Conference on. [S.1.: s.n.], 2006. p. 1 -7.

[44] LI, S.; SON, S. H.; STANKOVIC, J. A. Event detection services using data service middleware in distributed sensor networks. In: Proceedings of the 2nd international conference on Information processing in sensor networks. Berlin, Heidelberg: Springer-Verlag, 2003. (IPSN'03), p. 502-517. ISBN 3-540-02111-6. Disponível em: $<$ http://dl.acm.org/citation.cfm?id=1765991.1766026 $>$.

[45] HEINZELMAN, W.; MURPHY, A.; CARVALHO, H.; PERILlO, M. Middleware to support sensor network applications. Network, IEEE, v. 18, n. 1, p. 6 - 14, jan/feb 2004. ISSN 0890-8044.

[46] In: . [S.1.: s.n.].

[47] HEER, J.; AGRAWALA, M. Software design patterns for information visualization. Visualization and Computer Graphics, IEEE Transactions on, v. 12, n. 5, p. $853-860$, sept.-oct. 2006. ISSN 1077-2626.

[48] LI, Z.; LI, X.; XIA, M. Design and implementation of data access layer based on design pattern. In: Computer Application and System Modeling (ICCASM), 2010 International Conference on. [S.1.: s.n.], 2010. v. 14, p. V14-98-V14-100.

[49] ZHONG, B.; NIU, L.; CHEN, H. Design and implement of 3g mobile police system. In: Consumer Electronics, Communications and Networks (CECNet), 2012 2nd International Conference on. [S.1.: s.n.], 2012. p. $1752-1755$. 
[50] GARAY, J.; KOFUJI, S.; TIBA, T. Overview of a system amr based in computational vision and wireless sensor network. In: Communications, 2009. LATINCOM '09. IEEE Latin-American Conference on. [S.1.: s.n.], 2009. p. 1 -5.

[51] FLORIDO, I. R. Rede de sensores sem fio em ambientes veiculares baseada no padrão Zigbee. Dissertação (Mestrado) — Escola de Engenharia - Universidade do São Paulo, 2007.

[52] TORRES, J. C. Z. Uma metodologia para o desenvolvimento de aplicações de realidade aumentada em telefones celulares utilizando dispositivos sensores. Dissertação (Mestrado) - Escola de Engenharia - Universidade do São Paulo, 2008.

[53] DIONISIO, C. R. P.; KOFUJI, S. T. Through-wall 2d imaging using uwb radar. In: In: Latin America Workshop on Communications - LAWC. [S.1.: s.n.], 2009. p. 1 -5.

[54] ISO, I. O. for S. ISO/IEC14598 Information Technology - Software product evaluation. [S.1.]: Normas ISO, USA, 2001.

[55] SHYY, D. Military usage scenario and ieee 802.11s mesh networking standard. Military Communications Conference - MILCOM, v. 0, n. 1, p. 1-7 23-25, 2006.

[56] OMG, O. M. G. SysML Partners. USA, 2006. Disponível em: <http://www.sysml.org/>.

[57] INTEL-BERKELEY. Berkeley/Intel Website. [S.1.]: USA, 2003.

[58] COM, D. XBee Pro Serie 2. USA, 2008. Disponível em: <http://www.digi.com>.

[59] ARDUINO.CC. Arduino UNO. USA, 2012. Disponível em: $<$ http://arduino.cc/en/Main/ArduinoBoardUno $>$.

[60] ARDUINO.CC. Arduino Duemilanove R3. USA, 2012. Disponível em: $<$ http://arduino.cc/en/Main/arduinoBoardDuemilanove $>$.

[61] CORPORATION, M. TmoteSky - Mote Sensor. USA, 2008. Disponível em: $<$ http://www.citeulike.org/user/sensorweb/tag/tmote $>$.

[62] TINYOS-BERKELEY. Multihop Routing - MultiHopLQI. USA, 2003. Disponível em: $<$ http://www.tinyos.net/tinyos-1.x/doc/multihop/multihop routing.html $>$.

[63] LTD, C. C.-T. SMART iD ALARM CONTROL SYSTEM. USA, 2000. Disponível em: $<$ http://www.indexsecurity.co.uk/pdf/Smart.pdf $>$.

[64] GRAVES, H.; BIJAN, Y. Using formal methods with sysml in aerospace design and engineering. Annals of Mathematics and Artificial Intelligence, Kluwer Academic Publishers, Hingham, MA, USA, v. 63, n. 1, p. 53-102, set. 2011. ISSN 1012-2443. Disponível em: <http://dx.doi.org/10.1007/s10472-011-9267-5>.

[65] ARM. RaspBerry PI. USA, 2012. Disponível em: <http://www.raspberrypi.org/>. 